

\section{COMMITTEE ON INTERSTATE AND FOREIGN COMMERCE}

WARREN G. MAGNUSON, Washington, Chairman

JOHN O. PASTORE, Rhode Island A. S. MIKE MONRONEY, Oklahoma GEORGE A. SMATHERS, Florida STROM THURMOND, South Carolina FRANK J. LAUSCHE, Ohio RALPH YARBOROUGH, Texas CLAIR ENGLE, California E. L. BARTLETT, Alaska VANCE HARTKE, Indiana GALE W. MCGEE, Wyoming
ANDREW F. SCHOEPPEL, Kansas JOHN MARSHALL BUTLER, Maryland NORRIS COTTON, New Hampshire CLIFFORD P. CASE, New Jersey THRUSTON B. MORTON, Kentucky HUGH SCOTT, Pennsylvania

EdwARD JARRETT, Chief Clerk

John M. MCElroy, Assistant Chief Clerk

Harold I. Baynton, Chief Counsel

James E. Batley, Assistant Chief Counsel

Daniel B. Markel, Professional Staff Membor

III 


\section{CONTENTS}

Statement of-

Page

Brown, Harrison Scott, Ph. D., division of geological sciences, California Institute of Technology, Pasadena, Calif ............ . 80-116

Carritt, Dayton E., associate professor of oceanography and assistant director of the Chesapeake Bay Institute, Johns Hopkins University, Baltimore, Md

Iselin, Columbus O'D., D. Sc., Woods Hole Oceanographic Institution, Woods Hole, Mass _......

Koczy, Friedrich Frans, Ph. D., Marine Laboratory, University of Miami, 1 Rickenbacker Causeway, Virginia Key, Miami, Fla .....

Pike, Sumner, Lubec, Maine

Ray, Mrs. Dixy Lee, associate professor of zoology, University of

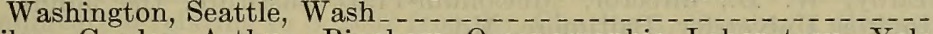

Riley, Gordon Arthur, Bingham Oceanographic Laboratory, Yale University, New Haven, Conn . . . . . . . . .

Schaefer, Milner B., Ph. D., Director of Investigations of the InterAmerican Tropical Tuna Commission and research associate of the Scripps Institution of Oceanography, University of California, Berkeley, Calif

Spilhaus, Athelstan Frederick, D. Sc., dean of the Institute of Technology, University of Minnesota, Minneapolis, Minn

Vine, Allyn C., Ph. D., physical oceanographer, Woods Hole Oceanographic Institution, Woods Hole, Mass

Wilbur, C. C., commander, USN, Office of Chief of Naval Operations, Navy Department, Washington, D.C _.......

Worzel, Dr. Lamar, Lamont Geological Observatory, Palisades, N. $\bar{Y}$. Statement submitted by-

Ewing, Dr. Maurice, professor of geology and Director of Lamont Geological Observatory, Columbia University, Palisades, N.Y ....

Proctor, Dr. Charles M., 2540122 d Avenue SE., Bellevue, Wash...-

Revelle, Prof. Roger R., Scripps Institution of Oceanography, LaJolla, Calif

Letters, reports, resolutions, etc.:

American Legion (resolution of the 41st Annual National Convention held at Minneapolis) St. Paul, Minn

Bader, Richard G., associate professor of oceanography, Agricultural and Mechanical College of Texas, College Station, Tex........

Bookhout, C. G., Ph. D., director, Duke University Marine Laboratory, Duke University, Durham, N.C

Committee on Hydrobiology of the American Institute of Biological Sciences, University of Hawaii, Honolulu, Hawaii

Committee for Research Planning of the Atlantic Estuarine Research Society (no address given)

Cronin, L. Eugene, director, Department of Research and Education, Solomons, Md _. . _ _

Dambach, Charles A., director, Natural Resources Institute, the Ohio State University, Natural Resources Institute, 1885 Neil Avenue, Columbus, Ohio _..........

District of Columbia Federation of Women's Clubs, Washington, D.C

Dow, Robert L., research director, Department of Sea and Shore Fisheries, State of Maine, Statehouse, Augusta, Maine

Eastern Pacific Oceanic Conference, Lake Arrowhead, Calif

Fish, Charles J., director, Narragansett Marine Laboratory, University of Rhode Island, Kingston, R.I

Fye, Paul M., Woods Hole Oceanographic Institution, Woods Hole, Mass. 
Letters, reports, resolutions, etc--Continued

Hargis, William J., Jr., Ph. D., director, Virginia Fisheries Laboratory, Gloucester Point, Va

Heydecker, Wayne D., 22 West First Street, Mount Vernon, N.Y..-

Hiatt, Robert W., chairman, AIBS Committee on Hydrobiology, University of Hawaii, Honolulu, Hawaii

Holle, Charles G., major general (USA (retired), president, American
Shore and Beach Preservation Association, 810 18th Street NW., Washington, D.C.

Houghton, Henry G., department of meteorology, Massachusetts Institute of Technology, Cambridge, Mass_._._.

Ichiye, Takashi, assistant professor in oceanography, Oceanographic Institute, Florida State University, Tallahassee, Fla_.........

Idyll, C. P., head, fisheries division, the Marine Laboratory (University of Miami) 1 Rickenbacker Causeway, Virginia Key, Miama, Fla

Interior Department, Bureau of Commercial Fisheries (research contracts either negotiated or in effect in fiscal year 1960) ........

Linton, M. Albert, president, the Academy of Natural Sciences of Philadelphia, Philadelphia, $\mathrm{Pa}$

Lipp, J. E., corporate director of development planning, Lockheed Aircraft Corp., Burbank, Calif. . . . .

MeElroy, W. D., director, MeCollum-Pratt Institute, the Johns Hopkins University, Baltimore, $\mathrm{Md}_{-}$

Redfield, Alfred C., Box 73, Woods Hole, Mass

Sanford, L. R., president, Shipbuilders Council of America, 21 West Street, New York, N.Y

Seibert, H. E., flight test group engineer, mail zone $6-186$, Convair, San Diego, Calif

Shannon, W. T., director, Department of Fish and Game, State of California, 722 Capitol Avenue, Sacramento, Calif . .......

Shrock, Robert R., chairman, department of geologv and geophysics, Massachusetts Institute of Technology, Cambridge, Mass . ....

Veterans of Foreign Wars of the United States 60 th National Convention, Los Angeles, Calif

Waterman, Alan T., Dr., Director, National Science Foundation, Office of the Director, Washington, D.C

Wiggins, Ira L., director, Natural History Museum, Stanford University, Stanford, Calif

Reports from Government agencies:

Bureau of the Budget, dated April 13, 1960

Comptroller General of the United States, dated November 17, $1959 .-$

Department of Defense (Navy), dated April 19, 1960

Treasury Department, dated April 25, 1960 .

\section{APPENDIX}

The following material is submitted for the record:

Bureau of Commercial Fisheries, Fish and Wildlife Service, Department of the Interior

Table 1. Bureau of Commercial Fisheries research contracts either negotiated or in effect in fiscal year 1960

Table 9. Bureau of Commercial Fisheries contracts negotiated with Saltonstall-Kennedy Act funds, fiscal years 1955-60 -

Table 12. Bureau of Commercial Fisheries contracts utilizing Saltonstall-Kennedy Act funds (analysis by contracting organization and location

National Science Foundation:

Letter from Dr. Alan T. Waterman, Director of the National Science Foundation to Senator Warren G. Magnuson, chairman of the Committee on Interstate and Foreign Commerce, relative to support of research by the Foundation in oceanography and limnology during fiscal year 1960

Table of Foundation grants for research in physical oceanography

Table of Foundation grants for facilities for physical oceanography --

Table of Foundation grants for research in biological oceanography and limnology

Table of Foundation grants for facilities for biological oceanography and limnology. 
Resolutions relating to S. 2692 adopted at Sixth Annual Eastern Pacific

Oceanic Conference-_. 41st Annual National Convention

Resolution endorsing oceanographic research adopted by the Veterans of Foreign Wars of the United States at 60th National Convention.

Resolution adopted by District of Columbia Federation of Women's Clubs supporting legislation relating to oceanography

Resolution of Committee for Research Planning of the Atlantic Estuarine Research Society

Comments on S. 2692 in behalf of Committee on Education and Recruitment of the American Society of Limnology and Oceanography, submitted by Dr. Alfred C. Redfield, chairman and senior oceanographer emeritus of Woods Hole Oceanographic Institution.

Report by Committee on Hydrobiology of the American Institute of Biolog. ical Sciences, submitted by Dr. Robert W. Hiatt, chairman, University of Hawaii, relating to S. 2692

Subsequent communication from Dr. Hiatt relating to report

Statement by the Executive Committee of Duke University Marine Laboratory, Durham, N.C., on S. 2692

Communications relating to S. 2692 from Dr. C. P. Idyll, head, Fisheries Division, University of Miami Marine Laboratory, Miami, Fla_._._-_.-

Communication relating to S. 2692 from Dr. Charles A. Dambach, director, Natural Resources Institute, the Ohio State University, Columbus, Ohio

Communication from Dr. Charles M. Proctor, Bellevue, Wash

Communication from Mr. L. R. Sanford, president, Shipbuilders Council of America

Communication from Dr. Richard G. Bader, Agricultural and Mechanical College of Texas, College Station, Tex

Communication from Dr. William J. Hargis, director, Virginia Fisheries Laboratory, Gloucester Point, Va

Communication from Mr. Robert L. Dow, research director, Department of Sea and Shore Fisheries, Augusta, Maine

Communication from Mr. W. T. Shannon, director, Department of Fish and Game, State of California, Sacramento, Calif

Communication from Dr. R. Tucker Abbott, Academy of Natural Sciences of Philadelphia

Communication from Dr. Takashi Ichiye, the Florida State University, Tallahassee, Fla

Communication from Maj. Gen. Charles G. Holle, USA, retired, president of the American Shore and Beach Preservation Association

126

127

132

133

137

138

140

141

117

142

142

143

144

145

147

152

152

Communication from W. D. McElroy, director, McCollum-Pratt Institute, the Johns Hopkins University, Baltimore, Md

Communication from Dr. Paul M. Fye, director, Woods Hole Oceanographic Institution, Woods Hole, Mass

Communication from Dr. Robert R. Shrock, chairman, Department of Geology and Geophysics, Massachusetts Institute of Technology, Cambridge, Mass

Communication from Dr. Henry G. Houghton, Department of Meteorology, Massachusetts Institute of Technology, Cambridge, Mass

Communication from Dr. Charles J. Fish, director, Narragansett Marine Laboratory, University of Rhode Island

Communication from Dr. Ira L. Wiggins, director, Natural History $\mathrm{Mu}$ seum, Stanford University, Stanford, Calif

Communication from Mr. J. E. Lipp, corporate director of development planning, Lockheed Aixcraft Corp., Burbank, Calif

Communication from Mr. H. E. Seibert, flight test group engineer, CONVAIR, San Diego, Calif

Communication from Mr. Wayne D. Heydecker, secretary-treasurer, Atlantic States Marine Fisheries Commission, Mount Vernon, N.Y.-.- 


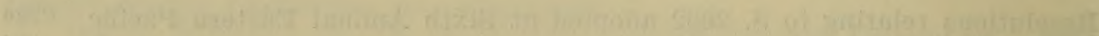

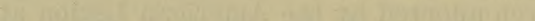

6.s.

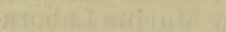

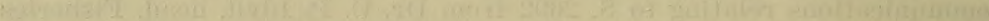

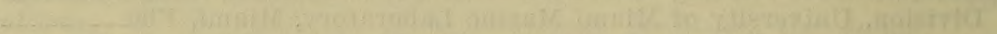

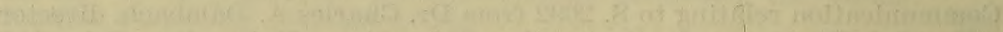

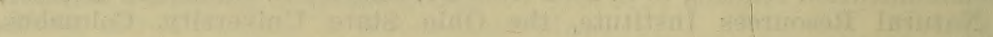

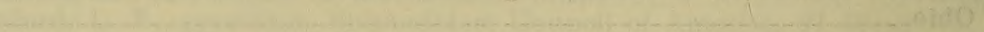

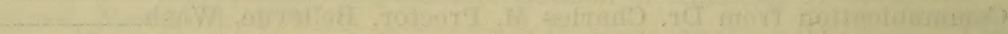
I.

1.

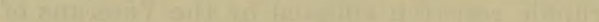

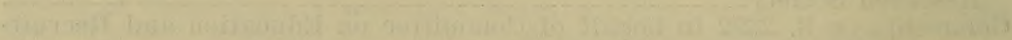

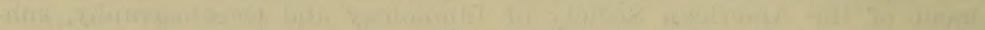

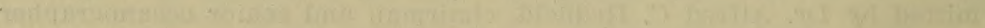

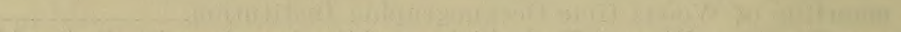

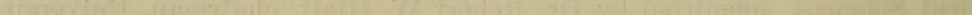

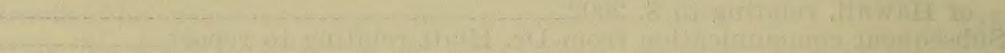
-

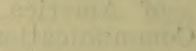

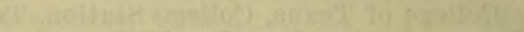
6.6.

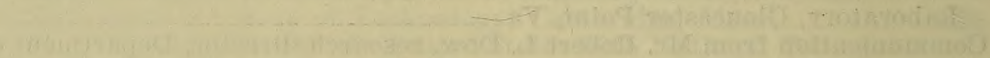

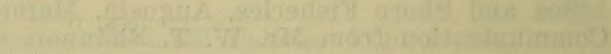

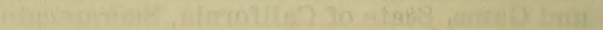

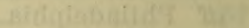

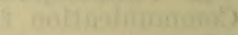

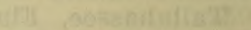

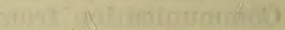

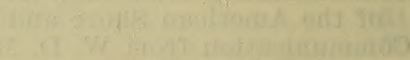

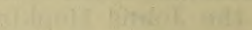

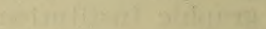

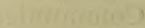

27y

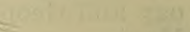




\section{MARINE SCIENCE}

\section{WEDNESDAY, APRIL 20, 1960}

\section{U.S. Senate, Committee on Interstate and Foreign Commerce, Washington, D.C.}

The committee met at $10: 55$ a.m., in room 5110, Senate Office Building, the Honorable Warren G. Magnuson (chairman) presiding.

The Chamran. The committee will come to order.

I want first to apologize to the witnesses since we were late getting in. The committee here usually meets at 10:30 so as a matter of habit most of them get here then, but there is a little subcommittee argument down below and they will all be along.

Since we have so many fine witnesses, we want to get started. The committee will consider S. 2692, the Marine Sciences and Research Act of 1959. Without objection, S. 2692 will appear in the record at this point.

(S. 2692 is as follows:)

[S. 2692, 86th Cong., 1st sess.]

A BILL To advance the marine sciences, to establish a comprehensive ten-year program of oceanographic research and surveys; to promote commerce and navigation, to secure the national defense; to expand ocean resources; to authorize the construction of research and survey ships and facilities; to assure systematic studies of effects of radioactive materials in marine environments, to enhance the general welfare; and for other purposes

Be it enacted by the Senate and House of Representatives of the United States of America in Congress assembled,

\section{SHORT TITLE}

Section 1. This Act may be cited as the "Marine Sciences and Research Act of 1959".

\section{DECLARATION OF POLICY}

SEC. 2. The Congress hereby declares that systematic, scientific studies and surveys of the oceans and ocean floor, the collection, preparation and dissemination of comprehensive data regarding the physics, biology, chemistry and geology of the seas, and the education and training of oceanographic scientists through a sustained and effective fellowship program is vital to defense against attack from the oceans and to the operation of our own surface and subsurface naval forces with maximum efficiency, to the rehabilitation of our commercial fisheries and utilization of other ocean resources, to the expansion of commerce and navigation, and to the development of scientific knowledge since many problems require an understanding of the waters which cover 71 per centum of the earth's surface, life within these waters, and the interchange of energy and matter between the sea and atmosphere.

The Congress further declares that sound national policy requires that the United States not be excelled in the fields of oceanographic research, basic, military or applied, by any nation which may presently or in the future threaten our general welfare, maritime commerce, security, access to and utilization of 
ocean fisheries, or the contamination of adjacent seas by the dumping of radioactive wastes or other harmful agents.

The Congress further declares that to meet the objectives outlined in the preceding paragraphs of this Act there must be a coordinated, long-range program of oceanographic research similar or identical to that recommended as a minimal program by the Committee on Oceanography of the National Academy of Sciences-National Research Council which requires but is not limited to the -

1. construction of modern, oceangoing ships for scientific research, surveys, fisheries exploration and marine development;

2. construction of laboratory and shore facilities adequate to service and supplement the research and survey fleets ;

3 . development and acquisition of new and improved research tovis. devices, instruments, and techniques including but not limited to bathyscaphs and other manned submersibles, manned and unmanned deep ocean buoys, modified icebreakers, accoustical equipment and telemetering devices, current meters, direct density, turbulence and radioactivity measuring devices, biological sampling instruments, precision salinometers and echo sounders, magnetometers, and deep sea underwater cameras ;

4. recruitment of prospective oceanographers from among undergraduate students of physics, chemistry, biology and geology and the facilitating of their advanced education in the marine sciences by a long-term fellowship program, where necessary, supported by or through the National Science Foundation or other appropriate agency of the Federal Government;

5 . improvement of the economic and general welfare by obtaining more adequate information in the field of oceanography concerning the occurrence, behavior, and potential use of fish, shellfish, and other marine life, and thereby to enhance the development and utilization of living marine resources;

6. establishment of a national oceanographic records center to assemble, prepare and disseminate all scientific and technical oceanographic and closely related data, including but not limited to physical, biological, fisheries, hydrographic and coastal survey, meteorological and climatological data. All nonclassified data shall be made available for public use; and

7. development of a formal international cooperation in the marine sciences on a reciprocal basis subject to approval by the President.

The Congress further declares that a coordinated, long-range program of oceanographic research requires establishment of a Division of Marine Sciences in the National Science Foundation, which shall include representation from Government agencies having duties or responsibilities connected with or related to the seas and oceans, and oceanographic scientists associated with universities, institutions affiliated with universities, laboratories or foundations, and which Division shall be authorized and directed-

(a) to develop and encourage a continuing national policy and program for the promotion of oceanographic research, surveys and education in the marine sciences: Provided, That the long range program for oceanographic research developed and projected by the Chief of Naval Research, Department of the Navy, and approved by the Chief of Naval Operations, known as project TENOC (Ten Years in Oceanography) be incorporated in the national program and policy ;

(b) to recommend contracts, grants, loans or other forms of assistance for the development and operation of a comprehensive national program of oceanographic research and education in the marine sciences ;

(c) to cooperate with and encourage the cooperation of the Office of Naval Research, the Hydrographic Office, the Bureau of Ships, the Coast and Geodetic Survey, the Bureau of Commercial Fisheries, the Atomic Energy Commission, the Maritime Administration, the United States Weather Bureau, the United States Coast Guard, the United States Geological Survey, the National Bureau of Standards, and other Government agencies dealing with problems related to the seas, and the National Academy of Sciences-National Research Council and administrators and scientists of all universities and institutions receiving assistance from Federal agencies for oceanographic or fisheries research or education in the marine sciences in the form of contracts, loans, grants, leases, donations, scholarships, fellowships or transfers of funds or property of the Federal Government; 
(d) to foster the interchange of information among marine scientists in the United States and foreign nations within the security provisions and limitations of the National Science Foundation Act of 1950 (64 Stat. ch. 171); and

(e) to evaluate the scientific aspects of programs of oceanographic and fisheries research and surveys undertaken by agencies of the Federal Government, universities and institutions receiving assistance from the Federal Government for oceanographic and fisheries research and ocean surveys.

\section{NATIONAL SCIENCE FOUNDATION, DIVISION OF MARINE SCIENCES}

SEc. 3. (a) Section 7 (a) of the National Science Foundation Act of 1950 is hereby amended by striking "and" after the semicolon in (3), redesignating (4) as (5) and inserting immediately after (3) the following new section:

"(4) Division of Marine Sciences; and".

(b) Section 8 (b) of the National Science Foundation Act of 1950 is hereby amended by substituting a semicolon for the period after "Board" and inserting immediately thereafter the following new proviso: "Provided, That the Division of Marine Sciences shall include among its membership a representative from the Office of Naval Research, the Hydrographic Office, the Coast and Geodetic Survey, the Bureau of Commercial Fisheries, the Atomic Energy Commission, the Maritime Administration, and at least six scientists from the universities and institutions receiving assistance from the foregoing agences."

SEc. 4. It is necessary in order to carry out the policies of S. Res. 136, Eightysixth Congress, and of this Act to have the National Science Foundation carry out, under laws, as amended, relating to such Foundation, specified duties as part of the general program for the development of the marine sciences in the United States. Appropriations authorized in this section shall be in addition to other appropriations provided for such Foundation to carry out its duties under law. There is hereby authorized to be appropriated to the National Science Foundation, during the ten-year period beginning with July 1 of the first fiscal year following approval of this Act by the President, the following sums :

(a) The sum of $\$ 9,950,000$ for the construction of oceanographic research ships ;

(b) The sum of $\$ 12,440,000$ for the operation of oceanographic research ships constructed under this Act;

(c) The sum of $\$ 8,250,000$ for construction of shore facilities for oceanographic research ;

(d) The sum of $\$ 37,200,000$ for basic oceanographic research operations: Provided, however, That the expenditure under this subsection (d) shall not exceed $\$ 8,000,000$ in any one year of the ten-year program.

(e) Such sums as may be adequate for specialized equipment for ocean exploration and research which may include bathyscaphs and other manned submersibles, manned and unmanned buoys, icebreakers and submarines converted for scientific use, acoustic telemetering devices, current meters, direct density measuring devices, cameras and underwater television, seismic equipment, turbulence measuring devices, biological sampling devices, precision salinometers, precision echo sounders, towed temperature recorders, magnetometers and other instruments and laboratory equipment: Provided, however, That expenditures under this subsection (e) shall not exceed $\$ 10,000,000$ in any one year of the ten-year program.

(f) The sum of $\$ 3,000,000$ for fellowships to graduate students training to become professional oceanographers: Provided, however, That annual costs of these fellowships shall not exceed $\$ 300,000$.

BUREAU OF MINES AND BUREAU OF COMMERCIAL FISHERIES, DEPARTMENT OF THE INTERIOR

SEc. 5. The Secretary of the Interior is authorized and directed, with such funds as may be appropriated or otherwise made available to him, to undertake a ten-year program of study and research as part of the general program for the development of the marine sciences in the United States. In furtherance of the purposes of this Act, the Secretary is authorized and directed to carry out, in addition to programs now underway, the following activities:

(a) Make grants of funds to qualified scientists, research laboratories or institutions in furtherance of the purposes of this Act, such grants to be used 
for basic and applied research programs, the purchase of equipment, acquisition or improvement of facilities, and for other uses necessary to carry out the work hereunder.

(b) Initiate and carry out a program for the replacement, modernization and enlargement in the number of oceangoing ships being used for research, exploration, surveying and the development of marine resources.

(c) Construct and operate a sufficient number of shore facilities and laboratories to support effectively the vessels provided for under the preceding item (b).

(d) Cooperate with other departments and agencies in the conduct of oceanwide surveys from which data relative to the study of ocean resources may be obtained.

(e) Conduct studies concerning the relation of marine life to radioactive elements, such studies to be directed toward determining the effect of distribution of radioactive elements in the sea on living marine organisms, and other such studies as the Secretary deems necessary to understand and evaluate the relation of radioactivity to the inhabitants of the marine environment.

(f) Conduct studies of the economical and legal aspects of commercial fisheries and the utilization of marine products.

(g) Request and obtain cooperation from other governmental agencies having an interest in the marine sciences, and cooperate with the several States, educational institutions, laboratories devoted to fishery research, marine science, oceanography, and with other public and private organizations and persons who may be of assistance.

(h) Determine the reserves of metals of industrial, commercial or monetary value in or beneath adjacent waters, and to ascertain techniques and probable costs of their recovery and extraction.

(i) Take such action and carry out other activities which he finds will accomplish the purposes of this Act.

SEc. 6. It is necessary in order to carry out the policies of S. Res. 136, Eightysixth Congress, and of this Act to have the Department of the Interior and its Bureaus and Offices carry out, under laws relating to such Department and its Bureaus and Offices, specified duties as part of the general program for the development of the marine sciences in the United States. Appropriations authorized in this section shall be in addition to other appropriations provided for such Department to carry out its duties under law. There is hereby authorized to be appropriated to the Bureau of Mines and the Bureau of Commercial Fisheries, Department of the Interior, during the ten-year period beginning with July 1 of the first fiscal year following approval of this Act by the President, the following sums:

(a) Such sums as may be necessary for construction of new ships for fisheries exploration and research : Provided, however, That in the construction of these ships, modern fisheries exploration and research vessels of other nations shall be studied with respect to design and performance with a view to increasing the Iseaworthiness, range, and efficiency of the United States fisheries research fleet.

(b) Such sums as necessary for operation of new fisheries research and exploration ships: Provided, however, That operation costs for new research ships placed in operation by the Bureau of Commercial Fisheries not aggregate in excess of $\$ 2,000,000$ per annum : Provided further, That in planning operations of the new research and exploration ships of the Bureau of Commercial Fisheries, the Secretary of the Interior shall give full consideration to the needs for such operation in the Gulf of Mexico, Bering Sea, other ocean areas of potential commercial importance, and the Great Lakes.

(c) Such sums as the departments deem adequate for capital expenditures in inaugurating, developing, or expanding new ocean resource studies and surveys, or constructing or procuring facilities for such studies including, but not limited to, unmanned buoys for automatic continuous oceanographic records, mesoscaphs for biological observations, automatic continuous plankton samplers, oceanaria and instrumentation for studies of marine life behavior, laboratories for research into marine survival, and establishment of an institute for research on diseases of fish, shellfish, and other marine life: Provided, however, That in constructing or procuring facilities for ocean resource studies, and in inaugurating such studies, full consideration be given to the fisheries resources of the Pacific and Atlantic Oceans north of 40 degrees north latitude, between 15 degrees and 40 degrees north latitude, the Gulf of Mexico, Bering Sea, other 
ocean areas of potential commercial value, and the Great Lakes, and that such facilities be located where they may provide maximum benefits to fishermen and other citizens residing in the United States.

(d) Such sums as are necessary for operations, excluding ship operations, of fisheries resource studies including, but not limited to, those stated above in (c) warime population sampling, biological surveys, ecological mapping, taxonomic development, genetics of marine organisms, pond fish culture and braking water farming, estuarine studies, transportations and nutrient increase research : Providal, howeter, That expenditures for operatious of new resources studies by the Bureat of Commercial Fisheries of the Delatiment of the Interior not exceed $\$ 10,000,000$ per annum.

(e) The sum of $\$ 6,500,000$ for continuing studies over a ten-year period of utilization of marine products for human consumption, animal feeds, industrial purposes, fertilizers and organic chemicals, and the development of new uses of marine products: Provided, howevcr, That in directing these studies the Secretary of the Interior shall give full consideration to their being carried on in existing institutions through the issuance of grants to said institutions, for continuing studies orer a ten-year period of the economics and law of commercial fisheries and for the investigation of the mineral deposits on the ocean floor and mineral resources in the sea.

DEPARTMENT OF COMMERCE

SEC. 7. The Secretary of Commerce is authorized and directed, with such funds as may be appropriated or otherwise made arailable to him, to undertake a ten-year program of study and research as part of the general program for the derelopment of the marime sciences in the United States. In furtherance of the purposes of this Act, the Secretary is authorized and directed to carry out the following activities:

(a) Request and obtain cooperation from other Government agencies having an interest in the marine sciences and ocean surveys, and cooperate with educational institutions and laboratories devoted to the marine sciences and oceanography, and with other public and private organizations and persons who may be of assistance.

(b) Establish within the Department of Commerce a National Oceanographic Records Center, which records center shall collect from other agencies and departments of the Federal Government, agencies of the several States, oceanographic institutions and laboratories and other sources all oceanographic data, and prepare and disseminate such oceanographic data for public use.

(c) Initiate and carry out a program for the replacement, modernization and enlargement in the number of oceangoing ships for use in ocean and coastal surveys by the Coast and Geodetic Survey.

(d) Construct and operate a sufficient number of Coast and Geodetic Survey shore facilities to support effectively the vessels provided for under the preceding item (a), and provide instruments and equipment essential for efficient utilization of such shore facilities or survey ships.

(e) Inaugurate in the Weather Bureau a comprehensive ten-year study of the interchange of energy between the oceans and the atmosphere, and to prepare, based on such study, climatological maps illustrating the balance of incoming and outgoing radiation and heat exchange between the oceans and the atmosphere. The provisions of this subsection (e) may be carried out by means of contracts with public or private organizations, or by grants to scientific institutions carrying on such studies.

(f) Require that the Maritime Administration construct ships of approximately five hundred tons and one thousand two hundred to one thousand five hundred tons displacement specifically designed for basic oceanographic research with due attention given to suitable arrangements of laboratory space and living quarters for scientists, space and power for winches and other auxiliaries, sea keeping and handling qualities at low speeds, quiet operation, efficient and economical scientist-crew ratios, and operation in all kinds of weather, such ships, when completed, to be made available, at the discretion of the Secretary, to nonprofit oecanographic research centers, to other agencies of the Federal Government, or, pursuant to negotiated contracts or grauts, to State institutions engaged to oceanographic research requiring oceangoing scientific ships, with preference given to such institutions which have engaged in such research prior to this Act. 
SEc. 8. It is necessary in order to carry out the policies of S. Res. 136, Eightysixth Congress, and of this Act to have the Department of Commerce and its Bureaus and Offices carry out, under laws, as amended, relating to such Department or such Bureaus and Offices, specified duties as part of the general program for the development of the marine sciences in the United States. Appropriations :authorized in this section shall be in addition to other appropriations provided for such Department to carry out its duties under law. There is hereby authorized to be appropriated to the Department of Commerce and its Bureaus and Offices, during the ten-year period beginning with July 1, of the first fiscal year following approval of this Act by the President, the following sums :

(a) The sum of $\$ 250,000$ for capital outlay in the establishment of a National Oceanographic Records Center.

(b) Such sums as are necessary for operating expenses of a National Oceanographic Records Center: Provided, hovever, That expenses for this purpose during the first year not exceed $\$ 100,000$, and that this amount shall not be increased more than 10 per centum per annum in each of the subsequent years of this program.

(c) Such sums as are necessary for construction by or for the Coast and Geodetic Survey of two survey ships of five hundred tons displacement, six survey ships or one thousand two hundred to one thousand five hundred tons displacement, and two survey ships of two thousand tons displacement or more.

(d) Such sums as are necessary for operations of new Coast and Geodetic Survey survey ships authorized under this Act during the ten-year life of this program-

for construction of new shore facilities for processing and evaluating Coast and Geodetic Survey data obtained through surveys and related research conducted from new oceangoing Coast and Geodetic Survey ships;

for expanded operations, excluding ship operations, of the Coast and Geodetic Survey during a ten-year period ; and

for establishment and operations of a ten-year study of the interchange of energy between the oceans and the atmosphere.

\section{DEPARTMENT OF HEALTH, EDUCATION, AND WELEARE, OFEICE OF EDUCATION}

SEc. 9. The Secretary of Health, Education, and Welfare is authorized and directed, with such funds as may be appropriated or otherwise made available to him, to undertake a ten-year program of obtaining new faculty in oceanography and marine sciences as part of the general program for the development of the marine sciences in the United States. In furtherance of the purposes of this Act, the Secretary is authorized to provide assistance through the Office of Education in the form of teacher salaries and equipment.

SEc. 10. It is necessary in order to carry out the policies of $\mathrm{S}$. Res. 136, Eighty-sixth Congress, and of this Act to have the Office of Education, Department of Health, Education, and Welfare carry out, under laws relating to such Department or Office, specified duties as part of the general program for the development of the marine sciences in the United States. Appropriations authorized in this section shall be in addition to other appropriations provided for such Department or Office to carry out its duties under law.

\section{ATOMIC ENERGY COMMISSION}

SEc. 11. In furtherance of the policies in S. Res. 136, Eighty-sixth Congress, and of this Act, and for the purpose of determining the effects of radioactive contamination upon the oceans and life within the oceans and their estauries, and for regulating in the interests of public safety, health and welfare, the introduction of radioactive materials in the oceans, the Atomic Energy Commission is hereby authorized to conduct, in the marine environment, an intensive ten-year program of control and monitoxing of radioactive waste disposal and studies including, but not limited to, circulation and mixing processes which affect the dispersion of introduced contaminants in coastal and estuarine environments and in the open ocean, inorganic transfer of radioactive elements from seawater to sediments, the effect of radioactive elements on living organisms in the oceans, coastal waters and estuaries and the genetic effects of radiation on such organisms. The Atomic Energy Comission is further authorized to carry out any of its duties or functions under this or other Acts, including the use of scientific ships and personnel, in cooperation with other agencies of the Federal Government, or through contracts with or grants to State institutions or 
independent scientific laboratories undertaking or equipped to undertake such programs: Provided, however, That those aspects of the program relating to regulating and monitoring the introduction of radioactive material in the ocean shall be carried out by the Coast and Geodetic Survey or the Public Health Service, or both, with funds made available by the Atomic Energy Commission.

SEc. 12. It is necessary in order to carry out the policies of S. Res. 136, Eighty-sixth Congress, and of this Act to have the Atomic Energy Commission carry out, under laws relating to such Commission, specified duties as part of the general program for the development of the marine sciences in the United States. Appropriations authorized in this section shall be in addition to other appropriations provided for such Commission to carry out its duties under law. There is hereby authorized to be appropriated to the Atomic Energy Commission, during the ten-year period beginning with July 1 of the first fiscal year following approval of this Act by the President, the following sums as are necessary-

for engineering studies in connection with control and monitoring as authorized in section 11 of this Act: Provided, however, That expenditures for this purpose not exceed $\$ 370,000$ in any one year of the ten-year program authorized by this Act;

for participating in international meetings of scientists and technical experts relating to international control and monitoring of radioactive waste disposal in the marine environment: Provided, hovever, That expenditures for this purpose not exceeded $\$ 30,000$ in any one year of the ten-year program;

for estuarine and coastal studies authorized in section 12 of this Act: Provided, hovever, That expenditures for this purpose not exceed $\$ 2,800,000$ in any one year of the ten-year program of estuarine and coastal studies authorized by this Act;

for research to determine circulation and mixing processes which control the dispersion of radioactive wastes introduced in deep waters of the open ocean: Provided, however, That the expenditures for this purpose by the Atomic Energy Commission not exceed $\$ 1,400,000$ per annum;

for studies of the inorganic transfer of radioactive elements from sea water to the sediments: Provided, however, That expenditures by the Atomic Energy Commission for this purpose not exceed $\$ 484,000$ in the first year of the program or $\$ 299,000$ in subsequent years of this ten-year period;

for studies of the effects of the biosphere on the distribution and circulation of radioisotopes in the ocean and its seas: Provided, however, That expenditures by the Atomic Energy Commission for this purpose not exceed $\$ 938,000$ per annum;

for studies of the genetic effects of atomic radiations on marine organisms: Provided, however, That expenditures by the Atomic Energy Commission for this purpose not exceed $\$ 100,000$ per annum :

for field experiments in confined bodies of water utilizing radioisotopes: Provided, however, That expenditures by the Atomic Energy Commission for this purpose not exceed $\$ 100,000$ per annum ; and

for two major open-sea tests of radiological contamination at sea, its effects on marine life, and its potential effects on humanity.

\section{DEPARTMENT OF THE NAVY}

SEc. 13. In order to carry out the policies of S. Res. 136, Eighty-sixth Congress, of this Act and of the Navy's long-range program for oceanographic research known as TENOC, the Secretary of the Navy is authorized and directed to undertake a ten-year program of expanded basis oceanographic research and hydrographic surveys as a part of the general program for the development of the marine sciences in the United States. The Secretary is authorized and directed with such funds as may be appropriated or otherwise made available to him for purposes of this Act, to carry out the following activities:

(a) Make grants of funds to scientists, research laboratories, or institutions in furtherance of the purposes of this Act, such grants to be used for the purchase of equipment, acquisition or improvement of facilities, employment of scientists and personnel, and for other uses necessary to carry out the work hereunder:

(b) Initiate and carry out a ten-year program for the replacement, modernization, and enlargement in the number of ships for use in basic research and 
hydrographic survers, and to supply, when available, ships designed for basic research to nonprofit scientific institutions: Provided, That when ships are supplied under this provision title to the ships shall remain with the United States Government and the ships shall be reassigned or returned to Federal operation upon termination of the grant or contract with the institution.

(c) Construct and operate a sufficient number of shore facilities and laboratories to support effectively the expanded program of basic oceanographic research and hydrographic surveys authorized for the Department of the Navy to undertake under this Act.

(d) Develop, construct, or acquire new or improved vehicles for ocean research and exploration, including but not limited to bathyscaphs and other manned submersibles, icebreakers and submarines converted for scientific use, seismic equipment, turbulence measuring devices, precision echo sounders, acoustic telemetering devices, and instruments for the study of the current structure of the ocean, oceanic temperatures, bottom topography, sediments, heat flow through the ocean bottom, sound transmission and velocities, ambient noise, biological activity and specimens, and water samples for salinities, phosphates, oxygen, nitrates, and other chemical or elemental components of the oceans.

(e) Continue and expand the Navy's support of civilian oceanographic laboratories as proposed in project TENOC approved by the Chief of Naval Operations, and substantially similar to the recommendations made in the report of the Committee on Oceanography of the National Academy of Sciences-National Research Council.

(f) Establish with the National Science Foundation or the National Academy of Sciences-National Research Council-a program of scholarships for selected students beginning at the senior level in undergraduate school, and carrying through with four years of graduate training and research in the marine sciences: Provided, That the Department of the Navy may recommend to the National Science Foundation the institutions qualified to participate in this program.

(g) Conduct a systematic and expanded program of three-dimensional ocean surveys including measurements or studies of depths, salinity, temperature, current velocity, wave motion, magnetism and biological activity.

(h) Continue a policy of expanding assistance and support to existing civilian laboratories and universities engaged in basic oceanographic research, foster the establishment and growth of new civilian laboratories for applied oceanographic research needed by the Navy. In the designation of new laboratories to receive Navy assistance consideration shall be given to oceanographic location with reference to the oceans, with the object of maintaining a balanced program of research in and adjacent to the seas and oceans bordering the United States.

(i) Request and obtain cooperation from other governmental departments and agencies having an interest in the marine sciences, and to cooperate with the several States, with educational institutions, laboratories, and other public and private organizations and persons who may be of assistance.

SEc. 14. It is necessary in order to carry out the policies of S. Res. 136, Eighty-sixth Congress, of this Act and of the Navy's long-range program for oceanographic research known as TENOC to have the Department of the Navy carry out, under laws relating to such Department, specified duties as part of the general program for the development of the marine sciences in the United States. Appropriations authorized in this section shall be in addition to other appropriations provided for such Department to carry out its duties under law. There is hereby authorized to be appropriated to the Department of the Navy, during the ten-year period beginning with July 1 of the first fiscal year following approval of this Act by the President, such sums as are necessary-

for the construction of nine one thousand two hundred to one thousand five hundred-ton displacement research ships: Provided, however, That not more than two of these ships shall be built the first year of the program; two in the second year; one in the third year; two in the fourth year, and one in succeeding years of the program:

for the construction of four two thousand to three thousand-ton displacement research ships: Provided, however, That not more than one such ship shall be built in any one year of the ten-year program;

for the construction of two survey ships of approximately five hundredton displacement;

for the construction of five survey ships of one thousand two hundred to one thousand five hundred-tons displacement: Provided, hovever, That not more than two of these survey ships shall be built in any one year; 
for the construction of three survey ships of two thousand tons displacement;

for the construction of one research ship of three hundred-tons displacement;

for operations of basic research ships in excess of present operating costs for such ship operations: Provided, however, That the operating costs of new one thousand two hundred to one thousand five hundred-ton research ships not exceed $\$ 120,000$ each per annum; that that of the two thousand to three thousand-ton ships not exceed $\$ 700,000$ each per annum, and that of the five hundred-ton ships not exceed $\$ 250,000$ each per annum;

for construction of new shore facilities for basic research ;

for basic research operations other than ships ;

for construction of new shore facilities for survey work;

for engineering needs for ocean exploration and research which may include bathyscaphs and other manned submersibles to be used for research, manned and unmanned buoys, icebreakers and submarines modified or converted for scientific use, acoustic telemetering derices, current meters, direct density measuring devices, cameras and underwater television, seismic equipment, turbulence measuring devices, biological sampling devices, precision salinometers, precision echo sounders, towed temperature recorders, magnetometers and other instruments and laboratory equipment for oceanographic research ; and

for establishing a program of scholarships for selected students as authorized in section 13 (f) of this Act: Provided, however, That costs to the Department of the Nary of these fellowships not exceed $\$ 300,000$ per annum.

\section{GENERAL}

SEC. 15. (a) Nothing in this Act shall operate to limit, restrict, or otherwise interfere with carrying out any work programed prior to enactment.

(b) All appropriations authorized in this Act shall be in addition to other appropriations provided for the various departments, agencies, bureaus, and offices to carry out their duties under law.

The Chammar. This is the first of sereral hearings to weigh the importance of the oceans and the Great Lakes to our security, welfare, and economy; the adequacy of our scientific knowledge of these deep waters, and what, if it is not adequate, we should do about it.

Except for the 28-mile thread of land at the Isthmus of Panama we are literally living on an island-a continental island less than 5 percent of the earth's surface.

We share this island with Canada, Mexico, and the small Central American Republics, and its total population is less than 10 percent of that of the world.

Outside the continental island we call North America the closest nation to us is not England, or Iceland, or France, or even Cuba. It is Soviet Russia which at its nearest mainland point is only 53 miles from our 49 th State. No nation of the free world except Canada and Mexico is that close.

Our ocean coastline is 12,255 miles long, and that of Canada is even longer. We are the only nations in the world with three oceans washing our shores, a circumstance that in this scientific age can prove either a tremendous asset or a fearsome menace.

The oceans are deep, dark, and mysterious. It has been frequently said that we know less about the 71 percent of earth's surface which they cover than we know about the back side of the moon.

Our witnesses today are scientists. They are members of the Committee on Oceanography of the National Academy of Sciences or of special panels of the committee.

Collectively they perhaps know more about the oceans than any similar group of scientists that could be assembled at one time in the United States. 
Equally important to their knowledge of the oceans is their complete awareness of what is now known about the oceans, and what is yet to be developed and discovered by scientific research and surveys.

That is what we are here to find out. To develop effective and constructive legislation we must take inventory of not only the basic facts about the oceans which are available to us, but of the gaps which exist in that knowledge.

We must appraise this knowledge of ours or absence of knowledge in relation to our commerce, communications, prosperity, health, climate, and national defense-yes, and in relation to the future peace of the United States and the free world.

We must determine our marine responsibilities and plan our course of congressional action in the light of what other nations are doing in the distinctive field of marine science, and particularly in the light of what the hostile or unfriendly nations alined against us are doing in the field.

In an article in a recent issue of U.S. Naval Institute proceedings a fighting officer of World War II and the Korean conflict, Capt. Daniel J. Carrison, U.S. Navy, reports:

The Soviet oceanographic research program far surpasses that of the free world.

Elsewhere he relates what we all know, that Russia has the world's largest submarine force and what I am sure is not widely known, that Red China ranks fourth in undersea power. These two nations share most of the other side of the Pacific Ocean.

Witnesses at today's hearing undoubtedly will tell us the relation between marine scientific research and development and submarine operation, and what it means also in terms of protection against and detection of enemy submarines.

Before the conclusion of these hearings, I think it will be amply demonstrated that not only the United States, but the entire free world has a vital stake in expanding our marine research.

As I stated several weeks ago in a talk before the Franklin Institute of Philadelphia, Russia's dominion over the oceans would give her control of 95 percent of the earth's surface and imperil the remaining 5 percent with ballistic missiles fired from submarines hovering along the Continental Shelf.

Control of the oceans would enable the Communist bloc to fragmentize the free world alliance, cut the lifelines to the United States, and block the supply lines from the United States to our oversea allies and bases.

Soviet Russia then would have the power to terminate our assistance, both military and economic, to other contries at the whim of the Kremlin, and to bully and blackmail the nations to which that aid has gone.

The Committee on Oceanography, members of which appear here today, issued its first report over a year ago and has since issued eight additional reports on special phases of the proposed program. Three reports remain to be published. They are "Oceanographic Research for Defense Applications," "History of Oceanography," and "Oceanwide Surveys." We will hear the substance of these forthcoming reports at these hearings. 
Shortly after issuance of the initial report the Committee on Interstate and Foreign Commerce unanimously approved and the Senate adopted Senate Resolution 136 commending the Committee-the outside committee-on Oceanography and its objectives.

At the close of the first session of the present Congress, 13 Senators, including myself, introduced S. 2692, designed to implement the major recommendations of the Committee on Oceanography calling for a comprehensive 10-year program of oceanograplic research and surveys.

Undoubtedly this bill, like most legislation when first drafted, can be improved as a result of the advice and counsels obtained during the course of these hearings, but I submit that the basic purpose of the proposed measure must stand.

That purpose is to assure the United States a fund of scientific knowledge of the oceans, their estuaries, and the Great Lakes second to that of no other nation, to provide the facilities for obtaining that knowledge, and to encourage the education and training of an adequate number of scientists and technicians to assemble that knowledge and to make maximum use of it after it is obtained.

This program, as envisioned by the Committee on Oceanography and in S. 2692, would entail an annual expenditure of about $\$ 65$ million. Is such an expenditure justified?

That question will, I believe, be resolved to the satisfaction of this committee during the course of these hearings. It must be weighed from the standpoint of both military and peacetime benefits. In time of war, I think it will be ably demonstrated, the benefits accruing from this program of oceanographic research would be incalculable. They could well spell the difference between defeat or victory, between death or survival. In times of peace, in my opinion, the returns from. such an investment in scientific knowledge will many times repay the anticipated expenditure.

There came to my desk today a thick book titled "Marine Boring and Fouling Organisms," edited by Dr. Ray, one of our prospective witnesses.

In this book I read the surprising statement that marine animals that burrow into piles, floats, wooden drydocks and ships' bottoms cause more than half a billion dollars damage annually in the United States alone, a considerable amount of this to Navy ships and installations. Marine biologists are working on the problem.

Seaborn hurricanes, a combined oceanographic-meteorological problem of great magnitude caused damage estimated by the Weather Bureau at $\$ 2,837$ million to coastal property of the United States between 1915 and 1955, and during the past 4 years caused damage aggregating \$205 million despite improved warning service. Oceanographers are learning much about the phenomena that causes thesedisastrous hurricanes. This promises much for commerce and coastal enterprises.

With mounting population and demand for protein-rich fisheries products our domestic catch is dropping while that of Soviet Russia has doubled in the past 6 years. American canned salmon production has fallen from 207 million pounds in 1950 to only 118 million pounds in 1959. The tuna catch of 399 million pounds in 1950 was down to 285 million pounds last year. Ground fish dropped from 187 million pounds in 1950 to 91 million in 1959, or less than half that 10 years: 
ago. Today 45 percent of all our food fish are imported; 10 years ago only 18 percent of the fisheries products we consumed were brought in from abroad.

Some of the causes are economic, and S. 2692 calls for economic studies in addition to scientific research. It is our hope that this will help restore a billion dollar industry that gives employment in normal years to half a million citizens of our Nation.

We all know of the fearful destruction that can be caused by tidal waves, or tsumami as they are known to scientists. That at Hilo, Hawaii, in 1946 caused a heavy loss of life and \$17 million damage. But in addition to these earthquake-induced catastrophes normal wave action each year causes property losses in the United States estimated at more than $\$ 15$ million.

The Beach Erosion Board of the Corps of Engineers is now making: significant contributions toward mitigating this damage.

I could go on with many other illustrations of the peacetime benefits that can be achieved by a comprehensive and coordinated longrange program of marine research and surveys. But I shall now turn this hearing over to the testimony of scientists who have come here from California, Maine, Washington, Florida, and four other States which have a direct and immediate interest in advancement of the marine sciences.

The first witness will be Athelstan Spilhaus of the University of Minnesota.

(A biographical sketch of Dr. Spilhaus follows:)

Athelstan Frederick Spilhaus, D. Sc.

Born: Cape Town, Union of South Africa, November 25, 1911; son of Karl Antonio and Nellie (Muir) Spilhaus.

Education: B. Sc., University of Cape Town, 1931; S.M., Massachusetts Institute of Technology, 1933; D. Sc. University of Cape Town, 1948.

Came to United States 1931; naturalized in 1946.

Research assistant, Massachusetts Institute of Technology, 1933-35 research on aeronautical and meterological instruments.

Assistant Director of Technical Services, Union of South Africa Defense Forces, 1935-36. Initiated first upper air meteorological investigations in South Africa.

Research assistant in oceanography, Woods Hole Oceanographic Institution, 1936-37. Model experiments in oceanography and development of bathythermograph.

New York University, meteorology, assistant professor 1937, associate professor 1939, professor 1942-48. Started new Department of Meteorology at New York University and was chairman from 1938 to 1947.

Investigator in physical oceanography, Woods Hole Oceanographic Institution, 1938 to date. Development and use of rapid measuring oceanographic instruments.

U.S. Army Air Forces, 1943-46. Research and development of meteorological equipment. Contributed to radar and radio upper wind finding, sferics, and meteorological instruments for measurements from aircraft in flight. Awarded Legion of Merit, 1946.

Director of research, New York University, 1946-48. Developed research division, covering fields of engineering and physical sciences.

Meteorological adviser to Union of South Africa Government, 1947. Reorganization of meteorological services.

Dean, Institute of Technology, University of Minnesota, since January 1949.

Scientific director of weapons effects of two Nevada atomic tests, 1951, and consultant, Armed Forces Special Weapons Project, Department of Defense. Recipient, Exceptional Civilian Service Medal, U.S. Air Force, 1952.

Member of the Baker Mission to Korea, July 1952 (civilian scientific mission sent by U.S. Army). 
Fellow, Royal Meteorological Society ; member, Royal Society of South Africa; fellow, American Rocket Society ; member, American Geophysical Union; member, American Meteorological Society; member, American Society of Limnology and Oceanography; registered professional engineer (Minnesota) and member, Minnesota Society of Professional Engineers; member, American Society for Engineering Education. Member, Sigma Xi, Tau Beta Pi.

Currently: Member, Advisory Panel on General Sciences, Office of the Secretary of Defense.

Member, U.S. National Committee for the International Geophysical Year, National Academy of Sciences-National Research Council (NAS-NRC).

Member, USNC Technical Panel on the Earth Satellite, IGY.

Member, Committee on Oceanography, NAS-NRC.

Member, Committee on Polar Research, NAS-NRC.

Member, U.S. National Commission, UNESCO.

Meuber, Board of Trustees, and Chairman, Scientific Advisory Committee,

Woods Hole Oceanographic Institute.

Inventor of the bathythermograph.

Author: "Workbook on Meteorology," "Meteorological Instruments," "Weathercraft," "Satellite of the Sun," "Turn to the Sea."

"Our New Age" (with Earl Cros), a weekly Sunday feature on science, and numerous articles in scientific journals.

\section{STATEMENT OF ATHELSTAN SPILHAUS, UNIVERSITY OF MINNESOTA}

Mr. SpILfaus. Mr. Chairman and Senators, I am Athelstan Spilhaus, dean of the Institute of Technology at the University of Minnesota, a distinguished institution about as far from the oceans in any direction as you can get in North America.

Mr. Chairman, I am also associated and have been since 1934 with the Woods Hole Oceanographic Institution of which I am presently a trústee.

I am deeply convinced that our Nation must stimulate and develop a broad thoroughgoing research program in all phases of oceanography, not only to secure our security by surveillance under the waters to lessen the danger of war, but also as an immense potential contribution to the national economy, to take our place in oceanography as a leader in this science, and to use research in the seas which are owned by no nation to lessen international tensions and promote cooperation between all the nations that border the seas.

The report of the National Academy of Sciences Committee on Oceanography has been prepared, as you said, Mr. Chairman, in about 12 chapters. The task that Dr. Harrison Brown set for his colleagues on the committee was no light one and was not taken so by any one of us and could not be accomplished properly in less than the 2 years that we have been working.

It involved visiting various oceanographic institutions, talking with all Government agencies concerned, collecting data preparatory to discussions and analysis culminating in the preparation of a series of reports.

Later on today, after Mr. Sumner Pike and I have introduced and summarized the recommendations, various members of our committee will present aspects of the total program in detail.

Shortly after World War II a cartoon appeared in the New Yorker magazine which depicted an encyclopedia salesman with his foot in the door trying to sell a housewife with the phrase, "For instance, what do you know about oceanography?" 
Up to that time most people hadn't even heard of oceanography nor could they pronounce the word. Now it is in truth a household word, not only in those States along our great coastline, but right to the middle of our country where I live.

You might ask why there has been this sudden increase in interest in the oceans and why it came at this particular period. I think there are several answers.

Laboratory science has developed new techniques and methods which we can apply to the sea. Engineering advances have produced vehicles not hitherto available which make it possible to explore the sea more thoroughly.

Moreover, scientists in recent years in many different fields have shown an awakening interest in the history of our planet, the history of the universe, the origin of life and its development.

One might say that these huge and wonderfully intriguing questions are the central ones of all science.

But this awakening means that now the most distinguished and imaginative minds in many, many different branches of science are finding that the oceans are a place to turn to apply their knowledge in order to find some of the answers which, fitted together, will some day tell this history.

Curiously enough, with our new vehicles and new techniques, many geophysical studies can be better carried out at sea than in man's natural habitat on land. For the history of the earth, the sea preserves records in its sedimentary layers like the pages of a book except that ocean sediments are less subjected to the weathering and other changes that make it difficult to interpret the history locked up in the rocks on land.

For the history of the universe, earth is our handy laboratory. The same laws that govern the universe govern processes on our planet. If we can understand these processes on earth, it will help us to understand the universe and space.

As to the origin of life and its development, life started in the sea and biological and ecological studies which relate to the oceans are fundamental in the understanding of all life, including our own, and including the life of organisms in other environments such as space and other planets.

The various phases of the oceanographic program that you will hear about from my distinguished colleagues will fall into one or the other of these five broad categories.

Under "observation" we will hear about oceanwide surveys, new devices for observation, research ships and the like.

Under "understanding," we will hear about the basic research that is necessary to analyze the observational data and the research that is necessary to design further experiments to answer special questions which in turn will call for new kinds of observations.

These two categories are followed by "prediction," "control" and "use."

Now, ocean resources, that is, conservation, exploitation and their contribution to our economy, to our defense applications, and aspects of radioactivity all fall under the various broad categories of prediction, control and use.

Finally, on the ways and means of carrying out a program of this magnitude, my colleagues will talk about how in the vast oceans we 
can pay attention to the manpower requirements. We have in our committee paid great attention and laid stress on the importance of the educational manpower requirements and on the importance of sharing this vast task internationally.

International cooperation will help us get the job done and will provide yet another way for us to strengthen ties of friendship with other nations.

We are also prepared to tell you a little of the history of oceanography which is but a prelude to what will come and sets it in its proper perspective. Or, as the taxidriver explained the inscription on the Archives Building here in Washington, in oceanography, like in anything else, "you ain't seen nothing yet."

For observation, we must have survey ships to give us an overall picture of what the oceans are like. They are so vast that our ignorance about them is abysmal.

In recommending increased emphasis for oceanography, I think it is well to point out that the fruits of this work will aid in the understanding and exploration of space. Just as we know that byproducts from the space program will help us to understand the oceans. For instance, the exploration of Antarctic waters with days of cloud cover is made extremely difficult by lack of navigational facilities. It is no use measuring precisely what is there in the oceans if we don't know where we are. If we don't know where "there" is.

The great achievement in the last few weeks of launching the first navigational satellite is the first step to lick this problem. Now, ships in all waters of the world will have a true lighthouse in the sky that clouds and storm cannot obscure. But in oceanography, our vessels will need the receivers and computers to interpret the radio signals, to understand the language of the satellite lighthouse.

For research observations too, we must also have surface ships. These differ from survey vessels in that the observations they make are designed to answer a specific question that some scientist proposes to ask the sea.

For oceanographic observations in the past, because the effort was so small, oceanographers have of necessity had to employ instruments built with their own stubby fingers. These have been imaginative and useful, but we now come to the time when the task is too great and when we should lean on the tremendous strength of our American engineering and productive capability to provide our newer instruments, to provide entirely new devices like bathyscaphs, floating and submerged buoys, sonor, and the like.

For "understanding" all these observations, there must be built up in proper balance sufficiently trained minds (this is education and manpower) with adequate shore-based laboratories in conjunction with our great universities and other institutions, so that the strength of scientists in the basic fields, like physics, chemistry, biology and mathematics, can be brought to bear on the problems of the oceans.

Understanding will lead in turn to prediction of happenings in the seas. We already predict tides. We predict the breakup and formation of ice, the drift of dangerous icebergs. Already a day can be saved in crossing the Atlantic by predictions of wind, waves, and currents. We must learn to predict conditions both biological and physical which hamper or assist our communications deep in the sea 
by sound propagation. Predictions will also be made for fishermen and the beginnings of these too are already successful.

Under "control" and "use" for defense applications, the most crucial problem can be summarized by saying that we must make the sea transparent. Not by changing the sea, but by finding ways that we can look right through it and have surveillance over the comings and goings just as our aircraft radar control networks do in the atmosphere and as the satellite Tiros is now doing for large-scale happenings on the earth as a whole.

Under "control" there are distant vistas of stirring the ocean waters to stimulate productivity, or of fertilizing the ocean with trace elements to promote growth of its life. But more urgent and closer at hand than the control of the unruly ocean are aspects of control that we may be exerting unwittingly by using the ocean as a radioactive garbage dump. We urgently need much more study by biologists, by radiochemists and radiophysicists to make sure that we are not doing something to the ocean in this way that our succeeding generations will blame us for.

Like any good science, oceanography, even if not directed to specific aims, will of itself develop byproducts which will help every man, woman and child; byproducts in new and more abundant foods, in medicine, in providing and distributing fresh water and in minerals.

When you hear about ocean resources in detail later, the emphasis will naturally be on fisheries which will become increasingly important for the supply of human protein as our population increases.

But, of course, the most useful substance we get from the sea is fresh water. We have not forgotten this but our committee felt that the artificial production of fresh water from the sea is presently being pursued vigorously and need not concern the oceanographer.

On the other hand, the understanding of the physics of clouds, of the natural evaporation from the sea, of the heat and material exchange across the sea's surface where it meets the air, these may all contribute ultimately to a possible control of rainfall which could then insure the better distribution of natural fresh water in time and space.

In conclusion, Mr. Chairman, I want to leave these most important topics of the scientific technological, military, and economic importance of the ocean which I have touched upon and turn to what this U.S. program in oceanography might contribute to the understanding among human beings and what it might contribute to the humanities.

Nine months ago there was an International Oceanographic Congress in New York where nearly 1,000 oceanographers from all over the world came together. There was some controversy, but it was the controversy of scientists who, irrespective of nationality, were bound together by their common interests. It was the healthy controversy of each propounding his explanation, of one building on another's mistakes. There was an atmosphere of fellowship on the recognition that the mistakes in science are the sturdy, lower rungs we ascend toward understanding.

Already the reports of this committee under Dr. Harrison Brown's chairmanship have had a profound effect in stimulating oceanographic work in other countries. We must by all means continue this 
friendly leadership in international oceanography. We nust promote our understanding of the oceans so we can intelligently take part in the treatymaking as to the law and ownership of the seas, so that wo will promote, through this treatymaking, international good will.

The seas have, throughout history and prehistory, provided the material which excited not only explorers, adventurers and discoverers and scientists, but also the artists and writers who have produced epics of the seas. And these, like all other good creative work, submerge differences between the people.

Like atoms for peace, we can use the oceans for peace. We must have leadership on the oceans in the face of the threat of war and equally we must have leadership on the oceans in our hopes and our work toward peace.

The Chatruas. Dr. Spilhaus, in your very excellent book, the summarization, "Turn to the Sea," in your conclusions you make this statement:

If we are unfortunate enough to have to wage war in the next few years, the inner space of the ocean will be without question a more important battlefield than outer space.

That would be a general conclusion.

The chairman of this committee happens to be on the Space Committee too, of the Senate, and I happen to be chairman of a subcommittee that handles their appropriations, so I wear a couple of hats here; three of them as a matter of fact.

But I said some weeks ago that a constructive long-range oceanographic program would cost us about $\$ 60$ million annually for the next 10 years, or approximately 6 percent of what we are spending for space research, exclusive of military applications.

Now, in view of what you have discussed and the conclusions of the committee, would you think as a taxpayer, with knowledge of the expenditure in these two fields, that 6 percent of what we spend for space would be too much for marine research and surveys, particularly in view of your statement here?

Mr. SpIlfadus. Well, Mr. Chairman, I am in somewhat the same position as you. I have been very much interested in the space program from its early beginnings.

As I said in my prepared statement, every bit of science, whether it be of space or of the oceans, contributes mutually to the advancement of all science-I would say, in direct answrer to your question, that 6 percent of the present space program might hardly be noticed in that program and would give us an oceanographic program of real significance.

The Chamrinan. And in which a great deal of what we would find out in the oceanography program would go toward the benefit of the whole space and depth program, whatever" we may have.

Mr. Spilhads. Yes, sir.

The Chamruax. Some of it overlaps, I suspect. Weather and things of that sort.

Mr. Sprlmaus. The basic scientific discoveries always overlap.

The Chairmax. Are there any questions, Senator Thurmond?

Senator Thurarond. Thank you, Mr. Chairman.

Is there any question in your mind that the research in oceanography would benefit the national defense? 
Mr. Spilhaus. I would put it even stronger than that, sir. In my opinion I think we can ill afford to neglect oceanography as we have done in the past from the point of view of national defense. We have fallen into the curious situation where people who travel the oceans are perhaps more concerned with outer space than they are with the medium that they are moving in.

Senator Thurmond. I am deeply concerned with the debt of the Federal Government, deficit financing, and spending and spending and spending, but I think the first obligation of this Government is to provide for the national defense and the survival of our people.

I have been impressed with the importance of this work in connection with that and I just wanted to get your opinion on how closely you felt this was tied in with the national defense.

Mr. Spilhaus. I think it is tied in extremely closely, Senator.

Senator Thurmond. Thank you.

The Chatrman. And would you not say, Doctor, that looking solely at the military aspect of the thing, that the emphasis on defense, or the emphasis on whatever are the military operations of the Soviet have completely shifted to the space and the under-the-water fields? Most of their efforts are shifting to those two phases?

Mr. SpILhads. There is certainly great emphasis in both those fields.

The Chatrman. Well, they have 500 submarines. Only this year they reduced their basic ground forces in order to use those people for this sort of thing.

So they have at least concluded that in anything in the future that may happen, this would be of vital importance.

Senator Thurmond. I was impressed with a figure given here by the chairman in his statementwhich incidentally I thought was a very fine statement, Mr. Chairman.

The Champian. Thank you.

Senator THURMrond. It is about the damage to vessels because of biological disturbances.

I am just wondering; besides the national defense and from the standpoint of food-it could be a main source of food in this country and I was reading yesterday that possibly by 1980 we may not be able to supply water in this country, that we are going to have to use the ocean water to furnish water to our people in cities and other parts of the country. That we have to go forward with that saline research project.

From the standpoint of defense, food and water and the prevention of the destruction of vessels which ply the seas come about. Now, what other results would result from research in oceanography?

Mr. SpILHaus. As a taxpayer I like to remember that while we must study the oceans for our national defense there are peaceful byproducts of this research. For example, during World War II research on marine fouling organisms paid for itself many, many times. I am sure that Dr. Ray or Dr. Iselin will tell you more of this work.

That is just one example of how a program that you must do for the necessity of national defense pays off in other ways. I am convinced that this is true of any oceanographic program of the nature we have suggested here. The byproducts for the taxpayer in his normal life will of themselves justify the program.

Senator Thurmond. Are there any other benefits to be derived? I was just trying to visualize other benefits or incidental benefits. 
Byproducts as you call them, besides national defense, and food and water.

Mr. SeiLhaus. Minerals.

Senator Truoriond. And the prevention of destruction of vessels. Mr. Spilhaus. Minerals.

Senator Thurmond. Do you feel it will be practical to salvage the minerals in the sea?

Mr. Spilmaus. I believe it may be in the future. As we exhaust the minerals on land, their value goes up. As we develop new techniques of exploitation of things in the sea, the cost of producing them comes down. At some point they may meet and more and more minerals may be exploited from the sea.

I think there are a number of other things that will become useful from the sea.

Senator Thurmond. What about fertilizer. Do you visualize any benefit to that extent?

Mr. Spiluads. I think when we come to the discussion on ocean resources and fisheries you will find that we not only use fish for human protein, but we also use fish for plant and animal food. In this respect fish are valuable to the farmer in the middle of our country.

It is possible that antibiotics may be obtained from the sea. There are all kinds of possibilities of this nature that we can't pin down.

The Chairman. We have hardly scratched the surface, as I understand it, on the medicinal possibilities of what we may find in the sea.

Senator Yarborough.

Senator YARBorougr. Among these byproducts you mentioned, assuming that we had complete security by disarmament and it was actually real, you say the byproducts of this study will pay for it.

I take it from that you think this is absolutely essential even aside from the issue of national defense?

Mr. Spilhaus. Yes, sir. I think if we had complete and secure peace, $I$ would still be here urging a program of this nature.

Senator YARBorodgh. I think I agree with you. I would still be supporting you.

I want to ask you this: Isn't this study necessary on one other fact-I am a little bit late; this may be covered. If it has, I will withdraw the question and save time, Mr. Chairman.

The ocean has been suggested as the best graveyard, or burying ground for atomic waste. Is not this study essential to learn where the currents of the oceans are, the deep, subsurface currents as well as the surface currents, in order to determine whether or not it is safe to use the ocean as the burial ground for atomic wastes and to what extent and in what proportions?

Mr. Sprlmaus. Yes, this is a most important study. It is one you will hear more about from Dr. Carritt later on. I did touch on it in my statement. I simply said that one of the reasons that we must have much more study by biologists and radiophysicists is to determine whether or not we are doing something to the ocean in this way that may be as harmful and that may plague succeeding generations.

Senator Y YRBOROUGH. Thank you. 
I have no further questions, Mr. Chairman.

The Chairman. Senator Engle.

Senator ENGLe. I compliment the Doctor on his excellent statement. The Chairman. Senator McGee.

Senator McGee. Could I make one observation. Since we want to put this on a national basis, we should hear from this side of the room and I presume $I$ have the proxy to speak for my colleagues on this side.

I would like to raise the question, Doctor, about the urgency in terms of time. This being research, I assume that what you would hope to break through on in many areas is unpredictable in terms of time and thus ought to be gotten underway sooner rather than later because of that uncertain time factor.

Mr. Spilfraus. There are two classes of problems, Senator.

There are the problems of basic research which, as you say, because of their basic nature, are unpredictable. This is very, very urgent because basic research gives us the foundation on which to build development of things that we need.

There is also, an urgency to make ocean surveys, to understand things about the sea in regard to sound propagation as a contributing factor to our surveillance and safety under the ocean. These problems we can see.

This is construction that also needs to be done with urgency. We feel a sense of urgency because we know how long it takes to build research vessels and survey vessels. Until you can get the vessel building program going you can hardly begin the attack on the major survey of the ocean.

Senator McGEe. In other words, if we would suddenly become aware-let's say next week or the week after-of the urgency of learning more than we now know, an act of Congress, an emergency session of the Congress or an executive order couldn't produce it any faster on the spur of the moment. We have to have this accumulation of knowledge continually in process.

Mr. Spilhaus. Yes.

Senator McGeE. This is one of the great problems, of course, we always have with the folks back home. They get excited when something blows up in our face and they are willing to go for it then, but how can you convince them that you cannot legislate on 7 days' notice for the kind of information that requires sometimes decades to arrive at? This is a really tough problem and I think partly behind what the Senator from South Carolina was alluding to as part of the spending is involved in that. I think nothing would better illustrate the productive research and productive growth than this whole area you have spelled out for us here this morning.

I think I have probably had a little private pressure put on over the weekend. Two members of my family want skindiving outfits and I think we should know more about where they are going.

That is all I have, Mr. Chairman.

The Chairman. I have here from the Department of Commerce late information on Soviet bloc reports of scientific activities in which we find, for instance, that they are putting out a 358-page illustrated book on the Bering Sea. We don't know anything about the Bering Sea, comparatively. 
We have the bathyscaph people here today. The Russians are ready to point out with great pride how they have developed a new underwater apparatus for research at great depths of the ocean.

Every time we make an advance we find them moving way out.

Here we have a long article about the Chinese making scientific studies for the first time in all their centuries of the marine deposits at the bottom of the Yellow Sea, the East China Sea, and at the mouth of the Yangtze River, the silting, and so forth. We have not done such intensive work, even out in Senator Yarborough's country beyond the Mississippi.

Are there any further questions of Dr. Spilhaus?

Again quoting from your pamphlet, Doctor, you say at page 41 :

Before we put these long-lived radioactive materials in the sea, we should wait for our research to tell us whether or not it is safe.

This is a logical statement. This is another problem I suppose we are going to be confronted with in the next 10 years, and the American people are going to ask us for the answers. They are going to ask us: "Is it safe?"

We won't have the answers. We might not even have them when the questions are asked, but at least we can say we have done something about it and are trying to do something about it.

Well, thank you, Doctor, unless you want to add something else.

I want to say to all witnesses, we will keep this record open so if anyone wants to add anything in the way of further figures or statements in the next few days, he can.

In that field we have Sumner Pike here and we would be glad to hear from him.

(The biographical sketch of Mr. Pike follows:)

Address : Lubec, Maine.

Sumner Tucker Pike

Born : Lubec, Maine, August 30, 1891.

Parents: Jacob Clark and Mary Susan (Tucker) Pike.

Degrees: B.A., Bowdoin College, 1913, LL.D., 1941; LL.D., Bates College, 1945 ; S.C.D., Centre College, 1947 ; L. .D., Colby College, 1948.

Professional career: Clerk in public utility companies, Boston, Savannah, Ga.; Lowell, Mass.; Beaumont, Tex., 1913 to 1919 ; vice president, Equipment Sales Co., Dallas, Tex., and Kansas City, Mo., 1920 to 1922; assistant to president, G. Amsinck \& Co., New York City, 1923 ; financial employee and secretary, Continental Insurance Co., New York City, 1923 to 1928; vice president and director, Case Pomeroy \& Co., New York City, 1928 to 1939; business adviser to U.S. Secretary of Commerce, Washington, D.C., 1939 to 1940 ; member, Temporary National Economic Committee, 1940 to 1941; Commissioner of Securities and Exchange Commission, Philadelphia, Pa., 1940 to 1946; Director, Fuel Price Division, Office Price Administration, Washington, D.C., 1942 to 1946 ; member, U.S. Atomic Energy Commission 1946 to 1951; chairman, Maine Public Utilities Commission, 1953 to 1956; was candidate to captain, CAC, Army, 1917 to 1919. Overseer, Bowdoin College, 1938-; chairman, Governor of Maine's Committee on Passamaquoddy Power.

Member: American Association Pet. Geology, American Statistical Association, American Geographical Society, Delta Upsilon, Phi Beta Kappa, Committee on Oceanography, NAS-NRC.

\section{STATEMENT OF SUMNER PIKE}

Mr. Pike. Thank you, Mr. Chairman.

My name is Sumner Pike. I am retired and live at Lubec, Maine. I am not an expert oceanographer, nor indeed an expert at anything. 
But a long and somewhat varied experience in both industry and Government may warrant me in making a few observations as to the present state of oceanography and the desirability of its expansion and betterment.

1. Oceanography has been a comparatively neglected branch of science.

2. It is of high and possibly supreme importance that oceanography be expanded in effort and improved in quality at the most rapid practical rate short of a wasteful "crash program."

3. The report of the NAS-NRC Committee provides a minimal outline toward that goal.

4. The cost, while considerable in dollars is a small percentage of the expected values to be returned in scientific, commercial, and military results.

1. A comparatively neglected science: Until recently, at least until World War II, the marine sciences were supported and studied in a somewhat routine way by various small uncoordinated sections of the Government and by several inadequately financed laboratories and institutions. To a great extent, in spite of a considerable expansion of support by the Navy, this is still the case.

The Chatrman. I might say right there, of course, that was the problem in drafting legislation in this particular case. There were many small activities going on at different places and it was an administrative problem rather than a basic problem of the need for the program. You have been in Government and you know what a problem this can become.

We have no pride of authorship in this particular matter. We want to get the program going.

Mr. Prke. Perhaps at this time I better apologize to you, Mr. Chairman, if I seem to be stealing from your Franklin Institute address. I can only give this excuse, that we must be thinking along the same lines because I hadn't seen it until I had drafted this statement.

Many of the ships, mostly unsatisfactory secondhand conversions in the first place, are obsolescent and approaching unseaworthiness.

To make up that deficit, we are going to have to have a full knowledge in shipbuilding in the next 4 or 5 years that brings it right out. To bring us up to where we should be now, it will mean a large shipbuilding program in the first part of this decade.

The shore installations are hard put to process and analyze even the inadaquate data made available by the ships and from other sources.

Manpower of adequate size and quality is difficult to recruit and train.

The young people are there but, in face of an uncertain and unpromising future, few of them are willing to devote themselves to the unusually long and arduous preparation required for professional competence in this branch of science.

The Chammiran. About the only school in existence is out in my town of Seattle.

Mr. PIKe. I believe it is the only institution in the country that gives advanced degrees in fisheries.

Perhaps that will go at advertising rates.

The second point: It is important that oceanography be expanded in scope of effort and improved in quality of performance. 
Instead of being a medium for navigation and a source of a minor fraction of the world's food, it has become suddenly apparent that the ocean is of the highest importance to national defense, indeed to our survival. It seems unnecessary to emphasize here the possible results of the development of nuclear submarines and guided missiles. My own personal reaction can be phrased briefly:

"Another nation caught us practically unawares upstairs; for heaven's sake, don't let the same thing happen to us down cellar."

With this problem thrust upon us, we become unhappily aware of the abysmal extent of our ignorance of the ocean in areas where knowledge both wide and accurate seems essential. Others will emphasize this point but I believe it to be completely factual.

3. The report of the committee provides a program toward its goal: To overcome this handicap, the committee has recommended what seems to me to be a well rounded, 10-year program of construction, operation, and education aimed at remedying present deficiencies and providing some of the most urgently required information.

Besides replacement of obsolete and aging ships and other equipment, it involves construction of additional sea and shore installations sufficient to allow roughly a doubling of our basic oceanic research effort.

Basic and applied research, development of better, more accurate instruments, extension of world surveying, combined with an expanded supply of well-qualified manpower, all are involved in the necessary coordinated advance on a broad front required to give us what we so sorely need, a better knowledge of the ocean in all its manifestations.

It should be emphasized that without this overall approach, maximum benefits will not be attained. Ships, shore laboratories, new devices, manpower, all are necessary and none of them is self-sufficient without the others.

4. The cost, while considerable, is not large in comparison with the benefits to be expected: To predict exact results from this program would be futile and misleading. In many instances even the problems cannot be clearly stated until the work is well underway. Based on previous experience, however, it seems reasonable to predict that discoveries of great value to the Nation and the world will result from a careful, intelligent, well coordinated attack upon the myriad problems presented by the ocean.

The concept that I have found helpful, Mr. Chairman, is to think that there is only one space, one fluid-filled space. Now, it happens one of those fluids is heavier than the other. That is water and that fills the ocean. The other fluid is air, which starts from the ocean up. The tie-in between the two is completely inevitable. The relationship between the two is as important to the human race as either one taken alone. The fact is, they cannot be taken alone.

From the defense point of view, it seems apparent that inner space, represented by the ocean, is at least as immediately important as outer space which now seems to capture the popular imagination.

An accurate worldwide survey of the ocean depths, its topographic features, its currents, its temperatures, and salinities, its ability to support marine life-an enormous source of foods for the human 
race-all these should be well on their way to accomplishment during the coming decade, if we start soon and carry through.

Other witnesses, experts in their fields, will supply your committee with detailed justification for our recommendations. I can only add that they were carefully worked out after long and fruitful discussion, with the aid of most competent people who gave freely of their time and knowledge.

They cannot be regarded as final or complete. Doubtless your committee, during these hearings, will note changes which should be made.

We are aiming at a fast-moving target. Even since the first of this year, 1960, man has descended to the ultimate depth of the ocean and has reported on his trip.

I had an uncle some years ago who went down and didn't come back. He never reported on his trip. He got drowned off Haiti.

In the last few weeks a satellite has gone into orbit which will lead to a breakthrough in weather observation and precise marine navigation.

What has not changed is the need for immediate, well-coordinated large-scale exploration of the ocean and its relation to the well-being of mankind.

For this purpose it does seem to me S. 2692 is well adapted.

Thank you, Mr. Chairman.

The Chairman. Are there any questions, Senator Thurmond?

Senator Thurmond. No questions.

The Chairman. Senator Yarborough?

Senator Yarborodgh. No questions.

The Chairman. Mr. Engle?

Senator Engle. No questions.

The Chatrman. Have you any information on the problem of dumping atomic wastes from your experience on the Atomic Energy Commission?

Mr. Prкe. Yes, I feel, and Dr. Spilhaus does, that we ought to know what we are doing before we dump any amount of these wastes in the ocean. Once it is done, it is irreversible. It is like capital punishment. When you change your mind, you can't get it back.

We ought to be very clear that if radioactive wastes are to be dumped in the ocean, they should be dumped in such places, at such times, and in such quantities only that we can prove to be completely harmless to the human race and indeed to other forms of life because after all, the human race depends upon other forms of life for its own existence.

Senator Thurmond. Isn't that especially true in view of the fact that it has been predicted by 1980 we will have to be using ocean water for our citizens?

Mr. PIKE. I do believe, Senator, that this adds to the problem. We must be absolutely sure that we are not doing any sort of harm.

Senator THURMOND. Today progress is being made and will be made in removing salt from the ocean water, and ocean water will be able to be used. I think it now costs $\$ 1$ a thousand gallons whereas it is 30 cents for the normal water. However, later on they will probably be able to reduce that cost of removing the salt. 
Mr. Pune. I think that is right, Senator. At $\$ 1$ a thousand, if there is no other way to get water, it is still pretty cheap because we have to have it to live on.

I believe that in the San Joaquin Valley in California they do have a little more salt in some of their water than they would like and they have recently put in some purification plants which have saved them some money. On the island of Aruba in the Caribbean where there is no natural water, they obtain water from the sea as a matter of course. They have spare heat there, so it doesn't cost them as much as it might. The cost of getting water from one place to another must be considered. Water is of no value as a resource unless it is used. If it ever gets scarce, it really becomes quite valuable.

Senator Thurmond. Can't you visualize that when a practical process has been devised to remove the salt from the ocean water, tremendous transportation systems that are now pumping oil and gas from one section of the country to another can be devised for pumping water and we will be able to provide water to the desert areas and into every area of the United States in due time?

Mr. PIKE. I think that is quite optimistic but it is certainly possible. It is still going to be an expensive thing to pipe any liquid, say 1,000 miles, as those of us who use natural gas in the Northeast find. Even that which is not liquid will cost four times as much in Boston as it does on the Louisiana coast.

Proper use of natural distribution systems will go a long way toward helping and may someday entirely cure the problem. However, by that time some of the boys dirtying up our natural waters will have to clean them up. We have a little stream going by here that could be improved without any great harm. This is the first approach.

Senator Yarborodgh. I want to express my appreciation to Dr. Spilhaus and Mr. Pike for the sentiments you have expressed here about the dumping of atomic wastes in the ocean before we know what it will do and what the dangers are.

Last year the Atomic Energy Commission issued permits to businesses to dump low-level atomic wastes in the Gulf of Mexico some few miles off the coast of Texas-less than 50 miles off the coast and, of course, well within the limits of the Continental Shelf. We vigorously protested that. They insisted they were going ahead with it, but finally rehearing has been granted and evidence was taken upon the rehearing and the matter is now pending.

It has been our thought that this atomic waste, even at a low level, shouldn't be dumped until we have more scientific knowledge. It certainly shouldn't be dumped close inshore to the Continental Shelf there, and in an area of the gulf whereby the motion of the Gulf Stream is flowing with its full vigor in that portion of the Gulf of Mexico.

The Champman. Now, if the Senator from Texas will wait just a minute here, we can hear a little more about that. I am sure he is deeply interested.

The next witness is Dayton Carritt, who is the top committee authority on radioactivity in the ocean.

Dr. Carritt, I want you to come forward. 


\section{(A biographical sketch of Mr. Carritt follows:)}

\section{DaYton ERnest CARRITt} Mà.

Address: Chesapeake Bay Institute of Johns Hopkins University, Baltimore,

Born: Boston, Mass., March 12, 1915 ; married, 1939 ; child, 1.

Major field of interest: Chemistry.

Degrees: B.S., Rhode Island State College, 1937; fellow Harvard, 1939-41; Ph. D. (analytical chemistry), 1948.

Professional career: Chemical technician, Woods Hole Oceanographic Institution, 1937-38; Research chemist, Bureau of Ships, U.S. Navy Department, Woods Hole, 1941-42; instructor in chemistry, Rhode Island State College, 1942-43; scientist, Manhattan district, Los Alamos, 1943-46 ; instructor, chemistry, Scripps Institution of Oceanography, La Jolla, Calif., 1947-51; associate professor, oceanography, Johns Hopkins University, 1951-. Was with Office of Scientific Research and Development, 1944.

Member: A.A., Chemical Society; Geophysical Union; Society of Limnology and Oceanography; New York Academy.

Scientific contributions in theory of the action of antifouling paints; atomic weight studies; polarography; plutonium chemistry; chemical properties of sea water.

\section{STATEMENT OF DAYTON E. CARRITT, JOHNS HOPKINS UNIVERSITY}

Mr. CaRRITT. Mr. Chairman and members of the committee, my name is Dayton E. Carritt. I am at present associate professor of oceanography and assistant director of the Chesapeake Bay Institute in the Johns Hopkins University.

My experience has included employment as a scientist in the Manhattan district, Los Alamos project, during the war, and more recently as a faculty member in the Scripps Institution of Oceanography, La Jolla, Calif., and in the Department of Oceanography at the Johns Hopkins University; and as an investigator at the Woods Hole Oceanographic Institution at Woods Hole, Mass.

I am a member of the National Academy of Science's National Research Council Committee on the Biological Effects of Atomic Radiation in Oceanography and Fisheries, and chairman of the working group of the Committee on Oceanography that did the study leading to NAS-NRC Publication No. 655 entitled "Radioactive Waste Disposal Into Atlantic and Gulf Coastal Waters."

I consider it both a privilege and a responsibility to come before this committee to discuss certain aspects of the radioactive waste problem as it applies to the marine environment.

First, I would say that I believe there is considerable misunderstanding with regard to the basic decision of whether or not we should use the marine environment as the receiving grounds for the controlled disposal of certain well-defined kinds of radioactive wastes.

I have the impression that a great many people in this country and abroad, both scientists and laymen, feel that so long as we do not deliberately add radioactive waste materials to the oceans, the oceans will remain free of all manmade radioactive contamination. I am firmly convinced that this is not so.

The Chamman. By this, Doctor, I assume you mean if it isn't deliberately dumped into areas like the Gulf of Mexico, as Senator Yarborough points out; if it is just left alone?

Mr. Carritr. That is right. 
That choice was lost when we, or in fact any nation, embarked on a program utilizing the fission process as a source of power production.

Neglecting all considerations of fallout from the testing and use of atomic bombs, we still are faced then with the generation of large quantities of radioactive materials in present and proposed peaceful uses programs. These include the use of radioactive materials in science and technology, the development of land-based powerplants, and the development of nuclear powered submarine and surface vessels.

As presently developed, and as far as I can tell there can be only minor changes in the foreseeable future, all of these peaceful uses will result in certain quantities of radioactive waste materials that must be released to our environment and which will inevitably find their way into the oceans. To be sure, the massive quantities of so-called high level wastes are and can be contained on land and so kept out of man's immediate environment.

Nevertheless, there remain rather large quantities, so far as bulk is concerned, of so-called low-level wastes that cannot be handled as are the high-level wastes. It is, I believe, safe to predict that regardless of all the safety precautions taken, accidents will happen in landbased powerplants, and nuclear powered vessels will be involved in collisions and sinkings, all of which will contaminate the world's oceans.

The Chatrman. I might say to the committee, we have a model of a ship over there, one of the old Savannah and the new Savannah and we still have a problem in fixing the liability in case something does happen. We still don't know what to do with it.

Go ahead.

Mr. Carritt. I am firmly convinced that the basic question that must be answered is not shall we or shall we not release radioactive wastes to the sea, but rather how much can be safely released to the sea without jeopardizing our present and planned uses of the marine resources.

I am also firmly convinced that if for some reason or other it became necessary to prevent the release of radioactive materials to the sea, our program of peaceful uses of radioactive materials would be so curtailed as to make in insignificant.

In answering the question, "How much activity can we safely release to the seas without curtailing our use of the marine environment?" the basic problem is that of protecting mankind from hazards that might result from those operations. Here we immediately are faced with two problems.

First, we must know the extent of damage that may result to man by various quantities of radioactive material in his environment.

Secondly, we must know enough about the marine environment to be able to predict the rate of return of radioactive materials back to man for various rates of disposal into the sea. We are asking questions here then in two broad fields of scientific endeavor: First, in medicine as it relates to radiation damage to man; and, second, in the earth sciences and especially oceanography, for it is from these latter studies that we will learn the capacity of various parts of the marine environment to receive radioactive wastes without returning them to man at hazardous levels. 
The answers to the first of these questions-the one regarding radiation damage to man-have been expressed in the publications of the National and the International Commission on Radiological Protection, and in the publications of the six National Academy of SciencesNational Research Council committees that examined various aspects of biological effect of atomic radiations-the so-called BEAR Committee reports.

The National Commission on Radiological Protection has examined the available information concerning the somatic damage to man associated with various quantities and kinds of radioactive material in man and in his immediate environment, and has made recommendations giving the maximum permissible body burden above which damage is likely to occur and below which man can expect to suffer no impairment of his normal biological functions for a period of at least 40 years. These data have been used as the basis for computing values of the maximum permissible concentrations of radioactive materials in drinking water and food.

The genetics panel of the NAS-NRC BEAR Committee has examined the available information concerning the genetic effects of radiation and has recommended-

The Committee continues to recommend that for the general population, the average gonadal dose accumulated during the first 30 years of life should not exceed $10 \mathrm{r}$ of manmade radiation, and should be kept as far below this as is practicable. This is in essential agreement with the most recent suggestion of the International Commission on Radiological Protection.

The Chatrman. What do you mean by $10 \mathrm{r}$ ?

Mr. CARritT. $10 \mathrm{r}$ is $10 \mathrm{rem}-\mathrm{a}$ measure of radiation. The average dental X-ray for example, produces a little less than one-half rem of $\mathrm{X}$-ray radiation.

The recommendations concerning permissible levels have formed the basis for some of the recommendations and conclusions in five National Academy of Sciences-National Research Council studies dealing with radioactivity and the oceans. The results of four of these studies have been published.

The first of these NAS-NRC publications, No. 551, entitled "The Effects of Atomic Radiation on Oceanography and Fisheries," was published in 1957 as one of the so-called BEAR Committee reports.

Publications No. 655 and No. 658 entitled "Radioactive Waste Disposal Into Atlantic and Gulf Coastal Waters," and "Radioactive Waste Disposal From Nuclear Powered Ships," respectfully, were published in 1959.

A fourth study dealing with radioactive waste disposal along the Pacific coast is now very nearly ready for publication. Basically all of these studies are an attempt to bring together all of the pertinent information regarding the physics, biology, chemistry, and geology of the seas to show the pathways and the rates of return of radioactivity to man in terms of the location of disposal and the rate of disposal.

Theoretically, we would limit the rate of disposal into any ocean area to that corresponding to a rate of return to man that would give the maximum permissible levels mentioned above. In actual practice the suggested maximum rates of disposal are certainly hundred of times, and very likely thousands of times below the rates that would approach these limits. 
The conservatism contained in these conclusions and recommendations was intentional. As practicing marine scientists we all recognized the many limitations and uncertainties in the data and observations regarding the behavior of the oceans that had to be evaluated in making a quantitative estimate of permissible rates of disposal and further, we felt that the recommendations of the genetics panel, to the effect that the accumulated dose by man should be kept as far below $10 \mathrm{r}$ as practicable, should be heeded.

Despite the limitations in our present knowledge of the behavior of the oceans, we feel that it is possible to recommend procedures that will be safe so far as protecting man from hazardous levels of radioactive materials coming from the sea is concerned, primarily in marine food products, yet which undoubtedly must be restrictive so far as this use of the sea as a natural resource is concerned.

The thought that the capacity of the oceans to receive radioactive wastes is a natural resource, that can and should be exploited, appears to be distasteful to many people. Nevertheless, it is so being used by at least two countries, the United States and England, and plans for controlled disposal into the seas are being made by the Japanese in connection with their nuclear power production program.

The contamination of the world's oceans is therefore assured.

The level of contamination at present certainly is well below hazardous levels; nevertheless, if the United States is to retain leadership in the nuclear fields and in all aspects of the utilization of the marine resources, it seems to me to be essential that we have detailed information regarding the consequences of disposal into the oceans. Not only must we be able to assure ourselves that our own actions are safe, but also we need a firm basis for the formulation of international agreements governing the joint use of the world's oceans.

The Chamman. Is that on the agenda of the Geneva Conference, this waste disposal?

Mr. CarritT. I don't believe it is.

Mr. Chatrman. We will look it up. I was just curious whether it was. We should be looking toward some international agreement on disposal.

Mr. CARRITT. There was a meeting in Monaco this past year, a meeting at which no agreements were made, but at which there was exchange of information by many of the countries who are involved in power production.

At the present time we can recommend safe but restrictive procedures. We are, however, unable to answer with any degree of certainty what the consequences might be if we, or some other nation, were to adopt procedures drastically different from those recommended.

The reason for this stems from our ignorance concerning the detailed behavior of many parts of the marine environment. The truth is that despite the large amounts of effort, time, and money that has been expended in exploring and studying the oceans there remain many areas in which we have practically no knowledge even of the simplest properties.

In 1958 the Committee on Oceanography of the National Academy of Sciences-National Research Council started a study designed to focus attention on the state of both our knowledge and our ignorance 
in the marine sciences. This study was made under the title "Oceanography 1960 to $1970 . "$ Chapter 5 of this study is entitled, "Artificial Radioactivity in the Marine Environment," and provides a broad outline of the kinds of studies that need be done to eventually permit a reasonably accurate evaluation of the consequencies of putting any stated quantity of activity in any stated part of the oceans.

Very briefly chapter 5 of the NASCO report indicates the most likely sources of radioactive wastes that will be introduced into various parts of the marine environment and then outlines the kinds of studies that will provide the information necessary in predicting the time and space distributions following disposal.

It seems to us that radioactive materials will reach the oceans from the following sources:

1. Nuclear powerplants. Present programs suggest that these will be :

(a) Land based;

(b) Seaborne, both submarine and surface craft;

(c) Airborne, with indications that these may be nuclear reactors, and less conventional types that utilize the disintegration energy from large quantities of radioactive materials.

2. Laboratories, hospitals, and industrial plants.

3. Large-scale oceanographic experimentation.

4. Atomic explosions. In addition to possible weapons testing programs, the peaceful uses for harbor construction and improvement now appears to be feasible.

The Chatrman. I notice operation of the first nuclear powerplant in the Chicago area started this week. It is right on the shores of the Great Lakes. I don't think they know what effect that may or may not have as of now. It may be below the minimum you suggest, but I don't think we know too much about continued operation in the Great Lakes.

Mr. SpIlhads. I think you are right, Senator. I think in some respects we know less about the Great Lakes than we know about the oceans.

The Chamranan. We just passed out a bill on pilots in the Great Lakes. This is opening up a great field of activity, both this way and every other way.

Proceed.

Mr. Carritr. Two examples can be used to illustrate the kinds of problems faced by oceanographers, as developments in the programs noted above continue. Nuclear-powered vessels, both surface and submarines, are now a reality. There is no reason to believe that the number and size of these crafts will not steadily increase. A significant portion of the coming nuclear-powered fleet will be built by maritime nations other than the United States.

At the present state of the art, these craft generate relatively small quantities of radioactive wastes that are discharged directly to the environment, and massive quantities of wastes that are handled in shore-based chemical processing plants.

Oceanographers have been asked to evaluate the consequence of the "normal" discharge from these vessels and to recommend preferred ocean areas where such discharges will least interfere with any utilization of other marine resources. We have been asked to evaluate to 
what extent the sinking of a nuclear-powered vessel, with rupture of the reactor, would limit further uses of any one of the major harbors of the world.

Although special precautions are taken in controlling the movements of nuclear powered vessels, it seems to me to be inevitable that some kind of accident involving one of these ships will occur. The question has been asked, "Suppose the Andrea Doria had been nuclear powered?"

Similarly, we have been asked for advice in connection with the possible establishment of near-shore disposal areas to receive packaged, low-level wastes. Is the procedure feasible?

What limitations should be placed upon such an operation?

During the past year two proposals have been presented for socalled atomic parks which would be centered around chemical plants for the processing of partially expended nuclear fuel elements, from which some level of release of activity during normal operation is inevitable, and massive releases would occur in cases of accident or malfunction. Both of these plants, according to the proposals, would be placed on the Atlantic coast near existing population centers.

In answering questions that arise from such operations we realize that we cannot treat the problems in a purely academic fashion. Our answers literally will affect the lives of large portions of the world's population, to say nothing of possible involvement with our Nation's prestige. Consequently, our answers have intentionally been conservative.

We now believe that we understand the basic framework within which answers to these kinds of questions must be developed. Chapter 5 of the NASCO report contains an outline of the programs that will furnish the information needed to fill out that framework, and in addition gives a reasonable estimate of the costs of such studies.

The division of the marine environment into two broad classifications, estuarine and coastal, and the open seas is a natural division based upon our present understanding of these areas. Estuaries and coastal areas are regions in which changes in properties occur much more rapidly and over greater ranges than in the open oceans. They are more closely linked to man geographically and economically, and they produce the major fraction of man's harvest of marine food products. Consequently the methods used to study these areas are not identical.

Basically chapter 5 outlines studies in (1) physical oceanography, which will lead to an understanding of transport and dispersion of a contaminant by the currents and mixing processes in the oceans, (2) biological oceanography, which will provide information concerning the accumulation or rejection of various waste elements by the plants and animals of the oceans and so enter the food chain that ends in man, and (3) geochemistry, which will show under what conditions suspended materials and bottom deposits may act to alter the distribution of waste components from those deduced solely from physical and biological transport.

The information leading from these studies is essential to an accurate prediction of the fate of wastes dumped, either intentionally or by accident, into many parts of the oceans, and consequently to 
our assessment of the hazard to man that might result from these actions.

There is no implication here that we are completely ignorant with regard to the behavior of the oceans. On the contrary, the oceanographers in this country are leaders in their respective fields, and it is due to their efforts that we are now able to recommend what are certainly safe but restrictive procedures, and to outline the framework within which detailed studies can provide the basis for safe and efficient uses of the marine resources.

Our present situation is one in which our inventory of trained oceanographers and oceanographic research facilities cannot keep pace with the demands for solutions to the problems caused by a rapidly expanding technology that either directly or indirectly becomes involved with the world's oceans.

The situation is urgent but not hopeless. There is time to make up our deficiencies, but no extra time. In my opinion we need a relatively long-term national policy that will (1) provide for the training of new oceanographers, primarily at the graduate and postgraduate levels, in a manner that will permit realistic competition with other science fields for the minds and talents of new scientists, and (2) provide the facilities, both land-based and seagoing, that will permit present and future marine scientists to carry on efficiently their studies of the sea. Given these, I feel sure American oceanography can resume its place as a leader.

The Chatrman. Well, Doctor, don't you think that we need to know this for another good reason? The world's oceans are the property of everyone. Other nations are embarking upon nuclear programs. It is obvious we are going to have to have some international agreements. How can we go to a conference and propose international agreements, or accept them, or take any leadership in them if we don't know what we are talking about when we get there?

Mr. Carritt. Precisely.

The Chairman. Or some other country at least assumes they know more about what they are talking about than we do.

Technically, we go in emptyhanded at some of these conferences.

Mr. CarritT. That is correct.

The Chamrman. And we have countries that are going to play with this dangerous thing and have no knowledge whatsoever. You cannot even suggest something to them because they won't take your suggestion as they know we are a little deficient in that knowledge.

It seems to me we just can't get away from the fact that there will have to be some international agreements in this whole matter, and I am not talking about the uses. They can be military or peaceful. You agree with me, do you not, Mr. Pike?

Mr. PIKE. Yes, sir.

The Chatrman. This is what people want to know.

Of course, I think we go secondhanded into most of these conferences anyway, but in this case we would have a definite assurance we would be going in secondhanded.

Mr. PrKE. I agree unless we take and keep the lead in the knowledge of what may happen to people if radiation gets up to a dangerous level, we cannot expect to lead other nations into an agreement about this ocean which is, after all, the common property of all mankind. 
It has never been reduced to any one person's ownership, and if it was the ocean itself wouldn't abide by it, so we have to be on the ball in this respect.

The Chamman. Thank you, Doctor.

Do you have any questions, Senator?

Senator Thurmond. I notice, Dr. Carritt, that you recommend training of new oceanographers and also to provide facilities, both land-based and seagoing as a solution to this problem.

Mr. CARRITt. Yes.

Senator Thurmond. Did you make any recommendation in your statement with regard to these wastes that you talk about during most of your statement, about what should be done about it?

Mr. Carritt. No, I did not make any such recommendations. These were made in the National Academy Report No. 655.

Senator THurmond. What is your opinion about these wastes? Should we begin to take some steps to try to prevent this?

Mr. CARRITT. I think first of all we have to realize what is meant by the term "radioactive waste."

Generally speaking, you can picture such wastes in two categories. One, these so-called high-level wastes, the massive quantities of waste. "These are the wastes that are put in tanks and held on land away from man.

Senator Thurmond. I might interrupt there and say at the Savannah River plant in my home county, Atomic Energy is placing the waste underground. They have a tremendous tunnel underground and they are placing the waste there and covering it up. They have it in tanks. I think it is a concrete tank. At any time, it is placed in a safe place, they say, underground.

Mr. Carritt. That is very likely the high-level waste, the large quantities of waste that everybody that $I$ have ever talked to agrees cannot be released to man's environment.

In addition to high level wastes there are smaller quantities of radiation associated with the normal running of industrial and university laboratories. The volume of this waste material is large in comparison to the amount of radiation involved. It is in the form of liquids, rags, carcasses, chemical glassware, and things of this sort. Each unit by itself does not constitute a hazard. It is the kind of thing that must be removed from the laboratory merely because it takes up space.

Some of this material can actually be dumped down the drain. If the concentration is low enough. This material goes out through the normal waste treatment processes in the city.

When the quantity of radioactivity gets a little bit above a certain amount according to regulations, it can no longer be dumped down the drain.

We are faced now with the problem of what to do with this material. Actually if we put it in a barrel we could sit on that barrel for 8 hours a day for the rest of our lives and receive no damage.

Now, the problem is, what should we do with this material.

One practice has been to dump it into specified locations in the oceans. After examining this problem in detail, the National Academy Committee suggested that a detailed survey be made of a group of locations, which were specified by latitude and longitude. These 
locations, so far as we could tell, met our requirements of the environment and yet we didn't have detailed information about it. It was suggested that these locations be examined in a detailed way to find out whether or not they would be suitable to receive low-level packaged wastes. It is these wastes, in very limited quantities, that the AEC has licensed certain disposal companies to take from the shore and drop into the oceans.

The Chairman. And there will be more of them as we advance, even in peaceful uses of nuclear energy.

Mr. CARRITT. That is right.

We have been criticized-I think unjustly-because we have said that in dumping a specific quantity of waste at a specific rate in these specific locations, and based on the recommendations of the National and International Committees on Radiological Protection, the return of these wastes to man (primarily through marine food products) will be well below that which will give anywhere near the maximum permissible dose.

As a matter of fact marine food products now actually have a lower concentration of fallout elements than do many foods that are taken from terrestrial sources. It appears that there is a rejection of some of these elements by marine organisms. There is also a great dilution because of the large volume of water in the ocean.

Senator THURMOND. I presume it is your opinion then, your counsel and advice, that we try not to dump anything in the ocean that we can avoid in the way of atomic wastes?

Mr. CARRITT. No, I don't believe I would say that.

The Chatrman. Unless we know.

Mr. Carritt. Unless we know. We know right now we could, for example, put a radioactive watch dial

Senator Thurmond. A radioactive what?

Mr. CARRITr. A radioactive watch dial in the ocean.

The question is, How many can we put in the ocean without creating a hazard to man in his other uses of the oceans?

The recommendations of the National Academy, I think, are similar to the situation that I think aircraft designers are faced with. They design an aircraft that, according to the drawing board, can be flown at, say 1,000 miles an hour, but during the first testing program of that aircraft the aircraft is flown at 200 or 300 miles an hour.

According to our best knowledge at the moment we feel that wo are recommending a practice comparable to flying that airplane at 200 miles an hour when the design tells us it could very likely be flown at a thousand miles an hour.

The whole business hinges on the quantity of radioactive wastes and the rate at which it gets back to man and into his normal food channels.

The Chatrman. Then $\mathrm{I}$ suppose another important thing is to designate a place to dump it, but you had better find out where it is going after you dump it?

Mr. Carritt. That is right.

The Chamman. It may go a lot of other places in the ocean besides where you dump it.

Mr. CARRITT. That is right.

To answer Senator Thurmond's question specifically, it is my feeling that the capability of the ocean to receive radioactive wastes 
and not return them to man at levels that would hurt him is a natural resource that should be exploited.

Senator Thurmond. Thank you very much.

The Chamanas. It is necessary that we recess until tomorrow. I know there are some of you here from out of town and I hope we won't inconvenience you. We will start tomorrow at 10:30, our regular time.

Mr. Spilhaus. Could I say just one word?

The Chamman. Yes.

Mr. Spllmaus. I don't believe Dr. Carritt emphasized what I am sure he believes. The relation of radioactive waste disposal to the oceanographic research program is simply that while we are making our recommendations in a conservative fashion we believe that we would be able to form our conclusions in a sounder fashion if we had the means to stimulate more biological research combined, for example, with research on circulation. Then we could get more of the answers upon which to base conservative conclusions.

The CHatrman. I think it is obvious we have to get some answers. I don't see how we can proceed unless we get some answers in this particular field because this is one that people are worried about, rightly or wrongly, and it is one that Congress is surely going to need some answers on, and to give the people, sooner or later.

It has been the cause of a great deal of concern largely because we don't know.

I think it is very important. It is as important as the disarmament of nuclear weapons.

Mr. Worzel and Mr. Riley, would you appear tomorrow too?

I am sorry to inconvenience you, but I do want to make this record complete so we will have a good record.

Thank you very much. We will recess until 10:30 tomorrow.

(Whereupon, at $12: 30$ p.m., the committee was recessed, to reconvene at $10: 30$ a.m., Thursday, April 21, 1960.) 


\title{
MARINE SCIENCE
}

\author{
THURSDAY, APRIL 21, 1960

\section{U.S. Senate, Committee on Interstate and Foreign Commerce, Washington, D.C.}

The committee met at 10:50 a.m., in room 5110, Senate Office Building, Hon. Warren G. Magnuson (chairman) presiding.

The Chamrian. The committee will come to order.

We have a long list of very distinguished witnesses this morning and we want to proceed as rapidly as possible because we would like to get this testimony printed and get it before the committee.

The first witness will be Dr. Milner B. Schaefer who represents the Tropical Tuna Commission and Scripps Institution of Oceanography.

Doctor, we will be glad to hear from you.

(A biographical sketch of Dr. Milner B. Schaefer follows:)

\section{Milner BaIley Schaffer}

Address: Inter-American Tropical Tuna Commission, Scripps Institution of Oceanography, La Jolla, Calif.

Born : Cheyenne, Wyo., December 14, 1912.

Major field of interest: Biology.

Degrees : B.S., Washington (Seattle), 1935 ; Ph. D. 1950.

Professional career: Assistant biologist, State fisheries department, Washington, 1935-36, biologist, 1936-38; scientists, International Pacific Salmon Fisheries Commission, New Westminster, British Columbia, 1938-42; aquatic biologist, Fish and Wildlife Service, U.S. Department of the Interior, Stanford, 194648, Honolulu, 1948-50; director investigations, Inter-American Tropical Tuna Commission, 1951- . Research associate, Scripps Institute of Oceanograpby, 1951, U.S. Navy, 1942-45.

Member: Association Ichthyology \& Herp: statistical association; Biomet. Society; Geophysical Union; Society of Limnology and Oceanography; Fisheries Society, Pacific Fishery Biology (president, 1940), Committee on Oceanography of NAS-NRC.

Scientific contributions in: Biology, life history and ecology of commercial marine fishes; population dynamics of marine animals; basic productivity of the sea; effects of atomic wastes in the sea.

STATEMENT OF DR. MILNER B. SCHAEFER, DIRECTOR OF INVESTIGATIONS OF THE INTER-AMERICAN TROPICAL TUNA COMIMISSION; AND RESEARCH ASSOCIATE OF THE SCRIPPS INSTITUTION OF OCEANOGRAPHY OF THE UNIVERSITY OF CALIFORNIA

Mr. Schaefer. I am Milner B. Schaefer, director of the Investigations of the Inter-American Tropical Tuna Commission, an international research organization operating under a convention among Costa Rica, Panama, and the United States of America; I am also a research associate of the Scripps Institution of Oceanography of the University of California. 
I am a member of the Committee on Oceanography and the Committee on Atomic Radiation.

Having been engaged for many years in various aspects of oceanographic research, and having also the privilege of close acquaintance with international aspects of the use of the sea, I have been especially impressed with the comparative smallness and inadequacy of the efforts which are being made by the United States to take advantage of the wealth of the oceans, and to solve the oceanographic problems which, as a maritime nation, we cannot afford to ignore.

In a very real sense - as the chairman noted in his statement yesterday-the United States is essentially an island nation. As such, in a world the terrestrial parts of which are becoming every day more populated, it is extremely important that we take full advantage of the seas which nearly surround us, not only for our military security, but also for our continuing economic and social well-being. This requires that we stay in the forefront in the gathering and application of new knowledge of the ocean and its contents through a continuing program of ocean research of adequate scope and magnitude.

One aspect of such a program which I would like to mention at this time is the study of the resources of the sea which support the fisheries and other extractive industries. The ocean contains living resources, of great value as a source of food and of raw materials for agriculture and industry, the utilization of which is, unfortunately, expanding much more rapidly by some other nations than ours. Although the living resources, which support the fisheries, are the most important of the extractive resources of the sea, there are also important unutilized mineral resources, the extent of which we are only beginning to recognize.

It may be noted that the United States is still the second, or perhaps third, most important nation of the world with respect to the size of its sea-fish harvest. However, the fisheries of other nations are, and have for some years been, growing faster than our own, and a rapidly increasing share of the fish we eat is imported from other nations, although these fish were mostly caught on the high seas. Many nations are turning to the sea fisheries as a source of new wealth, and the competition for the use of these resources is looming more important each year.

I have just returned from Geneva where the Second International Conference on the Law of the Sea is wrestling with the problems of the extent of the territorial sea and exclusive fishing zones, and I can assure you that the sharing of the harvest of the sea fisheries is a matter of great concern to the vast majority of the 88 nations in attendance.

The Chatrman. Dr. Schaefer, I don't want to burden this hearing with what went on at Geneva, though I do want to talk to you about it a little later. It is very important, as you know.

I am having lunch with Canadian members of Parliament today so I will have some discussion there, too.

During the last few years at this conference and other international assemblies there has become evident a tendency to give prior or exclusive rights in the near-shore fisheries to the adjacent coastal States. Thus the distant water fishermen of the United States and its allies must look forward to having to rely increasingly on the resources of the high seas, far offshore. 
For example, the United States-Canadian proposal at the present Geneva Conference calls for the phasing out of all historic fishing rights within 12 miles of shore during the next 10 years. There are other proposals before the Conference which would give the coastal States priority over a much greater distance.

Mr. Sch ${ }^{2}$ EFEr. If we are to increase our harvest of the sea fisheries, we must learn how efficiently to increase the production of our fishermen, both by properly conserving the stocks of fish we presently exploit, and by developing new fisheries on the stocks which are underutilized or completely unused, as well as by improving the effectiveness of the gear and fishing techniques.

At the same time the increased utilization of the vast protein food resources of the sea is one of the important means of increasing the welfare of some of the overpopulated, underfed foreign nations.

Senator Smathers. Could we have the witness read a little louder?

Mr. Schaerer. The realization of the increased harvest of the sea requires, however, improved knowledge of the geographical distributions of the living resources, and their variations in abundance in space and time in relation to variations in the elements of their oceanic environment, as a basis of locating new rich fishing areas, and of forecasting variations in the location and abundance of the harvestable stocks.

It also requires additional fundamental knowledge of the behavior of the organisms, as a basis of radical improvements in fishing techniques.

Detailed knowledge of the ecology and population dynamics of the organisms supporting the fisheries is also required as a basis of regulating the fisheries to maintain the maximum harvests year after year. Nor should be overlook the possibility of "farming" the sea, of increasing the harvests, in at least some areas, by suitable modifications of the environment and control of the organisms.

The new knowledge needed as a basis of more effective exploitation of the living resources of the sea requires an expansion of research, of wide scope, closely integrated with other kinds of oceanographic research-physical, chemical, and biological.

There are, in addition, legal, economic, and technological aspects of fisheries utilization which need to be included in a comprehensive research plan.

The National Academy of Sciences' Committee on Oceanography in the chapter of its report on "Ocean Resources" has attempted to outline the kinds of research which are especially required, to identify particular research problems which are in our opinion most critical, and to estimate the additional funds which will be needed for an adequate program over the next several years.

I cannot overemphasize, however, that this recommended program of resources research is only one part of a broader program of increased oceanographic study, and that parts of the program outlined in other sections of the report, such as the sections on "Ocean Surveys," "New Devices," and "Basic Research," are also of fundamental importance to the solution of the problems of utilization and management of the sea fisheries.

Certain newly discovered mineral resources of the sea floor, such as the ferromanganese nodules which are abundant in some places, also 
appear to warrant modes expenditures to assess their abundance and value, and for engineering studies of means of mining them.

I note with great pleasure that the Senate bill, S. 2692, introduced by Senator Magnuson and others, contains authorization for various appropriate Government agencies to carry out the researches recommended by our committee in the field of ocean resources, and also provides for means of coordinating the work of different agencies through a new office in the National Science Foundation.

I sincerely hope that this, or similar legislation may be passed in the near future.

The Chamman. I would like the committee members to meet three young men who are here. If you come up here, they might want to ask a few questions. The three who went down in the bathyscaph. Could you come up here?

This will be off the record.

(Discussion off the record:)

The Chatrman. On the record.

Now, Dr. Iselin of the Woods Hole Institute of Oceanography, we will be glad to hear from you.

Senator Engle. May I ask one question of Dr. Schaefer before you proceed with the next witness?

The Chamman. Yes. Are there any questions of Dr. Schaefer?

Senator ENGLE. I just wanted to ask one question. It is a little collateral to your testimony, but I observed on page 2 you were over at Geneva. This fishing matter, of course, is of great concern to us all. It is involved with the whole problem of oceanography. Can you tell us how we are getting along at Geneva? Are we coming out all right or not?

Mr. Schaefer. It is a little difficult to say. The conference today and tomorrow is at its critical stage. The U.S.-Canadian proposal of a 6 -mile territory with an additional 6 -mile exclusive fishing zone at which the rate would be phased out in 10 years, got a vote of 33 to 53 with 12 abstentions.

Senator Engre. Does it look like we will get two-thirds?

Mr. Schaefer. This is rather critical now. It went to the plenary session yesterday and it is a matter of attracting sufficient votes to this proposal by one means and another to achieve the two-thirds majority and it is in something of a critical stage at the moment, as I understand it.

In other words, if I were a bookmaker, I would probably takes six to five either way.

Senator EngLe. The chairman has a great interest in it and so have all of us who live in areas adjacent to the ocean where fishing is an industry of great importance.

I am not so sure that we are so happy with even this compromise which would seem to be a rather tenuous matter at the present time.

Mr. SchaEFer. There is evident a considerable tendency to give some kind of a priority to the fish harvest to the adjacent coastal States in addition to this. There was an Icelandic proposal to this effect which won a majority of the committee with a large number of abstentions and there are several other proposals before the Congress.

The Chamman. This is the old story of the Russians getting their way because there is a two-thirds vote and there are nations with the 
same vote we have in the conference that have no interest in coastlines or fisheries-direct interest, I mean. They have an interest, naturally.

The 6 miles would close up about 64 straits; wouldn't it? Something like that?

Mr. Schaerer. I believe so.

The Chamman. The Russians wanted 12 miles which will add about 3 million square miles to the Soviet bloc territory.

Mr. Schaerer. I think one of the significant things, Mr. Engle, from the standpoint of your fishermen in California and the other fishermen of the United States, is that even with the U.S. proposal, even if it does win, distant water fishermen are going to have to develop other fishing areas, further off shore. This is one area where oceanographic research is of importance. The distant water fisherman will be barred from some of the traditional fishing areas within a 10year period.

Senator ENGLe. We might have to go down there 7 miles and catch one of those flat fish.

Mr. Schaefer. Or you may have to do a great deal more fishing four or five or six hundred miles offshore.

Senator BARTLETT. The historic fishing rights will be out in 10 years.

Mr. Schaefer. Yes.

The Chairman. You have no chance to negotiate within the 10 years-two nations such as the United States and Canada-perhaps for perpetual rights. They will ring the bell on us in 10 years.

Mr. Schaefer. You can always make bilateral arrangements. In other words, a country can make a bilateral arrangement to permit another country to fish.

The Chairman. But no country is going to do it with the 10-year provision in there.

Senator BARTLETT. Where did we suffer that defeat?

Mr. Schaefer. I don't know whether you would call it a defeat or not. This was a compromise between the Canadian proposal and the U.S. proposal. Canada had an original proposal of a 6-mile territorial sea with a 6 -mile exclusive fishing zone to commence immediately. The United States had a proposal of a 6-mile territorial sea with a 6 -mile exclusive fishing zone, recognizing historic fishing rights in the outer 6 miles in perpetuity.

They arrived at a compromise between those two proposals which was jointly sponsored by the United States and Canada in this form.

The Champman. Your fellows can't come down to Seattle with your fish. Is it your impression that Dean is doing as good a job as he knows how on this thing?

Mr. Schaefer. Yes, it is my impression that not only Mr. Dean, but all the members of the U.S. delegation are working very hard and very ably. They are doing extremely well under very, very difficult circumstances.

The Chatrman. Of course, the U.S. Navy is not going to be happy about this.

Mr. SchaEFER. They will probably be happier with the 6 miles.

The Chatrman. They will be happier with the 6 than the 12 , but it should be the 3 . The 12 would close something like 114 strategic straits in the free world, including Gibraltar and the English Chan- 
nel. There is the overall problem of getting any agreement at all. And then it leaves it wide open. Here is Peru claiming 150 miles or something like that, for tuna rights.

Mr. SCHA EFer. A minimum of 200 actually.

The Chamman. Well, thank you very much, Dr. Schaefer. We appreciate it.

Now, Dr. Iselin of Woods Hole Institution and Dr. Lamar Worzel of the Lamont Observatory.

(The biographical sketches of Dr. Iselin and Dr. Worzel follow:)

\section{Columbus O'Donnell Iselin}

Address: Woods Hole Oceanographic Institution, Woods Hole, Mass.

Born: New Rochelle, N.Y., September 25, 1904, married, 1929; children, 5.

Major field of interest: Oceanography.

Degrees : A.B., Harvard, 1926 ; A.M., 1928; honorary D. Sc., Brown, 1947.

Professional career: Assistant professor, 1936 to 1939; associate professor, 1939 to 1960 ; professor of physical oceanography, 1960, Harvard ; professor physical oceanography, 1959-, MIT; physical oceanographer, 1932 to 1940, director, 1940 to 1950 , senior physical oceanographer, 1950 to 1956 ; director, 1956 to 1958 ; Henry B. Bigelow Chair of Oceanography ; 195s-; Woods Hole Oceanographic Institution: trustee, Bermuda Biological Station, 1936-; Marine Biological Laboratory, 1941 to 1952; American Museum of Natural History, 1951-; member, Committee on Undersea Warfare, 1946-, and Committee on Oceanography, 1957, National Academy of Sciences-National Research Council.

Awards: Medal of Merit, 1948; National Academy (Agassiz Medal, 1943), Philosophical Society.

Scientific contributions in oceanic circulation, underwater acoustics, marine resources.

\section{J. LAMAR WORzEL}

Address : Lamont Geological Observatory, Palisades, N.Y.

Major field of interest: Gravity at sea.

Born : February 21, 1919, West Brighton, N.Y.

Degrees: B.S., Lehigh University, 1940; M.S., Columbia University, 1948; Ph. D., Columbia University, 1949.

Professional career: Research associate, WHOI, 1940 to 1946 ; geodesist, Columbia University, 1947 to 1949 ; research associate, geology, Columbia University, 1948 to 1949 ; instructor, Columbia University, 1949 to 1951 ; assistant professor, Columbia University, 1951 to 1952 ; associate professor, Columbia University, 1952 to 1957 ; professor, Columbia University, 1957-; assistant director, Lamont Geological Observatory; Columbia University, 1951-.

Member: AAAS, Geological Society of America, American Geophysical Union, American Physical Society, Seismological Society of America, Society of Exploration Geophysics.

Scientific contributions in gravity at sea, seismic at sea, underwater photography, underwater sound transmission, earthquake seismology, marine sedimentation, submarine topography.

\section{STATEMENTS OF COLUMBUS O'D. ISELIN, WOODS HOLE OCEANO- GRAPHIC INSTITUTION, AND LAMAR WORZEL, LAMONT OBSER- VATORY}

The Chamrana Dr. Iselin wants to talk about the defense application of marine science, which is very important to this committee.

You may proceed.

Mr. IseliN. Since 1937 I have been intimately connected with the many applications of marine science to warfare at sea. While the chapter of our report which I am summarizing and which attempts to deal with is this subject entitled "Defense Applications," I would like to emphasize at the outset that oceanography is just as important 
in attack as it is in defense, and moreover that is frequently a factor in both tactics and strategy.

This chapter is now in its final draft and for reasons which I will try to explain, it has been a difficult one to edit because we hope to issue this as an unclassified document.

What has been happening during the last 22 years can be summarized as follows:

As weapon systems have become more and more complex, nature imposes increasing limitations on their effectiveness. In the moderm complex systems one simply cannot ignore the limitations imposed by the environment. Wars are not always fought in fine weather and there exists the equivalent of very bad weather within the sea that is more critical to the performance of most weapon systems employed in undersea warfare than the real weather is to land warfare or aerial warfare.

Because of security it will not be easy to illustrate this statement by citing specific examples involving advanced design weapon systems. I will have to fall back on early World War II devices, but there exist several excellent classified reports by various other committees and panels that discuss the limitations imposed by nature on weapon systems of the future as we now envision them.

In fact, it has become the fate of oceanographers to try to think ahead 15 years or more, so as to be able to explain the effects of environmental factors on systems that have not yet been designed. Thus, to a considerable extent, we have to keep well ahead of reality and at the same time we can only talk about what actually happened 15 or more years ago. As you well know, we are living in an age when science and technology is making extremely rapid progress. This has largely come through research carried out at university laboratories working in the classifiable fields of science. Oceanography has had a much shorter and somewhat different history. The engineering phase of oceanography has hardly begun, but the marine sciences are clearly going to contribute greatly to advanced engineering that strives for greatly improved offensive and defensive capabilities.

I will try next to be somewhat more specific in the case of underwater acoustics, and I think that I can do this best by discussing some of the past history of this subject and by explaining some of the contributions made by oceanographers.

The Chairman. Doctor, would you say, generally speaking, looking torvard the future in undersea warfare, that the problem of acoustics in one of the primary priorities in a general sense?

Mr. Iselin. Yes. In $1937 \mathrm{I}$ was asked to help out in some tests off Guantanamo, Cuba, of some experimental searchlight-type sonar gear. It had been noticed that frequently during the afternoon the range of detection of a submerged submarine was seriously reduced. It was rather quickly shown in the 1937 operation that warming of the near-surface waters on days when the winds were less strong than usual caused sharp downward refraction of the cone of sound produced by the transducer. In effect, there exists at times thermal hills within the ocean behind which a submarine can hide.

There is a geography to this near-surface thermal situation and there are also pronounced seasonal and shorter period changes. 
During World War II, largely through funds supplied by the Office of Scientific Research and Development, rapid progress was made in explaining the behavior of sound gear to the operating forces in the Navy and also in designing equipments that could hope to overcome some of the environmental factors. We had particularly good luck in the prosubmarine applications.

During the war period, Dr. W. M. Ewing realized that the ocean was relatively transparent to low frequency sound and that there existed within the ocean favorable paths by which low frequency energy could be transmitted over very long distances. Various means of exploiting these favorable characteristics of the medium have been vigorously exploited by the Navy ever since.

A very recent event which is unclassified will serve to emphasize this point. Within the past few months hydrophones on the bottom of Bermuda have picked up signals from the research vessel Vema that were made near Australia and also in the Indian Ocean. Thus, the permanent sound channel at mid-depths has been shown to provide for reliable acoustical communication over distances of many thousands of miles.

In other words, we have transmitted acoustical signals past the end of Africa. This is a rather better form of communication than radio signals.

Senator EngLe. Let's understand that. Do you mean to say they broadcast a signal near Australia?

Mr. Iselin. They were near Australia and the people at Bermuda heard it.

Senator EngLe. In order to do that, it had to go around the continent because of separation by land masses?

Mr. IsELIN. There is a permanent sound channel that exists nearly everywhere in the ocean. It acts like a speaking tube and when you use it right, you can transmit low frequency signals over great distances.

We have known for 15 years that we could do this back and forth across one ocean but what we haven't known is that we could signal from one ocean to another.

Senator ENGLE. And that is a level in the ocean?

Mr. Iseutn. Yes.

The Chatrman. But subject to change at times. That is what we want to find out. Is it a permanent window or is it moving around?

Mr. IseLIN. This business of the coherence of the signal and so on are perhaps things I shouldn't be talking about, but a lot is known about this now and the whole subject has been going ahead at a very satisfactory rate. The significant thing I want to emphasize here is that this was not developed by statisticians but by people doing basic oceanographic research.

It is hardly an exaggeration to state that most of the modern submarine-detection systems stem from concepts put forward by Dr. Ewing and his collaborators now nearly 20 years ago, and the fact that Dr. Ewing had the opportunity to take his particular kind of science to sea has gained us a great many years' advantage over other people.

Amphibious warfare is another area in which oceanography made important contributions during World War II. Under the leader- 
ship of the late Dr. II. U. Sverdrup means of predicting on a day-today basis the characteristics of the surf on a given beach were quickly worked out and were used with great success during the latter half of the war.

It is now fairly evident that other types of environmental forecasts of the three dimensional characteristics of large areas in the deep ocean could play a vital part in the success of any future war at sea. From the technical standpoint such forecasts seem quite feasible and a good beginning is being made to establish such a service at the Hydrographic Office. A large bonus can be expected from the oceanographic data gathering network that is now envisioned. It can undoubtedly contribute much to improved long range weather forecasting.

Oceanographers and meteorologists are eager to gain the sorts of understanding that will permit reliable predictions of what will take place in both mediums. The Navy is making rapid progress in understanding how their operations can be made more efficient in this way.

As we sit here this morning, four of our small ships are conducting the most ambitious piece of research that has ever been attempted in support of a marine environmental forecasting service. The combined scientific parties total about 45 experienced men. The cost of this operation is roughly $\$ 10,000$ a day and it will last for nearly 3 months.

The last time that we attempted any such operation was nearly 9 years ago and it has taken until now before we could be certain that we could improve significantly on these earlier preliminary results.

Besides the four ships, there is a plane acting as the weather permits, as the quarterback of the operation. The plane has means of observing sea-surface temperature. It transmits this information to the ships and they are employed accordingly to develop the third dimension of the observed surface temperature distribution over an area extending from southern New England nearly to Bermuda and eastward as far as the Grand Banks.

This is the beginnings of synoptic oceanography. Day before yesterday I was briefed on the results of the first 10 days of the operations and they are mighty encouraging. But only a handful of people in the country know that this is going on and fewer still understand its full significance.

If theoretical considerations that we have good reason to expect to be correct are confirmed by this large and expensive operation, then an airplane and a few carefully instrumented buoys can continue to monitor this whole large area and we can know what part of the ocean is doing day by day.

This is both scientifically exciting and an important part of the problem of detecting and destroying enemy submarines equipped with ballistic missiles. I am sorry that I can't enlarge on this statement.

This operation has been made possible through the cooperation of several agencies, both governmental and private. The cooperation between the fellows who are working actually at sea today or in the air or beneath the seas, the cooperation is excellent. Even the pilots of the planes are willing to expend some of what they call their wife's gasoline in order to assure the success of the operation. 
People are working around the clock, not for a day but for days on end.

From where I sit, what bothers me is that the entire operation has had to be organized at the working level. The senior members of the cooperating agencies have really no time to understand what we are trying to do, or what it really means to them in terms of the efficiency of their service.

In my opinion, Mr. Chairman, the most important thing that any bill that you can devise in support of marine science could do is to remind the heads of agencies (agencies which are in fact cooperating at the working level) that they, too, should take part in the planning of such future operations and that they should be cooperating as vigorously as the fellows who are struggling with seasickness and airsickness this morning.

Senator ENGLE. What was this remark about ballistic missiles?

Mr. IsELIN. I said this particular operation cuts to the heart of the problem of setting up a surveillance system that would monitor this area and enable you to know in plenty of time that something you didn't want was there.

Senator Engle. Do you mean by underwater devices of some type, is that what you are talking about?

Mr. Iselix. This operation is the key to understanding how to design a sure-fire underwater surveillance system.

The Chatrman. And in a broad area?

Mr. Iselin. Yes.

Senator Engue. With regard to this channel, or level where you can transmit practically around the world, that is low-frequency, is it not?

Mr. IseLin. Yes, because low frequencies are not attenuated in sea. water as rapidly as high frequencies. The channel also transmits higher frequencies but the lower you go the further your range can be expected.

Senator Engle. This evidently isn't a line-of-sight business such as it is with the very high frequency radio transmission where you have to have line of sight and an obstruction can frustrate the signal?

Mr. Iselin. Perhaps Mr. Worzel could say whether he thinks he is getting reflected signals.

The Champman. Dr. Worzel is here. He is with the Lamont Observatory and he can also talk about specifics a little bit. How this affects the undersea warfare and defense.

Mr. Worzel. I am John Lamar Worzel, professor of geophysics at Columbia University and assistant director of Lamont Geological Observatory.

In answer to your question, Mr. Engle, the path was the great circle path from Australia to Bermuda. In the usual maps we look at this path is not obvious, but on a globe it becomes immediately obvious that it is a great circle path. If there is an obstruction such as a continent or an island in between on the great circle path, it will obstruct the sound. We do get reflections, however, from many surfaces and we haven't yet learned how to use these as well as we have the directly transmitted sounds.

Senator ENGLE. You haven't gotten so you could bounce a sound off a place under the water like you bounce a sound off the Moon? 
Mr. Worzec. Oh, yes, we have, sir. About 5 years ago we plotted nearly all the sea mounts and most of the shorelines of the Atlantic Ocean from Bermuda by the sounds reflected by the depth charges we were using in another experiment.

Senator EngLe. That is very interesting.

Thank you, Mr. Chairman.

The ChaIrican. The importance of that is, of course, as submarines are able to go deeper and deeper, they have to have a roadmap just like a person driving a car, and we are finding sea mounts all over the ocean we never knew existed.

Dr. H. B. Stewart, of the Coast and Geodetic Survey, who returned on the Explorer yesterday, said they found a new submerged reef off Cuba.

I think Dr. Worzel will point out in his statement the real problem is when research vessels go out they can't concentrate particularly on some exciting thing like this; they have to be doing a hundred and one things because of bad equipment and the fact the vessels are not adequate.

How old is the Explorer; 20 years old, isn't it? I think they told me yesterday it is 20 years old.

Go ahead.

Mr. Worzel. I am substituting actually for Prof. Morris Ewing, the director of our laboratory.

Senator Engle. Mr. Chairman, I have to leave to go to the floor and $I$ am intensely interested in what is in your statement with regard to oceanographic laboratories.

I was out on a ship equipped for oceanographic studies off the Pacific coast. It is operated by the University of Southern California, by Captain Hancock out there. They showed me some devices they had for collecting information under the water. I would like to ask this question: Do you have something specific to suggest as to how we can improve the equipment we have?

Mr. Worzes. We are attempting to improve our equipment ourselves right along, as are all the other major oceanographic laboratories within the limitations of our funds and personnel. To try to be specific on any one item I could take the rest of the day very readily.

Senator EngLe. They let down a grappling hook, I notice.

The Chatriman. We will put your statement in the record in full. It is just a short one here.

The doctor says there is a great need for more moderm and able ships and the ships must be available on a long-term basis to the laboratories to which they are assigned and not be subject to being withdrawn on short notice for more urgent programs, which is another name for applied research.

Then this could be accomplished by transferring ships to nonprofit laboratories which the bill envisions. They could be exchanged.

I would think that all the testimony, even from the Government agencies, would be unanimously of the opinion that all our ships are obsolete and inadequate. There is no question about the need for new ships in this whole field and the assignment of these ships to a job that the scientists think they can do and pursue. 
You point out in a 10-months cruise of one vessel, a great number of programs are undertaken. In other words, the soup is getting too thin on some of them, isn't that right.

Mr. Worzes. We don't feel justified in sending a ship around the world without their undertaking as many programs as can be supported on the ship. The limitation is on the size of the ship and her space for scientists.

The Chatrman. Also, Dr. Ewing's statement will be put in too. It refers to seismic refraction at sea. If you will explain that briefly to us we will put this in the record, of course.

Mr. Worzer. Do you wish me to read the statement?

The Chamman. You can summarize it and we will put it in in full.

Mr. WORZEL. In seismic refraction studies one fires an explosive from one ship and listens to the sounds which travel through the body of water and through the various layers in the bottom of the ocean to another ship at distances varying between a few miles and up to 60 miles. These studies are of importance geologically in understanding the structure of the ocean bottom. From them we can determine the velocity of sound in the layers beneath the bottom and the thickness of the layers and we can then make reasonable judgments about the type of materials that are in the layers. In essence, seismic refraction is an "X-ray" technique for looking at the bottom of the ocean.

In the course of this work, it is necessary to determine the velocity of sound in the water layers throughout the ocean. This study led Dr. Ewing to his thoughts about the sound channel.

Seismic studies at sea were the forerunner to the development of techniques which the petroleum industry now uses in their offshore exploration work. They have taken our work and extended on it for their own purposes.

The Chatrman. Then Dr. Ewing also points out the great amount of good will that has come from all of us working together, with some of the other people in the free nations, and I suppose a lot is due to the International Geophysical Year too. From that we have found out a few things.

Mr. WorzeL. Yes, sir.

The Chamriran. It has some international aspects too because the seas are international.

Mr. Worzec. Oceanography both benefits by and contributes to international cooperation.

If you will notice the paper entitled "International Relations," we have worked with our ships, cooperatively with the ships of the following nations: Chile, South Africa, Spain, Brazil, Argentina, and Australia.

In addition to this, we have entertained on board our ships, and the other institutions have done likewise, 15 Argentinians, 8 Italians, 6 South Africans, 5 Chileans, 5 Spaniards, 4 Germans, 4 Peruvians, 4 Australians, 4 Turks, 1 Greek, 1 Hollander, 1 Algerian, 1 Japanese, and 1 Bermudian.

The great diversity of nationalities that are on our ships raises a great interest in the foreign ports that our ship touches and invariably there is an item in the press favorably extolling the international cooperation that is exhibited by just one of these small ships operating in this way. 
The Ciramiran. With regard to what the Russians are doing in this whole field, I have the distinct impression-I don't know whether the results are as good as some of the things we have been trying to do, but at least their activity in the field of oceanography is much greater than ours. Would that be a correct statement?

Mr. Iseurn. Yes, they cranked up their oceanography about 10 years ago. They are not very good at it yet, but if money and people count, why they have got it.

Senator LAUSCHe. Repeat that.

Mr. Iselin. I say if money and numbers of people count in scientific achievement, they should be doing well soon.

The Chatrmin. In other words, they are putting much more of their efforts to this task and spending a great deal more upon this.

Senator LAUSCHE. What is the source of your observation on the quantity of money and people that they are applying to the task?

Mr. ISELIN. We know the number and size of their laboratories and about how many people are in them.

Senator LaUSCHE. How was that obtained?

Mr. Iselin. Through the International Geophysical Year there has been a very free exchange of information. We have visited their laboratories, they have visited our laboratories. We read their publications; they read all of ours too. We have a good idea of what is going on in the nonmilitary aspects of the earth sciences in Russia.

We have very little knowledge about what they are doing in the military applications.

The Chatrman. But if a nation has approximately 500 submarines of all types, surely there must be a similar activity, of necessity, in the military applications.

Mr. IseLiN. I spent a whole summer with the help of around 60 very smart guys trying to answer this question and we have yet no evidence that they are particularly sophisticated in the use of these submarines.

Senator Lausche. That is, their submarines are short-range and not in the long-range category that they have?

Mr. IseLin. No, they have long-range submarines, but I have no evidence that they are able to use them as smartly as we are able to use our submarines.

Senator Ladsche. Now, to what do you ascribe our sophistication in the face of the fact that they have given it more money and more people?

Mr. Iselin. We got started 20 years ahead of them. No Russian oceanographer went to sea until after World War II.

Mr. WorzeL. They had no program in marine geophysics until about 10 years ago and we have had a program in marine geophysics since about 1935 in this country.

Senator LAdSCHE. Do you know whether they have developed any commercially feasible extraction of minerals out of the seas?

Mr. IsELIN. I don't think they have.

Senator Ladsche. Have we done it?

Mr. IsELIN. Well, we are getting bromine and we are extracting a few chemicals out of the sea.

Senator LAUSCHE. What about magnesite, where they are taking the magnesium out of water and mixing it with dolomite and making magnesite brick. 
Mr. Iseurn. I don't know about this.

Senator Ladsche. Do you know about it, Dr. Schaefer?

Mr. Schaefer. Yes, sir, we have been extracting magnesium from sea water both in California and also I believe it is in Freeport, Tex., for quite a number of years. Actually I don't think the Russians are using this technique because of terrestrial sources. Magnesium is one thing we don't have much of from other sources and we take it out of the sea. It is a well known technique, however, and can be done anywhere in the world.

As far as these mineral deposits on the sea floor are concerned, no one has started exploiting them as yet. In fact, it was only during the International Geophysical Year and some of the expeditions since then that there have been discovered deposits of minerals that are sufficiently rich so that it looks as if feasible engineering techniques can be developed to recover them. Expect that we will be mining them within the next 5 or 6 years.

Senator Ladsche. Now, I would like to ask this further question: They started later than we did and it is for that cause that they are in back of us, from the standpoint of sophistication.

Are they making progress now indicating that they are catching up?

Mr. Iselin. They are catching up quite rapidly in some areas. For example, in the geophysical techniques, and they are very good at seismology and so on. Their main interest, as you can see in reading their papers, seems to be in biology.

Senator LAUSCHE. In both physics and seismology they have shown signs of progress. Now, what are some of the other fields in which they have not?

Mr. IseLin. In the classical field of physical oceanography-that is, the understanding of the movements of the water and variability of these movements and learning how to predict these movements, there is very little evidence in their literature that they are even beginning this problem. They will begin on it but their first major effort was to train a large number of people and the ships they are using, they are using in a rather routine way as part of a schooling system to build up a stockpile of people familiar with the marine sciences.

Mr. Schaefer. Mr. Chairman, if I could interpolate one remark with respect to marine biology and fisheries so that you won't get a wrong impression, actually the Russians have been doing rather advanced work on marine biology and particularly oceanography in support of fisheries development for about as long as we have.

In fact, they had a three-vessel expedition working in the Bering Sea in 1935 and 1936. They have made a thorough survey there of the fisheries and the currents and the types of bottom and so on and in the fisheries resource development field their work is every bit as good as ours and in some cases it is advanced.

For example, one of their submarines, the Severyanka, has been converted into a machine with windows in it and sampling devices to study the upper reaches of the ocean, particularly in relation to the distribution of the herring and other fish in the North Atlantic. They have made some interesting discoveries with the submarine. This is one field where they are at least abreast of us.

Senator LaUSCHE. From an applied standpoint, have they made advances in excess of ours, if at all? 
Mr. Schnerer. I would say equal to ours. One example of this is the use of the Severyanka in the herring fisheries in the Norwegian and Barents Sea. By using this submarine they were able to make observations on the behavior of the herring. On the basis of these observations they were able to design gear to greatly improve their catches. This is just one example.

I wouldn't say they are ahead of us, but they are certainly abreast and they are certainly working at it very hard.

Senator Ladsche. What do you suggest in brief words is essential to be done by our Government to properly attack this problem so that it will be developed to the best advantage of our country?

Mr. Iseuin. Well, we suffer from projectitis. That is, we get our money in relatively small packages and the package specifies in rather considerable detail what you do with the money. In other words, there is very little untagged money available in support of the marine sciences. You have to dream up a project, the project has to look good, you come down to Washington and you get the money but the fact that you were able to dream up this project means you almost knew the answer before you came. So projects are not basic research. But the money comes to you as projects.

Now, projects are good because you have to have some control over the money and all I am really saying is that you need perhaps 30 percent of untagged money in order to be able to use these ships imaginatively and get at entirely new things.

Senator LAUSCHE. That is to apply the 30 percent in the field of scientific research instead of applied-

Mr. Iseuin. No; we get applied money for applied research. I am talking entirely about basic research. It is just that you need a certain amount of "adventure" money, money that you can't tell a fellow sitting at a desk here in Washington just what you are going to do with it.

Senator LaUsche. That is all I have.

The Chatrman. And the size and number of Russian research ships exceed ours, do they not?

Mr. Iselin. Yes. We think their ships are too big, that they are inefficient, and that we couldn't possibly afford to run such big ships, and I think they are quite unnecessarily big except they are using them as a kind of a graduate school for trained technicians.

The Chatrmas. We do have a lack, do we not, in your opinion, of equipment-let's say ships, and equipment?

Mr. Iselin. Yes. Our ships are getting old and we know how to design very much more effective ones. They have got to be replaced. The Government laboratory ships are all on their last legs and were conversions in the first place. We have got to start a building program both for the Government laboratories interested in the sea and for the private laboratories.

Now, the main thing that you have to design into these new ships is great quietness. Many of our techniques involve using underwater acoustics. We are exploring the sea in many different ways, including biological ways, by using acoustical devices. Tell, if you are using acoustical devices, you want a quiet platform on which to use them. So that getting great quietness in the new ships is a primary design difficulty. Other factors such as stabilizing the ship is fairly straightforward. We know how to do this. 
These ships will be an experiment in quietness. In other words, these will be the first ships that were ever built where the primary effort in the design was for quietness rather than efficiency of the powerplant. Through this I am quite certain that the Navy is going to learn a great deal about quieting their own ships and by quieting their own ships their abilities to detect submarines will be greatly improved.

The Chatrman. And, of course, that conclusion would dictate, because of the very nature of this thing, that you must have a plan; and No. 2, you must get at it because it takes 3 or 4 or 5 years to get one of these things ready.

Mr. IsELIN. And what you learn out of building the first ship should be applied to the design of the second and third, and so on.

This could be the greatest experiment in naval architecture that was ever pulled off, because these ships can be studied, they can be instrumented, and you can do things with a small ship that you can't do in a large one.

The Chairman. Thank you, Dr. Iselin. Are there any questions?

We will put all of the other statements in the record. (The papers submitted by Dr. Worzel follow:)

\section{INTERNATIONAL RELATIONS}

The cooperative assistance of international groups on oceanographic research which have not been formalized by international agreements or committees is large. For example, our present cruise will be the fourth cooperative effort with the Argentines. They have provided one or more ships to work with $R$. V. Vema each of the past 4 years, and have supplied a major part of the logistical support.

We have supplied much of the scientific know-how and most of the instrumentation for seismic refraction work, magnetic work, topographic surveys, and coring work. A great deal has been accomplished in detailing the Argentina continental slope and shelf in the Scotia Sea, and the passages near Tierra Del Fuego. The most cordial relations prevail and over 15 of their people have spent a reasonable time on our ship being trained in our kinds of operations and at least 10 of our people have worked on their vessels for various lengths of time assisting them in installing and operating various equipment.

Similar, but less extensive, cooperative work has been accomplished with the Chileans, South Africans, Spanish, Brazilians, and Australians.

In addition, many foreign scientists have been accommodated for periods of a week or more to observe and participate in the oceanographic work. For example, on our ship we have had 15 Argentines, 8 Italians, 6 South Africans, 5 Chileans, 5 Spaniards, 4 Germans, 4 Peruvians, 4 Australians, 4 Turks, 1 Greek, 1 Netherlander, 1 Algerian, 1 Japanese, and 1 Bermudian spend between a week and up to several months working on board. The great diversity of nationalities working cooperatively on board is always an object of great interest in the foreign ports at which we touch and almost invariably exerts favorable comments from the local press.

\section{Researoh Vegsels of the Private Oceanographic Laboratories}

The research vessels of the private oceanographic laboratories differ somewhat from each other and greatly from those of the Government agencies. This is due to the great variety of investigations that are undertaken on each of these vessels ; to the primary concentration of each of the laboratories on different aspects of the oceanographic problems; and to the great duration of a cruise in order to determine the geographic distribution of the various phenomena and to see how representative areas investigated in great detail are related to other areas of the world.

As an example, on a 10-month cruise of one vessel the following programs were undertaken: Submarine topography, carbon 14 studies of oceanic circulation, 
hydrographic observations, bottom sediment coring, bottom and mid-depth photography, bathythermograph measurements, continuous magnetic field measurements; plankton sampling, bottom biological trawls, ocean floor temperature gradients, seismic refraction transmission studies, and gravity measurements. One of the major laboratories concentrates heavily on the hydrography and sonar work and a third on seismic refraction measurements and ocean cores.

Consequently, the ships for each laboratory must have great versatility and a primary space allocation for their major field of research. In some cases this means equipment for mid-depth operations, in another equipment for aerological work, in another complex electronic systems for acoustical analysis, in another heavy equipment for frequently operating on bottom, and in another a large capacity for carrying explosives. These varying requirements demand different arrangements and qualifications for the ships; much more than a fairly standardized observational program for surveys. It is therefore felt to be important that each ship be designed largely to fulfill the requirements of the laboratory which will use it.

There is a great need for additional modern and more able ships. These ships must be available on a long-term basis to the laboratories to which they are assigned and not subject to being withdrawn on short notice for more "urgent" (another name used for applied research) programs. This can probably best be accomplished by transferring the ships to the nonprofit laboratory. Similarly it is important that the jurisdiction of supporting facilities be vested in the nonprofit laboratories.

The funding of ship operations poses a great headache on a project basis. Sometimes ships have had to depart on long cruises without sufficient funds to assure the completion of over half the cruise. This is caused by the uncertainty of the continuation of an active project up for renewal several months after the ship has put to sea. In other cases it results from the uncertainty of funding a new project in a new fiscal year. This uncertainty causes poorer cruise planning than could be desired, and considerable inefficiency and difficulty to secure the necessary funds for the completion of a cruise. Funds for operations of privately owned vessels operating for basic research are as vital to the continued healthy growth of basic research in oceanography as for Government vessels.

It is vital to have the operation of research vessels in basic research under the direct control of the operating laboratory and the chief scientist on board, if great opportunities are to be seized when they offer themselves, rather than a strict adherence to schedule. It is also vital to the esprit de corps as well as the cooperative working of the professional seamen and the professional scientists. There are difficulties enough on small ships operating in distant oceans without the additional controversies arising from divided operational control.

\section{DEFENSE APPLICATIONS}

\section{SEISMIC REFRACTION AT SEA}

These studies result in the geological information of layer thickness and velocity. From the velocity reasonable conclusions can be made about the types of rocks or sediments. These data have defense applications in defining the acoustic impedance of the bottom which controls the fraction of incident energy reflected from bottom. Sonar systems which may use bottom reflections therefore depend on this work for any possibility of predictions. The earliest work in seismic refractions in deep water led to the consideration of the whole velocity depth profile in the deep ocean. This velocity depth profile suggested to Dr. Ewing the possibilities of the system now referred to as Sofar which has been covered in some detail br Dr. Iselin.

The bottom topography studies record the water depths along ship's tracks and try to relate these to physiographic provinces. Just after World War II, the state of knowledge of the physiographic provinces were so primitive that it was thought that the ocean floors were flat featureless plains which were occasionally interrupted by continents, islands, trenches, and a few ridges such as the Mid-Atlantic Ridge.

Now we recognize that these were only the major features and mans physiographic features such as the continental rise, abyssal plains, multitudinous seamounts, small rises, midocean canyons, and plateau-like steps exist. 
It was found that the abyssal plains were so flat that with the instruments available it was not possible to determine how flat they were. This led to the development of the precision depth recorder, now called the PDR, in order to determine how flat the abyssal plains really are.

They have proved to have features less prominent than about 1 foot and in many cases to be more level than the best of billiard tables. This instrument has proved to be ideal for many defense problems, and over 50 of these have been put into operation on classified projects. Soundings have, of course, been used for navigation since before Revolutionary days.

The new accuracy and detail available with the PDR makes the ocean depths eren more useful for navigational purposes. Needless to say, it is only useful to the accuracy to which it is originally located. The private laboratories have done the greatest part of the precision sounding work to date and unfortunately they must rely on celestial navigation and dead reckoning and loran (within about 500 miles of the United States) to locate these features. It is unfortunate that the more accurate navigation systems available to the Defense Deparment have not been available for these primary studies. An outgrowth of the PDR is the SDR (sub-bottom depth recorder) which records echoes from beneath the sediments of the ocean floors. This work is quite new and its usefulness for defense applications is still imperfectly known. It does promise to find features in the sub-bottom where the bottom is too featureless to use in navigation. These studies will aid in designing the foundations for Texas towers, and other structures to be built in the ocean for defense purposes. They have already been used very successfully in the foundation studies of bridges and tunnels and in the search for petroleum in water-covered areas.

Magnetic detection techniques were introduced in World War II for the detection of submarines. This equipment has been modified so that it is now used to measure the earth's magnetic field continuously wherever many of our oceanographic research vessels travel. We have found that there are clear magnetic signatures near the margins of continental shelves and over seamounts and other structures. Needless to say, these are potentially useful for navigation. In some areas there are features which can easily be confused for submarine signatures. In such areas defense groups could potentially waste much time chasing ghosts. It is obviously urgent to locate each of these areas and delineate them. Once again the limitation for the use of these features for navigation is the accuracy of their original position determination.

Gravity observations have been made at sea on submarines since 1954 . Despite many efforts it only became possible to make measurements at sea on a surface vessel in November 1957 . Since topography is of primary importance in making a gravity signature, the gravity measurement is potentially the secure sounder. This is so since it makes no signal that anyone can detect, and it is unjammable by man as yet. In addition, there are features of the gravity field caused by the sub-bottom structure in regions where topography is featureless. The potential use of gravity measurements for navigation is obvious. Gravity measurements are also useful to determine the precise shape of the worldapproximately an oblate ellipsoid. Gravity measurements provide the only means to obtain the absolute deflection of the vertical at a location. Unfortunately, almost all systems for position determination depend on the direction of the vertical. In many places, particularly near continental borders, islands, oceanic ridges, and deeps, the vertical may be deflected enough to mislocate oneself by a mile or more.

Better navigation in the broad reaches of the ocean is urgently needed for all oceanic operations. The ability to use topographic, magnetic, gravity, or other features for navigational purposes is limited by the accuracy of their original location. For this purpose it is not important that the system could be jammed in a conflict or that its use betrays the user. Once the other features are located the jammability or self-betrayal of the parent system no longer is vital. Probably the system most likely to succeed is the use of Sofar. To date, every attempt to check the accuracy of the Sofar system has yielded the errors of the system against which it is checked. Logistically, it is impractical to jam a Sofar system for a long period of time.

It is probable that it will be necessary to use a combination of the various possible navigation systems for defense purposes. In some cases, one will be superior and in others another will be superior. In general, more than one will be required. The inertial and electronic systems will have to be checked and restarted in the event of electronic failure. At sea the topographic and geo- 
physical signatures will permit these procedures only if these features are well located in advance. It is vital to provide the best navigational devices to the pioneers in these geophysical methods at the earliest possible moment.

It is possible that artificial satellites may povide a suitable navigation system. It is yet too early to evaluate the accuracy and reliability potentially available.

(A biographical sketch and statement submitted for Dr. Maurice Ewing follow :)

\section{MaURice Ewing}

\section{Address: Lamont Geological Observatory, Columbia University, Palisades,} N.Y.

Major field of interest: Geophysics, particularly seismology and oceanography. Born : Lockney, Tex., May 12, 1906.

Degrees : Rice Institute, B.A., 1926 ; MA., 1927 ; Ph.D. 1931.

Honorary degrees: Washington and Lee, 1949; University of Denver, 1953; Lehigh University, 1957; Utrecht Unirersity, Netherlands, 1957.

Professional career: Instructor, plysics, Pittsburgh, 1929-30; Lehigh, 1930-36; assistant professor, Lehigh, 1936-40; associate professor, Lehigh, $1910-43$; on leave for work at Woods Hole Oceanographic Institution during the war, 1940-45; associate professor, Columbia University, 1944-47; professor (geology), Columbia University, 1947-; presently Higgins professor of geology and director of Lamont Geological Observatory, Columbia University.

Awards: Hohenthal scholar, 1923-26; Guggenheim fellow, 1938-40; Joseph Henry lecturer, 1949; distinguished lecturer, American Association of Petroleum Geologists 1947 and 1953 ; Westbrook lecturer, 1951 ; U. S. Navy Distinguished Service Award, 1955; Order of Naval Merit, Argentine Republic, 1957; Agassiz Medal, 1955; Day Medal, 1949; William Bowie Medal, 1957; National Academy of Sciences; American Academy or Arts and Sciences; Royal Netherlands Academy of Sciences and Letters; honorable member, Society of Exploration Geophysicists; American Philosophical Society; Vetlesen Prize, 1960.

Member: Geological Society of America, fellow ; American Geophysical Union, vice president, 1953-56, president, 1956-59; Physical Society; American Association of Petroleum Geologists; Society of Exploration Geophysicists; Seismological Society of America, president, 1955-57; Panel on Seismology and Gravity and Panel on Oceanography, IGY; ex officio member, U.S. National Committee for the IGY; National Academy of Sciences, Committee on Oceanography, University Committee on Polar Research and Mohole Committee; U.S. Panel on Seismic Improvement; NASA Space Sciences Working Group on Lunar Explorations.

Leader: Oceanographic and marine geophysical expeditions, 1936 to the present.

Scientific contributions in earthquake seismology ; submarine geology ; gravity ; ocean-bottom photography; submarine acoustics; seismic refraction and reflection surveys; magnetic surveys; oceanography; climatology; structure of the earth's crust and mantle.

Statement of Dr. Miurice Ewing, Professor of Geology and Director of Lamont Geological Observatory, Columbia Universits, on the Magneson MARINE ScIENCES BILL

Senator Magnuson and members of the committee, I regret that I cannot be present at these important hearings. I must leare for Argentina to join our research vessel Vema at sea near Cape Horn. This is Tema's fourth expedition into high southern latitudes, and I value so highly the splendid cooperation of our Argentine colleagues that I wish to be aboard the ship for the duration of our work with their vessel Capitan Canepa.

The National Academy of Sciences' Committee on Oceanography has, in its report, attempted to analyze both the status of our knowledge of the oceans, and the need for increasing this knowledge. It is clear that the oceanographic research of our country must be greatly expanded if we are to maintain our position as a Nation whose power and scholarship are second to none.

My own work has been devoted to the applications of the disciplines of mathematics and physics to the study of the earth. Through the years as my rork developed, the most significant and interesting problems about the earth as a planet appeared to be solvable onls b5 a closer study of the oceans and the 
crust and mantle beneath them. This study is my life's work. Thus, it is evident that my point of view might be characterized as that of the so-called "pure scientist" who is not primarily concerned with the application of his studies. Yet I can truthfully say that the instruments developed by me and others at Lamont Observatory, and the papers published by us in reporting on our work have made as important contributions to the science of antisubmarine warfare as has the work of any other group. This is an example only. We have also played an important part in several other Defense Department programs. I say this not to boast, but to point out that basic research and applied research overlap and also stimulate each other. That is the reason why we have never found it irksome to have our financial support come not only from the National Science Foundation, but also from the Office of Naval Research, the Bureau of Ships, and the Atomic Energy Commission. The problems which are important to them are important to us too-although sometimes for different reasons. In general, these agencies realize that as well as we, and have given us commendable freedom to plan our own research program.

Our oceanographic research program aboard $\nabla e m a$ has also afforded us wonderful opportunities to work with the scientists of other countries. To make the seismic refraction measurements which are a major part of our program at sea, we need at least two ships-one to set off the sound source, and one (preferably more) to record the arrivals of the sound waves. We have not been able to send out two ships on our long expeditions, and have sought the cooperation of other navies and scientific institutions. In the last 3 years we have worked with ships and men of Italy, Greece, Turkey, Spain, Union of South Africa, Australia, New Zealand, Brazil, Chile, and Argentina. Now I am speaking only of those who provided ships. We have had joint programs with individuals in many additional countries.

Working together creates new friendships, not only for us at Lamont, but for the United States and its scientific establishments. A good example of this may be seen in the relationship between the Argentine Government and our laboratory. It began in 1957 as a cooperative program with our ship Vema and the Argentina Hydrographic Office ship Bahia Blanca. From that it has grown to a program which now includes four successive oceanographic expeditions, one IGY seismological station near Buenos Aires, a young Argentine seismologist studying at Lamont for a year, a very gifted man from the Argentine Oil Co. (YPF) working here on a Guggenheim feliowship have helped them to build more instruments. We share data obtained jointly and also independently in the areas where we both work. Our contacts with Argentine scientists have led to their friendship with Americans at other institutions and to still more joint programs among these groups. Most valuable to me, our efforts to find a vessel to work with Vema have led to warm and indestructible friendships with Comdr. Luis Capurro, Capt. Jorge Palma (in Washington), Admiral Grunwaldt (in Buenos Aires) and numerous others. We set out to accomplish a program of work, but we have been rewarded with far more than scientific results.

Similar cases could be cited regarding other nations with which we have worked, but I am sure that I have made it clear that the oceanographic research programs of the U.S. institutions give unequaled opportunities to establish good relations with other countries.

I repeat that I am sorry not to be with you today, and assure the committee that I stand ready to help in any way possible. Mail sent to me at my office will be forwarded to the ship, and I will be pleased to try to answer any questions. Dr. J. Lamar Worzel and $I$ have been friends and colleagues for nearly 30 years, and the testimony he gives represents my own views very closely. Very sincerely yours,

MaUrice Ewing.

The Chatruan. We will recess until 9:30 tomorrow morning.

(Whereupon, at $12: 15$ p.m., the committee was recessed, to reconvene at 9 :30 a.m., Friday, April 22, 1960.) 


\section{MARINE SCIENCE}

FRIDAY, APRIL 22, 1960

\section{U.S. Senate, \\ Committee on Interstate and Foreign Commerce, Washington, D.C.}

The committee met at $9: 30$ a.m., in room 5110, Senate Office Building, Hon. Frank J. Lausche, presiding:

Senator Lausche. Mrs. Ray, if you will step forward, please.

(A biographical sketch of Mrs. Ray follows:)

\section{DIXY-LEe RAY}

Address: Department of Zoology, University of Washington, Seattle 5, Wash.

Major field of interest: Marine biology.

Born: Tacoma, Wash., September 3, 1914.

Degrees: B.A., Mills College, 1937; M.A., 1938; Ph. D. (biology) Stanford: University, 1945.

Professional career: Instructor zoology, University of Washington, 1945-47; assistant professor, 1947-57; associate professor, 1957-; member staff, Friday Harbor Laboratories, 1947-; executive committee 1958-.

Awards: Guggenheim fellow, 1952-53.

Member: American Association for the Advancement of Science, American Institute of Biological Science, Western Society Naturalists.

Scientific contributions in: Microbiology; fish morphology ; marine invertebrates; cellulolytic activity of marine wood-boring animals.

\section{STATEMENT OF DIXY LEE RAY, ASSOCIATE PROFESSOR OF ZOOLOGY, UNIVERSITY OF WASHINGTON}

Mrs. Rar. My name is Dixy Lee Ray. I am associate professor of zoology at the University of Washington where my time is divided: between instruction in invertebrate zoology on the Seattle campus, and research and graduate training at the university's marine field laboratories at Friday Harbor. The area of my special interest is marine biology. It is a pleasure to be here today and to have this opportunity to speak in support of an expanded program of research in oceanography.

That it is in the best interests of our Nation to increase our knowledge and deepen our understanding of the world we live in, is sufficiently self-evident so as to require little justification. The present and vital need to focus attention upon study of the sea, and the reasons why this must be a truly national endeavor have already been pointed out by Senator Magnuson in his opening statement.

I would like to add only this: that I am wholeheartedly in accord with what he has said. And it is my opinion that the points he stressed express also the convictions of biologists generally. 
My colleagues on the Committee on Oceanography have already presented testimony concerning the broad objectives of the program envisioned in the report, Oceanograph 1960-70, and many aspects of the recommendations have already been considered in some detail. It is now my privilege, and my responsibility, to discuss for a few brief moments the vast and significant topic of basic research in oceanography.

Basic research is a subject so broad in its scope and so profound in its implications as to defy a simple or superficial exposition. Yet it is easy to say what it is: Basic research is the unfettered quest for new knowledge; it is the study of questions that are asked out of wonder and puzzlement; it is investigation motivated only by curiosity and interest; it is the search for understanding without concern for the practical application of the results or economic exploitation of the information obtained.

All of these statements are true, yet they are also somewhat misleading. Many problems of great economic import have been and continue to be studied because they are intrinsically interesting and conversely, unexpected applications constantly arise from research of the "purest," most nonapplied character.

History is full of illustrative examples in every discipline in science; let me cite one or two from the field of marine biology. For some years I have been interested in marine invertebrates that burrow into various materials in the sea, and we became intrigued by one, a minute crustacean, that not only burrows into wood in sea water but also feeds on the material that it excavates.

Now, few animals can really eat wood, but this one does. The piles that support a dock or wharf and the wood of floats and boats are just as palatable as driftwood. That the feeding and burrowing of this insignificant creature causes the destruction of waterfront and maritime structures and consequent monetary losses of a high degree is really incidental to our concern to learn how this animal can digest so insoluble and umpromising a substance as cellulose. But, during the course of our studies, we have learned enough about the creature's activities to suggest some new approaches to the problem of protecting wood from biological deterioration.

Another illustration of the dynamic interplay between the indulgence of curiosity and the usefulness of new information-just before the turn of the century, a group of French biologists on a cruise in the Mediterranean wondered what makes a jellyfish sting. Thinking that some poison was implicated, they ground up jellyfish tentacles; small amounts of this material were injected at short intervals of time into experimental animals. The result was the first induced case of anaphylactic shock, and the science of serology was born.

Many other examples from marine biology could be listed including studies of the curious vertical migrations of planktonic organisms that we now realize may be significant in transporting materials, including radioisotopes, from deeper waters up to shallow areas. The whole question of nutrient cycles in the sea, with all its implications for future exploitation, reaches out into every discipline, requiring, for its thorough understanding, information about the behavior and ecology of micro-organisms, the formation of communities and aggregations, about the interplay between species, the movements of 
water masses and their chemical composition. Truly the sea is a dynamic system with constant interaction between organism and environment.

The point that I am trying to emphasize is that we cannot draw a sharp line and say, "on this side we have basic research and on the other we have applied; that there is an identifiable or predictable area of knowledge that is useful and one that is not." Indeed, there is an incessant feedback and reciprocal fertilization that highlights a symbiotic relationship between these two.

And yet there is a real difference. There is a distinctive intellectual flexibility, a freedom from any obligation to find an answer to a specific question that, if it is not unique for basic research, is most characteristic of the approach and the climate in which the uncommitted search for new knowledge is best fostered. Further, if basic research were to be justified wholly on the grounds of future or possible usefulness, there is a danger that science will come to be equated with technology and looked upon only as a means to practical ends.

Such motivation would greatly lessen the chances for novel discoveries and fundamental advances in understanding. It is of the utmost importance to all men, and to the general welfare of all our people in a philosophical as well as a practical sense, that continued and increased opportunities for basic research be vigorously supported and jealously guarded.

Recognizing this, the Committee on Oceanography has identified many of the broad, significant problems that are unique to the sea, whose solution will require a major effort in basic research. These problems touch upon questions of the greatest import in each of the marine sciences. They can be grouped roughly into five categories as follows:

(1) History of the oceans: As our horizons expand to encompass new appreciation of the physical universe, we are increasingly aware of our acute ignorance about the evolution of our own planet; about the origin of the waters; their separation from land; the changes in geographical regions corered by the seas and in the bottom contours; the dramatic fluctuations in climate during ages past. Nany of these secrets are locked in the sediments and materials on the ocean floor. Probing with new tools and greater insight, the depths of the sea will reveal much that has till now remained shrouded in mystery and speculation.

(2) Life in the sea: More than 90 percent of the earth's different kinds of animals are marine. Of the 28 or so well-recognized phyla of animals, representatives of all live in the sea and many are confined wholly to the marine environment. It is likely that animal life as we know it originated in the sea and our present knowledge of its great diversity and richness, though extensive, is still fragmentary indeed. Recent findings of creatures like Latimeria, long believed to be extinct, and Neopilina, not previously known to zoologists, serve to illustrate this.

Who knows how many other new forms may yet be found. The knowledge gained from a more complete study of marine life would help to fill in the gaps that make charting the course of animal evolution so perplexing. The structure of marine communities, the interdependence between species, their fluctuations in abundance, the role 
of micro-organisms, the turnover of organic matter through photosynthesis and feeding, the great migrations of various species, the diverse biochemical activities, the fact that no marine invertebrate is known to suffer from cancer or any tumorous condition, bioluminescence, the production of underwater sound and its use in recognition, communication, and animal migration; all these and many, many others are areas of basic research interest.

(3) Motion of the waters: The restless sea, and how the waters more has always excited the imagination. Indeed, much has been learned about the great patterns of circulation and movement, especially of the surface waters. Now it is clear that large water masses are also moving in the depths, and that enormous streams flow along the bottom and at intermediate depths. Upwelling, convergence and divergence, turbidity streams, the morements of identifiable water masses or cells within the larger body, are related phenomena whose study new techniques have now made possible.

(4) Relationships between ocean surface and the atmosphere: That the winds driving across the sea set the surface water into motion, create waves, absorb heat, take up moisture that later falls as rain, and in general modulate the climate of continents is well recognized. But it is not so well understood just how these things happen. Studies of the heat and water budget, of carbon dioxide interaction between water and air, of the transportation of salt and nutrients, of the birth of storms, information that will lead, for example, to more accurate long range weather predictions; these are but a few of the fertile fields for research.

(5) Coastal waters, estuaries, rivers: These places, though far remored from the main body of the open ocean, are nevertheless in greater or lesser continuity with it and are areas of intense basic interest. Here land and water meet. What is the nature of their interaction, and what are the consequences? We know that inshore waters are high in biological productivity; can we learn with greater precision and certainty why this is so? What causes the molding, destruction, building of the shore; how do sediments collect in near shore waters; what do river's contribute to the sea?

Clearly these are questions for basic research, and clearly it is in the best interests of the Nation that such knowledge should be sought.

The problems are big, like the sea itself. At present, we can only dimly see how they could be clarified, for ignorance is difficult to define. But we have the natural resources in keen, competent, and ingenious human minds. Such people, given the opportunity for free, undirected inquiry, will help to retain our position of intellectual leadership before the world. We have only to remember always that man conquers nature, not by force, but by thorough understanding.

Senator LAUsche. Dr. Ray, you are associate professor of zoology at the University of Washington, is that correct?

Mrs. RAY. That is correct.

Senator LaUSCHE. How long have you been in that position?

Mrs. RAY. I have been at the University of Washington for 15 years. I started as an instructor in 1945 .

Senator Lausche. Are you associated as a member with any of the groups that are making studies of this general subject, or making recommendations that studies should be made? 
Mrs. RAY. There is a great deal of activity going on not only, of course, at the University of Washington, but other places too. St udies of the sea are being carried out, biological, chemical, and physical.

I am familiar with most of the ones taking place at the University of Washington, yes. I am not sure

Senator I $\triangle A$ USCHE. You are here then in the interests of your profession and in the interests of the country. That is, are you connected with any agency that is financially interested or otherwise in this general subject?

Mrs. R.r. Well, speaking for my own work, aside from the support of the university that provides all the facilities and materials and so on that I need, my research is supported by contract with the Office of Naral Research. There are other groups within the university that have contracts with the National Science Foundation for the support of research.

The National Institutes of Health is supporting one of our medical students. So that at the present time, yes, there are at least three major agencies supporting basic research that has to do with the marine environment in the area in which I am working.

Senator LAusche. You seem to be rather firm in your conviction that whether practical use is or is not dereloped-whatever might be discorered-should not be the dominating force in making our decision. Basic research should be made because of the richness that it contributes to our understanding of the rorld and because out of it may come and probably will come practical application of the discoveries.

Mrs. RAY. That is right.

Senator LaUsche. I think that will be all and thank you very much for your interesting paper.

Mrs. RaY: Thank you.

Senator Lausche. Dr. Gordon Arthur Riley.

(A biographical sketch of Mr. Riley follows:)

\section{GoRDON ARTHUR RILEY}

Conn.

Address: Bingham Oceanographic Laboratory, Yale Untrersity, New Haren,

Major field of interest: Biological oceanography.

Born: Webb City, Mo., June 1, 1911.

Degrees: B.S., Drury College, 1933; M.S., Washington Universit5, 1934; Ph. D., Yale University, 1937.

Professional career: Sterling fellow, Yale, 1937-3S: marine biologist, Bingham Oceanographic Laboratory, 1938-42; marine physiologist, Woods Hole Oceanographic Institution, 1940-48; associate professor, Bingham Laboratory, 1948-52; presently professor of oceanography and associate director Bingham Laboratory, research associate Woods Hole Oceanographic Institution, president Bermuda Biological Station, member board of advisels, Narragansett Marine Laboratory.

Member: American Society of Limnology and Oceanography, American Geophysical Union, Connecticut Academy of Sciences.

Scientific contributions in: Ecology and population dynamies of plankton, chemical and physical oceanography.

\section{STATEMENT OF GORDON A. RILEY, YALE UNIVERSITY}

\section{Mr. RILEx. I am Gordon A. Riley of Yale University.}

In common with other members of the NAS Committee on Oceanography, I am deeply aware that our country needs to expand its 
efforts in oceanography. We need more research ships, more shorebased laboratories, more instruments, and more men. We are not at the present time squarely meeting practical oceanographic problems that we need to solve in order to make our defenses more secure and our harvest from the sea more rewarding. Along with these practical studies, we must stimulate broad and imaginative basic research, without which the science will grow sterile, thereby gradually weakening the vigor of our attack on all oceanographic problems, practical or otherwise.

An increase in oceanographic effort must be geared to our ability to attract young people of high intellectual quality and to train them to a high level of competence in oceanography. To lower our standards in order to produce oceanographers on a crash program basis would be a sheer waste of time and money. Our committee felt that a reasonable rate of growth would permit a doubling of the oceanographic population in the next 10 years. We are not talking about a large number of people. This would mean turning out about 40 Ph. D.'s per year, which is about double the current output, and about 80 people with lesser training at the master's and bachelor's level.

Having said this much by way of introduction, I would like to take up the various training problems individually for brief discussion.

First, how are we going to attract the kind of men that we want?

The most important thing here is simply to create an awareness that this is an important field in which there is a shortage of good men. The country is now well on the way toward such an awareness, for this year oceanography has had more good publicity than ever before. I believe it is no coincidence that this year for the first time my laboratory had more good applicants for graduate training than we had room for.

In the second place, although oceanographic training is mainly done at the graduate level, it would be desirable for more colleges and universities to have at least one good undergraduate course in the subject. This would broaden the students' background and would help young men to decide whether an oceanographic career seems appealing. Equally important, they would be able to get advice about the undergraduate courses that are needed in preparation for the profession. One might go a step further and say that some oceanog raphic teaching should trickle down to the public school level.

If a man wants to take a master's or doctor's degree in oceanography, he is generally advised to do most of his undergraduate work in the basic disciplines-physies, biology, and so forth-majoring in one of his choice and taking as many other science courses as his schedule permits. Most of his oceanographic training is reserved for graduate school. Even in the latter there is likely to be fairly intensive study of basic disciplines. Some universities have departments of oceanography and grant degrees in the subject. Others give a degree in a basic science and simply add a few courses and thesis supervision in oceanography. It is an arguable point as to which kind of training is better. The fact is that both kinds are useful in an oceanographic laboratory, and each complements the other.

There are several reasons why the support of graduate students in oceanography is more difficult than in the basic disciplines. 
First, the necessity of competence in both basic science and oceanography tends to make it a long course, and in most cases students need to be supported longer than if they were getting a simpler sort of degree. Secondly, they are in many instances cut off from common means of support that are available in other branches of learning.

For example, the commonest support of graduate students in basic disciplines is teaching assistantships, in which they help professors teach the undergraduates in the department. But in an oceanography department with no undergraduate body, this means of support is denied them. There remain fellowships and part-time research assistantships as the main sources of support. But the latter further lengthen the already long career of the student. Nor are they of any use to a man who wants to do thesis research in a remote place, away from the job opportunities of the campus. These are the reasons why our committee felt that fellowship support should be granted to a higher percentage of oceanography students than is the common practice in basic disciplines. We feel that this must be done in order to compete for good students.

A second type of support that is needed is for expansion of teaching staff's. This is required both for distributing the increasing teaching load and for creating a better balance in teaching staffs. Many of the small university laboratories consist almost entirely of biological oceanographers. Addition of physical oceanographers to their staffs is particularly important, because the most severe manpower shortage exists in this branch of the field. We do not feel it is necessary to create many new institutions, if any, but existing ones should be strengthened where additional strength is needed, and it should be made possible for nonteaching institutions to work in cooperation with universities in developing teaching functions.

Finally, additional staff and students will put an impossible burden upon already crowded laboratories. We did not specifically recommend expenditure for teaching facilities as distinct from research, but additional laboratory space that we have requested is expected to fulfill both functions.

Senator Lausche. How long have you been associated with Yale University?

Mr. RiLey. Except for a short period during the war when I was away, I have been there since 1938 .

Senator Lausche. Have you been connected with that division which deals with oceanography during the entire period?

Mr. Riley. Yes. I am primarily a biological oceanographer working in problems of productivity of the sea.

Senator Lausche. How many students do you have on this subject. in your department now?

Mr. Risey. We have a total of eight graduate students at the moment. They are not all working in the same field. There are various aspects of biological oceanography.

Senator Lacsche. You have eight of them that are in the graduate school?

Mr. Riler. Yes, sir. We turn out on the average between one and two oceanographers a year.

Senator LAUSCHE. In your statement you declared that because of the favorable publicity that has been given to the subject, your student body has increased in number. 
Will you explain that in a little greater detail?

Mr. RrLeY. Each year we get applications from students who want to enter graduate school. We, of course, choose the best ones. We choose as many as we have facilities to handle. That is, space in our laboratory and teaching facilities. It takes quite a lot of time to supervise the thesis research of graduate students, and each institution can handle only a limited number at a time.

Senator Lausche. In talking with students whom you believe are likely prospects, what answers do you get describing why they hesitate entering the field?

Mr. Rmex. There are two main problems in the student's mind when he enters the field.

First, "Is it a field I will be really interested in?"

Second, "What will be the job opportunities when I get out?"

So far we have been able to tell him that there is a shortage in the field. I hope there will be enough new staff positions created so we will continue to have a moderate shortage for some time.

Senator LAusche. Then their thinking would be divided into two classes - one that may be basically interested in the intellectual development of himself and, secondly, the one who is thinking about the practical use that he will be able to make of his learning as a means of income and in the commercial world.

Mr. RILEY. I think practically all of them have both of these thoughts in mind. They are interested in the field intellectually and they want to have an opportunity to find out whether that is what they want to make marine sciences their lifework.

Senator LAUSCHE. What is the field of opportunity into which they can go specifically? Where are jobs available? I am not thinking of their knowledge of biology and chemistry and physics, but this particular subject. Where can they go to find a position?

Mr. RiLey. We have placed most of our students in other oceanograplic laboratories who were hiring new staff members.

Senator Ladsche. Is Government employment one of their main avenues?

Mr. Rruey. No, sir; I am sorry to say it is not. This is a common attitude among many of the graduate students, that they feel that the opportunities for research are better in the private institutions than they are in the Government. I think this is an attitude that we can change.

Senator Lausche. Yesterday a Dr. Schaefer testified. I think he was mainly interested in the marine life, wasn't he?

Mr. Rileey. Yes.

Senator Lausche. You state it requires extensive knowledge in sciences and, therefore, protracted courses, and that is a deterrent in getting students?

Mr. RILEy. No, I believe it is not a deterrent provided we can give them proper financial help. Most of these graduate students have to earn their way.

Senator LAUSCHE. What is the means presently of providing financial help for them as an inducement to continue their studies? Will you catalog them if you will, please?

Mr. Riley. Well, primarily in oceanographic laboratories it is research assistantships. These are generally simply assisting the permanent staff members on research on Government contracts. 
Senator Lauscrue. That is, they are hired then and in that way aided to continue their studies?

Mr. Riley. By doing part-time work they earn their way.

Senator Lauscrie. What other source of financial help is available?

Mr. Rilex. Fellowships either from Federal sources or from the university.

Senator Lausche. Is there any other source?

Mr. Riner. In universities which grant a degree in a basic discipline with some oceanography attached, they would be able to take teaching assistantships in this department, whatever it may be; biology or physics.

Senator Lausche. It is your opinion, however, that the sources of help are not adequate to properly stimulate prospective students?

Mr. Riler. Economically speaking, our students are second-class citizens. They don't earn very much. Usually these stipends are of the order of $\$ 1,500$ to $\$ 3,000$ and there are not enough sources of such help available.

Senator Lausche. What do you specifically have in mind from the standpoint of the Federal Government that might be done to help solve this complication?

Mr. Ricex. We would like to create fellowships, more fellowships than are available now and perhaps have a certain freedom in choice as to whom they should go.

As things stand now, you see only about the upper 10 or 15 percent of our students are likely to obtain Federal, or university fellowships.

It seems to me it would be rery desirable to be able to grant them to other people who are perhaps not so outstanding but at least a verage graduate students who desperately need this kind of help.

Wre have problem cases of students who have families to support and that sort of thing. We should be able to give more help to these cases.

Senator LAtsche. That will make it possible for you to use the moneys you get out of Federal research assignments to hire these assistant tearcher's and otherwise? Is it stipulated in the contract? Do you have an understanding with them or how do you proceed?

Mr. Riuex. Yes. Then we write a proposal for a research grant ordinarily we put in a certain amount of money for an assistant and we are then free to take on anybody who is qualified for this work.

Senator Luuscie. Do I understand you correctly then to say that the amount allocated for taking on assistants isn't adequate?

Mr. Riley. Generally speaking this kind of support probably is adequate. The only difficulty is that the amount of time spent on assistance work seriously cuts into their own student efforts.

Senator Lausche. That specifically then do you recommend by way of support?

Mr. Rilex. I think the best means is certainly fellowships which require no work. It is simply money that the student can live on while he is spending full time as a student.

Senator LAUSche. Is there anything further you desire to offer, Doctor?

Mr. Rilex. No, I believe not, sir.

Senator Liusche. Thank you very much.

Dr. Allyn Vime. 


\section{(A biographical sketch of Dr. Vine follows:)}

\section{Alluyn Vine}

Chairman of Panel on Engineering Needs for Ocean Exploration; physical oceanographer, Woods Hole Oceanographic Institution.

Date and place of birth: June 1, 1914, Garrettsville, Ohio.

Education: A.B. Hiram College in 1936; M.S. in physics, Lehigh University 1938.

Physical oceanographer at Woods Hole during and since the war working on thermal structure, current measurements, undersea warfare, underwater sound, instrumentation.

Trustee, Ocean Resources Institute 1952-; American Physical Society, American Geophysical Union, Acoustical Society.

\section{STATEMENT OF ALLYN VINE, WOODS HOLE OCEANOGRAPHIC INSTITUTION}

Mr. VIne. My name is Allyn Vine and I am a physical oceanographer at the Woods Hole Oceanographic Institution.

It is a great honor to be here today to discuss the problems and objectives of oceanography, particularly "New devices and engineering aids for oceanography" which is chapter 7 of the report. As such it is my pleasure to discuss how advanced design vehicles and instruments can speed up oceanographic research and open up new concepts of doing research and engineering at sea.

However, before going into details I have three justifications for oceanography that may be of interest to you.

As a typical worker in oceanography $I$ find it a stimulating and interesting branch of science.

Present day engineering applications require a better knowledge of applied oceanography if the United States is to intelligently plan, and to economically carry out many aspects of undersea warfare, weather prediction, fisheries, and nuclear engincering. I firmly believe oceanographic research is an excellent financial investment.

In considering the future, the 2 billion people now on earth and the billions more that will be born here will mostly live and die on our planet Earth. Their future and our country's future will depend on how successfully we adapt to each other and to the resources of the Earth. The ultimate importance of the ocean is uncertain but it must be enormous and I am impressed by the fact that even a hundred years after Columbus discovered America most Europeans felt that North America was pretty useless. It would seem that the marine sciences would be a good place for the United States to have national competence in the decades to come.

The detailed recommendations for new vehicles, devices, and instruments to aid the marine scientist in his research are described in chapter VII entitled "Engineering Aids for Ocean Exploration." In the limited time available, I shall briefly summarize that chapter and explain the reasoning behind those recommendations. Please feel free to ask any questions. 
Senator Magnuson commented earlier on the fact that the ocean is usually regarded in a negative sense. 'Throughout history seagoing has been regarded as uncertain, difficult, and dangerous. Romantic novelists since Homer, traders since the Phoenicians, and more recently poorly equipped marine scientists have tended to emphasize negative aspects of the ocean such as: distance, storms, and waves. In recent years many oceanographers have come to believe that this negative attitude about the ocean is not justified and with improved technology - such as buoys, submersibles, instruments, and more ships working at sea can be vastly improved; in fact, many things can be done better at sea than on land.

For example: Maneuverability over the water in a reasonable ship is much easier than traveling through swamps, jungles, or mountains.

Lowering instruments 3 miles down from a ship on a wire is fundamentally much easier than raising instruments 3 miles above the surface of the earth. A normal size submarine can carry enormous payloads compared to our largest satellite or airplane.

\section{TEMIPERATURE VARIATIONS}

The great temperature extremes found in outer space are not present in the depths of the sea where temperatures are uniform to within a few degrees or even a few hundredths of a degree.

Background noise is so much less at sea than on land that the French oceanographer Costeau titled his book "The Silent World." There is also reason to believe that a seismograph station on the bottom of the ocean can be made much more sensitive than one on land.

\section{POLITICAL AND GEOGRAPHIC FREEDONI}

We can wander over and explore the high seas without a treaty, a passport, or a trade agreement.

In past years the great size and depth of the ocean have proven to be formiclable obstacles to the limited vehicles, instruments, and techniques which have been available to oceanographers.

By developing new techniques and by making wider use of the best existing techniques there is every reason to believe that within the next decade the ocean can be "brought down to a manageable size" and seagoing scientists and engineers can approach their problems with techniques and background data more comparable to those of present day scientists on land.

Modern techniques will help the marine scientist in two ways. They will, through such derices as the bathyscaph, return him closer to the use of his basic senses and methods in new regions of exploration. The biologist can use a modified butterfly net again, and the geologist a modified prospecting pick.

Senator Lausche. Illustrate that in thought. I just can't follow it.

Mr. Vine. With a newly designed vehicle that can cruise along the bottom equipped with a manipulating arm the scientist sees a rock or a marine creature that he wants to pick up, can take a sample and bring it back. 
Senator Lausche. With the maneuverable arm?

Mr. VINe. With the maneuverable craft and with the maneuverable arm.

In other words, with modern technology we can do much more purposeful experiments than we could on the end of a wire 3 miles long.

In addition, other new devices will extend his senses in speed and ability. For example, drifting and anchored buoys can extend simultaneous geographic coverage greatly, and make possible longtime series of continuous data.

At the present time we don't have any longtime series measurements in the open ocean. Better winches and electric cable techniques, as well as cableless telemetering devices will enable the oceanographer to make more sophisticated chemical and physical measurements in situ. Data recording, analyzing, and storage devices will reduce much of the tedious portion of measuring programs.

\section{MANNED SUBMIERSIBLES}

One of the most important and exciting of the new techniques is the manned deep submersible.

The work by the Swiss, French, and the recent record dive of the Trieste have laid the groundwork for serious scientific studies and the design of deep submersibles that can carry a bigger scientific payload and have much more mobility. The concept of having a mobile underwater laboratory in which one can conduct purposeful experiments is of tremendous potential. With remote handling arms the geologist can select the rock he wants, scoop up the sediments of interest, photograph the unusual, and follow and map the geological outcrops. The biologist can observe deep sea life as it exists, and observe the bottom conditions that foster marine life. He can move up and down with the scattering layer and observe with his eyes as well as his instruments how complex life is in the oceans' principal pasture.

The engineer can observe how deep sea instruments work, he can drive surveyors' stakes and sight along them, he can maneuver huge grab buckets from surface ships to pick up rocks or equipment from the bottom of the ocean. In only a few years we may develop the capability to find, inspect, and retrieve aircraft that have been lost at sea.

The geophysicist and acoustician can place and adjust complicated seismographs, tidemeters, and current meters on the bottom of the ocean.

Naval scientists can become experienced with the advantages of being "down under" with the reverberation behind them just like World War I aviators liked to be "on top" with the sun behind them. The whole technology of building for high pressures will be given impetus. Manned submersible programs need emphasis and continuity.

\section{OCEAN RESEARCH STATION}

In the past our ships have been built to go from one shallow harbor to another shallow harbor and the handling equipment was designed for use at a dock. A midocean laboratory and observatory where observations can be made for long periods of time or where 
researchers can try out new equipment seems essential. We have seismological observatories, high altitude observatories; a leading maritime power should have a true midocean observatory.

\section{UNMANNED BUOYS}

Probably the only way we can ever obtain continuous measurements at sea from many places is to install a network of anchored buoys which record or telemeter meteorological and underwater weather. Such a data collecting system will be needed to furnish the desired data of the future. Five hundred such high seas buoys would be needed even if each buoy monitored an area as large as Texas.

From the standpoint of air safety, it might be wise to have a line of moored buoys with short range navigational aids and recording check points along every major over-ocean airline route.

\section{SPECIALIZED SURVEY AND RESEARCH INSTRUMENTATION}

The development of rapid, foolproof instruments for survey and research is essential to use ships efficiently. For example, a better winch might speed survey work as much as doubling the size of the ship's main propulsion plant. Reliable instruments may permit three ships to do what otherwise would require four ships. Center wells on ships will encourage new kinds of instruments and instrument handling.

These ships need the best available instruments. For example, oftentimes research ships are some of the last ships to get new equipment.

There is the problem of the new research instruments. Those which are developed by individual scientists without the aid or the need of any master plan such as ours. Here it is important that those individuals be financed through the existing working level por= tions of the Government who have proven so capable here.

In summary, it is essential that an instrument and special vehicle program be pushed vigorously, that industry become more heavily involved in instrumentation. The budget for new devices is about 15 percent of the total or about $\$ 10$ million a year.

Of course, the vast bulk of the new devices which are associated with applied engineering problems would be paid for as priority engineering items by the user.

The items that we have been talking about here are those experimental devices used for oceanography, to serve as a basis for improving the technology of working at sea so that when the Nary or the fisheries, or $\mathrm{AEC}$ has big problems at sea they will have the technology to draw on.

Senator Lausche. The Woods Hole Oceanographic Institution; would you identify it, please?

Is it privately endowed? What are its functions and so forth?

Mr. Vine. It was set up as a private organization with Rockefeller funds in 1929. In fact, it was set up as the result of recommendations by the first Academy Committee on Oceanography.

At the same time the Scripps Institution of Oceanography was enlarged at the University of California. 
Senator Latusche. Where is it located?

Mr. Vine. Woods Hole Oceanographic is located at Woods Hole, Mass., on Cape Cod.

Senator Lausche. How many people does it have in its work?

Mr. VINE. We have about 350 people including the crews of the ships and we have about 100 scientists that are carrying out individual research work.

Senator LaUsche. And it is completely endowed by private grants and otherwise?

Mr. Vine. I think that its own income from the original grant is now about 10 percent of the total budget. Most of the research funds are supplied by contract from the Navy, the National Science Foundation, and the Atomic Energy Commission.

Senator Lausche. Do you do any contract work for private industry?

Mr. VINE. There has been a little bit over the years.

Senator Lausche. What has been the nature of that work?

Mr. Vine. A typical example was a model study of the flushing of Barataria Bay on the gulf coast. There was a question of whether the oil was seeping into Barataria Bay and interfering with the biology of the area.

Senator Lausche. Have you done any research work for the extraction of metals out of the ocean waters?

$\mathrm{Mr}$. VrNe. There has been no direct work as far as engineering application is concerned. There have been several of the people at Woods Hole who have been interested in the formation of manganese nodules and things of that caliber.

Senator Lausche. What do you specifically have in mind about what the Federal Government could and ought to do to help in the development of this important work?

Mr. Vine. Perhaps the most important thing is to recognize the fact that marine technology is a broad field. It is much more than just a navy field. In the past there has been a great tendency to think that the Navy is the only part of the Federal Government that should be interested in the ocean.

In this connection the Navy needs - there needs to be more support than the Navy gires. There needs to be a wider diversity of interest. Senator Lacscue. Now, what other departments have an interest in it?

Mr. Vine. The Atomic Energy Commission, for example. They have problems of disposal. The problems involved in experimental work on harbors, things of that nature all need oceanographic background information to know whether a project is wise or how we should go about it.

Senator Lausche. You have the Navy and the Atomic Energy Commission. What is the other department?

Mr. Vine. The Bureau of Commercial Fisheries has the whole big problem ahead of it of farming the sea, for example. These problems go far and beyond the questions of conservation. How does one look at the ocean in the sense that the agriculturalists look at the land?

Senator Lauscue. What about the Commerce Department? Since that bill is with us, with the Commerce Committee, I presume it does have a relation to it. 
Mr. Vine. In the question of surveying the oceans, in the past we have not done large-scale surveying of the ocean and we have tended to use the techniques which exist. Any organization which looks forward to many years of intensive survey wants to be sure that they are developing the equipment and the instruments both for making those measurements and for analyzing those measurements.

Senator Ladsche. Are you able to say what amount of money the Federal Government through the Department of the Navy and whatever other departments are participating, is spending in this general subject?

Can anyone on our staff answer that?

Mr. VIne. In the field of new devices, I would estimate that perhaps 5 percent of the total.

Senator Lausche. And what is the total? Five percent of the total appropriation to the Navy?

Mr. Vine. No; only 5 percent of that which goes to oceanography. Senator Lausche. Where does the other 95 percent come from?

Mr. VINE. Five percent of the money which goes into oceanography goes into new devices. This might be a million dollars a year.

Senator Lausche. That comes from the Federal Government?

Mr. Vine. Most of that comes from the Federal Gorernment.

Senator Ludsche. May I ask the staff, is there anything in the record about how much is being spent and what is being recommended?

Mr. Markel. We have that. I can bring it over. I don't have it right here.

Senator Lausche. Is it in the record?

Mr. Markel. No, sir.

Senator Lausche. May it be put in the record?

Mr. MARKel. It will be put in the record.

Senator Linsche. You are unable to give specific help on this subject?

Mr. Markel. No, I would say not.

Senator Lausche. Thank you very much, Dr. Vine.

(The information requested by Senator Lausche follows. Table $I$ is a breakdown of current and prospective expenditures on marine science by agency as reported by the Subcommittee on Oceanography of the Federal Council for Science and Technology. Table II is the breakdown of expenditures by the Navy Department on oceanographic research during the current fiscal year.) 


\section{TABLE I.-Oceanography program by agency}

[Thousands of dollars]

\begin{tabular}{|c|c|c|c|}
\hline & $\begin{array}{c}\text { Fiscal year } \\
1959 \text { program }\end{array}$ & $\begin{array}{l}\text { Fiscal year } \\
1960 \text { program }\end{array}$ & $\begin{array}{l}\text { Fiscal year } \\
1961 \text { plan }\end{array}$ \\
\hline $\begin{array}{l}\text { Navy: } \\
\text { Research } \\
\text { Ship construction } \\
\text { Ocean surveys } \\
\text { Facilities } \\
\text { Data processing }\end{array}$ & $\begin{array}{r}\$ 5,646 \\
13,800 \\
0 \\
0 \\
295\end{array}$ & $\begin{array}{r}\$ 11,230 \\
5,200 \\
0 \\
0 \\
295\end{array}$ & $\begin{array}{r}\$ 17,724 \\
4,900 \\
0 \\
0 \\
295\end{array}$ \\
\hline - & 9,741 & 16,725 & 22,919 \\
\hline $\begin{array}{l}\text { Commerce (U.S. Coast and Geodetic Survey and Weather } \\
\text { Bureau): } \\
\text { Research } \\
\text { Ship construction. } \\
\text { Ocean surveys. } \\
\text { Facilities } \\
\text { Data processing }\end{array}$ & $\begin{array}{r}2,033 \\
3,187 \\
0 \\
0\end{array}$ & $\begin{array}{r}162 \\
2,033 \\
3,478 \\
0 \\
0\end{array}$ & $\begin{array}{r}413 \\
6,900 \\
5,670 \\
250 \\
0\end{array}$ \\
\hline Total & 5,220 & 5,673 & 13,233 \\
\hline $\begin{array}{l}\text { Interior (Bureau of Commercial Fisheries, U.S. Geological } \\
\text { Survey, Bureau of Mines): } \\
\text { Research } \\
\text { Ship construction } \\
\text { Facilities. } \\
\text { Data processing }\end{array}$ & $\begin{array}{r}5,500 \\
0 \\
0 \\
0\end{array}$ & $\begin{array}{r}6,050 \\
100 \\
220 \\
0\end{array}$ & $\begin{array}{r}5,213 \\
2,055 \\
180 \\
0\end{array}$ \\
\hline Total & 5,500 & 6,370 & 7,448 \\
\hline $\begin{array}{l}\text { National Science Foundation: } \\
\text { Research } \\
\text { Ship construction. } \\
\text { Facilities } \\
\text { Data processing }\end{array}$ & $\begin{array}{r}2,476 \\
0 \\
0 \\
0\end{array}$ & $\begin{array}{r}3,300 \\
3,000 \\
500 \\
0\end{array}$ & $\begin{array}{r}4,350 \\
4,250 \\
600 \\
80\end{array}$ \\
\hline Total & 2,476 & 6,800 & 9,280 \\
\hline $\begin{array}{l}\text { Atomic Energy Commission: } \\
\text { Research } \\
\text { Data processing }\end{array}$ & $\begin{array}{r}1,575 \\
0\end{array}$ & $\begin{array}{r}1,820 \\
0\end{array}$ & $\begin{array}{r}2,200 \\
10\end{array}$ \\
\hline Total & 1,575 & 1,820 & 2,210 \\
\hline $\begin{array}{l}\text { Health, Education, and Welfare (Public Health Service): } \\
\text { Research } \\
\text { Facilities }\end{array}$ & - & $\begin{array}{r}340 \\
0\end{array}$ & $\begin{array}{r}664 \\
0\end{array}$ \\
\hline Total & -nen & 340 & 664 \\
\hline Grand total & 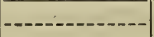 & 37,728 & 55,754 \\
\hline
\end{tabular}

1 Cost of converting 3 oceanographic research ships from R. \& D. funds. 
TABLE II.-Navy oceanographic research, development, test, and evaluation program

Scripps Institution of Oceanography.

Lamont Geological Observatory.

\section{Naval Flectronics Labora-} tory.

University of Washington

Chesapeake Bay Institute

Texas Agricultural \& Mechanical College.

New York University

Narragansett Marine Laboratory.

Marine Laboratory, University of Miami.

Oregon State College.

National Academy of Sciences

Fiscal year
1960

Oceanic circulation; marine geology and geophysics; oceanographic instrumentation; waves; tides: underwater acoustics: physical, chemical, and biological oceanography; marine meteorology.

2, 250 Similar in scope to W HOI research listed above but more emphasis in marine geophysics and geochemistry. Acoustic work is more directed toward theory and instrumentation than at WHOI.

Marine geophysics including seismic, magnetic, gravimetric, and geothermal measurements; geochemistry; oceanic circulation: blological oceanography and oceanographic instrumentation.

Scientific program of the bathyscaphe Trieste, arctic oceanography; wave and thermocline studies: and sea floor studies.

Physical, chemical, and biological oceanography; model studies; and oceanographic instrumentation.

Estuarine studies including $d y-$ namies, chemical, light extinction, and flushing of estuarine waters; oceanographic instrumentation; and gravity wave studies in inshore waters.

General understanding of the oceanographic characteristies of Gulf of Mexico; energy exchange through ocean-atmosphere boundary; thermal structure and internal waves.

Air-sea boundary energy exchanges; wave and circulation studies.

Biologically produced underwater sounds; the use of plankton to determine circulation and other oceanographic factors.

Tropical oceanography emphasizing studies of Florida Current, its fluctuations and associated phenomena; radio chemical studies; biological oceanography; and ambient noise in the sea.

Investigations of estuarine and offshore waters including temperatures, pollution, light scattering and flushing of estuaries.

Support for NAS-NRC Committee on Oceanography which acts as adviser, consultant, and planning group for oceanographic problems.

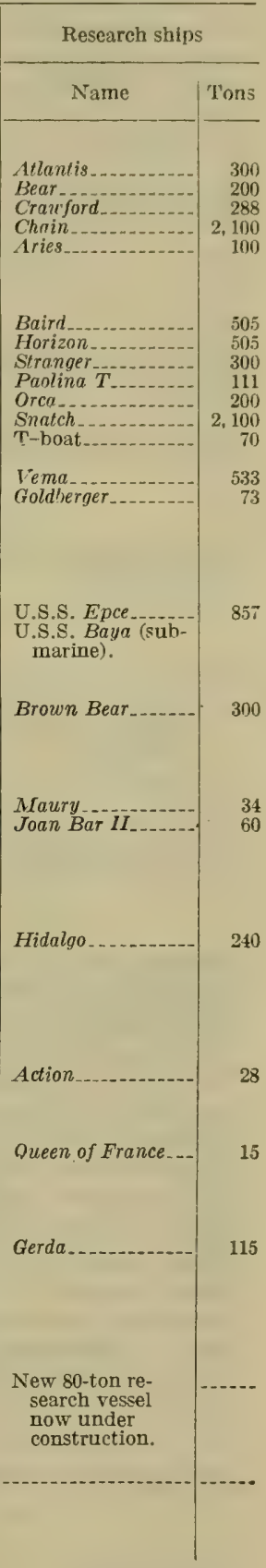


TABLE II.-Navy oceanographic research, development, test, and evaluation program - Continued

\begin{tabular}{|c|c|c|c|c|}
\hline \multirow{2}{*}{ Institution } & \multirow{2}{*}{$\begin{array}{l}\text { Fiscal year } \\
1960\end{array}$} & \multirow{2}{*}{ Type of research } & \multicolumn{2}{|c|}{ Research ships } \\
\hline & & & Name & Tons \\
\hline Hudson Laboratories_.........- & $\begin{array}{l}\text { Thousands } \\
\$ 2,650\end{array}$ & $\begin{array}{l}\text { Environmental effects on sound } \\
\text { transmission in the oceans; am- } \\
\text { bient and man sounds in the } \\
\text { sea; nonacoustic methods of } \\
\text { submarine detection; signal proc- } \\
\text { essing; communication systems; } \\
\text { and instrumentation develop- } \\
\text { ment. }\end{array}$ & Gibbs.. & 2,800 \\
\hline $\begin{array}{l}\text { Military Sea Transportation } \\
\text { Service. }\end{array}$ & 1,400 & $\begin{array}{l}\text { Operational cost of Chain for } 4 \\
\text { months of } 1960 \text { and operational } \\
\text { cost of Gibbs for all of } 1960 \text {. }\end{array}$ & 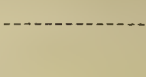 & 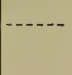 \\
\hline $\begin{array}{l}\text { Convair Division of General } \\
\text { Dynamies. }\end{array}$ & 130 & $\begin{array}{l}\text { Instrumentation for recording, } \\
\text { transmitting and stowing oce.n- } \\
\text { ographic data. Investigations } \\
\text { into general high speed data } \\
\text { handling. }\end{array}$ & & \\
\hline $\begin{array}{l}\text { Other universities, contrac- } \\
\text { tors, and Polaris. }\end{array}$ & 973 & $\begin{array}{l}\text { Investigations carried out in the } \\
\text { field of basic oceanographic re- } \\
\text { search at a variety of organiza- } \\
\text { tions both as a part of the con- } \\
\text { tinuing overall Navy program } \\
\text { and long term research for } \\
\text { special weapons systems. }\end{array}$ & & --- \\
\hline $\begin{array}{l}\text { Total, fiscal year } 1960 \ldots \\
\text { Planned total, fiscal } \\
\text { year } 1961\end{array}$ & $\begin{array}{r}13,886 \\
17,724\end{array}$ & & & \\
\hline
\end{tabular}

Senator Lausche. Dr. Koczy?

(The biographical sketch of Dr. Koczy follows:)

\section{Friedrich Frans Koczy}

Address: Marine Laboratory, University of Miami, 1 Rickenbacker Causeway, Virginia Key, Miami, Fla.

Major field of interest: Oceanography.

Born : Vienna, Austria, June 16, 1914.

Degrees: Ph. D., physics, University of Vienna.

Professional career: Assistant in physics, Oceanographic Institute of Goteborg, 1939 to 1943; assistant professor of physics, Oceanographic Institute of Goteborg, 1943 to 1947 ; oceanographer, Swedish deep sea expedition, 1947 to 1948; assistant professor oceanography, Board of Swedish Fisheries, 1948 to 1955 ; associate professor aceanography, Oceanographic Institute of Goteberg, 1955 to 1956 ; associate professor oceanography, Board of Swedish Fisheries, 1956 ; associate professor oceanography, marine laboratory, University of Miami, 1957 to 1958 ; professor, marine sciences, marine laboratory, University of Miami, 1959 to present.

Member: American Geophysical Union, Geochemical Society, American Society of Limnology and Oceanography, National Academy of Sciences' Committee on Oceanography.

Scientific contributions in: Chemical oceanography, eddy diffusion, geochemistry, oceanic circulation, geochronology.

\section{STATEMENT OF FRIEDRICH FRANS KOCZY, MARINE LABORATORY, UNIVERSITY OF MIAMI}

Mr. Koczr: My name is Fritz Koczy, the marine laboratory of the Tiniversity of Miami. I am a former member of the Oceanographic 
Institute of Goteborg, Nweden, trained physicist, now working mainly in geochemistry and the application to oceanographic problens.

The rapid development of oceanographic institutions during the last 2 () years seems to be only the begimning of an inevitable and necessary scientific evolution. This growth has been accelerated by the increasing demands of the Navy, the Atomic Energy Commission, Bureau of Commercial Fisheries, and other agencies concemed with problems of the sea. Oceanographic research is rather expensive mostly because of the high construction, maintenance, and operational costs of research vessels, with the additional, relatively moderate, cost of the scientific crew necessary to evaluate the collected data. Universities were not able to absorb the high costs in their budgets and therefore contributions for the support had to be given by the above agencies. The stabilization of this support, the construction of an appropriate fleet of research vessels with supporting shore facilities, is a necessity which the United States cannot neglect if it hopes to-

1. permit the education of needed manpower;

2. achieve the level of knowledge required by the interested agencies;

3. maintain its leading position in scientific research of the

\section{seven seas.}

Oceanography is a science which describes and attempts to understand the processes in the ocean. The descriptive phase is still in progress. Very large areas of the oceans are known only fragmentarily. In order to demonstrate the present state of affairs, let us take a chart of one of the better known ocean areas in the northeast Pacific Ocean and plot all expedition routes in this area. When we then take a chart of the United States and cover it by the same pattern of expedition routes, we can easily see that we would miss large geographic features such as the Grand Canyon and the Ozarks.

Another example will make it similarly clear how far behind our knowledge is, when we compare the density of all permanent weather stations $m$ the Tnited States which take observations four times daily with the network of only occasionally occupied stations in the northeast Pacific.

Perhaps it may be pointed out that our dense traffic on land and in air requires an intense knowledge of this environment and for that reason we have better corerage than of the sea. But, on the other hand a glimpse at a standard chart of the stars visible to the naked eye will reveal that we have named and charted more of these features than of sea mounts in the ocean. Here, I think all will agree that for immediate practical purposes, it is more important to know the ocean than the distribution of stars. However, that should not detract from our interest in stars, I mention this point only as an example of our limited knowledge of the ocean.

Moreover, the density of observations in our standard area is still smaller than the ship s-track network corered by the expeditions: because, these could only concentrate on one or a few scientific objectires within the time limits of an expedition. The specific reasons for this limitation are that the research ressels are generally too small in size or that the expedition was too short of available manpower. 
Our knowledge is certainly fragmentary and we need badly to speed up a survey program in order to investigate the 72 percent of the earth's surface covered by the oceans. Thorough knowledge always represents power and the more industrialized a country is, the easier and faster it can apply this knowledge toward increasing living standards, giving security, and favorably enlarging the military and economic forces.

A few examples of the practical applications which will be made possible by an oceanwide survey program can now be given. Weather forecasting is only partially satisfactory on a short-time basis and nearly impossible on a long-range basis. It has been shown that the ocean surface influences the weather orer several months and perhaps over more than a year, nonetheless we are lacking the data necessary to establish this as a predictable fact, and to make use of it. The atmosphere together with the ocean forms a large heat engine which takes its fuel from the sun, but the exact mechanism is not yet understood. We know, only roughly, the current systems and we are not able to read the fine print in the oceans. If we understood the general circulation and the mechanism of the heat engine driving it, we would also be able to predict weather over a long range and we might obtain a method of controlling the climate.

Another feature of the sea important to mankind is the distribution of nutrients along with plankton and fish, which together determine the productivity of the sea. Phytoplankton as the primary producer of organic matter in the ocean needs nutrients which are stored in the deep water masses. When this deep water is brought up to the sea surface and light, the phytoplankton can use it to start the food chain in the ocean. This chain follows through small animals and finally reaches the edible fish which store a part of the sun's energy which we may later use as proteins. At present, we recover only a small part of proteins from the sea, but the increasing population pressure will force mankind to use this source to a higher extent.

We need therefore to know more about the transport of the nutrients to the surface, about the distribution of plankton, about the productivity at a given place and about the density of fish. When we understand where and why the nutrients are coming up, into the realm of light, we will be able to predict the amount of fish which may be caught at that place per year. Tuna, as an example, are known to be found near the tops of sea mounts. Sea mounts seem to influence the vertical transport of water masses; consequently, the study of the bottom topography is important in order to facilitate the recovery of tuna.

Bottom topography may, in addition, be important to know for future submarine ocean transports where escape from wave action and the severe weather conditions of the surface is possible. The narigation of submarines is more dependent on a knowledge of ocean depth than that of a surface vessel. Captains of these vessels would narigate according to a depth chart and sound beacons may guide them.

Geochemical processes accumulate manganese ores on the sea floor. We do not know why, how, and where they are found. Therefore a surrey of the ocean floor has to be carried out to locate them. When we have better achieved an estimate of the total amount available, 
we might seriously undertake the mining of manganese on the ocean floor: A feasibility study has already demonstrated the possibilities of mining this ore.

In all the above-mentioned aspects of the oceanographic survey, the Navy has a particular interest. I future war very likely will be three-dimensional. It will involve a range from the stratosphere down to the ocean floor. It is necessary to know the medium as accurately as possible and for this we have to produce the manpower necessary to carry out the valuable collection and reduction of data.

I have discussed mainly the application of this survey, but we should not forget that by achieving a better description of the ocean, we will learn more about the phenomena within it and we will detect new features which we have never imagined before. We will learn to understand the ocean and we will receive new impulses for further developments.

Our techniques are already so advanced that an intense worldwide survey is possible and a rough one can start immediately. In order to avoid umnecessary duplications, a body or an agency should be established which can guide the survey, make the necessary preparations, organize the reduction of data, improve the survey techniques in order to save manpower and ships time, and finally, publish the data as rapidly as possible. The agency carrying out the survey would be the Hydrographic Office, Coast and Geodetic Survey, Fish and Wildlife and related agencies.

The research institution would participate mainly for quality control, data analysis, and development of new techniques. The survey which must be carried out can be divided according to topies and the distribution of space and time. The topics have to cover the following investigations :

(1) Bottom morphology and the sediment carpet.

(2) Geophysics: geomagnetism, heat flow and gravity measurements.

(3) Productivity, plankton and fish distribution, and fish migration.

(4) Distribution of water properties such as temperature, salinity, density, and sound velocity.

The time element dictates that the survey be made in a specific fashion in order to achieve the following results:

(1) Synoptic data.

(2) The average conditions.

(3) Seasonal variations.

(4) Secular variations.

The main emphasis for the descriptive aspects should be given to the gathering of data. Research work should be carried out on the important topics so that we may continue along the main objectives in an economical fashion.

According to the conclusion arrived at by a panel on this survey, a total of 340 ship-years are needed to carry out an ocean survey. It is expected that all nations interested in the ocean should participate and the panel found it appropriate that the United States contribute up to 30 percent of the total survey which would amount to about 100 ship-years. When we also count on the 11 survey vessels that will be available at the end of the 10 -year period, it 
was concluded that we can now start with about 4 vessels involved in this paramount survey work in the ocean. In the near future a wide grid of about $1^{\circ}$ spacing could be laid over the ocean. Later, when sufficient ship time is available, this grid can be refined to a spacing of about 10 miles.

Senator LAUSCHE. The Senator from California?

Senator EngLe. No questions.

Senator Lauscire. The Senator from Texas?

Senator Yarborodgh. I have no questions. I would like to compliment you on this fine statement.

Senator LaUsche. The Senator from Washington?

The Chatrman. I have no questions except this: What do you mean by a ship-year? Is that an operation 365 days, 24 hours a day?

Mr. Koczy. It would be about 250 days. There are times when the ships must be in the yard.

The Chatrman. When you speak of a hundred ship-years, you say that is spaced over a 10-year period. That would be 10 ships.

Mr. KoczY. Yes, we estimate that the U.S. share would be about 10 ship-operation years. The total job, counting contributions by other countries, will involve about 34 ships for 10 years.

The Chairman. Operating?

Mr. Koczy. Operating.

The Chamman. An overall total of 34 ships but 10 would be our contribution.

Mr. Koczy. Yes, sir.

The Chatrman. Thank you.

Senator LaUsche. I dont' think I have any questions.

Thank you very much for a very informative paper.

Senator Yarborodgri. You speak of this ship-year and the number required to carry out the survey. That survey would require getting a quantity of information on all of the subjects mentioned on page 3 of your report; is that right?

Mr. KoczY. Yes.

Senator YARBOROUGH. It wouldn't take anything like that to measure the depths of the ocean, where the ranges are.

Mr. Koczy. That is right.

Senator Yarborough. Not scientific uses but certain defense uses.

We would use electronic equipment for depth determination.

Mr. Koczy. Yes.

Senator Yarborocgri. You are speaking of a comprehensive scientific survey of the ocean floor, and determining what is in the five layers of water in between the surface and the bottom.

Mr. Koczr. Yes, we would measure the properties of the ocean water masses, the bottom and other features.

Senator Yarborovgr. And there would be surveys of these questions raised in Dr. Ray's statement this morning, about the movements of these masses in water and the different types of organisms.

Mr. Koczy. Yes.

Senator Yarborocgr. I hare no further questions.

Senator LACsche. You are connected with the marine laboratory of the University of Miami; is that correct? 
Mr. Kóczy. Yes.

Senator Lausche. To what extent have they discovered areas of fish through the researches that have thus far been made and what are your expectations of the potentials in this field?

$\mathrm{Mr}$. Koczr. In order to discover fish?

Senator Lausche. Yes. That is, the farming of fish and so on.

Mr. Koczx. We at Miami have worked mainly on shrimp in the Tortuga area which covers certainly one of the most valuable fish in the States and we are studying billfish in the straits and in the Caribbean. But our range of investigatiton is very restricted becanse we have only a small, 76-foot vessel.

Senator Lausche. You stated in your paper that tuna are usually found at mount tops.

Mr. Koczr. That is a result of the investigation made by the Tuna Commission, and Dr. Schaefer, specifically.

Senator Lauscine. What does that sort of portend? You say we should make studies-

Mr. Koczy. When we know more about where sea mounts are, fishermen can find more places where tuna is found and fishing for tuna becomes more economic.

Senator Lausche. And I suppose this general principle which you apply to tuna may become applicable to all other attributes of the ocean.

Mr. Koczy. That is right.

Senator Lausche. That is all I have.

Mr. Koczy. Thank you.

Th Chatrinan. Dr. Brown?

Ir. Brown is of the California Institute of Technology, the Division of Geological Sciences.

Dr. Brown, you are also chairman of the Committee on Oceanography of the National Academy of Science?

Mr. Brown. That is right.

(The biographical sketch of Mr. Brown follows:)

\section{HARRISON SCOTT BROWN}

Address: Division of Geological Sciences, California Institute of Technology, Pasadena. Calif.

Major field of interest: Geochemistry.

Born: Sheridan, Wyo., September 26, 1917.

Degrees : B.S., California, 1938. Ph. D. (chemistry), Johns Hopkins University, 1941.

Professional career : Instructor chemistry, Johns Hopkins University, 1941-42 ; research associate chemistry, University of Chicago, 1942-43; assistant director chemistry division, Clinton Labs. Oak Ridge, 1943-46; assistant professor, chemistry instructor. Nuclear studies, Chicago, 1946-1S, associate professor 1948-51; presently professor of geochemistry, California Institute of Technology, 1951_- Also civilian with Office of Science Research and Development, 1914.

Awards: Lasker Foundation award, 1958; A.A. (prize, 1947) ; National Academy; Chemical Society (award, 1952).

Member: Geological Society, Physical Society, National Academy of Sciences.

Scientific contributions in mass spectroscopy ; thermal diffusion, fluorine and plutonium chemistry: meteorities; geochemistry; planet structure; and geochronology. 


\section{STATEMENT OF HARRISON SCOTT BROWN, DIVISION OF GEOLOGI- CAL SCIENCES, CALIFORNIA INSTITUTE OF TECHNOLOGY}

Dr. Brown. As Jou have mentioned, my name is Harrison Brown and I am professor of geochemistry at the California Institute of Technology and Chairman of the Committee on Oceanography of the National Academy of Sciences.

I am very grateful to the Interstate and Foreign Commerce Committee for the opportunity of appearing before it for the purpose of commenting on bill S. 2692.

I should like to stress at the outset that the Committee on Oceanography has worked very hard since $195 \uparrow$ in an attempt first to attain a realistic picture of the status of oceanography in the United States and to prepare recommendations for remedial action. I am not myself an oceanographer by profession, although my own work has bearing upon it.

As a result, I believe that in helping to guide the committee's activities I have been able to make reasonably impartial and objective judgments.

We found first of all that the situation with respect to oceanography-

The Chamman. For the record, the committee now has studiedthe panels within your group have studied different phases of this problem.

Mr. Brown. That is correct.

The Chatrman. And you have released nine publications? There are two or three in process, as I understand.

Mr. Brown. Yes.

The Chamman. Which will be released in the very near future.

Mr. Brown. Yes. There will be 12 all together.

The Champinan. They constitute the nature of what I have in my hand here?

Mr. Brown. Yes.

The Chamman. In your report of the Committee on Oceanography you have made a summary of recommendations.

Mr. BRown. The first chapter consists of a general summary of all the recommendations which we have made, yes.

The Chatrman. Which, of course, bears directly upon the legislation before us.

Mr. Brown. That is correct.

First, concerning the situation which we found, we found it to be very critical indeed and in our opinion urgent.

Let me give one concrete example: We are all very proud of the achievements of the three young men who were here yesterday who went down in the bathyscaph to the very bottom of the ocean. I believe our self-praise, certainly our national praise should be tempered, however, by the realization that the bathyscaph was not conceived in the United States, it was conceived in Europe; it was not built in the Tnited States, it was built in Europe, it was not piloted by an American but by a Swiss national. This does not detract from the wonderful scientific achievements nor does it detract from the boldness of the operation, nor from the imagination of the Navy in carrying out the negotiations. 
I would just like to stress that had we been paying enough attention to oceanography in the past, the bathyscaph could well have been something of greater national pride than it is today.

You have already heard details concerning the urgent situation and indeed the critical situation that exists and I would now like to spend just a few moments discussing recommendations.

I would like to stress that the report of our Committee should be looked upon as a first approximation. There are probably many recommendations that we have made which should be modifierl.

The Chammax. And also, Dr. Brown, as I suggested in the beginning, the legislation is only here for suggestion or modification and changes. It is something to start with, and chew on, as it were, sort of following in the pattern of the recommendations.

Mr. Brown. Yes.

When I read the proposed legislation, however, I was pleased indeed that the group of persons sponsoring the bill apparently followed a great many of our recommendations, or at least our rerommendations and yours coincide.

In going through the proposed legislation rather carefully, however, there are a few modest recommendations which I would like to bring up and if I may take just a few moments I would like to comment no certain individual sections.

Before doing this I would like to say that I believe myself that something like S. 2692 is essential. On the whole I personally consider it an excellent bill and I believe the vast majority of my colleagues believe this, also.

In your discussion of education-

The Chatrman. I think for the record, as long as you are summing up here, it might be well to take the recommendations as they are. For instance, No. 1: "The U.S. Gorernment should expand its support of the marine sciences at a rate which will result in at least a doubling of the basic research activity in the United States during the next 10 years." We would like your comments as they relate to the bill.

For instance, the question that would come to me immediately: Would the bill do this?

Mr. Brows. I would be very happy to put it in those terms.

First of all, all of our recommendations hinge upon this very first one which is that the U.S. Government should expand its support of the marine sciences at a rate which will result in at least a doubling of basic research activity during the next 10 years. We have said that we should be able to achieve a doubling and then we have asked ourselves what has to go with that in terms of manpower, in terms of ships, and in terms of all of the corollary activities.

Second, we recommended that the increase in support of basic research should be accompanied during the next 10 years by a new program of oceanwide surveys. This will require a twofold expansion of the present surveying effort.

Now if I may just stop at this point and comment on those aspects of the bill which have bearing upon those first two recommendations.

One of the keys involved in increasing basic research activity is that of increasing manpower. Increasing trained manpower. Indeed the manpower situation is the primary rate limiting factor, whether it be for basic research or for ocean wide surveys. 
Now, the bill makes certain recommendations which are fine but we believe that the bill should be broadened. For example, you advocate the establishment of graduate fellowships and scholarships but there are other kinds of fellowships that are extremely useful in bringing competent men into this field.

I might cite here the postdoctoral fellowship where you will take a man who has just received a Ph.D. in chemistry, biology or in physics and then you give him a postdoctoral fellowship in oceanography and enable him to apply his own field of specialization to the oceanographic area. We find this very useful in geochemistry, for example.

Now, in terms of the doubling of -

The Cinamman. We have had this problem with regard to encouraging, supporting and financing "science" for quite a while and we have approached it by several different methods. I suppose it started with the lack of scientists. It has been with the chairman ever since 1945 when I authored the first National Science Foundation bill. Vannevar Bush used to sit around and tell me that we had a 7 -year drought of scientists because of the war situation and we had to do something to go forward.

No. 1, we have added research in all phases of Government activity all the way from the National Institutes of Health to the Bureau of Standards, and to the Navy hydrographic people. We have given them more money for research. But when we came to manpower about the best we have been able to do has been to suggest more fellowships under the Science Foundation authority; with the thought that when we make a grant to a university of some kind, it would encourage an interest in that particular field. Then, of course, we have the basic act we call the Defense Act, which provides for further scholarships.

In this particular case, I just don't know what other approaches we can make to the basic problem of getting more people interested. I don't think Government should go too far on graduate fellowships where people are already interested. They get in on the projects or they get in on the research. But how do we arrive at a broad base?

As it was testified yesterday, the Russians are not so sophisticated but certainly they have a broader base in this particular field. How can we do it without sticking our noses into education. There is some trouble up here occasionally about that.

Mr. Brown. In your bill what you have recommended is fine and it will be very useful. I believe that were you to broaden it to include postdoctoral fellowships that it would be more useful. of.

The Cramman. That is the kind of suggestion that $I$ am thinking

Mr. Brown. Let us suppose that Scripps, or Woods Hole were to have a series of post-doctoral fellowships, let's say sponsored by the National Science Foundation or some suitable agency, in oceanography, particularly designed so that a man who gets a $\mathrm{Ph}$. D., let us say at Johns Hopkins, or at the University of California in chemistry, in physics, in biology or geology, is then given the opportunity right after he gets his $\mathrm{Ph}$. D., to apply his knowledge to the marine environment. This would be a way of luring him into this field, so to speak. A fellowship of that sort might run somewhere between $\$ 6,000$ and $\$ 8,000$ a year, for a man's salary plus the amount of money that would be required to permit him to undertake the research activity. 
The Cunirman. Of course, we did have a further problem: What vehicle do we use to do this? The best $I$ could think of offhand was the National Science Foundation.

Now, the Defense Department can do this if they want to. They can use their funds with wide latitude, in research.

I deliberately drew the National Science Foundation bill so that they have pretty wide authority. They can do pretty much what they want, subject, of course, to telling Congress what they need the money for.

They will be up here in about 2 weeks and I have to handle their appropriation. They have wide authority to go into this field.

Incidentally, the committee might want some comments on the report of the Science Foundation on this bill, you haven't seen it.

Mr. Brown. I have not seen it myself.

The Chamman. Well, it is typical of Government ciepartments: "We favor the objectives, but"

I suppose by these hearings alone we create an interest in this thing. People who perhaps have never thought of oceanography before get interested in it.

Mr. BRown. I think that is correct.

The Chairmax. And by your committees and by everything else you and we are doing. Until I can get some further suggestion, I don't know any other place to put it but in the Science Foundation, which we are discussing now?

Mr. Brown. Shall I continue?

The Chatrman. Yes.

Mr. Brown. Concerning the necessity for oceanwide surveys I know that is not mentioned in the bill. We consider this a matter of key importance. Just the routine getting of the geography of the ocean, of the salinities, the temperatures, and the really good maps of the ocean bottom, the geologic maps and so forth.

This has considerable fundamental importance and a great deal of rather obvious and practical importance as well.

The Champman. Now, where would you put that in the Government structure? In Coast and Geodetic?

Mr. BRown. I believe that certainly two of our agencies should be involved. One is the Coast and Geodetic Survey, where I believe the charter of the survey should be broadened so that very clearly and unequirocally they may go beyond the Continental Shelf.

The Chamrmax. I got that bill passed to get them beyond the shelf. I don't know whether it has been signed yet or not. It passed the House, and I don't know whether it has been signerl. I don't know why that should be vetoed, but we can't tell.

You suggest the Coast and Geodetic and the Hydrographic Office of the Navy.

The Champinas. The latter has broad authority to do this, too.

Mr. Browr. In addition to that, I believe we may well considel seriously haring certain parts of this survey job undertaken by private industry. There are industries which conceivably could be broadened to the point where they might undertake this much in the way that certain industries do geophysical surveying, for example.

The Chamrin. Now, in that case I suppose practically you would have to say to the Science Foundation you can contract with 
Scripps, let's say, or WVoods Hole, or someplace else-the University of Miami, or the University of Washington, to do this sort of thing?

Mr. Brown. Or contract with a private company.

The Chamman. Or with a private company.

Mr. Brown. Yes.

The Chairman. That authority would come under the broad authority of the Science Foundation, even now.

Mr. Brown. Or conceivably in certain other Government agencies the same type of contracting might be carried on.

The important aspect of this, however, would be that it be well coordinated so that one agency knows what the other is doing, and what responsibility it is taking for its part of the overall job.

We found in our own survey of the oceanographic situation that this is perhaps one of the most difficult aspects of improving the status of oceanography, particularly within the Government. This is a field which as you know completely cuts across numerous Government agencies. Almost every agency in one way or another has oceanographic interests and the problem is how should this be coordinated?

Our own committee discussed this at great length. There were some of us who at one time felt that perhaps some kind of a central agency should be established. There were others who felt we ought to attempt to maintain independent development within individual agencies as much as possible and after thrashing this out we came to the conclusion that we favored a compromise between the central agency and the independent development approach.

In other words, we favored the establishment of some kind of a coordinating group but nevertheless to encourage the independent approach within each agency.

The Chamman. That might logically follow if we can get this program started, because that was the pattern on space. We started out with different agencies and finally we said, "Well, let's have a separate space agency," which we now have.

Mr. Brown. Now, I believe that the decision that your own committee makes in this legislation far transcends oceanography, itself. I believe it will get at the core of the very basic fundamental problem of decisionmaking, concerning science and technology in Government. Just how does one go about handling it? Your bill may well establish some kind of a precedent and for that reason we believe that it is something that really has to be thought through extremely carefully.

If the coordination is to be done under the National Science Foundation as you propose in the legislation, we believe that there should be a broadening of the wording. We believe the wording as it is now is unnecessarily restrictive. For example, the scientists who are representatives of the proposed panel would be, as it is now written, scientists who are from institutions which have oceanographic contracts. Tre believe that other scientists who hare no direct oceanographic interests should be included as well in order to maintain a degree of impartiality, shall we say.

If we are to double our support of the

The Charrican. I thoroughly agree with you on that, too. The Science Foundation fell into a pattern over the past 8 or 9 years where they started to go to one or two institutions and finally we found nearly 80 percent of everything they were doing up in one section. In 
four or five institutions. I need not mention the institutions. You people are all familiar with them. They are up in this northeast corner up here. Of course, we drift into that pattern but we should have a spread.

Mr. Brown. My other comments on the doubling of basic research activities, surveying and so forth involve financing so perhaps I should go ahead and for the record put in the second two recommendations and then discuss those all in terms of finaneing of new research ships, facilities, and so forth.

Our third recommendation is that the Inited States should expand considerably its support of the applied marine sciences particularly in military defense, marine resources, and marine radioactivity.

Our fourth recommendation is that the Navy and the National Science Foundation should each finance about 50 percent of the new basic research activity, except ship construction; the Navy should finance 50 percent of the new research ship construction, with the Maritime Administration and the National Science Foundation sharing the remainder.

The Navy, through the Hydrographic Office, should finance 50 percent of the deep ocean surveys while the Coast and Geodetic Survey should finance the balance.

The Navy should sponsor completely all military research and development operations.

The Bureau of Commercial Fisheries should finance the greater part of the recommended ocean resources program.

The Atomic Energy Commission should finance the major part of the research dealing with the problems of radioactive contamination of the ocean.

The National Science Foundation and the Office of Education should sponsor jointly the proposed program for increasing scientific and technical manpower in the marine sciences.

Efforts aimed at fostering international cooperation in the marine sciences should be sponsored by the Department of State, the International Cooperation Administration, and the National Science Foundation.

Other agencies should take responsibility for certain aspects of the proposed program, particularly the Public Health Service, the Geological Survey, and the Bureau of Mines.

Concerning the practical applications of oceanography, I read with great interest your statement concerning the-

The Ciratricis. Well, before we leave that, would you say that any bill should give any of these agencies, or a combination, or any one agency, the broad authority to participate with prirate institutions, such as universities, Scripps, Woods Hole, or the rest, regardless of-

Mr. Browx. I believe all Govermment agencies with legitimate interests in oceanography should be authorized to enter into contracts and so forth and to give research grants to prirate institutions.

The Charriras. I think the committee will look very favorably upon that in any legislation.

Mr. Brown. Evell though the agency concerned does not have a research organization of its own, by entering into contracts and being empowered to give grants it keeps in contact with current work and with what is going on. 
I know that in the legislation, the operating areas in which fisheries studies may be undertaken are rather clearly specified in terms of latitude and so forth: We believe that this is a mistake, that really we should be empowered to undertake fishery studies any place in the world. I thought about this last night and thought how a corresponding piece of legislation before the Japanese equivalent of Congress might read. I doubt very much that they would specify any particular region in which they could undertake fishery studies.

The Chamman. I probably had in mind there, thinking of certain problems in certain places, I was trying to push them into those places.

Mr. Brown. I fully agree that studies in the places mentioned by your programs should be undertaken but I believe it should be broadened.

The Chairman. I agree it should be broad.

Mr. Brown. Now, perhaps from the point of view of expenditures, the major part of the program involves shipbuilding and the construction and operation of new shore facilities.

In connection with shipbuilding, I know there is no sum mentioned for funding authorizations for the Maritime Administration for research ships. Also, we believe that the statementss concerning funds for construction of new shore facilities shonld be broadened to include the expansion of existing facilities.

If I interpret the wording of the legislation correctly, you could go out and build a new institution, but were the Chesapeake Bay Institute at Johns Hopkins University desirous of broadening activities and building new facilities that would not be possible under the legislation as it is now written. So I believe that that section could be broadened.

The Crampman. Do you still agree with the number of ships under a 10-year program as listed on page 12 ?

Mr. Brown. Yes. That, I believe, gives a pretty clear picture of what, in the opinion of our committee, we need.

The Champax. And the breakdown as to the sponsors? The Navy should have approximately 38; Coast and Geodetic Survey, 10; Bureau of Commercial Fisheries, 14; Science Foundation, 4; and Maritime Administration, 4 ?

Mr. Brown. Yes.

Again concerning funding authorizations, no sum is mentioned for the Department of Health, Education, and Welfare, and also in connection with marine resources development, a smaller sum is mentioned in the bill than we believe is required for marine resources development.

In conclusion, however, I would like to stress again that in the opinion of our committee this bill, as it is written, is a very fine one. We suggest the modifications but after much deliberation those are all of the modifications that we have to suggest at the present time.

The Chamman. And then you have the scheduling of new ships which, of course, would have to be subject to flexibility. You may not get them all in the same year.

Mr. Brown. I should perhaps mention one aspect of this shipbuilding program. We suggested that a certain number of ships are needed and we mapped out a rough proposed schedule. This rough proposed schedule, when you add everything together, puts a peak in the total budget for oceanographic research, as a function of time. 
Now, this peak, I am told by friends of mine within the Government, that peaking a budget is an extremely difficult thing to do. That is something much more in your area than in ours.

The Crimrins. The total cost for the 10 -year program would be in the neighborkhood of $\$ 212$ million?

Mr. BRown. That is right. I might point out

The Chaman. Or approximately $\$ 20$ million a year?

Mr. Brown. Yes.

The Champins. I can't help but remark, we put that in one capsule, going the other way.

Mr. BRown. I might point out I happen to be a member of what is called the Space Science Board of the National Academy. This is a group which serves as a general advisory group in the National Aeronautics and Space Administration, and this appears to be rather small potatoes compared with the figures we used over there.

The Chairifan. I am sure that Dr. Glennan and the rest of them would endorse this program. They would consider it necessary and I think vital, along with their program. I am sure they would.

Mr. Brown. I don't think there is any question about it. As a matter of fact, my own research is more intimately involved in the space program than it is with oceanography, and thus I can say, without any prejudice whatsoever, in my opinion the carrying out of a program such as that outlined here is just about the most important long-range activity that our Government could get involved in from the scientific point of view, and from the practical point of view.

The Chatrman. Well, this is a very good breakdown, as much as could be done when you are estimating and looking into the future and I want to suggest that the breakdown beginning on page 12 of the tables, up to 17 , page 8 -page 16 will be put in the record, which shows the operating costs, the numbers, the suggestions made.

Senator Yarborougr. Shouldn't we print this whole thing in the record?

The Chatrman. Yes, I think the whole thing should be printed in the record.

Mr. Brown. An extensive part of this was introduced into the record some months ago, I believe, by Senator Humphrey.

The Chamman. I want it in our record here.

(The document referred to follows:)

OCEANOGRAPHY, 1960 TO 1970

\section{Chapter 1-Introduction and SUmmary of Recommendations}

First chapter of a report ${ }^{1}$ in progress by the Committee on Oceanography of the National Academy of Sciences-National Research Council, Washington, D.C.

COMMITTEE ON OCEANOGRAPHY

Harrison Brown, professor of geochemistry, California Institute of Technology, Chairman.

Maurice Ewing, Lamont Geologieal Observatory, Colmmbia Lniversity, Palisades, N.Y.

The complete report of the Committee will include the following additional chapters: 2, "Basic Research in Oceanography During the Next 10 Years"; 3, "Ocean Resources" ; 4. "Oceanographic Research for Defense Applications" ; 5, "Artificial Radioactirity in the IIarine Environment"; 6. "New Research Ships" ; 7, "Engineering Needs for Ocean Exploration": 8, "Education and Manpower"; 9, "Oceanwide Surreys"; 10, "International Cooperation"; 11, "History of Oceanography"; 12, "Marine Sciences in the United States, 1958." 
Columbus O'D. Iselin, Woods Hole Oceanographic Institution, Woods Hole, Mass. Fritz Koczy, Marine Laboratory of the Unirersity of Miami, Miami, Fla.

Sumner Pike, Lubec, Iaine, formerly Commissioner, U.S. Atomic Energy Commission.

Colin Pittendrigh, Department of Biology, Princeton University, Princeton, N.J. Roger Revelle, Scripps Institution of Oceanography, La Jolla, Calif.

Gordon Riley, Bingham Oceanographic Laboratory, Yale University, New Haven, Conn.

Milner B. Schaefer, Inter-American Tropical Tuna Commission, La Jolla, Calif.

Athelstan Spilhaus, Institute of Technology, University of Minnesota, Minneapolis, Minn.

Richard Vetter (executive secretary), on leave from the Geophysics Branch of the Office of Naval Research, Washington, D.C.

\section{INTRODUCTION}

Two-thirds of the earth's surface is covered by the waters of the seas. The waters themselves greatly affect our lives-they play a major role in governing our climate; the provide inexpensive transportation : from them we derive important quantities of nourishment: they have traditionally provided protection against military attack. Beneath the surface a myriad of wonders is concealed. there are trenches, the floors of which are as much as 7 miles below sea level. Mountains which approach Mount Ererest in height rise up from the ocean floor. Sediments in the ocean deeps contain detailed records of earth history and, associated with it, life history The more than 300 million cubic miles of water contain huge assemblages of living matter of fantastic variety.

As our technological civilization increases in complexity, as human population grow more and more rapidly, as problems of military defense become increasingly difficult, as man pushes forward with his relentless quest for greater understanding of himself, his origins and the universe in which he lives-as all of these changes take place, detailed knowledge and understanding of the oceans and their contents will assume ever greater importance.

Man's knowledge of the oceans is meager indeed when compared with their importance to him. Recognizing that neglect in this area of endeavor might well result in our being placed in a precarious position from the scientific, technological, and military poiffints of view, the National Academy of Science National Research Council decided in 1957 to form a Committee on Oceanography. In May of that sear Presicent Detler Bronk appointed Harrison Brown, professor of geochemistry at the California Institute of Technology, Chairman of the Committee. The Committee itself was formed during the following months and its first meeting was held in November 1957.

The work of the Committee was made possible by the sponsorship of several Government agencies, all of which have interests in the oceans; Atomic Energy Commission, Bureau of Commercial Fisheries, National Science Foundation, and Office of Naval Research.

The Committee was organized as a part of the Dirision of Earth Sciences of the National Academy of Sciences-National Research Council.

At the request of President Bronk, the Committee has made a survey of the present status of the marine sciences in the United States. It has attempted further to assess the major problems of operation, administration, and funding in this area and to evaluate the probable needs for oceanographic knowledge in the years ahead. On the basis of its findings, the Committee has drawn up a series of recommendations which, if followed, can result in a strengthening of the marine sciences during the next 10 years to a level which is consistent on the one hand with the assessed needs, and on the other with limitations such as the rates at which ships and laboratories can be built and new oceanographers can be trained. It should be stressed, howerer, that the Committee considers its recommendations minimal ones. Action on a scale appreciably less than

2 This is the third NAS-NRC Committee on Oceanography. The first was established in 1927 under the chairmanship of Dr. Frank R. Lillie. The second, chaired by Dr. Detlev Bronk, was established in 1949 . The reader is referred to the following publications for additional background material on these two committees :

(1) "Oceanography," Henry B. Bigelow, Boston and New York: Houghton Miffin Co.,

(2) "International Aspects of Oceanography," Thomas W. Vaughn et al., Washington, D.C. National Academy of Sciences, 1937.

(3) "Oceanography 1951," NAS-NRC Publication 208, Washington, D.C., 1952 (out of print). 
that recommended will jeopardize the gosition of oceanowraphy in the Lniter States relative to the position of the science in other major nations, thereby accentuating serious military and political dangers, and placing the Nation at a disadvantage in the future use of the resources of the sea.

The deliberations of the Committee were complicated by a number of factors: oceanography embraces many sciences-indeed "oceanography" encompasies the scientific study of all aspects of the oceans, their boundaries and their contents; research is undertaken in a variety of private and Government laboratories; numerous Govermment agencies have direct but differing interests in the orean: funds are derived from many somres. In order to expedite the formulation of recommendations moler these circumstances, several specialized lyanels ${ }^{3}$ were formed for the purpose of making specific stuclies: Occanographic Research Ships, New Devices for Exploring the Oceaus, ocean Resources, Radioartirity in the Oceans, and Interuational Cooperation in the Marine Sciences.

The memberships of the panels are listed in the appendix. The Committee on Oceanography is greatly indebted to the lanel members, who give extensively of their time to these studies, and without whose help the recummendations could not have been formulated.

The complete reports of the panels have been incorporated into the final report of the Committee. Chapter headings of the final report are listed below the table of contents of this summary. Individual chapters will be made arailable separately through the National Academy of Sciences as soon as possible. In addition, a condensed rersion of the Committee's report shortly will be made available for widespread distribution. The reader is referred to individual chapters of the report for more detailed discussion of the background, facts, and reasoning which have led to the recommendations summarized in ". Nection II-General Recommendations."

\section{THE IMPORTANCE OF THE PROBLEM}

The Committee has found that relative to other areas of scientific endearor, progress in the marine sciences in the United States has been slow. There has been a substantial amount of excellent work, more often than not undertaken under extremely difficult and trying circumstances. But generally speaking, progress has not been rapid when compared with the essential and exciting information yet to be obtained by probing the rast and dark, but penetrable, depths of water which cover so much of the earth's surface.

The seas present a challenge to man which in magnitude approaches that of space. At least we have been able to observe the moon, planets and stars directly with our telescopes. But the ocean depths, shrouded in darkness, have been obsculed from our view. The know less about many regions of the oceans todas than we know about the lunar surface. Yet we have learned enough to know that major features of the ocean floor-35,000 foot deep trenches: 2,000 -nilelong fracture zones; flat-topped under sea mountains; broad ocean long ridges: absssal plains as flat as a calm sea-are uniquely different from anthing either on the surface of the moon or on the land surfaces of earth. How and when were these features formed and why are they so different? An answer to these questions is essential if we are to decipher the history of our planet and its sister planets. Part of the auswer lies in the recordis of ancient earth history locked in deep sea sediments: part will come from an intensive study of the rocks under the ocean. These studies, combined with studies of the waters and the living creatures of the sea, will also tell us much about the origin and evolution of life on earth.

During the last few years, four great subsurface ocean currents-rirers in the depths of the sea 1,000 times greater in flow than the Mississipyi-hare been discovered using newly derelojed current meisuring techuiques. We suspect that others exist and we need to know where the waters come from and where they go.

On the practical side the problems to be solved concerning the oceans are at least as urgent as those of space. How many fish are in the sea? No mau knows, nor do we know what determines the number of fishes in different regiums. the quantities of plant and animal materials on which thes feed, or what could be done to increase these numbers. We must learn these things if we are to help' solve the increasingly acute problems of providing animal protein foud for the

3 The Committee as a whole acted as a panel on basic research, on education and manpower, and on problems of operations, sponsorship, and funding. 
srowing numbers of underfed people in the world. Given more study man can economically harvest considerably more food from the seas than is now possible. C'onsidering the position of the United States in the community of nations, it seems appropriate, even essential, that we lead the way in this respect.

About a third of the energy of sunlight is used to evaporate sea water. This eraporation and the subsequent condensation are the primary means by which solar energy is absorbed in the atmosphere. There is good reason to believe that changes in the location where interchange of matter and energy takes place between sea and air affect persistent weather patterns. We know that the average weather conditions we call climate can change over a few decades, and we suspect that changes in the storage of gases and heat in the oceans will profoundly influence the process. Studies of the mechanisms of interchange between the air-sea boundaries of regions where intense interchange occurs and of the slow mixing between the ocean deeps and the surface which controls storage of heat and gases are essential for further understanding, hence for prediction and possibility of control.

From the point of view of military operations there is no comparison between the urgencies of the problems of the oceans and those of outer space. The submarine armed with long-range missiles is probably the most potent weapon system threatening our security today. It seems clear that the pressures of establishing effective bases, and of protecting ourselves from attack, are relentlessly driving us into the oceans.

The problems involved in military operations in the sea are enormous. We will not be able to navigate under the oceans with adequate precision until our knowledge is greatly expanded. Nor will we be able to detect submerged submarines efficiently unless we learn far more about the ocean depths than we now know. We will not be in a position to negotiate an adequate international submarine control and monitoring system until we have the ability to make the oceans transparent so that we can track all submarines in the oceans, both our own and all others. To accomplish this, we must place greater national emphasis on research in the marine geophysical sciences, on surveys of the ocean background against which tracking must be accomplished, and on the development of effective devices to achiere such oceanwide surveillance. The Committee's recommendations constitute an essential first step in these directions.

With these problems and prospects in mind, this Committee has attempted to assess the steps which should be taken in order that the United States might possess outstanding capabilities in the oceanographic field, and in order that we might obtain sufficient knowledge in time to avelt a "crash" program-which would be wasteful in terms both of money and raluable technical manpower.

The cornerstone of our oceanographic endeavors is basic research. We need to understand waves and the interactions between the atmosphere and the oceans. The need to know more about ocean currents and upwellings. More intensive studies should be made of the properties of sea water and of processes of sedimentation. We should systematically study the life forms in the oceans in three dimensions. We should study the sea floor with instruments and we should send men down to look at it in many localities.

In view of the complexities of these problems the Committee has recommended that the level of basic research in these fundamental areas be substantially increased during the next 10 years. This will require increases both in manpower and in facilities. Of particular importance among the facilities are ships, which are to the oceanographer what cyclotrons or reactors are to the nuclear physicist. He simply cannot undertake adequate research without them.

Our oceanographic research ships are inadequate for the job which must be done. Most of the ships are old and outdated. Many are obsolete and should be replaced by ships of modern design which will be more efficient to operate and from which a greater variety of scientific observations can be made. In addition, the number should be increased.

The oceanographer also needs improved instruments if he is to penetrate the water barrier and learn in detail about conditions at great depths. Thus far oreanographer's have not been able to take full advantage of recent technological revelopments and, accordingly, the committee has recommended the establishment of a program of broad scope, aimed at developing and using new instruments and derices for exploring the sea. Using new deep-diving vehicles, for example, it is now possible for man to observe directly the ocean deeps. It seems highiy like that within the next 10 years men will descend through the water nearly 7 miles to the deepest point on earth. 
An integral aspect of a program for learning about the oceans involves our surveying them more or less routinely. The topography of the ocean floor should be mapped in detail. We should arrive at a complete picture of gravitational and magnetic forces and of ocean currents in three dimensions. Sufficient biological information should be gathered so that we can prepare accurate mans of the distribution of life in the sea.

All of these studies, together with others like them, will have bearing upon the more immediate practical problems which confront us in the military area and in the area of ocean resource development. In addition to this, however, it is clear that the applied research and development programs in these areas should be expanded.

In the committee's attempts to give quantitative indications of the relative amount of effort which it believes should be placed upon various aspects of the proposed program by individual Government agencies, suggested budgets have been compiled for a 10-year period. These suggested budgets, in the committee's opinion, present a reasonable representation of the magnitude and kind of effort and the degree of interagency cooperation which will be required if the recommended goals are to be achieved. In addition, a budget permits a direct comparison of efforts in this field relative to the efforts in other fields of scientific and technological endeavor.

\section{GENERAL RECOMMENDATIONS}

The key to the growth of oceanography in the United States lies in basic research-research which is done for its own sake without thought of specific practical applications. The very nature of basic research is such that the problem which will be attacked and the results which will be obtained cannot be predicted. The very nature of applied research is such that its success depends upon the size of the reservoir of fundamental knowledge upon which it must draw. The rate of progress in the applied marine sciences will be determined in the long run by the rate of progress in the basic marine scienes.

The committee has concluded that both the quantity and quality of basic research in the marine sciences can and should be increased substantially during the years ahead. Specifically the committee recommends :

1. The U.S. Government should expand its support of the marine sciences

at a rate which will result in at least a doubling of basic research activity during the next 10 years. ${ }^{4}$

It should be emphasized that doubling the basic research activity will require more than doubling the total expenditures.

A large part of the deliberations of the committee were devoted to discussions of the conditions under which basic research can flourish. First and foremost, progress depends upon the interests, experience, and creative imaginations of individual scientists. But the individual scientist does not work in a vacuum. He must have instruments and facilities. He must live in an atmosphere which is conducive to creative activity. These necessities in turn give rise to problems invalving marine research laboratories-problems of leadership, financial stability, flexibility, growth, academic associations, and physical facilities.

Not only for research but in order to exploit and use the oceans we need more detailed knowledge which can be obtained only through systematic surveys in three dimensions. These surveys should include such features as depth, salinity, temperature, current velocity, wave motion, magnetism, and biological activity. It is essential that these surveys be conducted on an oceanwide ocean-deep basis as quickly as possible. Our knowledge is now largely limited to waters 100 miles from shore and even here it is inadequate for present and future needs. Accordingly, the committee recommends:

2. The increase in support of basic research should be accompanied during

the next 10 years by a new program of oceanwide surveys. This will require a twofold expansion of the present surveying effort.

We believe that, on a long-range basis, basic research coupled with systematic acean surveys are of paramount importance in solving a number of urgent practical problems involving military defense, the development of ocean resources and possible future increases of radioactive contamination of the seas resulting from the rapid development of atomic energy. Howerer, research and surress

* In 1958 about $\$ 23$ million were spent for applied and basic oceanographic research. The basic research share of the total was not over 9 million. About 8 million of this, including the 1958 share of IGY expenditures, were Federal funds.

$55401-60-7$ 
must go hand in hand with a vigorous and imaginative applied research and development program. Accordingly, the committee recommends :

3. The United States should expand considerably its support of the applied marine sciences, particularly in the areas of military defense, marine resources, and marine radioactivity.

The implementation of these general recommendations requires action upon a number of broad fronts. More marine scientists must be educated. Additional ships and shore facilities must be built. New instruments and techniques must be developed. International cooperation in the marine sciences must be strengthened.

To achieve these aims in the next 10 years will necessitate many agencies of the Federal Government working together both in planning and in providing the moneys. ${ }^{5}$ Taking into account the relative degrees of interest and importance of oceanography to individual agencies, the committee recommends :

4. The Navy and the National Science Foundation should each finance about 50 percent of the new basic research activity except ship construction. The Navy should finance 50 percent of the new research ship construction with the Maritime Administration and the National Science Foundation sharing the remainder. The Navy through the Hydrographic Office, should finance 50 percent of the deep ocean surveys, while the Coast and Geodetic Survey should finance the balance. The Navy should sponsor completely all military research and development operations. The Bureau of Commercial Fisheries should finance the greater part of the recommended ocean resources program. The Atomic Energy Commission should finance the major part of the research dealing with the problems of radioactive contamination of the oceans. The National Science Foundation and the Office of Education should sponsor jointly the proposed program for increasing scientific and technical manpower in the marine sciences. Efforts aimed at fostering international cooperation in the marine sciences should be sponsored by the Department of State, the International Cooperation Administration, and the National Science Fundation. Other agencies should take responsibility for certain aspects of the proposed program, particularly the Public Health Service, the Geological Survey, and the Bureau of Mines.

Although the bulk of oceanographic research and survey work must of necessity be financed by the Federal Government, the value of State and private funds cannot be overestimated. Such funds are especially helpful for supporting initial exploratory basic research and for starting new laboratories. Accordingly, the committee recommends:

5. Private foundations and universities, industry, and State governments should all take an active part in the recommended program of expansion.

\section{Specific ReCommendations}

\section{A. EDUCATION AND MANPOWER}

(1) The universities now providing graduate education for oceanographers should be encouraged to increase the nmbers and quality of their output. Some institutions which now teach oceanographic in only certain branches of oceanography should add professors in other fields to their faculties. These measures will require financial support.

(2) Institutions which undertake considerable research, but provide no regular formal teaching in oceanography, could contribute greatly to the education of oceanographers at the highest level by close formal affiliations with universities. Conversely, universities should recognize their responsibilities in the education of oceanographers. They should welcome this affiliation with marine laboratories and arrange for the interchange of faculties. This will require financial support.

(3) It may be desirable to develop oceanographic education at new centers. However, a critical mass of faculty in the basic sciences is essential for successful teaching of oceanographers. Such new centers should, therefore, be developed at universities which possess strong faculties in the sciences.

(4) In order to finance new faculty in oceanography at existing or new teaching centers, the U.S. Government should provide funds on long-term commit-

\footnotetext{
${ }^{5}$ One method suggested for developing more effective interagency cooperation is through the proposed Federal Council for Science and Technology. This Council is described in "Strengthening American Science," a recent report of the President's Science Advisory Committee.
} 
ments. This committee recommends that about $\$ 500,000$ per year be appropriated for salaries and the equipment and indirect costs associated with such positions. This program could be operated through the office of Education.

(5) In order to attract competent graduate students to the long and somewhat arduous schooling required of well-qualified oceanographers, it will be necessary to provide substantial long-term fellowships. It is believed that 80 fellowships should be supported on a 5-year basis and at an average stipend of $\$ 3,500$ to $\$ 4,000$ per student each year. This will produce 12 to 15 new Ph. D.'s per year (allowing a reasonable attrition factor) at an annual cost of about $\$ 300,000$. This would provide approximately one-third of the student support that will be needed in order to double the number of oceanographers at the Ph. D. level during the next 10 years.

It is desirable that fellowships permit students to attend more than one university. This can provide students with well-rounded educations in all branches of oceanography without each university having to provide a full curriculum. Such a program should be handled through the National Science Foundation.

(6) Efforts should be made in research and survey programs to use larger numbers of assistants at the bachelor and master's level in order to utilize more efficiently the limited number of persons available at the doctoral level.

(7) Oceanographers should undertake more active recruiting of prospective. oceanographers among undergraduate students of physics, chemistry, biology, and geology.

$$
\text { B. NEW SHIPS FOR RESEARCH, DEVELOPMENT, AND SURVEYING }
$$

(1) A shipbuilding program should be started aimed at replacing, modernizing, and enlarging the number of oceangoing ships now being used for research, surveying, and development. Specifically in the period 1960-70 the research, development, and survey fleet should be increased from its present size of about 45 ships to 85 ships. Taking into account the replacement of ships which must be retired during the next decade, this means that 70 ships should be constructed at a total estimated cost of $\$ 213$ million.

(2) The size ranges recommended for new oceangoing ships are: about 500 tons, 1,200 tons, and 2,200 tons displacement.

(3) The conversion of vessels, which were originally designed for other purposes, into research, development, or survey vessels is to be discouraged. Such conversions are generally uneconomical.

(4) The recommendations for the construction of ships for specific purposes (basic research, military research and development, oceanic surveys, resources, and fisheries) are given in table 1.

(5) The recommended size distribution for new ships is given in table 2.

(6) The Navy should provide about 50 percent of the financing for the construction of new ships for basic research, all of the financing for new ships for military research and development, and 50 percent of the financing for new ships for oceanic surveys. The Coast and Geodetic Survey should provide 50 percent of the financing for the construction of new ships for oceanic surreys. The Bureau of Commercial Fisheries should finance the construction of all of the new ships for marine biological resources and fisheries studies. The National Science Foundation and the Maritime Administration should each provide about 25 percent of the financing for new ships for basic research. The numbers of ships in each size category which should be built by each of the sponsoring agencies are given in table 3.

(7) Detailed recommendations for the scheduling of ship construction by each of the sponsoring agencies are given in table 4 . Estimated capital costs by year and by agency are given in table 5, based upon the assumption that a 500 -ton ship will cost about $\$ 1.65$ million, a $1,200-1,500$-ton ship will cost about $\$ 3.80$ million, and a 2,000-ton ship will cost about $\$ 5$ million.

(8) The Maritime Administration should be consulted in the designing of all ships paid for from public funds and used for marine studies.

(9) Research ships operated by private institutions like those operated by the Navy, Coast Guard, and Coast and Geodetic Survey should be exempt from those existing legal requirements for liring accommodations, safety and the licensing of crews, which are practical and sensible only on large (3,000 tons) merchant ships.

(10) All noncombatant surface ships used for research, derelopment, or surveying should be operated by the laboratory or agency directly concerned and should have civilian crews. 
(11) In most cases the annual costs of operating vessels for basic research by non-Government laboratories should be paid for separately from the other expenses of research, for example, through a long-term facilities contract distinct from any research contracts.

(12) The costs of ship operations paid by the Federal Government should be subdivided as follows: the Navy should pay for 50 percent of the operational costs of ships used for basic research, all of the operational costs of ships used in military research and development, and 50 percent of the operational costs of ships used for oceanic surveys.

The Coast and Geodetic Survey should pay for 50 percent of the operational costs of ships used for surveys. The Bureau of Commercial Fisheries should pay for the operations of ships used for resources and fisheries studies. The National Science Foundation should pay for 50 percent of the operational costs of ships used for basic research.

(13) Estimated costs of ship operations, both by function and by agency, are given in tables 6 and 7 .

\section{Ten-Year Plan for Increasing the U.S. Fleet of Oceanographic Ships}

TABLE 1.-Function of ships

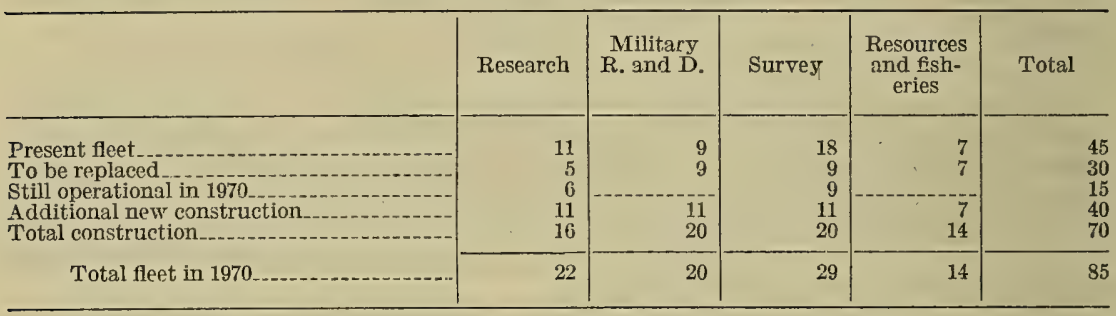

TABLE 2.-Recommended size distribution of new ships

\begin{tabular}{|c|c|c|c|c|c|}
\hline Size & Research & $\begin{array}{l}\text { Military } \\
\text { R. \& D. }\end{array}$ & Survey & $\begin{array}{l}\text { Resources } \\
\text { and } \\
\text { fisheries }\end{array}$ & Total \\
\hline $\begin{array}{l}500 \text { tons } \\
1,200-1,500 \text { tons } \\
\text { Larger than } 2,000 \text { tons }\end{array}$ & $\begin{array}{l}5 \\
9 \\
2\end{array}$ & $\begin{array}{r}10 \\
6 \\
4\end{array}$ & $\begin{array}{r}4 \\
11 \\
5\end{array}$ & $\begin{array}{r}12 \\
2 \\
---\end{array}$ & $\begin{array}{l}31 \\
28 \\
11\end{array}$ \\
\hline Total_........ & 16 & 20 & 20 & 14 & 70 \\
\hline
\end{tabular}

TABLE 3.-Recommended sponsors of new ships

\begin{tabular}{|c|c|c|c|c|}
\hline & 500 tons: & $\begin{array}{c}1,200-1,500 \\
\text { tons }\end{array}$ & $\begin{array}{l}\text { Larger } \\
\text { than 2,000 } \\
\text { tons }\end{array}$ & Total \\
\hline Navy & 12 & 18 & 8 & 38 \\
\hline Coast and Geodetic Surrey & 2 & 6 & 2 & 10 \\
\hline $\begin{array}{l}\text { Bureau of Commercial Fisheries } \\
\text { National Science Foundation }\end{array}$ & $\begin{array}{r}12 \\
3\end{array}$ & 2 & 1 & $\begin{array}{r}14 \\
4\end{array}$ \\
\hline Maritime Administration & 2 & 2 & - non & 4 \\
\hline Total__ & 31 & 28 & 11 & 70 \\
\hline
\end{tabular}


MARINE SCIENCE

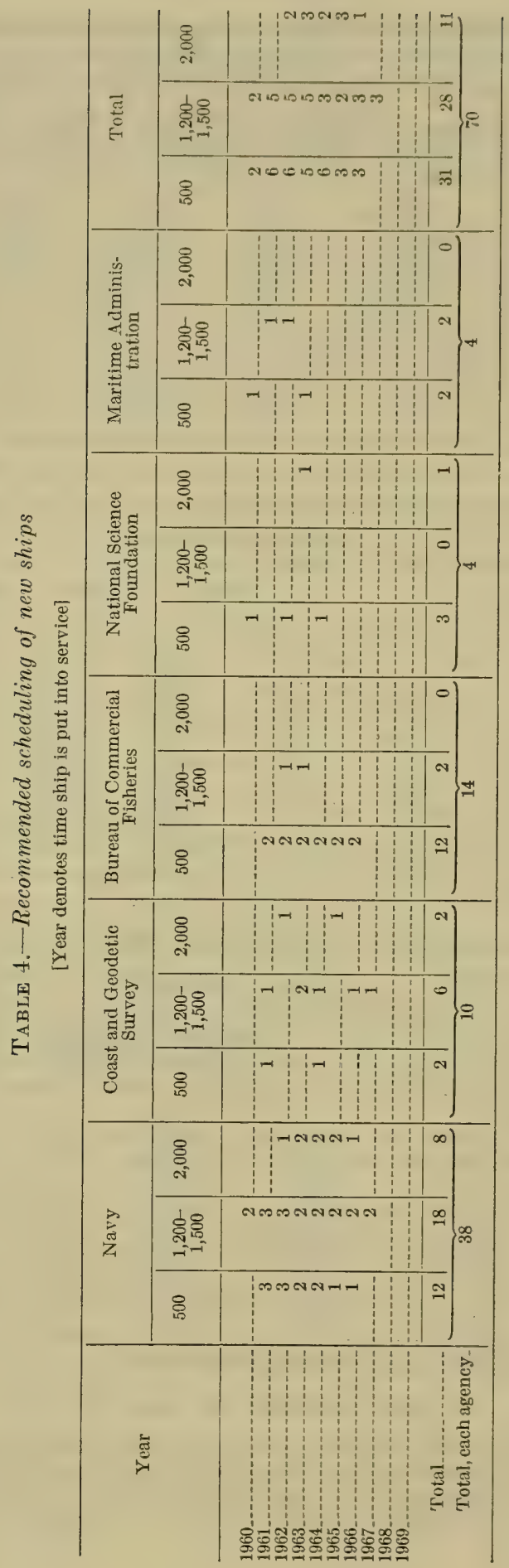


TABLE 5.-Estimated capital costs for new oceanographic ships by agencies

[Millions of 1958 dollars] ${ }^{1}$

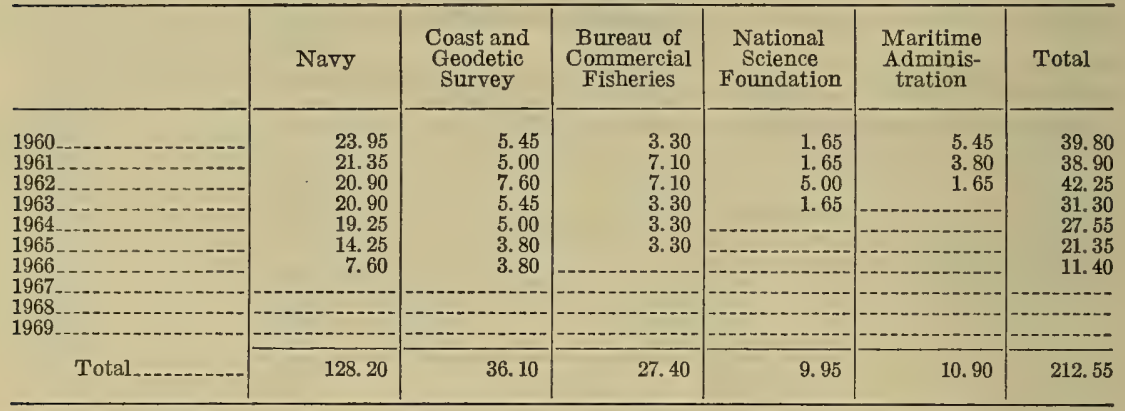

1 Budget allocations have been assigned to the year immediately preceding that in which the ship is to be put into service.

TABLE 6.-Estimated ship operations costs above present level by function.

[Millions of 1958 dollars]

\begin{tabular}{|c|c|c|c|c|}
\hline Year & Research & Survey & $\begin{array}{l}\text { Resources } \\
\text { and fisheries }\end{array}$ & Total 1 \\
\hline \multicolumn{5}{|l|}{1960} \\
\hline 1961 & 0.60 & 0.65 & 0.30 & 1. 55 \\
\hline 1962 & 1. 20 & $\begin{array}{l}1.30 \\
\text {. }\end{array}$ & .55 & 3.05 \\
\hline 1963 & 1.80 & 2.00 & .85 & 4.65 \\
\hline 1964 & 2.35 & 2. 60 & 1.15 & 6.10 \\
\hline 1965 & 2.95 & 3. 30 & $\begin{array}{l}1.40 \\
1.40\end{array}$ & 7.65 \\
\hline 1966 & 3.55 & 3.90 & 1.70 & 9.15 \\
\hline 1967 & 4.15 & 4.60 & 1.70 & 10.45 \\
\hline 1968 & 4.15 & 4.60 & 1. 70 & 10.45 \\
\hline 1969 & 4.15 & 4. 60 & 1.70 & 10.45 \\
\hline Total & 24.90 & 27.55 & 11.05 & 63.50 \\
\hline
\end{tabular}

1 Excluding military research and development ship operations:

TABLE 7.-Estimated ship operations costs above present level by agency

[Millions of 1958 dollars]

\begin{tabular}{|c|c|c|c|c|c|}
\hline Year & Navy ${ }^{1}$ & $\begin{array}{c}\text { Coast and } \\
\text { Geodetic } \\
\text { Survey }\end{array}$ & $\begin{array}{l}\text { Bureau of } \\
\text { Commercial } \\
\text { Fisheries }\end{array}$ & $\begin{array}{l}\text { National } \\
\text { Science } \\
\text { Foundation }\end{array}$ & Total 1 \\
\hline $\begin{array}{l}1960 \\
1961 \\
1962 \\
1964 \\
1965 \\
1966\end{array}$ & $\begin{array}{l}0.62 \\
1.25 \\
1.90 \\
2.47 \\
3.13 \\
3.72 \\
4.38 \\
4.38 \\
4.38\end{array}$ & $\begin{array}{r}0.33 \\
.65 \\
1.00 \\
1.30 \\
1.65 \\
1.95 \\
2.30 \\
2.30 \\
2.30\end{array}$ & $\begin{array}{r}0.30 \\
.55 \\
.85 \\
1.15 \\
1.40 \\
1.70 \\
1.70 \\
1.70 \\
1.70\end{array}$ & $\begin{array}{r}0.30 \\
.60 \\
.90 \\
1.18 \\
1.47 \\
1.78 \\
2.07 \\
2.07 \\
2.07\end{array}$ & $\begin{array}{r}1.55 \\
3.05 \\
4.65 \\
6.10 \\
7.65 \\
9.15 \\
10.45 \\
10.45 \\
10.45\end{array}$ \\
\hline Total & 26.23 & 13. 78 & 11.05 & 12.44 & 63.50 \\
\hline
\end{tabular}

I Excluding military research and development ship operations.

\section{SHORE FACILITIES FOR BASIC RESEARCH}

In order to derive the maximum knowledge from observations and collections made at sea, it is estimated that 60 technical persons must be available for the average ship involved in high seas research activity. Most of these persons are involved in land-based activities which require laboratories and associated facilities. 
(1) It is recommended that for every additional oceangoing research ship put into operation, an average investment of $\$ 1.5$ million be made for essential shore facilities. These costs should be divided between the Navy and the National Science Foundation.

(2) It is estimated that the costs of research other than ship operations will average about $\$ 1.2$ million per ship per year. The committee recommends that Federal funds for this purpose be divided between the Nary and the National Science Foundation.

The costs to each agency, by years, are given in table 8. Capital allocations are assigned to the year preceding the placing of a new research ship into operation. Although table 8 shows no increase in the operating costs of shore-based facilities for basic research until 1961, when the first new ships are completed, we expect that plans now being made by various Federal agencies (mainly the National Science Foundation and the Navy) involving budgets for basic oceanographic research will be able to maintain the 1958 level of activity and allow for some buildup of staff. Such plans should be strongly supported by the agencies, the Bureau of the Budget, and the Congress in order to avoid a serious relapse of our present capabilities.

TABLE 8.-Capital and operating costs of basic research other than ships

[Over and above present level in millions of 1958 dollars]

\begin{tabular}{|c|c|c|c|c|}
\hline \multirow{2}{*}{ Year } & \multicolumn{2}{|c|}{ Navy } & \multicolumn{2}{|c|}{$\begin{array}{c}\text { National Science } \\
\text { Foundation }\end{array}$} \\
\hline & Capital & Operating & Capital & Operating \\
\hline $\begin{array}{l}1960 \\
1961 \\
1962 \\
1964 \\
1965 \\
1968\end{array}$ & $\begin{array}{r}0.75 \\
.75 \\
.75 \\
1.50 \\
2.25 \\
1.50 \\
.75 \\
\\
\end{array}$ & $\begin{array}{r}1.60 \\
1.80 \\
3.00 \\
4.80 \\
6.00 \\
6.60 \\
6.60 \\
6.60\end{array}$ & $\begin{array}{r}0.75 \\
.75 \\
.75 \\
1.50 \\
2.25 \\
1.50 \\
.75 \\
-0 .- \\
-0 .-1\end{array}$ & $\begin{array}{l}0.60 \\
1.20 \\
1.80 \\
3.00 \\
4.80 \\
6.00 \\
6.60 \\
6.60 \\
6.60\end{array}$ \\
\hline Total & 8.25 & 37.20 & 8.25 & 37.20 \\
\hline
\end{tabular}

D. OCEANWIDE SURVEYS

The capital and operating costs for ships involved in surveys of the world ocean have been given in a previous section. However, it is estimated that substantial shore facilities are required for the purpose of evaluating the data collected at sea. It is estimated that capital costs for shore facilities for each new survey ship will average about $\$ 0.75$ million. It is further estimated that operating costs for shore facilities will amount to about $\$ 0.75$ million per survey ship per year.

(1) The committee recommends that for every new survey ship put into operation an investment of about $\$ 0.75$ million be made for essential shore facilities.

(2) It is recommended that an average of $\$ 0.75$ million be allocated each year ror the operation of shore facilities for each new surrey ship placed in operation.

These costs should be divided between the Navy and the Coast and Geodetic Survey. The costs to each agency, by jear, are given in table 9. Capital allocations are assigned to the year preceding the placing of a new survey ship into operation.

(3) Consideration should be given to conducting some aspects of the surrey program through contracts with commercial organizations aud prirate institutions. 
TABLE 9.-Capital and operating costs for shore facitities for survey work

[Over and above present level in millions of 1958 dollars]

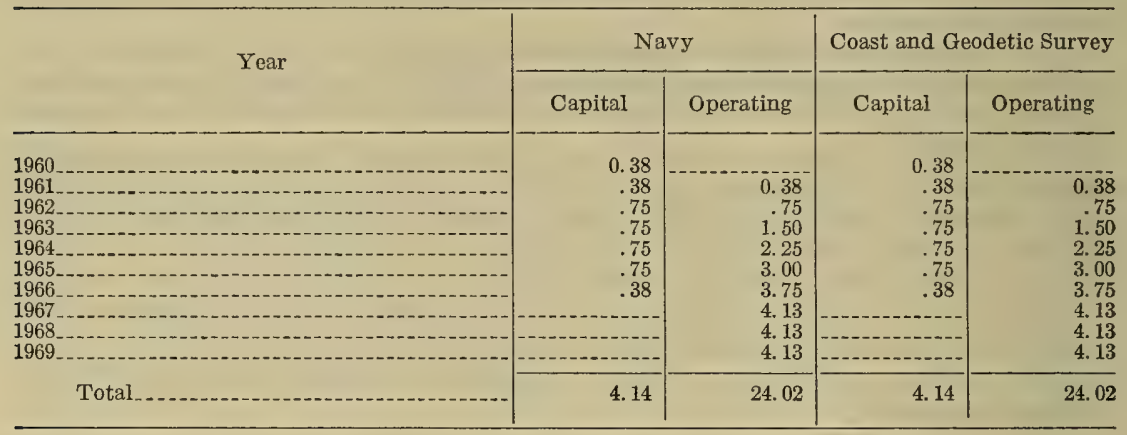

\section{E. ENGINEERING NEEDS FOR OCEAN EXPLORATION}

(1) A vigorous program should be conducted for the development of manned submersibles that can operate down to and on the bottom of most of the ocean:

(a) An improved bathyscaph, using the best materials and techniques available, should be designed and built immediately.

(b) Following up the recent commendable ONR action in bringing the bathyscaph Trieste to the United States, it is recommended that funds be made available for a mother ship ${ }^{6}$ together with auxiliary equipment in order to make maximum use of this deep submersible.

(c) A continuous design and development program should be initiated aimed at building deep and middepth manned vehicles as the need arises and as the state of the art progresses.

(2) The need for open-ocean manned research platforms which are stable, and which can remain in place so that time studies can be made, seems essential, and the design for such a buoy should be started.

(3) A major program should be supported aimed at developing and using anchored and drifting buoys for obtaining space and time coverage of ocean characteristics.

(4) It seems likely that aircraft can be used effectively for some research and surveys on the open ocean, particularly for studies involving the joint problems of oceanography and meteorology. Nearly all laboratories will need single engine planes; several will need twin-engined amphibious planes; some will need four-engined commercial-type aircraft.

(5) Surface icebreakers are of limited value to arctic oceanographic research compared to properly equipped submarines. Efforts should be made to develop a submarine capable of breaking into and out of the ice.

(6) Instruments should be developed for survey purposes which are more accurate, effective, and trouble free than those now in use. The techniques needed to use them more effectively should be developed. Specialized devices such as loran C, inertial navigation equipment, gravity meters, and stable platforms should be made available for research as well as surveys as soon as possible.

(7) A major program aimed at developing new high-seas engineering techniques should be started. Our abilities to handle heavy equipment and to conduct such operations as drilling and bottom sampling at sea, limit our operations at present. Many of these difficulties would be appreciably lessened given proper effort. We have not included the very important problem of drilling to the Mohorovicic discontinuity in our budget because another academy group is studying this problem.

(8) Machine aids to computation and data storage have much to offer and should be budgeted.

(9) High pressure facilities to permit controlled physical and hiological experiments in the laboratory are needed.

\footnotetext{
This is listed in the section on new ships.
} 
(10) Efforts should be made to secure the active particination of private industry in the development and manufacture of new devices and instruments for oceanographic research and surveying.

(11) The unpredictable aspects of new devices makes difficult the formulation of an exact budget over a 10 -year time scale. The committee recommends that $\$ 48$ million be allocated during the next 5 years. It further recommends that a minimum of $\$ 10.5$ million be allocated each year thereafter. 'The cost of this program should be divided between the Bureaus of the Navy and the National Science Foundation.

Budget breakdowns are given in tables 10 and 11.

TABLE 10.-Estimated annual budget for engineering needs for ocean exploration [Millions of 1958 dollars]

\begin{tabular}{|c|c|c|c|c|c|}
\hline & 1960 & 1961 & 1962 & 1963 & 1964 \\
\hline Deep manned vehicles $\ldots . . . . .$. & 2. 0 & 2.0 & 3. 0 & 4.0 & 4.0 \\
\hline 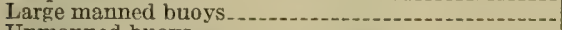 & .3 & 2. 0 & 1.3 & 2 & .2 \\
\hline Unmanned buoys . . & .8 & .8 & .9 & 1. 0 & 1.0 \\
\hline Aireraft . . . & .6 & 1.3 & 1. 0 & 2.0 & 1. 2 \\
\hline 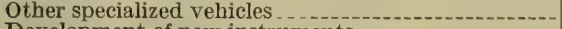 & 2. 0 & 1. 0 & 1. 0 & 1. 0 & 1. 0 \\
\hline Development of new instruments & .6 & 1. 2 & 1.2 & 1.5 & 1. 8 \\
\hline Other & 1.1 & 1. 2 & 1.2 & 1. 2 & 1. 3 \\
\hline Total & 7.4 & 9.5 & 9.6 & 10.9 & 10. 5 \\
\hline
\end{tabular}

TABLE 11.-Estimated annual budgets for enginecring needs for ocean exploration by agency

[Millions of 1958 dollars]

\begin{tabular}{|c|c|c|}
\hline Year & $\begin{array}{l}\text { Navy } \\
\text { bureaus }\end{array}$ & $\begin{array}{l}\text { National } \\
\text { Science } \\
\text { Foundation }\end{array}$ \\
\hline $\begin{array}{l}1960 \\
1961 \\
1963 \\
1965 \\
1966 \\
1968\end{array}$ & $\begin{array}{l}\text { 3. } 70 \\
\text { 4. } 75 \\
\text { 4. } 80 \\
\text { 5. } 45 \\
\text { 5. } 25 \\
\text { 5. } 25 \\
\text { 5. } 25 \\
\text { 5. } 25 \\
\text { 5. } 25 \\
\text { 5. } 25\end{array}$ & $\begin{array}{l}\text { 3. } 70 \\
\text { 4. } 75 \\
\text { 4. } 80 \\
\text { 5. } 45 \\
\text { 5. } 25 \\
\text { 5. } 25 \\
\text { 5. } 25 \\
\text { 5. } 25 \\
\text { 5. } 25 \\
\text { 5. } 25\end{array}$ \\
\hline Total & 50.20 & 50.20 \\
\hline
\end{tabular}

F. RADIOACTIVITX IN THE OCEANS

The widespread use of nuclear energy for peaceful or military purposes necessitates studies to determine the effects of radioactire contamination upon the oceans and the life therein. The Committee on Effects of Atomic Radiation on Oceanography and Fisheries in its report to the National Academy of Sciences made certain general recommendations concerning national polic5 in this area. Both the Committee on Oceanography and the Committee on Effects of Atomic Radiation on Oceanography and Fisheries beliere that more specific and detailed recommendations can now be made.

(1) A single agency should be giren the overall responsibility and authority for regulating the introduction of radioactire materials in the oceans. Monitoring of disposal sites should be done by some agency other than the regulating agency. It is recommended that either the Coast and Geodetic Surrey or the Public Health Service be made responsible for engineering studies in and near disposal areas, for routine monitoring of disposal areas and their surroundings, and for a continuing assessment of the effects on the environments of added radioactive materials.

(2) Vigorous programs should be started for the purpose of determining the circulation and mixing processes which control the dispersion of introduced contaminants in coastal and estuarine enriromments and in the open ocean. These studies represent the major part of the proposed budget in this area. 
(3) A program should be pursued aimed at determining the inorganic transfer of radioactive elements from seawater to the sediments.

(4) Studies should be made of the effects of living organisms on the distribution of radioactive elements introduced into the sea.

(5) The genetic effects of radiation upon marine organisms should be studied.

(6) A variety of biological field experiments should be conducted utilizing radioisotopes.

(7) The proposed budgets for the programs are given in tables 12 and 13. The greater part of the program should be financed by the Atomic Energy Commission.

TABLE 12.-Radioactivity in the oceans-Summary of budget estimates [Annual cost in 1958 dollars]

\begin{tabular}{|c|c|c|c|}
\hline & $\begin{array}{l}\text { Without } \\
\text { ship time }\end{array}$ & Ship time & Total \\
\hline $\begin{array}{l}\text { Control and monitoring } \\
\text { Estuarine and coastal studies. } \\
\text { Research in open ocean } \\
\text { Sedimentation processes } \\
\text { Effects of the biosphere } \\
\text { Genetic effects. } \\
\text { Biological field experiments }\end{array}$ & $\begin{array}{r}\$ 370,000 \\
1,920,000 \\
1,000,000 \\
1449,000 \\
678,000 \\
100,000 \\
100,000\end{array}$ & $\begin{array}{r}\$ 880,000 \\
400,000 \\
35,000 \\
260,000 \\
\end{array}$ & $\begin{array}{r}\$ 370,000 \\
2,800,000 \\
1,400,000 \\
2484,000 \\
938,000 \\
100,000 \\
100,000\end{array}$ \\
\hline $\begin{array}{l}\text { Total, 1st year } \\
\text { Total, subsequent years } \\
\text { About } 1 / 3 \text { is now underway. } \\
\text { Net cost of new program: } \\
\text { 1st year. }\end{array}$ & $\begin{array}{l}4,617,000 \\
4,432,000 \\
3,078,000\end{array}$ & $\begin{array}{l}1,575,000 \\
1,575,000\end{array}$ & $\begin{array}{l}6,192,000 \\
6,007,000 \\
4,128,000\end{array}$ \\
\hline $\begin{array}{l}\text { Subsequent years. } \\
\text { If } 2 \text { large open sea tests are conducted, } 1 \text { in } 1962 \text { and } 1 \text { in } 1966 \text {, } \\
\text { the additional costs in those years will be. }\end{array}$ & $\begin{array}{l}2,954,000 \\
1,400,000\end{array}$ & $\begin{array}{r}1,050,000 \\
600,000\end{array}$ & $\begin{array}{l}4,004,000 \\
2,000,000\end{array}$ \\
\hline Total in those years & $4,354,000$ & $1,650,000$ & $6,004,000$ \\
\hline
\end{tabular}

$1 \$ 264,000$ after 1st year.

$2 \$ 299,000$ after ist year.

TABLE 13.-Radioactivity in the oceans-Summary of budget estimates for new research

[Millions of 1958 dollars]

\begin{tabular}{|c|c|c|c|}
\hline Year & $\begin{array}{l}\text { Cost without } \\
\text { ship time }\end{array}$ & Ship time & Total \\
\hline 19601962 & $\begin{array}{l}\text { 3. } 08 \\
2.95 \\
\text { 4. } 35 \\
2.95 \\
2.95 \\
2.95 \\
\text { 4. } 35 \\
2.95 \\
2.95 \\
2.95\end{array}$ & $\begin{array}{r}11.05 \\
11.05 \\
1.65 \\
1.05 \\
1.05 \\
1.05 \\
1.65 \\
1.05 \\
1.05 \\
1.05\end{array}$ & $\begin{array}{l}4.13 \\
4.00 \\
6.00 \\
4.00 \\
4.00 \\
4.00 \\
6.00 \\
4.00 \\
4.00 \\
4.00\end{array}$ \\
\hline Total & 32.43 & 11. 70 & 44.13 \\
\hline
\end{tabular}

1 Primarily through use of ships now in service.

\section{G. OCEAN RESOURCES}

Lack of adequate understanding of the occurrence, behavior, and potential harvest of fish and other marine organisms serves as a serious barrier to extensive economic development and utilization of marine biological resources. Existing knowledge is inadequate to evaluate the feasibility of creating a marine mineral industry.

(1) The sea and its contents should be studied on a broad basis to enlarge our knowledge of its potential resources. 
(2) In order to elucidate the problem of population fluctuations of commercial fish stocks, which in large part is due to variable infant mortality, laboratory studies of the survival requirements of larval and juvenile stages of commercially important fish and shellfish are needed urgently.

(3) There is an urgent need for facilities for studies of fish behavior in the laboratory under controlled conditions. 'This will require aquarium facilities of sizable physical dimensions.

(4) Greater attention should be given to studies of the genetics of fish and other marine organisms.

(5) Investigations should be made of the feasibility of adding nutrients to the euphotic zone of the sea in order to increase the productivity of marine organisms.

(6) A program to investigate the possibilities of transplanting useful organisms from one region of the sea to another should be conducted.

(7) More research is needed on the nature of the aggregations of organisms in the sea.

(8) Biological surveys in the seas should be intensified and programs should be initiated, aimed at utilizing new devices such as unmanned buoss and the mesoscaph.

(9) A data center for all oceanographic research should be established for the storage, routine processing and "read-out" of such information as sea surface temperatures, currents and meteorological data. This data center would not perform the functions of more specialized computing centers such as will be required for oceanographic forecasting.

(10) There is a need for scientific, sociological and engineering studies directed toward the wider utilization of marine products in protein-deficient areas of the world.

(11) There is a pressing need for studies of the economic and legal aspects of commercial fisheries, especially in comparison with other industries, in order to provide a basis for national policy decisions.

(12) A scientific study of salt water fish pond culture should be started, aimed at providing a basis for greatly increasing the efficiency and productivity of this industry and thereby increasing the protein food supplies in proteindeficient areas such as southeast.Asia.

(13) Many aspects of the potential mineral resources on the deep sea floor should be investigated. Such work should be supported through the Bureau of Mines.

(14) An expanded prognam of estuarine research is recommended in order that we can make most effective use of this habitat of important resident stocks of food fish and shellfish and the nursery areas for other stocks which are later harvested from the open ocean.

(15) Many lines of marine research depend upon precise definition of species. The study of species is centered in research museums which generally have been supported very poorly. It is recommended that established museums having significant study collections be given financial support so that this kind of work can be carried forward.

(16) It is recommended that a program on diseases and other toxic effects in the marine environment be established.

The proposed budgets for these recommendations are given in tables 14, 15, and 16. The mineral resources investigation should be sponsored by the Bureau of Mines with the balance being supported by the Bureau of Commercial Fisheries through grants, contracts and in its own laboratories and with the assistance of other branches of the Department of the Interior. Programs involving international cooperation and technical assistance to other countries budgeted under this heading should be supported at least in part by the International Cooperation Administration and the State Department. 
TABLE 14.-Capital costs for new ocean resources studies ${ }^{2}$

[Millions of 1958 dollars]

\begin{tabular}{|c|c|c|c|c|c|c|c|c|c|c|c|}
\hline & 1960 & 1961 & 1962 & 1963 & 1964 & 1965 & 1966 & 1967 & 1968 & 1969 & Total \\
\hline Laboratory survival studies. . ... & 0.50 & & & & & & & & & & 0.50 \\
\hline Supplementary data collection & .04 & 2.10 & & 1.90 & & 0.04 & & & 0.04 & & $\begin{array}{r}4.00 \\
.12\end{array}$ \\
\hline Unmanned buoy utllization...... & ...... & .20 & 0.20 & .30 & 0.30 & .50 & 0.50 & & - & & 2.00 \\
\hline Mesoscaph utilization & 25 & 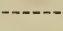 & $-\cdots$ & $\therefore$ & 1.00 & & & & & & 1.00 \\
\hline $\begin{array}{l}\text { National Data Center } \\
\text { Disease and related studies....... }\end{array}$ & 20 & & 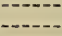 & .80 & & & & & $\cdots$ & & .80 \\
\hline \multirow{3}{*}{$\begin{array}{l}\text { Total } \\
\text { Mineral resources investigation.- } \\
\text { Total }\end{array}$} & .79 & 2. 30 & .20 & 3. 00 & 1. 30 & .54 & .50 & ----- & .04 & - & 8.67 \\
\hline & & & & & & & & . & 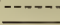 & & .1 \\
\hline & 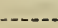 & & & & & & & & & & 8.77 \\
\hline
\end{tabular}

1 Does not include capital costs of ships, which will be found in the section on "New Ships."

TABLE 15.-Operating costs for new resources studies ${ }^{1}$

[Millions of 1958 dollars]

\begin{tabular}{|c|c|c|c|c|c|c|c|c|c|c|c|}
\hline & 1960 & 1961 & 1962 & 1963 & 1964 & 1965 & 1966 & 1967 & 1968 & 1969 & Total \\
\hline 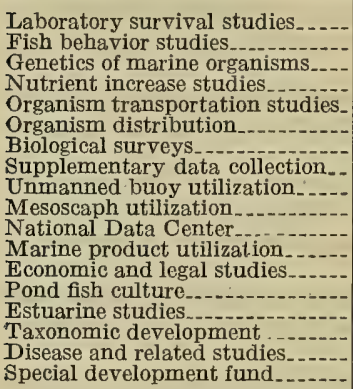 & $\begin{array}{l}.10 \\
.30 \\
.20 \\
.10 \\
.20 \\
.55 \\
.10\end{array}$ & $\begin{array}{r}.20 \\
.12 \\
.05 \\
.05 \\
1.80 \\
.11 \\
.03\end{array}$ & $\begin{array}{r}0.24 \\
.48 \\
.20 \\
.12 \\
.05 \\
.05 \\
1.80 \\
.11 \\
.06 \\
.12 \\
.30 \\
.20 \\
.10 \\
.50 \\
.55 \\
.10\end{array}$ & $\begin{array}{r}0.24 \\
.48 \\
.20 \\
.15 \\
.05 \\
.05 \\
1.80 \\
.11 \\
.11\end{array}$ & $\begin{array}{r}0.24 \\
.95 \\
.20 \\
.15 \\
.05 \\
.05 \\
1.80 \\
.11 \\
.15 \\
.15 \\
.30 \\
.20 \\
.30 \\
.50 \\
.55 \\
.20 \\
.10\end{array}$ & $\begin{array}{r}0.24 \\
.95 \\
.20 \\
.15 \\
.05 \\
.05 \\
3.60 \\
.22 \\
.23 \\
.64 \\
.16 \\
1.00 \\
.20 \\
.30 \\
.50 \\
1.00 \\
.20 \\
.10\end{array}$ & $\begin{array}{r}0.24 \\
.95 \\
.20 \\
.15 \\
.05 \\
.05 \\
3.60 \\
.22 \\
.30 \\
.64 \\
.18 \\
1.00 \\
.20 \\
.30 \\
.50 \\
1.00 \\
.50 \\
.10\end{array}$ & $\begin{array}{r}0.24 \\
.95 \\
.20 \\
.15 \\
.05 \\
.05 \\
3.60 \\
.22 \\
.30 \\
.64 \\
.20 \\
1.00 \\
.20 \\
.30 \\
.80 \\
1.00 \\
.50 \\
.10\end{array}$ & $\begin{array}{r}0.24 \\
.95 \\
.20 \\
.15 \\
.05 \\
.05 \\
3.60 \\
.33 \\
.30 \\
.64 \\
.22 \\
1.00 \\
.20 \\
.30 \\
.80 \\
1.00 \\
.50 \\
.10\end{array}$ & $\begin{array}{r}0.24 \\
.95 \\
.20 \\
.15 \\
.05 \\
.05 \\
3.60 \\
.33 \\
.30 \\
.64 \\
.24 \\
1.00 \\
.20 \\
.30 \\
.80 \\
1.00 \\
.50 \\
.10\end{array}$ & $\begin{array}{r}2.16 \\
6.66 \\
2.00 \\
1.41 \\
.50 \\
.50 \\
27.00 \\
1.87 \\
1.78 \\
3.20 \\
1.61 \\
6.50 \\
2.00 \\
2.20 \\
5.30 \\
7.75 \\
2.60 \\
1.00\end{array}$ \\
\hline $\begin{array}{l}\text { Total for Bureau of Com- } \\
\text { mercial Fisheries. } \\
\text { Mineral resource investigation } \\
\text { (Bureau of Mines) }\end{array}$ & 3.88 & $\begin{array}{r}4.16 \\
.25\end{array}$ & $\begin{array}{r}4.98 \\
.25\end{array}$ & $\begin{array}{r}5.27 \\
.25\end{array}$ & $\begin{array}{r}6.00 \\
.25\end{array}$ & $\begin{array}{r}9.79 \\
.25\end{array}$ & $\begin{array}{r}10.18 \\
.25\end{array}$ & $\begin{array}{r}10.50 \\
.25\end{array}$ & $\begin{array}{r}10.63 \\
.25\end{array}$ & $\begin{array}{r}10.65 \\
.25\end{array}$ & 76.04 \\
\hline Total... & 4.13 & 4.41 & 5. 23 & 5. 52 & 6.25 & 10.04 & 10.43 & 10.75 & 10.88 & 10.90 & 78.54 \\
\hline
\end{tabular}

I Excluding ship operations.

TABLE 16.-Capital and operating costs for new resources research ${ }^{1}$

\begin{tabular}{|c|c|c|c|c|c|}
\hline \multirow{2}{*}{ Year } & \multicolumn{2}{|c|}{$\begin{array}{c}\text { Bureau of Commercial } \\
\text { Fisheries }\end{array}$} & \multicolumn{2}{|c|}{ Bureau of Mines } & \multirow{2}{*}{ Total } \\
\hline & Capital & Operating ${ }^{2}$ & Capital & Operating & \\
\hline 1960 & $\begin{array}{r}0.79 \\
2.30 \\
.20 \\
3.00 \\
1.30 \\
.54 \\
.50 \\
.04 \\
\end{array}$ & $\begin{array}{r}3.88 \\
4.16 \\
4.98 \\
5.27 \\
6.00 \\
9.79 \\
10.18 \\
10.50 \\
10.63 \\
10.65\end{array}$ & 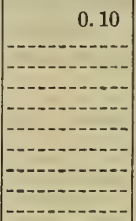 & $\begin{array}{l}0.25 \\
.25 \\
.25 \\
.25 \\
.25 \\
.25 \\
.25 \\
.25 \\
.25 \\
.25\end{array}$ & $\begin{array}{r}5.02 \\
6.71 \\
5.43 \\
8.52 \\
7.55 \\
10.58 \\
10.93 \\
10.75 \\
10.92 \\
10.90\end{array}$ \\
\hline Total & 8. 67 & 76.04 & .10 & 2. 50 & 87.31 \\
\hline
\end{tabular}

1 Excluding ships and ship time.

2 Programs involving international cooperation and technical assistance to other countries budgeted under this heading should be supported at least in part by the International Cooperation Administration and the State Department. 


\section{H. IN'TERNATIONAL COOPEIRATION}

It is clear that, as in other sciences, a very large part of the pioneering research and new idleas concerning the oceans must come from individual scientists or small groups working independently. But international cooperation in work at sea is essential in several kinds of marine research and should also greatly facilitate surveys of the ocean floor and of the waters.

There is at present a high level of international cooperation among physical and chemical oceanographers of different countries resulting from the International Geophysical Year. This cooperation should be maintained and broadened throughout all aspects of the marine sciences, particularly including biology. To this end, the Committee recommends :

(1) The United States through the National Science Foundation should give its proportionate share (amounting to perhaps $\$ 20,000$ per year) of financial and other support to the Special Committee on Oceanic Research of the International Council of Scientific Unions. The Committee on Oceanography has been designated as the U.S. national committee for this long-range cooperative program.

(2) Grants should be sought also from foundations and governmental sources. to support special projects such as the proposed yearlong international expedition to the Indian Ocean by covering the increased expenses to U.S. oceanographic institutions and by making the participation of other countries possible. Special funds needed for the Indian Ocean project are estimated at about $\$ 2$ million.

(3) An intergovernmental conference of the maritime countries should be called, after suitable preparation, to discuss means by which the governments can cooperate in increasing man's knowledge of the oceans. Specifically, agreements should be sought regarding the means of carrying out oceanwide surreys, including allocation of responsibility to different countries, intercalibration of techniques, and free exchange of data. It would be expected that the U.S. proportion of this international responsibility for surveys would be about the same as its proportion of financial responsibility for support of United Nations agencies. This conference should be a first step toward the establishment of a World Oceanographic Organization; a United Nations specialized agency corresponding to the World Meteorological Organization.

(4) In the study and conservation of the living resources of the sea, regional international organizations, such as the various international fisheries commissions, have proven effective.

In developing formal intergovernmental cooperation in the marine sciences, the Federal Government should give special emphasis to the establishment and adequate support of such regional organizations, and should seek to broaden their charter to allow an integrated research program on all aspects of a particular oceanic region.

(5) In order to increase the effectiveness of cooperation between U.S. marine scientists and laboratories and marine scientists in other countries, the U.S. State Department should be prepared to assist positively, sympathetically, and promptly in facilitating research ship operations and the exchange of information, persons, equipment, and supplies.

(6) The need for increased protein foods from the sea is especially urgent in underdeveloped countries. The International Cooperation Administration in its programs of technical assistance should give greater emphasis to marine resources surveys and to research projects and training programs in the marine sciences. The Federal Gorerument also should encourage United Nations specialized agencies such as UNESCO and FAO in their efforts to aid underdeveloped countries to achieve greater utilization of marine resources. The funds needed for both these purposes have not been budgeted separately in this report but are included in the budget for ocean resources studies.

\section{BUDGET AND OPERATIONS}

The total recommended budget for the period 1960-70 broken down by category and agency is given in tables 17 and 18. It should be emphasized that although the budget includes the capital costs of ships involred in strictly military research and development, it does not include the other costs which are involved in such work. 
Concerning the actual funding and operations, the committee recommends:

(1) A higher percentage of longer term funding must be made available in oceanographic research. Past funding has been inefficient, and has held back much longer term imaginative research. A reasonable portion (30 to 50 percent) of the annual operating budget should include 5-year money which is refreshed annually. Existing laws permit allocation of many funds on a 5-year basis. The military is accustomed to making long-term commitments of 5 to 10 years when they adopt a new weapons system and it is equally essential that they make long-term commitments for research.

(2) Administrators of research and laboratory directors must have a higher percentage ( 25 to 50 percent) of their funding free to spend on those good research problems which emerge without the benefit of planning.

(3) Government organizations which presently fund or carry on extensive research and development in oceanography should continue to do so in the field of their special interests. For example, the Navy, the Atomic Energy Commission, and the Bureau of Commercial Fisheries all have their own important oceanographic problems. It is recommended that each bureau and organization sponsor and finance much of the research which it needs to meet the demands of its present and future objectives. Any duplication of effort which might be involved appears trivial compared to the value of insuring that scientists are in close touch with changing bureau problems.

(4) There will still remain a need for a great deal of research which should be funded by the National Science Foundation. This agency should carry a much heavier portion of the long-term basic research in the Nation. A reasonable percentage of grants should be made to individuals and a reasonable portion should be allocated for long-term funding of institutional activities such as vehicles, facilities, and major expeditions.

(5) Foundations, States, and industries should take an active part in the support of marine research. Their support is particularly valuable in new and unusual research programs, in filling technological gaps and through appropriate assistance insuring that private laboratories and academic groups do not become solely dependent on Federal assistance.

TABLE 17.-Summary of budgets for new oceanographic activity ${ }^{1}$

[Millions of 1958 dollars]

\begin{tabular}{|c|c|c|c|c|c|c|c|c|}
\hline Year & $\begin{array}{l}\text { Educa- } \\
\text { tion and } \\
\text { man- } \\
\text { power }\end{array}$ & Ships & $\begin{array}{c}\text { Shore } \\
\text { facilities } \\
\text { (research) }\end{array}$ & $\begin{array}{c}\text { Shore } \\
\text { facilities } \\
\text { (surveys) }\end{array}$ & $\begin{array}{l}\text { New } \\
\text { devices }\end{array}$ & $\begin{array}{l}\text { Radio- } \\
\text { activity }{ }^{2} \\
\text { in oceans }\end{array}$ & Resources & Total \\
\hline $\begin{array}{l}1960 \ldots \\
1961 \\
1962 \\
1963 \\
1964 \\
1965 \\
1966 \\
1967 \\
1968 \\
1969\end{array}$ & $\begin{array}{l}0.80 \\
.80 \\
.80 \\
.80 \\
.80 \\
.80 \\
.80 \\
.80 \\
.80 \\
.80\end{array}$ & $\begin{array}{l}39.80 \\
40.45 \\
45.30 \\
35.95 \\
33.65 \\
29.00 \\
20.55 \\
10.45 \\
10.45 \\
10.45\end{array}$ & $\begin{array}{r}1.50 \\
2.70 \\
3.90 \\
6.60 \\
10.50 \\
12.60 \\
13.50 \\
13.20 \\
13.20 \\
13.20\end{array}$ & $\begin{array}{l}0.76 \\
1.52 \\
3.00 \\
4.50 \\
6.00 \\
7.50 \\
8.26 \\
8.26 \\
8.26 \\
8.26\end{array}$ & $\begin{array}{r}7.40 \\
9.50 \\
9.60 \\
10.90 \\
10.50 \\
10.50 \\
10.50 \\
10.50 \\
10.50 \\
10.50\end{array}$ & $\begin{array}{l}3.08 \\
2.95 \\
4.35 \\
2.95 \\
2.95 \\
2.95 \\
4.39 \\
2.95 \\
2.95 \\
2.95\end{array}$ & $\begin{array}{r}5.02 \\
6.71 \\
5.43 \\
8.52 \\
7.55 \\
10.58 \\
10.93 \\
10.75 \\
10.92 \\
10.90\end{array}$ & $\begin{array}{l}58.36 \\
64.68 \\
72.38 \\
70.22 \\
71.95 \\
73.93 \\
68.89 \\
56.91 \\
57.08 \\
57.06\end{array}$ \\
\hline Total_.......... & 8.00 & 276.05 & 90.90 & 56.32 & 100.40 & 32.43 & 87.31 & 651.41 \\
\hline
\end{tabular}

1 Not including special funds for basic research projects involving extensive international cooperation sucil as the proposed year-long international expedition to the Indian Ocean (estimated cost: $\$ 2,000,000$ ).

2 Plus ship time charges of $\$ 11,700,000$ to be subtracted from other categories. 
TABLE 18.-Summary of budget for new oceanographic activity by agency ${ }^{2}$

[Millions of 1958 dollars]

\begin{tabular}{|c|c|c|c|c|c|c|c|c|c|}
\hline Year & Navy ${ }^{2}$ & $\begin{array}{l}\text { Coast } \\
\text { and } \\
\text { Geodetic } \\
\text { Survey }\end{array}$ & $\begin{array}{l}\text { Burcau } \\
\text { of Com- } \\
\text { mercial } \\
\text { Fisheries }\end{array}$ & $\begin{array}{c}\text { Maritime } \\
\text { Admin- } \\
\text { istration }\end{array}$ & $\begin{array}{l}\text { National } \\
\text { Sclence } \\
\text { Founda- } \\
\text { tion }\end{array}$ & $\begin{array}{c}\text { Oflice of } \\
\text { Engl- } \\
\text { neering }\end{array}$ & $\begin{array}{c}\text { Atomic } \\
\text { Energy } \\
\text { Com- } \\
\text { mission }\end{array}$ & $\begin{array}{l}\text { Bureau } \\
\text { of Mines }\end{array}$ & Total \\
\hline $\begin{array}{l}1960 \\
1961 \\
1962 \\
1963 \\
1964 \\
1965 \\
1966 \\
1967 \\
1968 \\
1969\end{array}$ & $\begin{array}{l}28.78 \\
28.83 \\
30.40 \\
33.80 \\
35.22 \\
32.68 \\
27.45 \\
20.36 \\
20.36 \\
20.36\end{array}$ & $\begin{array}{l}5.83 \\
6.09 \\
9.75 \\
8.70 \\
9.30 \\
9.20 \\
9.88 \\
6.43 \\
6.43 \\
6.43\end{array}$ & $\begin{array}{r}7.97 \\
13.86 \\
12.83 \\
12.42 \\
11.75 \\
15.03 \\
12.38 \\
12.20 \\
12.37 \\
12.35\end{array}$ & $\begin{array}{r}5.45 \\
3.80 \\
1.65 \\
1.65 \\
\\
\end{array}$ & $\begin{array}{r}6.40 \\
8.35 \\
12.65 \\
11.60 \\
11.98 \\
13.32 \\
14.08 \\
14.22 \\
14.22 \\
14.22\end{array}$ & $\begin{array}{r}0.50 \\
.50 \\
.50 \\
.50 \\
.50 \\
.50 \\
.50 \\
.50 \\
.50 \\
.50\end{array}$ & $\begin{array}{l}3.08 \\
2.95 \\
4.35 \\
2.95 \\
2.95 \\
2.95 \\
4.35 \\
2.95 \\
2.95 \\
2.95\end{array}$ & $\begin{array}{r}0.35 \\
.25 \\
.25 \\
.25 \\
.25 \\
.25 \\
.25 \\
.25 \\
.25 \\
.25\end{array}$ & $\begin{array}{l}58.36 \\
64.63 \\
72.38 \\
70.62 \\
71.95 \\
73.93 \\
68.89 \\
56.91 \\
57.08 \\
57.06\end{array}$ \\
\hline Total & ${ }^{3} 278.24$ & 878.04 & 123.16 & 10.90 & ${ }^{3} 121.04$ & 5.00 & 532.43 & 2. 60 & 651.41 \\
\hline
\end{tabular}

1 Not including special funds for basic research projects involving extensive international cooperation such as the proposed year-long international expedition to the Indian Ocean (estimated cost: $\$ 2,000,000$ ).

2 Not including military research and development operations.

3 Less payments by A EC totaling $\$ 11,700,000$ for ship time.

1 Includes recommended expenditures by the International Cooperation Administration and the State Department, for projects involving international cooperation and technical assistance to other countries.

${ }_{6}$ Plus $\$ 11,700,000$ for ship time, averaging $\$ 1,170,000$ per year.

\section{Membershtp of Panels}

\section{PANEL ON OCEANOGRAPHIC RESEARCH SHIPS}

Clifford A. Barnes, University of Washington.

Adm. L. O. Colbert (retired), Arctic Institute of North America.

John Isaacs, Scripps Institution of Oceanography.

Columbus O'D. Iselin (Chairman $)^{1}$.

Vito Russo, Maritime Administration.

Herbert Seward, Yale University.

\section{PANEL ON NEW DEVICES FOR EXPLORING THE OCEAN}

Robert Frosch, Hudson Laboratories, Columbia University.

James Lipp, Lockheed Aircraft Corp.

Philip Mandel, Massachusetts Institute of Technology.

Andreas Rechnitzer, the Navy Electronics Laboratory.

Athelstan Spilhaus. ${ }^{1}$

Allyn C. Vine (Chairman), Woods Hole Oceanographic Institution.

Rear Adm. George Weaver (retired), George Washington University.

R. F. Nigrelli (consultant), New York Zoological Society.

III. PANEL ON OCEAN RESOURCES

Richard L. Meier, University of Michigan.

H. W. Menard, Scripps Institution of Oceanography.

John R. Menke, Nuclear Development Corp.

Milner B. Schaefer. ${ }^{1}$

Oscar E. Sette, Bureau of Commercial Fisheries.

Robert G. Snider (Chairman), the Conservation Foundation.

Lionel A. Walford, Bureau of Commercial Fisheries.

IV. PANEL ON INTERNATIONAL COOPERATION IN THE MARINE SCIENCES

Columbus O'D. Iselin. ${ }^{1}$

Fritz Koczy. ${ }^{1}$

Roger Revelle ${ }^{2}$

Milner B. Schaefer. ${ }^{2}$

Athelstan Spilhaus (Chairman).'

1 Committee on Oceanography members. 


\section{PANEL ON RADIUACTIVITY IN THE OCEANS}

(This group continues to be active as the Committee on the Effects of Atomic Radiation on Oceanography and Fisheries of the National Academy of Sciences' Study of the Biological Effects of Atomic Radiation. It responds to inquiries from but is not officially a part of the Committee on Oceanography.)

Howard Boroughs, Instituto Interamericano De Ciencias Agricolas.

Dayton Carritt, the Johns Hopkins University.

Walter Chipman, Bureau of Commercial Fisheries.

Harmon Craig, Scripps Institution of Oceanography.

Lauren Donaldson, University of Washington.

Richard Fleming, University of Washington.

Richard Foster, General Eelectric Co.

Edward Goldberg, Scripps Institution of Oceanography.

John Harley, U.S. Atomic Energy Commission.

Bostwick Ketchum, Woods Hole Oceanographic Institution.

Louis Krumholz, University of Louisville.

Charles E. Renn, the Johns Hopkins University.

Roger Revelle (Chairman). ${ }^{1}$

Milner B. Schaefer. ${ }^{1}$

Allyn C. Vine, Woods Hole Oceanographic Institution.

Lionel A. Walford, Bureau of Commercial Fisheries.

Warren S. Wooster, Scripps Institution of Oceanography.

\section{Consultants}

Theodore R. Folsom, Scrippts Institution of Oceanography.

Arnold Joseph, Atomic Energy Commission.

Robert Reid, Texas A. \& M. College.

Donald Pritchard, the Johns Hopkins University.

\section{Nationat Academy of Sciences-National Research Council}

The National Academy of Sciences-National Research Council is a private, nomprofit organization of scientists, dedicated to the furtherance of science and to its use for the general welfare.

The Academy itself was established in 1863 under a congressional charter signed by President Lincoln. Empowered to provide for all activities appropriate to academies of science, it was also required by its charter to act as an adviser to the Federal Government in scientific matters. This provision accounts for the close ties that have always existed between the Academy and the Government, although the Academy is not a governmental agency.

The National Research Council was established by the Academy in 1916, at the request of President Wilson, to enable scientists generally to associate their efforts with those of the limited membership of the Academey in service to the Nation, to society, and to science at home and abroad. Members of the National Research Council receive their appointments from the president of the Academy. They include representatives nominated by the major scientific and technical societies, representatives of the Federal Government, and a number of members at large. In addition, several thousand scientists and engineers take part in the activities of the Research Council through membership on its various boards and committees.

Receiving funds from both public and private sources, by contributions, grant, or contract, the Academy and its Research Council thus work to stimulate research and its applications, to survey the broad possibilities of science, to promote effective utilization of the scientific and technical resources of the country, to serve the Government, and to further the general interests of science.

The Chairman. Do you have anything else, Dr. Brown?

Mr. Brown. I have nothing further.

The Chatrman. I think of no further questions. We have covered it quite thoroughly here. We will have, I think, a very readable record which will contain justification for these suggestions.

Of course, we run into the cost all the time, and the Bureau of the Budget, and the problem of how much we can afford. I think Con-

\footnotetext{
1 Committee on Oceanography members.
} 
gress has done a pretty good job in the past 8 or 9 years of being alert to this whole scientific problem. I think much nore than they ever rere before, and we have gone along in other fields to an extent greater than I ever thought we would 10 years ago.

I hope in this field we will feel the same way about it, so that we can get going, as it were.

I want to thank all of you people for coming here. You have given your own valuable time and I know this is of deep interest to you, as it is to us. I again apologize for the seeming moving in and out, but this is a busy season around here. All the Senators were not here at different times. They were here sometimes. That doesn't mean they won't read this whole thing. They have a real interest in it.

I think our real problem now is the justification and the cost. Surely the witnesses here up to date have, I think, put in the record and have given to us testimony as much as they can on why they think this cost would be justified over thís so-called 10-year period.

$\mathrm{Mr}$. Brown. Before I leave, may I introduce for the record a very brief statement by Professor Revelle on the international relations aspect.

(The document referred to follows:)

\section{Statement By Roger R. Revelle}

The oceans belong to no man and no nation, yet they are of vital importance to all men and all nations, not only because of their human and scientific interest, but because of their effect on weather and climate and the resources for human welfare they contain. The seas are vast, yet their waters are all interrelated; what happens at any one place on the oceans affects the waters everywhere.

No one nation can find out unaided all that it needs to know then about the oceans. International cooperation in the study of the seas is essential, just as it has proven essential in studying the atmosphere and the stars. The United States has an unparalleled opportunity to exert world scientific leadership in developing this cooperation. Both before and during the International Geophysical Year, American oceanographers played an important role as scientists in planning and carrying out the initial steps in international cooperative oceanography. They were backed with funds appropriated for the IGY by Congress. New opportunities are now arising and these will also require funding. To prepare for these opportunities, action by Government agencies is now needed.

An intergovernmental conference has been called by UNESCO for next July in Copenhagen. At this conference it is hoped that interested gorernments will be able to work out ways in which they can cooperate effectively in charting the floor of the sea, measuring its properties, and the movements of its waters, and in surveying the seas' living resources. I recently attended the preparatory meeting for this conference in Paris as one of four U.S. delegates. Representatives of 25 nations were present, including a 4-man Russian delegation. It was evident that the U.S.S.R. is determined to push very hard on their share of any international program that may be decided upon at Copenhagen. But it also appeared that they would be willing to exchange a great deal of the data to be obtained and to work cooperatively in planning surveys and intercalibrating instruments.

One very important ocean where our knowledge is almost negligibly small and our ultimate U.S. interests are large is the Indian Ocean. There under the leadership of the Special Committee on Oceanic Research of the International Council of Scientific Unions, a real possibility exists of obtaining a rich store of knowledge by pooling the activities of many different countries in a multiship, 3-year long, International Indian Ocean Expedition. We expect that Australia, Japan, Pakistan, India, South Africa, the United Kingdom, France, and the U.S.S.R. will all play an active part in this program. U.S. oceanographers believe that they could send at least four ships into the Indian Ocean as part of this program provided support becomes arailable. For this "little IGY" a special appropriation of perhaps \$4 million mas be necessary.

Many countries are turning to the sea as they look to the future, and rell $55401-60-8$ 
they might in the face of burgeoning populations and rapidly increasing consumption of food, materials, and energy. Our own population and our own needs are increasing. For investment purposes alone the effort and funds needed (as outlined in our report) to further develop our Nation's capability in the marine sciences is a small price to pay to see to it that our children and their children can claim and make effective use of the store of food and materials that are waiting in the seas. And this investment will pay immediate dividends in greater effectiveness for our naval forces, in increased efficiency of our merchant marine, in international good will, and in new scientific understanding.

The Chatrman. We will leave the record open for any additions and changes. There are a lot of people I know in your group who would have liked to have been here and testified but who could not and they might want to add something.

In about 3 weeks we will have the record, and it will be available to you and others who are interested. I think it is going to be a very valuable compilation of this whole field of research to everyone, particularly to lay persons.

After we get the record printed the committee will probably meet and discuss amendments to the bill, or suggestions, and see if it cannot be passed out on the floor and get it moving. Time is running out on us a bit. The session is moving toward a close, if we are to quit to go about our other business in July.

However, I wouldn't be discouraged, if this shouldn't happen to pass in this session of Congress. The wheels up here grind slowly. The 5 or 6 months until we come back again isn't going to make a great difference if we get the program through then.

We are laying a lot of foundation for this program, and have a lot of things behind us.

Are there any questions?

Senator ENGLE. I have no questions.

I would like to compliment Dr. Brown and his committee on the very excellent work they have done and the contribution you have made to the public interest in the long sessions you have had. I attended one of those, and I know you worked diligently and hard on these problems. This report is a carefully considered one, and one in which you have given a great deal of time and attention to details and to practical and minimum things that should be done to help in this field.

It does constitute the minimum we ought to do, and I hope we can proceed to get on with it. The country owes you and your associates a great debt of gratitude.

Mr. Brown. Thank you.

The Chatruan. The Senator from Texas.

Senator YARBOROUGH. I take it, Dr. Brown, you think these recommendations make up the minimum program that should be undertaken rather than the maximum to be scaled down?

Mr. Brown. Right.

Senator YARBOROUGH. I agree with you that I think we should start with this as a minimum program and not, as it is rumored, that some bills are introduced with a large figure with the idea that they will be scaled down.

I think this is a minimum figure and shouldn't be scaled down any.

Mr. BRown. We tried to be as realistic as we could. 
Senator Yarbonougr. I take it you feel this is something like investing in sweetpotatoes.

You make a little slit in the ground and you take out a great deal in comparison to what you put in the soil.

The Cimamiran. You are talking about Texas soil, no doubt.

Senator YArbonougir. I would like to say this, Mr. Chairman: I want to thank this committee for its work and to ratify what the chairman has said, that our attendance is no evidence of lack of interest by the members of this committee. I am very much interested in this subject. Yesterday we had six different committees meeting at one time and only two of them were marking up bills, and we had to go where the money was being allocated on those matters.

I think the chairman is due a debt of gratitude by the rest of us of the committee to assure these hearings going on.

Under our Senate procedures, when this bill is considered, the minute this bill comes up a printed copy of all this testimony is placed on the right-hand corner of everybody's desk. You can reach down and get it without having to look at where it is. It will be introduced chronologically by the days you testified and indexed alphabetically by your name.

So if some Senator was in here for a couple of hours and he heard certain testimony, he can turn to a given day and find what he rvants, even though he doesn't remember the day the witness testified.

With our system of indexing these records, none of your testimony will be lost and those presenting the bill, if any question is raised, the committee staff will have it indexed page by page. They will hand it to Senator Magnuson, who will present the bill and all this testimony is valuable. It may be invaluable at any point in the debate, but I did want to point out that under our Senate procedures every bit of this testimony is there and generally in a bill of this importance it is used on the floor of the Senate before the bill is passed.

I want to thank you for your patience and assure you that there is no senatorial indifference.

The Chairian. Now, do you want to look at these slides for 15 minutes? We will have to turn the lights off.

\section{STATEMENT OF COMIMANDER WILBUR, U.S. NAVY, OFFICE OF CHIEF OF NAVAL OPERATIONS}

Commander Wilbur. I am Comdr. C. C. Wilbur with the Office, Chief of Naval Operations, presently attached to the progress analysis. I previously served primarily 12 years in submarines, having had command of two of them and more recently having had command of a destroyer which probably is the most interesting part of generating an interest in oceanography. I consider it a particular honor to be here today with our presentation on the conquest of inner space and I want to thank Mr. Markel and the members of the Coordinating Committee on Oceanography for their interest and support.

Now, one thing I would like to clarify a little bit:

This is an educational slide presentation for Naval Research personnel. We have it out in the field. It is available by request by interested civic groups and high schools which may support some of the educational aspects that you are concerned about. 
The Chamran. All right.

Commander Wirbur. Slide No. 1. Galaxy: If you were to observe our solar system from a vantage point in outer space, you would see a colorful parade of the planets.

Slide No. 2. Planets: You would see Venus, surrounded by her green clouds of gas. You would see Saturn's rings, Jupiter's moon and the reddish crust of Mars.

Slide No. 3. Earth: But if you focus your attention on the planet Earth, you would be immediately struck with the fact that Earth differs from all other planets. Three-fourths of its surface is covered by water. We would then clearly understand why Earth is called the "water planet." It is equally obvious that such an expanse of ocean must play a major part in life on this planet.

Slide No. 4. Title slide: The "Conquest of Inner Space" may well be the key to the future welfare, and possibly even the continued existence of mankind. And, to date we have less information about this vital area than we have of the surface of the Moon. The world's oceans have truly guarded their secrets more jealously than outer space.

Slide No. 5. SNN Around the World: Today's Nautilus-the world's first true submarine-has given us great freedom of movement throughout the inner space- the oceans which cover most of the earth's surface. It has reemphasized how little we know about the vast hidden world beneath the seas.

Slide No. 6. Land, Shelf, Bottom: To date, we have explored most of the earth above these oceans and seas-but, know very little of what lies beneath the surface of the water, 324 million cubic miles in volume.

It is therefore most important at this point in our Nation's history that we take a new and searching look at this inner space, the world beneath the seas.

This examination is necessary to determine how the Navy and the Nation can better prosecute and obtain additional support for their vital oceanographic research programs.

Let us first take a look at some of the characteristics of the sea that we already know.

Slide No. 7. Mountains and Valleys: We know that shrouded in the darkness of the oceans lie mountain ranges whose peaks rival Mount Everest in height - trenches whose dark depths plunge 7 miles beneath the surface. We also know of subsurface currents-virtually rivers in the depths of the sea-1,200 times greater in size than the Mississippi.

Slide No. 8. Sonar Mapping: But only in recent years have we had the tools with which to determine with accuracy the contours of the bottom of the seas and even with these, it is like mapping the Grand Canyon blindfolded. By bouncing sound waves off the ocean floorand recording the echoes-some of the many mysteries of the ocean depths began to reveal themselves.

Slide No. 9. Three Levels of Ocean: The general undersea topography is already well established. It falls into three widely different geographical areas. The Continental Shelf, shown by the yellow arrow - the continued slope, red arrow-and the floor of the sea, blue arrow.

Slide No. 10. Continental Shelf: The Continental Shelf is the area most resembling land, with sunlight penetrating most of its extent. 
It is rich in plant and fish life and other resources. 'The shelf begins at the coastline and extends seaward in gentle sloping plains.

Slide No. 11. Continental slope: Once beyond the edge of the shelf, the steeper Continental Slope begins - with its gathering darkness, growing pressure, and the absence of all forms of plantlife. 'These slopes are the most imposing features of the surface of the earth, interlaced with submerged canyons, in some places reaching the impressive depths of over 36,000 feet.

Slide No. 12. Bottom Sediment: The floors of the deep ocean basins are probably as old as the sea itself. Here in the eternal cold and darkness lie the undersea mountain ranges and the strange, flat-topped sea mounts. Underlying the ocean bottoms are a number of sedimentary layers, averaging one-half mile in depth-the product of a billion years of deposits of debris.

Slide No. 13. Waves: Although the sea is impressive from a standpoint of sheer size and depth, an even more impressive characteristic is the constant motion of the sea in the form of waves, tides, and currents. Most waves are a result of the action of wind on water.

Slide No. 13A. Breakers: The force of waves is almost incredible. It is estimated that a 12-foot wave strikes with a force of 113 tons for every foot of its width.

Slide No. 14: Tides, Sun, Moon, Earth: Tides are another form of mass movement of the oceans. There is no drop of water in the ocean, not even on the deepest ocean floor, that does not respond to the forces that create the tides. No other force which affects the sea is so strong. Tides are the natural result of the gravitational pull of the Sun and the Moon.

Slide No. 15. Global Thermostat: Because water is unique in its heat transfer characteristics, the oceans act as a global thermostat. They keep temperatures within limits which can support life. They regulate the world's climate and weather.

Slide No. 16. Ocean Currents: By redistributing heat received from the Sun, ocean currents are a major factor which tend to make up for the uneven heating of the globe.

The currents are literally rivers in the sea-some with a volume of flow that makes the Amazon a meadow brook by comparison.

Slide No. 17. Gulf Stream: Perhaps the best known example is the Gulf Stream which keeps Great Britain $35^{\circ}$ warmer than would be normally expected at her latitude.

This current, 40 miles wide and 3,000 feet deep, moves more than 50 miles a day up the coast of Florida toward Cape Hatteras where it turns eastward toward Europe and then divides into sereral branches. One branch moderates the climate of northern Europe turning around North Cape to give Russia its ice free Murmansk coast. Another branch turns toward Africa and the Azores then westward across the Atlantic.

Slide No. 18. Humboldt Current: In contrast to the warm Gulf Stream is the cold Humboldt Current, which flows up the west coast of South America. As a result of this cold current less than 1 inch of rain per year falls on the arid western coast. For no apparent reason, a small shift in the course of the Humboldt Current occurs about once every 10 years and brings disaster in the form of torrential rain and floods. 
Slide No. 19. Storm damage: A large number of buildings on Peru's west coast are destroyed and many lives are lost in the sudden deluge of tropical rains. This is a classic example of the results of a minor shift in the equilibrium of the ocean circulation.

The effect of the oceans on mankind are by no means confined to the temperature and climate.

Slide No. 20. Trade routes: We all know that for centuries the oceans have provided the high roads of commerce and colonizationthey are largely responsible for the political complexion of our planet. With the advent of the true submarine, a third and virtually unlimited dimension of sea travel under the ocean was opened-and we entered a new era.

Slide No. 21. Ocean bottom: Within the depths of oceans lie many of the answers to our future welfare. This is an actual photograph of the deep sea floor. Let us now look at the implications of this element from a scientific, economic, and military point of view.

Slide No. 22. Scientific knowledge: First, from the scientific viewpoint-we find that the ocean is a storehouse of scientific knowledge. A storehouse whose contents are only partially known to man.

Slide No. 23. Oceanographer: The scientist of the seas, the oceanographer, is the modern scientific explorer of the last frontier on this planet. Results of his explorations may prove to be vital to the continued existence of man.

Slide No. 24. 70 percent water: The realm of the oceanographer is the vast hidden world beneath the surface of the seas. It has a volume 14 times greater than the volume of all land above sea level. To date only a small portion of this area beneath the sea is known to man.

The U.S. Navy, long a pioneer in the study of oceanography, is supporting, in whole or in part, some of the more advanced programs of today's scientific efforts.

Slide No. 25. Ocean tower: Off San Diego, Calif., the Navy Electronics Laboratory has constructed this ocean tower to study the marine life and the dynamics and physical properties of the water in our Continental Shelf area. While the results are of primary interest to the Navy from a military standpoint, these results-as in all basic scientific research-are useful to scientists in all fields.

Slide No. 26. SCUBA: With the use of SCUBA, a self-contained underwater breathing apparatus, U.S. Navy scientists and divers have gone to depths of 300 feet. It has permitted firsthand examinations of areas previously made only by instruments.

Slide No. 27. Two-man sub: New vehicles for underwater exploration are being developed. This two-man submarine is used by the Navy Electronics Laboratory to explore costal waters. It is able to penetrate deeper and cover a larger area than SCUBA equipped divers.

Slide No. 28. Underwater TV: The self-propelled, wire-guided underwater television camera is coming into use for both scientific and military application. It will be used to explore the floor of the Continental Shelf areas and to detect the presence of mines, submarines, and other objects beneath the surface. This vehicle will be equipped to obtain bottom samples and recover submerged objectssuch as missile nose cones, torpedoes, etc. 
Slide No. 29. Bathyscaph Trieste: In August of 1958, the Navy procured the bathyscaph, Trieste, to assist in the study of the areas of the ocean previously inaccessible to man. Navy oceanographers hold the world's record in their recent descent to 35,800 feet in the Marianas Trench off Guam. The T'rieste looks and acts like an underwater blimp. The upper tank-like the gas bag-is for buoyancy. The lower sphere-or gondola-containing the crew, is constructed of heavy steel to withstand the pressures of the ocean depth.

Slide No. 30. Mohole: The Navy is also assisting in the Mohole project-a project for drilling a hole 5 miles through the ocean floor to the boundary between the eartl's crust and the underlying mantle of extremely dense dock. The U.S. National Academy of Sciences, which is backing this project, has four drilling areas under consideration. Initial explorations are being conducted in the vicinity of Bermuda-one of the areas where the earth's crust is believed to be the thinnest. Wherever it is sunk, the Mohole will give scientists a better idea of the structure of the earth and a priceless record of sediments that have settled since the earth was young.

Let us now consider the second major reason for exploring the frontier of the seas-and this is one which touches us all-that of economics.

Slide No. 31. Population: Our world is facing an explosive increase in its population with a daily increase of over 100,000 human beings. Even today, 70 percent of the world's population is undernourished. To support this increasing population, we must make every effort to discover new sources of food and minerals.

Slide No. 32. Fish: The sea is presently supplying only a small percent of its potential food harvest. Although 35 million tons of fish in various forms are taken annually, this might well be increased 10 times or more.

Slide No. 33. Diatoms: Challenging and more visionary is the possibility of harvesting minute plants and creatures of the sea-for example, the mass cultivation of sea water algae for foodstuff.

This is not as farfetched as it sounds. Japanese scientists have already prepared algae bread, algae noodles, algae soup, and algae ice cream. Those who ate these algae foods found them palatableeven delicious.

Slide No. 34. Minerals: The sea is also rich in minerals-in fact, oceanic waters contain more minerals than have been mined by man in all history. Each cubic mile of sea water contains 18 million tons of dissolved salts of sodium, potassium, calcium, bromine, and phosphorus.

There is enough gold in the sea to make every inhabitant of the world a millionaire.

In addition, on the floor of the deep seas-in the form of noduleslie deposits of cobalt, copper, nickel, iron, and manganese.

Slide No. 35. Oil wells: As each day passes, our world requires more fuel to produce energy.

Offshore-under the sea on the Continental Shelves-lies 40 percent of the world's known petroleum-20 billion barrels of it.

As commercial atomic power becomes a practical reality, the world's oceans offer a promising fuel source. Sea water is a source of both uranium for fission-produced power and deuterium or heary hydrogen for thermonuclear power. 
Slide No. 36. Missile launching sub: The third major reason for exploring this new frontier is a military one. Emphasizing the urgency in this area, a report of the National Academy of Sciences states-

from the point of view of military operations there is no comparison between the urgencies of the problems of the oceans, and those of outer space. The submarine, armed with long-range missiles is probably the most potent weapon system threatening our security today. It seems clear that the pressures of establishing effective bases and of protecting ourselves from attack are relentlessly driving us into the oceans.

Slide No. 37. Nautilus: The submarine Nautilus marked the beginning of a tactical revolution at sea. Because of the fantastic ability of the modern, nuclear submarine, both submarine and antisubmarine tactics are being completely rewritten.

With these new capabilities, also come new problems, both in making our own submarines completely effective, and in defending against similar types which we may expect the enemy to possess in the near future.

Slide No. 38. Sub in sea depth: The world beneath the sea is the operating area of the true submarine. Information about this environment, previously of little consequence to surface ships and aircraft, assumes tremendous importance to the submariner. Although the seas cover three-fourths of the surface of the earth, less than 1 percent of the deep sea floor has been mapped with any degree of reliability.

The tasks of navigating a submarine at high speed and deep submergence without accurate bottom information can be compared with driving a 10-ton truck on the freeway blindfolded.

Slide No. 39. U.S.S.R. sub: On the other side of the coin, we must be able to defend our cities and our merchant convoys against the threat of the world's largest submarine fleet. Current estimates of Soviet submarine strength run from four to five hundred. They are rapidly replacing the older units with modern ones. It is reasonable to assume that a number of these new submarines will be equipped with long-range ballistic missiles.

Slide No. 40. Submerged submarine: The problem of locating and identifying enemy submarines at distances beyond the effective range of their weapons is a difficult one. To date the most effective means of locating and identifying submerged targets is by use of sound techniques, called sonar. These techniques involve echo ranging, that is, bouncing a sound beam off a submerged target, or, listening to the noises made by the target.

Slide No. 41. Thermal layer: But in water, sound transmission varies with changes in the temperature, density and salt content of the water. Temperature differences between water layer's present the most critical problem, for the sound beam is reflected or refracted to a varying degree.

Slide No. 42. Steamship and whale: Once a submerged object has been detected by the sonar beam, the problem becomes one of identification - is it a whale? School of fish? Friendly surface ship? Or enemy submarine? All give sonar reflections.

Slide No. 43. Sea noises: In addition, when we listen for target noises we discover that the ocean which has been characterized as a "silent world" is, in fact, anything but. Actually the ocean is a "liquid 
jungle." Survival depends upon how well we know this enviroment, and whether, like 'Tarzan, we can tell the friendly sounds from the unfriendly ones - the monkeys from the tigers.

Slide No. 44. ASW team: Victory or defeat in future wars may well hinge upon superior knowledge of the seas. One of the vital supporting elements of seapower is oceanographic research. 'Through this research the Navy will be in a better position to perform its missions under-on-and over the sea.

Our scientific, economic and military future may well be locked in the world's oceans. The key to this future lies in study and research. in the vast ocean areas.

Slide No. 45. Oceanographer on ship: Although our small corps of oceanographers and supporting scientists have made a good start on an effective oceanographic research program-"making do" "with existing equipment--there is an urgent requirement for new equipment and modern facilities.

We need new ships, laboratories, and engineering facilities plus trained manpower.

Slide No. 46. Three Scientists: Manpower is critical. In support of each scientist at sea, three or four scientists and technicians in laboratories ashore are needed to develop new theories, extract and interpret data, and design new instrumentation.

Slide No. 47. United States vs. U.S.S.R.: Today we trail the Soviets in numbers, tonnage, and quality of seagoing research ships; we also trail in manpower devoted to the job of exploring the seas; and probably in supporting facilities of all kinds.

Slide No. 48. Research Ships: The United States-the richest country in the world-has only 45 research ships scattered among civilian, military, fishery, and geodetic activities; while the Soviets have a modern armada of more than 100 ships.

Slide No. 49. Soviet Research Ship: Many of their ships are quite large, displacing up to 6,000 tons. Unlike ours, their ships have been designed from the keel up for research and specialized scientific undertakings.

Urgently needed, then, is a clear-cut, long-range program designed to regain our country's lost leadership in the exploration of inner space. This program must give our Navy, our oceanographic institutions, and our universities the type of support that they so urgently need.

Slide No. 50. Ten-Year Program: Fortunately, we have such a plan in the report of the Committee on Oceanography of the National Academy of Sciences-National Research Council.

In support of this national program, the Nary has dereloped its own 10-year program. The Navy's program, in coordination mith other governmental agencies, calls for increased emphasis in the following areas:

Slide No. 51. Woman in Lab: Basic and applied research. The Navy is expanding its support of both of these two types of research. They go hand in hand. Through basic research we obtain fundamental knowledge- without thought of specific application. The success of applied research, however, depends upon this fundamental knowledge.

Slide No. 52. NEL: The Nary program calls for more new laboratory facilities-and financial support for the education of future oce- 
anographers. Increased emphasis in both are basic to an expanding oceanographic program.

Slide No. 53. Oceanographic Research Ships and Equipment: Increased procurement is being programed progressively over the next 10 years. This is necessary to amass the tremendous amount of data necessary, particularly for anticipated military needs.

Slide No. 54. Futurama: The future possibilities of the oceans are limited only by the imagination, awaiting exploitation by men of vision.

The major development in the case of almost every science has been the result of a breakthrough in the iron curtain of ignorance. And it has come only by the combined efforts of many individuals in all walks of life, working together in a common cause. In the case of oceanography, the breakthrough is still ahead. How far ahead is dependent not only on the amount of research conducted, but on the public interest shown in each step forward. There are unheard-of opportunities in this fascinating new science. Those of us here today, may or may not have a direct connection with the breakthrough in oceanography, but by our interest, support, and knowledge, we will play an increasingly important part.

Slide No. 55. Trident of Neptune: The United States is part of an island continent. Its safety and future greatness depend upon our understanding and control of the sea. A brave beginning has certainly been made. But it is most important that the oceanographic programs of the Navy and the Nation be continued on an expanding basis.

This will require the understanding and support of each of us as responsible American citizens.

Thank you, sir.

The Charrman. Thank you, Commander.

Again the committee thanks all of you for your contribution here to us in this whole field.

(Whereupon, at $11: 50$ a. m., the committee recessed.)

(The following was subsequently submitted for the record by Dr. Harrison Brown, Chairman of the Committee on Oceanography :)

\section{Committee on Oceanography Comment on a National Oceanographio RECORDS CENTER}

In chapter 3, Ocean Resources, of the Committee on Oceanography report, 1960 to 1970, the need for a National Oceanographic Records Center is discussed. Two pertinent paragraphs from this chapter read as follows:

"The most economical method for establishing the National Oceanographic Records Center would be to add it to an existing expandable facility in a Federal bureau concerned with technical and scientific matters, and with an interest in sea studies. Such a group should have both a tradition for performing public services and the competence and experience to handle large quantities of technical data.

"The U.S. Coast and Geodetic Survey and the U.S. Weather Bureau, both of which are in the Department of Commerce, most nearly meet these criteria. The former has the more direct interest in the sea; the latter has the greater facilities for mass processing of data. The U.S. Hydrographic Office also is concerned with technical and scientific matters; and it has even more widespread interest in oceanography, but it serves Navy needs primarily and civilian needs secondarily. All three collect, preserve, and disseminate certain types of oceanographic data. The panel considers that the National Oceanographic Records Center's function would be primarily to serve the public and that it should reside in a civilian agency in order to render this service effectively." 
Recently a plan to establish such a center at Suitiond, Ma., physically adjacent to the U.S. Hydrographic Oflice but financed and administered cooperatively by the Navy, the Coast and Geodetic survey, the Burean of Commercial Fisheries, the Atomic Energy Commission, and the National Science Foundation has been proposed. In our opinion, such a center could meet the main objectives outlined in the preceding paragraph, that is, service to the public, and avoid unnecessiry duplication of facilities. Accordingly our chapter 4, Defense Applications, (soon to be published) states:

"The U.S. Navy Iydrographic Office has accumulated what is perhaps the world's largest collection of hydrographic data. The Office provides many important services to the Navy and on a low priority basis to civilian agencies and institutions. We believe that by emphasizing the development of oceanographic forecasting techniques, by participation in systematic oceanocraphic aud hydrographic survey programs and through the development of an expanded data facility (cooperatively managed and financed by the Navy, the Coast and Geodetic Survey, the Bureau of Commercial Fisheries and the National Science Foundation) the contribution which this Office could make to naral, national, interuational, and scientific interests would be greatly enhanced. We heartily endorse and encourage the steps which are being taken in this direction."

HARRISON BROWN,

Chairman, Committee on Oceanography.

\section{(The following statement was submitted for the record:)}

\section{Statement of Dr. Charles M. Proctor, Bellevue, Wash.}

I am pleased to have been invited to submit a statement in connection with the hearings on S. 2692 for the support of marine sciences. The views presented here are my own, as an oceanographer, and are not a statement of views or policies of the Boeing Airplane Co. where I am employed.

The NAS-NRC Committee on Oceanography has presented a comprehensive, 10-year program for expanded research in the ocean and connecting waters at an estimated cost of $\$ 65$ million per year. This estimate is based on current prices and it is hoped that the probability of rising costs will be considered when a final, long-term budget is prepared by the Congress.

The major goal of an expanded program of marine research should be to attain a better understanding of the aqueous portion of our planet, without regard for financial return. It is inevitable, however, that any significant extension of knowledge of the sea will be of direct and often immediate benefit to fisheries, coastal and offshore engineering, weather and climatological forecasting, shipping, naval operations, and other marine activities.

If, for example, we assume that the results of this program were to indirectly increase the effectiveness of our submarine fleet by only 5 percent (this is surely a very conservative figure), then this entire proposed expenditure for research would yield as great a return in fleet effectiveness as a similar amount spent for new construction alone. This increased effectiveness would also be realized in lower requirements for personnel and support functions.

Among the major needs of oceanography in the United States are:

1. Efficient ships, with adequate operating budgets.

2. Reliable, sensitive instruments for in situ measurements and improred sampling devices.

3. Data recording, reduction, and processing systems which are compatible with the instruments and with modern computers.

4. Additional shore facilities including well equipped research laboratories.

5. An expanded program of academic grants that will attract many more graduate students of high caliber into the marine sciences.

The sole purpose of the ships, instruments, sampling derices, and laboratories is to provide the oceanographer with a description of the enrironment and to provide data with which to test his theories and to predict the future state of the oceans. The goal is thus to make observations and reduce them to usable form in the most expeditious manner. In the realm of phrsical measurements particularly, it is now possible to consider the entire problem, from sensing element to final calculation, as a data flow system. The technology exists, part of it in such diverse fields as medical research, oil well logging, communication theory, and missile telemetry. The job now is to translate these data and skills into a compatible system. 
The system should be capable of handling sensing elements to measure temperature, pressure, conductivity, illumination, sound velocity, radioactivity, etc., which could be carried on one or several vehicles. These vehicles might be towed, anchored, free floating, or self-propelled so an acoustical telemetering system would probably be preferable. The data should be stored in such form that an intelligible readout is available on shipboard for monitoring the operations while they are underway and so the data can be automatically processed for machine computation, either ashore, or on board the larger vessels. The stored data or any part of it should be easily reproduced and sent to another ship or laboratory for comparison purposes, or to combine with its own data for computation. In a well designed system, such a transfer of data could be made with a minimum of manual processing.

I would therefore propose that one agency, such as the National Science Foundation, be given primary responsibility for development of instrumentation and data processing methods at least in the first few years of the program. The responsible agency should then select one man, or a small group, whose primary duties will be to review the work that has been done and the work in progress on instrumentation and data handling at various oceanographic laboratories as well as the applicable work from fields other than oceanography.

A set of plans and specifications for a complete data flow system could be drawn up based on this review and on discussions with theoretical oceanographers who will interpret the data to be collected. After testing of prototypes, equipment can be built and made arailable to each ship and laboratory in accordance with its needs.

This proposal is not presented as an ultimate answer to oceanographic instrumentation, but as a plan for development of a working system, which can be built now, to collect and process many kinds of oceanographic data using modern rapid machine methods and thus facilitate the work which would be supported by this bill.

The scientific and material benefits to be gained from an increase in our knowledge of the sea have been pointed out by many people in these hearings and elsewhere. I would add my voice to theirs in asking that urgent consideration be given to this bill for increased support of basic research in the marine sciences.

\section{APPENDIX}

(The following material was subsequently received for the record:)

TABLE 1.-Bureau of Commercial Fisheries research contracts either negotiated or in effect in fiscal year 1960

\begin{tabular}{|c|c|c|}
\hline Contractor & Brief description of work & Amount \\
\hline National Fisheries Institute. & Research program to improve quality of fishery products.- & $\$ 55,000$ \\
\hline $\begin{array}{l}\text { University of Washington, Fish- } \\
\text { ery Research Institute. }\end{array}$ & $\begin{array}{l}\text { Effects of logging on productivity of pink salmon streams } \\
\text { in Alaska. }\end{array}$ & $47 ; 800$ \\
\hline Do & Salmon tagging off west coast of Prince of Wales Island & 12,500 \\
\hline Do... & Salmon tagging in Cook Inlet and Prince William Sound.- & 12,500 \\
\hline Do_ & Tagging salmon in offshore waters of north Pacific & 256,000 \\
\hline Do. & Analysis of past Alaskan fishery research data & 5,600 \\
\hline Do. & Observation of red salmon in the Kuichaic River system.. & 46,700 \\
\hline 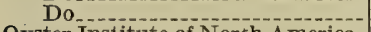 & Study of red salmon in Nushagak River & 20,000 \\
\hline Oyster Institute of No & Biological research on Atlantic blue crab & 25,250 \\
\hline University of Souther & Study of king crab in Cook Inlet Area, Alaska & 18,709 \\
\hline University of Delaware & The assay of fish products for poultry diets......... & 5,000 \\
\hline $\begin{array}{l}\text { Alaska Department of Fish and } \\
\text { Game. }\end{array}$ & Investigation of removal of salmon predators & 18,400 \\
\hline University of Minnesota....... & Determination of structure and analysis of acids in fish & 15,200 \\
\hline Barkley and Dex & Automatic bone inspection in fish fillets. & 22,689 \\
\hline Philip R. Park & Study on methods of handling and freezing fish at sea & 17,000 \\
\hline University of Conn & $\begin{array}{l}\text { Determination of the metabolizable energy and digestibil- } \\
\text { ity of fish meals. }\end{array}$ & 11,800 \\
\hline University & Study of the eggs and larvae of pink shrimp & \\
\hline & $\begin{array}{l}\text { Economic study of the factors that affect demand for cod } \\
\text { and haddock. }\end{array}$ & 19,00 \\
\hline University & Statistical reasrch on fur seal populations & 2,725 \\
\hline University o & $\begin{array}{l}\text { Study of disease-causing organisms and pathology of east- } \\
\text { ern Amercian oyster. }\end{array}$ & 1,7 \\
\hline University & Economic study of shrimp industry & \\
\hline Texas A. and M. Foundatic & $\begin{array}{l}\text { Hydrological studies for the Corps of Engineers proposed } \\
\text { Mississippi River-gulf project. }\end{array}$ & 80 \\
\hline $\begin{array}{l}\text { Rutgers University } \\
\text { University of Minnesota..-. }\end{array}$ & $\begin{array}{l}\text { Study of oyster mortality } \\
\text { Odor and nutritional studies on fish oils }\end{array}$ & $\begin{array}{r}9,000 \\
28,500\end{array}$ \\
\hline
\end{tabular}


Table 1.-Burcan of Commereial Fisheries research contracts rither negotiated or in effect in fiscal year 1960-Continued

\begin{tabular}{|c|c|c|}
\hline Contractor & Brief deseription of work & Amount \\
\hline Duke University & Biological research on Atlantic blue crab & $\$ 18,000$ \\
\hline $\begin{array}{l}\text { University of Wash } \\
\mathrm{F} \text {. Mansficld \& Son }\end{array}$ & Survival of salmon released by Spring Creek Hatchery & 10,000 \\
\hline F. Mansficld \& Sons ....... & $\begin{array}{l}\text { Commercial-seale test of proposed methods for control of } \\
\text { oyster drills. }\end{array}$ & 4,600 \\
\hline $\begin{array}{l}\text { Alaska Department of Fish and } \\
\text { Game. }\end{array}$ & Investigation of growth rates of king crab, Kodiak area... & 5,000 \\
\hline Gulf Coast Research Laboratory - - & $\begin{array}{l}\text { Biologieal study of Gulf of Mexico menhaden to identify } \\
\text { population units. }\end{array}$ & 33,000 \\
\hline Oregon Fish Commission & Columbia River fisheries & $\begin{array}{r}40,000 \\
2000000\end{array}$ \\
\hline $\begin{array}{l}\text { Scripps Institution of Oceanog- } \\
\text { raphy }\end{array}$ & $\begin{array}{l}\text { Oceanographic and climatic influences on distribution and } \\
\text { behavior of tunas, eastern tropical P'acific. }\end{array}$ & 200,000 \\
\hline $\begin{array}{l}\text { Woods Hole Occanographic Insti- } \\
\text { tution. }\end{array}$ & $\begin{array}{l}\text { Oceanographic and elimatic influences on environment of } \\
\text { fish in the north Atlantic. }\end{array}$ & 40,000 \\
\hline Oyster Institute of North America- & $\begin{array}{l}\text { Study of spawning and setting of cornmercial mollusks in } \\
\text { salt water ponds. }\end{array}$ & 10,000 \\
\hline $\begin{array}{l}\text { University } \\
\text { Virginia F }\end{array}$ & Functional morphology of shellfish drills & 11,000 \\
\hline & Study of oy: & 10,000 \\
\hline $\begin{array}{l}\text { University of Washington, School } \\
\text { of Fisheries. }\end{array}$ & $\begin{array}{l}\text { Study of king crab populations, Kokiak and A laska Penin- } \\
\text { sula areas. }\end{array}$ & 3,500 \\
\hline \multicolumn{3}{|l|}{ TECHNOLOSY } \\
\hline Truesdail Laboratories & Tuna flesh compositio & 5,000 \\
\hline & tion of fish meal & \\
\hline & Oxidation of fish oils & $\begin{array}{r}23,692 \\
5,00\end{array}$ \\
\hline $\begin{array}{l}\text { Univ } \\
\text { Sam. }\end{array}$ & Unknown growth factors in fish meals. & \\
\hline $\begin{array}{l}\text { Sam John } \\
\text { Hormel I }\end{array}$ & $\begin{array}{l}\text { Herring filleting studies } \\
\text { Fatty acid structure studies. }\end{array}$ & $\begin{array}{r}8,300 \\
13,900\end{array}$ \\
\hline $\begin{array}{l}\text { Hormel I } \\
\text { Do }\end{array}$ & $\begin{array}{l}\text { Fatty acid structure studies } \\
\text { Odor-protein studies }\end{array}$ & 13,900 \\
\hline Do Dinnesota School of Mines & Chemical reactions of fatty acids & 7,000 \\
\hline Minnesota School of Mines. & Ore-flotation studies using fish oils.... & 15,055 \\
\hline & & $1,285,472$ \\
\hline
\end{tabular}

U.S. Department of the Interior, Fish and Wildlife Service, Bureau of Commerciat Fisheries

[AFAC, 10th meeting, Old Point Comfort, Va., Oct. 7-9, 1959]

TABLE 9.-Contracts negotiated with saltonstall-Kennedy Act funds, fiscal years 1955-60

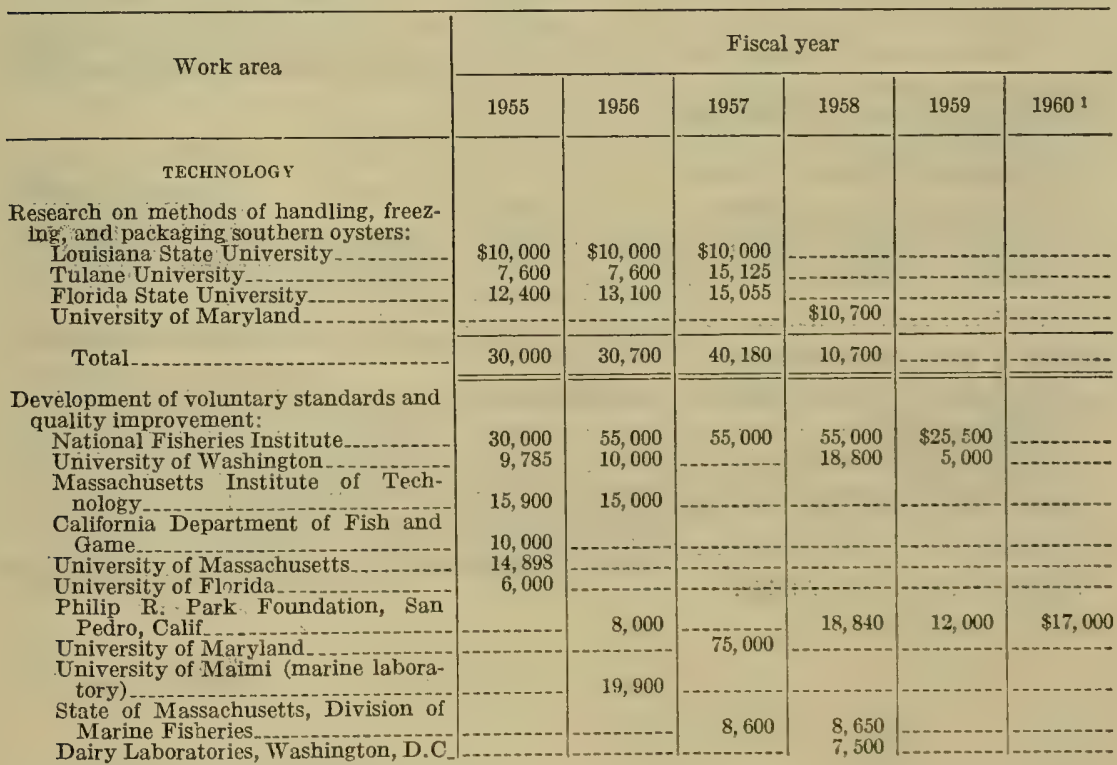

See footnotes at end of table. 
TABLE 9.-Contracts negotiated with Saltonstall-Kennedy Act funds, fiscal years 195.5-60-Continued

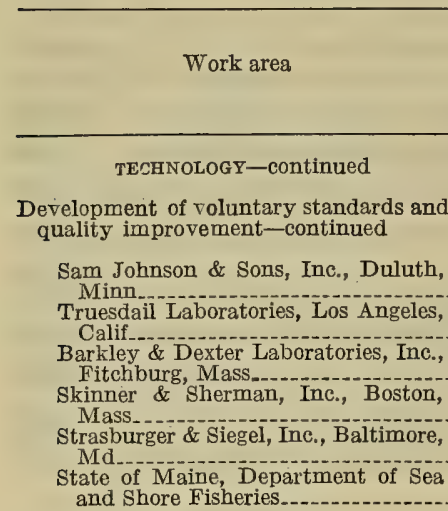

Total.

Quality index for fish meal and new uses for fish oils:

Maryland State College

University of Minnesota

North Carolina State University.---

Texas A. \& M

Uni

Floride Southern College

University of Connecticut

University of Southern California

Oregon State Colle:e

Arthur D. Little Co., Boston, Mass

Reedville Oil \& Guano Co., Reedville, Va

University of California.

University of Wisconsin ---

Alaska Fisheries Experimental Commission.

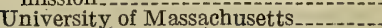

PML Laboratories, Sarasota, Fla

Lime Crest Research Laboratory, Newton, N.J

Total.

Radiation preservation:

University of Maryland (Maryland State College)

Oregon State College.

Massachusetts Institute of Technology

Food, Chemical, and Research Laboratory, Seattle, Wash.

Florida State University

University of California

Total.

Exploratory fishing and gear research Gulf Marine Ways, Pascagoula, Miss. Steam Ways Corp., Tampa, Fla_...Vessel charter, Maine.

Vessel charter, Fla

Vessel charter, Gulf of Mexi-.......

Dwight Simpson Co., Boston, Mass.-

Ebasco Services, Inc., New York City

Total.

See footnotes at end of table.

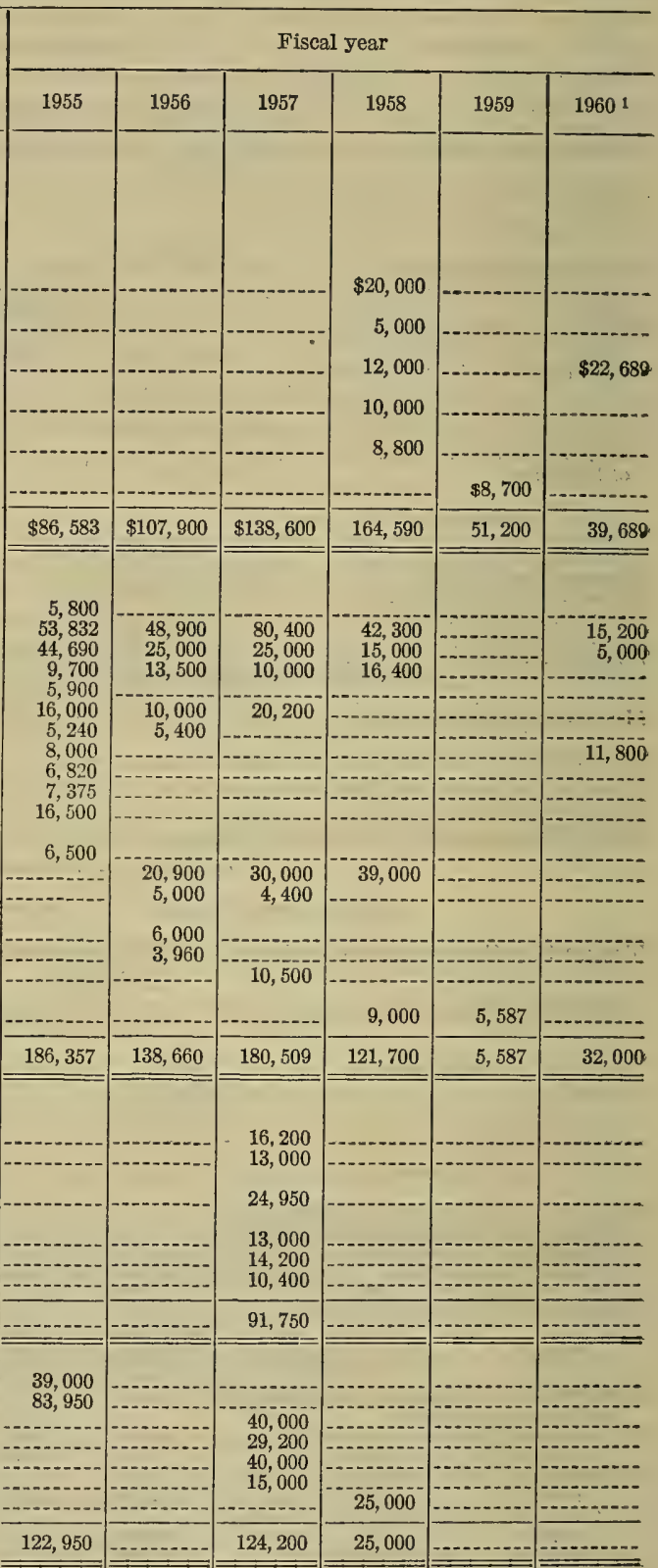


TABLe 9.-Contracts negotiated with Sallonstall-Kennerly Act funds, fiscal years 1955-60-Continued

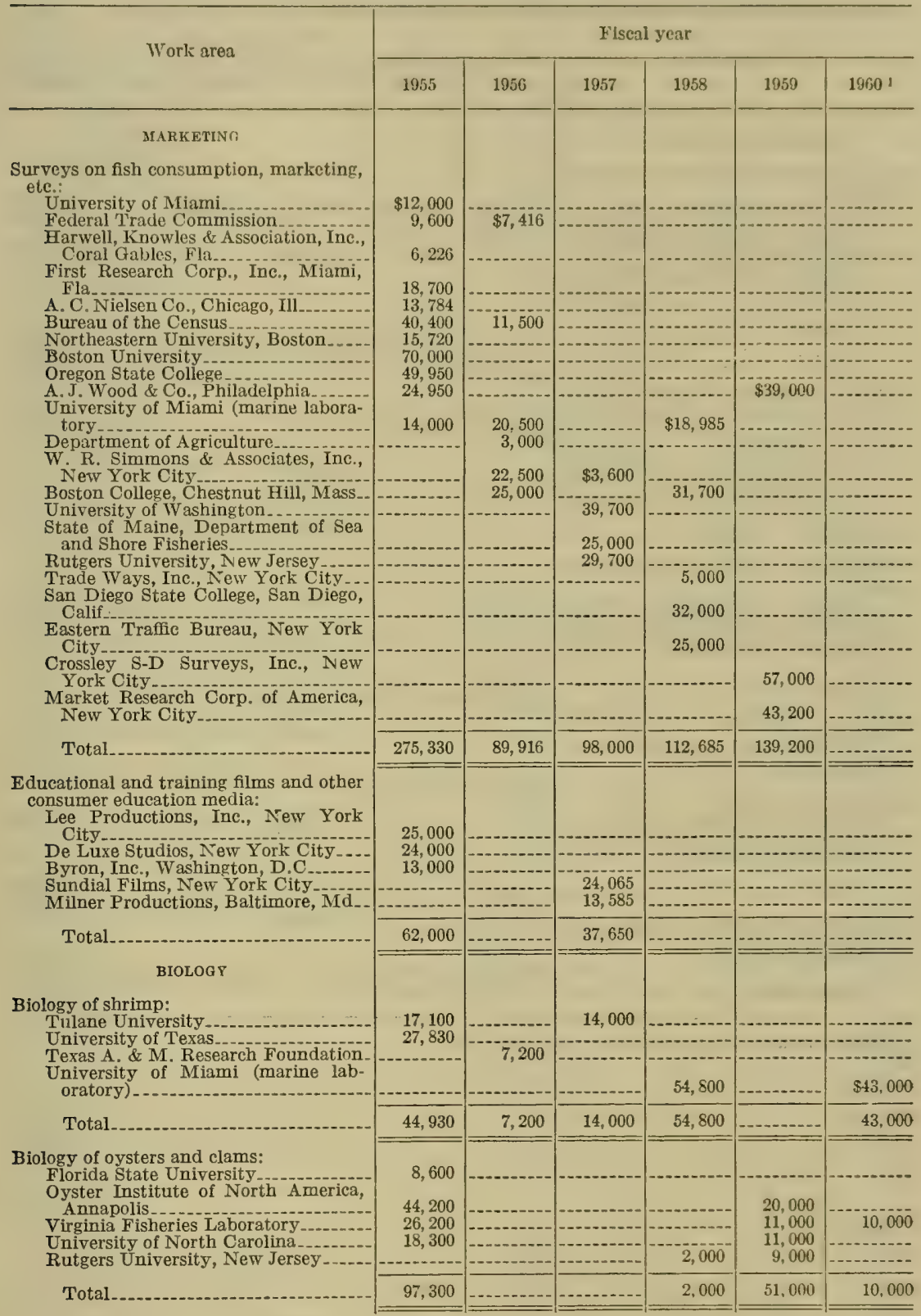

\section{See footnotes at end of table.}


TABLE 9.-Contracts negotiated with Saltonstall-Kenned $\xi^{5}$ Act funds, fiscal years 1955-60-Continued

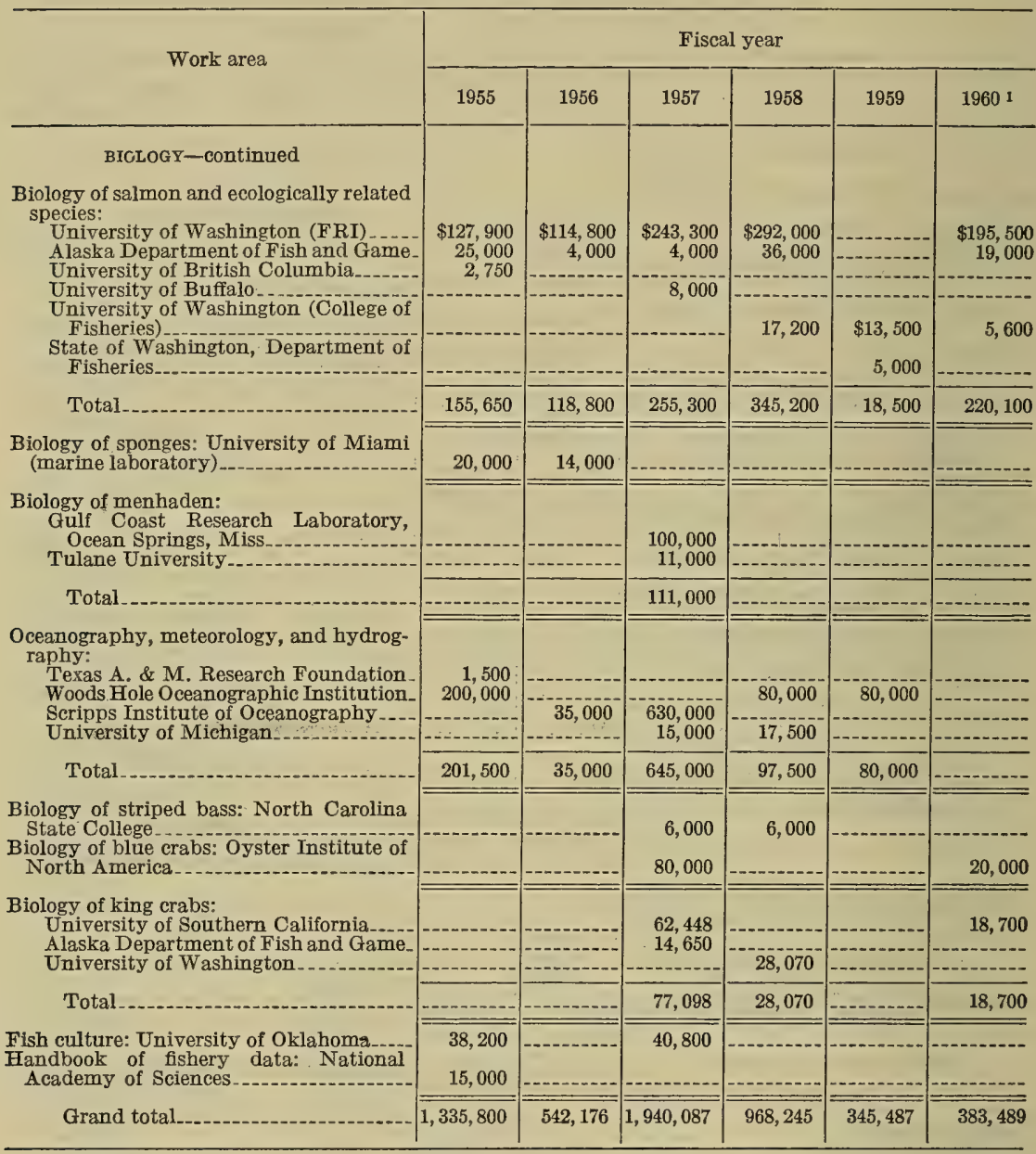

1 Other contracts may be awarded for fiscal year 1960 . 
TABLE 12.-Contracts utilining Saltonstall-Kcnnody Act funds, fiscal years 1955-60 (analysis by contracting organization and location)

The total value of contracts for 6 years amounts to $\$ 5,515,284$ involved in 218 contracts with 82 organizations.

Of these 82 organizations:

36 are colleges and universities located as follows:
1 -British Columbia
4-California
1-Connecticut
1-Delaware
4 - Florida
2-Louisiana
2-Maryland.
5-Massachusetts
1 -Michigan
1-Mississippl
1-New Jersey
1-New York
1-Ohlo
1-Oklahoma
1 -Oregon
2 - Texas
2-Washington
1 -Wisconsin
7 are State agencies located as follows: 1 -Massachusetts
1-California
1 -Maine
1-Virginia
1-Washington

4 are Federal ageincies in Washington, D.C.

35 are private organizations and industry associations located as follows:
2-California
3-Washington, D.C
5 - Florida
1 -Illinois
1-Maine
3-Maryland
5-Massachusetts

$$
\begin{aligned}
& \text { 1-Minnesota } \\
& \text { - Mississippi } \\
& \text { 9-New York } \\
& \text { 1-Pennsylvania } \\
& \text { 1-Virginia } \\
& \text { 1-Washington }
\end{aligned}
$$

COLLEGES AND UNIVERSITIES

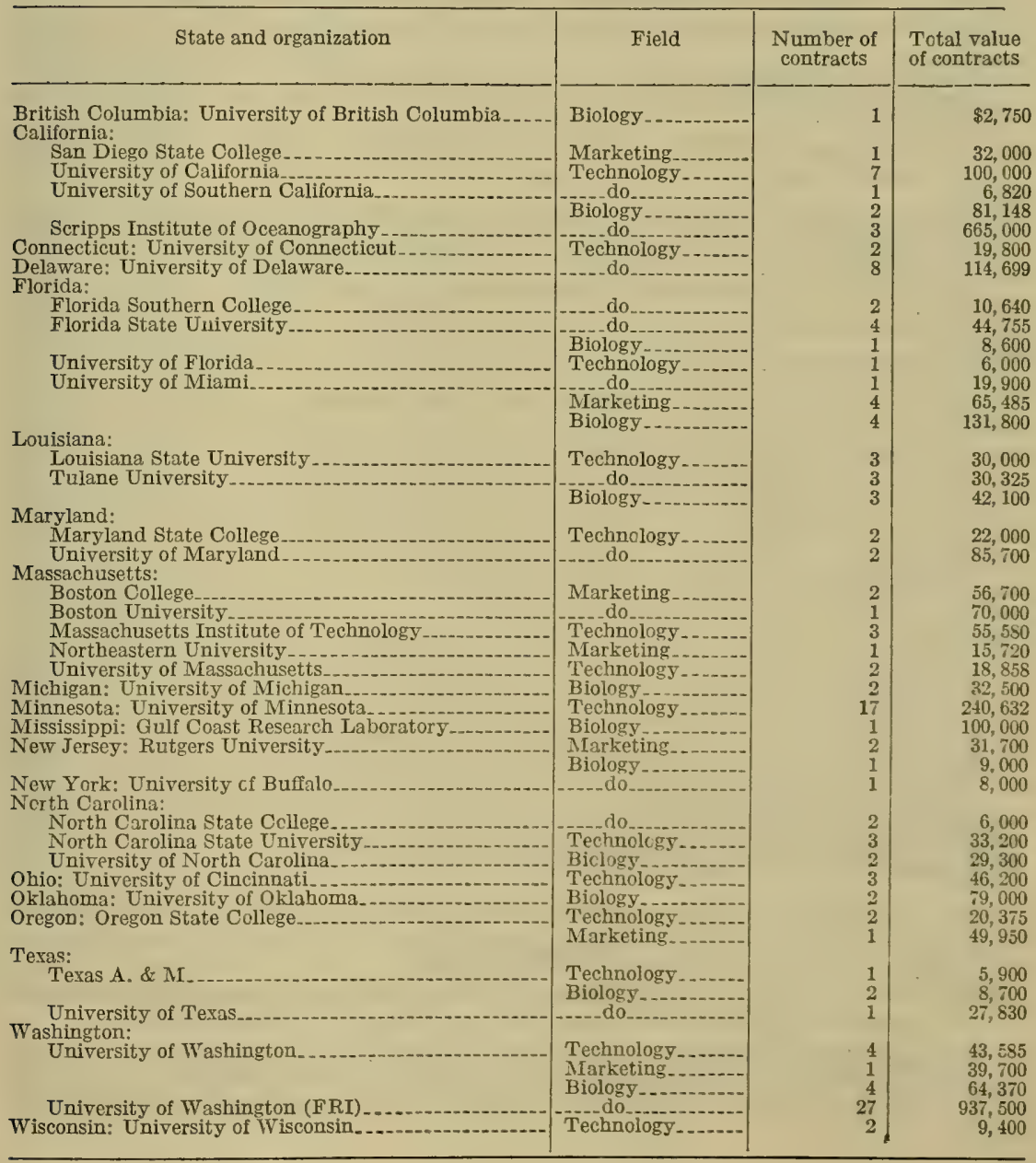


TABLE 12.-Contracts utilizing Saltonstall-Kennedy Act funds, fiscal years 1955-60 (analysis by contracting organization and location)-Continued

\section{STATE AGENCIES}

\begin{tabular}{|c|c|c|c|}
\hline State and organization & Field & $\begin{array}{l}\text { Number of } \\
\text { contracts }\end{array}$ & $\begin{array}{l}\text { Total value } \\
\text { of contracts }\end{array}$ \\
\hline $\begin{array}{l}\text { Alaska: } \\
\quad \text { Alaska Fisheries Experimental Commission. } \\
\quad \text { Department of Fish and Game } \\
\text { California Department of Fish and Game } \\
\text { Maine Department of Sea and Shore Fisheries. } \\
\text { Massachusetts Division of Marine Fisheries } \\
\text { Virginia Fisheries Laboratory } \\
\text { Washington Department of Fisheries }\end{array}$ & 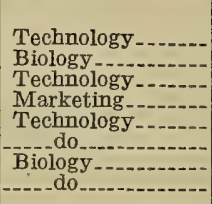 & \begin{tabular}{l|l}
1 & \\
6 & \\
1 & \\
1 & 1 \\
2 & \\
3 & \\
1 &
\end{tabular} & $\begin{array}{r}\$ 6,000 \\
102,650 \\
10,000 \\
25,000 \\
8,700 \\
17,250 \\
47,200 \\
5,000\end{array}$ \\
\hline
\end{tabular}

FEDERAL AGENCIES

\begin{tabular}{|c|c|c|c|}
\hline $\begin{array}{l}\text { Washington, D.C.: } \\
\text { Department of Agriculture } \\
\text { Bureau of the Census } \\
\text { Federal Trade Commission } \\
\text { National Academy of Sciences. }\end{array}$ & 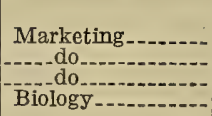 & $\begin{array}{l}1 \\
2 \\
2 \\
1\end{array}$ & $\begin{array}{l}\$ 3,000 \\
51,900 \\
17,016 \\
15,000\end{array}$ \\
\hline
\end{tabular}

\section{PRIVATE ORGANIZATIONS AND INDUSTRY ASSOCIATIONS}

California:

Philip R. Park Foundation

Truesdail Laboratories.

District of Columbia:

Byron, Ine

National Fisheries Institute

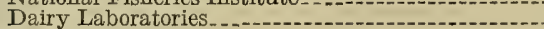

Florida:

First Research Corp

Harwell, Knowles \& Associates.

PML Laboratories

Steam Ways Corp.

Illinois: A. C. Nielsen Co

Maryland:

Milner Productions

Oyster Institute of North America

Strasburger \& Siegel

Massachusetts:

Arthur D. Little Co.

Dwight Simpson Co

nographic Institution

Skinner \& Sherman, Inc.

Mississippi:

Gulf Marine Ways

Vessel Silver Bay

New Jersey: Lime Crest Research Laboratory......

New York:

Deluxe Studios

Ebasco Services.

Iee Productions, Ine--at

Sundial Films

W. R. Simmons \& Associates

Eastern Traffic Bureau.

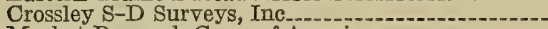

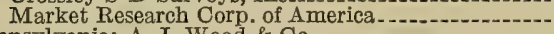

Virginic: Reedville Oil \& Guano Co

Washington: Food Chemistry and Research Laboratories.

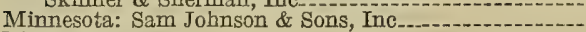

Trade Ways, Ine

Pennsylvania: A. J. Wood \& Co

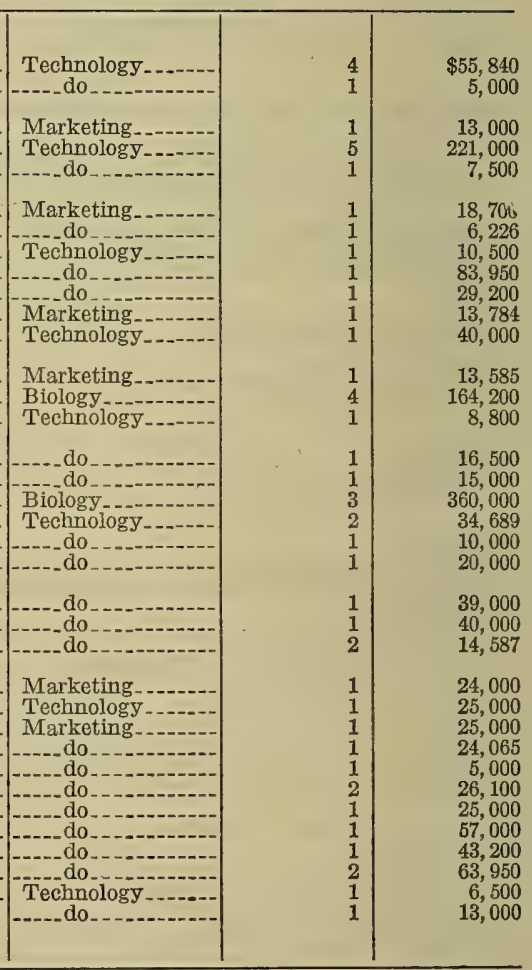

\section{RESOLUTIONS}

Resolutions adopted by the Sixth annual Eastern Pacific Oceanio Conference, Held at Lake ArRow Head, Calif., December 9-11, 1959

Whereas Senate Resolution 136 has endorsed the report of the National Academy of Sciences' Committee on Oceanography and the TENOC plan of the U.S. Navy and whereas Senate bill 2692 has been introduced to authorize in- 
creased Federal support of resenrch in the marine sciences, and whereas the Subcommittee on Oceanography of the House of Representatives has held and published hearings on the desirability for Federal action: Now be it

Resolved, That the Eastern Pacific Oceanic Conference, recognizing the need for increased research in both civilian and military aspects of the marine sciences, notes with great interest and pleasure the legislative activity toward providing increased Federal support for research in the marine sciences.

Resolution Adopted by tre Stxtit annual Eastern pacific Oceanic Conference, Held at Lake Arrow itead, Calif., December 9-11, 19:59

Whereas Senate bill 2692 provides for the establishment of a National Oceanographic Data Center, and whereas the Coordinating Committee on Oceanography has initiated action leading to the establishment of such a center: Now, therefore, be it

Resolved, That the Eastern Pacific Oceanic Conference renews its expression of need for a facility for the centralization and dissemination of ciata from the oceans and recommends the creation of a National Oceanographic Data Center to be established, supported, and operated jointly by the appropriate Gorernment agencies ;

And that a continuing advisory panel composed of members from both governmental and other oceanographic activities be established to set the policies for its operation. The center should be so organized and conducted as to serve adequately all public needs, civilian governmental, nongorernmental, and military, for access to ocean data;

And that the existing World Data Center (A) (Oceanography) should continue its activities for the present. The question of international archives and of international exchange of data should be reviewed.

Resolution Adopted by the American Legion at its 41st Annual National Convention in Minneapolis-St. PaUl, Minn., AUgUSt 25-27, 1959

\section{RESOLUTION 604-OCEANOGRAPHIC RESEARCH}

Whereas the knowledge of the scientific phenomena related to the world's oceans at present is extremely meager compared to their paramount importance; and

Whereas the world's oceans cover three-fourths of the earth's surface and are daily increasing in importance to the destiny of the free world; and

Whereas increased utilization of marine resources proride a promising food potential in the face of the explosive increases of the Torld's population; and

Whereas the world's oceans provide a future scurce of atomic fuel, mineral resources, and fresh water supply; and

Whereas there is an increased mutual interdependence of the nations of the free world for nonindigenous strategic materials in riew of expanding technological applications ; and

Whereas the United States and the free world depend for sea lift of 99 percent of all materials exported; and

Whereas the United tSates depends largely upon utilization of the world's oceans by its naval forces for its capability to cope with limited war and international crises all over the world ; and

Whereas the threat of enemy submarine launched missile attack against the United States is now a reality; and

Whereas there is an urgent need to provide a comprehensive long-range program for oceanographic research embodying an accelerated increase in oceanographic research and survey ships, laboratories, schools and scientific personnel: now, therefore, be it

Resolved, That the American Legion National Convention, assembled in Minneapolis, Minn., August 24-27, 1959, endorses the overall 10-5ear plan for oceanographic research as outlined in the report of the Committee on Oceanography of the National Academy of Sciences and the U.S. Nary. 
Resolution Adopted by the Veterans of Foreign Wars of the United States at its 60th National Convention, Held in Los Angeles, Calif., August 30 SEPTEMBER 4, 1959.

\section{RESOLUTION NO. 235-ENDORSING OCEANOGRAPHIC RESEARCH}

Whereas the knowledge of the scientific phenomena related to the world's oceans at present is extermely meager compared to their paramount importance; and

Whereas the world's oceans cover three-fourths of the earth's surface and are daily increasing in importance to the destiny of the free world; and

Whereas increased utilization of marine resources provide a promising food potential in the face of the explosive increases of the world's population; and

Whereas the world's oceans provide a future source of atomic fuel, mineral resources, and fresh water supply ; and

Whereas there is an increased mutual interdependence of the nations of the free world for nonindigenous strategic materials in view of expanding technological applications; and

Whereas the United. States and the free world depend for sea lift of 99 percent of all materials 'exported; and

Whereas the United States depends largely upon utilization of the world's oceans by its naval forces for its capability to cope with limited war and international crises all over the world; and

Whereas the threat of enemy submarine launched missile attack against the United States is now a reality ; and

Whereas there is an urgent need to provide a comprehensive long-range program for oceanographic research embodying an accelerated increase in oceanographic research and survey ships, laboratories, schools, and scientific personnel: Now, therefore, be it

Resolved by the 60th National Convention of the Veterans of Foreign Wars of the United States, That we strongly and wholeheartedly support the overall 10year plan for oceanographic research as outlined in the Report of the Committee of Oceanography of the National Acadmy of Sciences and the U.S. Navy's TENOC (Ten Years of Oceanographic Progress, prepared by the Office of Naval Research and the Chief of Naval Operations) ; and be it further

Resolved, that the 60 th National Convention of the Veterans of Foreign Wars of the United States express approval of the interest and leadership manifested by the President and Congress of the United States and the National Scientific Committee in the urgency of this field of scientific study.

Approved by the 60th National Convention, Veterans of Foreign Wars of the United States., Los Angeles, Calif., August, 30-September 4, 1959.

Resolution Adopted by the District of Columbia Federation of Women's CluBS, JANUARY 25, 1960

\section{INCREASED MARINE RESEARCH}

The sea has always mystified and amazed us. We have delighted in its changing moods, in the delicacies that it provides for our tables-succulent fish, shellfish, mollusks. We in the United States have basked in the protection provided by great bodies of water on all our borders. For some years now, however, we have noticed that something unpleasant is happening to these waters-our oceans, bays, estuaries, and our Great Lakes. Be it resolved, That-

Whereas many of our table delicacies, our oysters in particular, but also other sea life, are being killer or contaminated by various pests and diseases, thereby endangering the livelihood of tens of thousands of U.S. citizens;

Whereas, due to lack of funds to enforce our off-shore boundaries limits, foreign vessels are frequently guilty of dumping oil waste and other forms of pollution into our waters, making many of our beaches unpleasant to visit and in some cases closing them; and

Whereas pollution from our own streams and rivers is also polluting some areas, causing the death of fishes and other marine life; and

Whereas severe erosion is eating away our shorelines; and

Whereas it became apparent at the first Oceanographic Congress held at the United Nations in the fall of 1959 that other nations have made great strides in 
scientific progress to unveil the secrets of the sea, even to farm the sea as an additional source of food for hungry peoples of the world ; and learn the plains, valleys, and mountains or the floor of the sea as one learus the land above water ; therefore be it

Resolved, That we encourage and support Federal and private agencies concerned with oceanography; that we support present and pending legislation on these matter's vital to our national economy and to our national security lest we lose the freedom of the seas and the vast untouched treasures, mineral, plantlife and animal life, the energy and source of fresh water to nations whose ideologies are opposed to those of the free nations.

Attest:

Mrs. T. David Gates, President. Mrs. Harvey O. Craver, Secretary.

Resolution from Committee for Researcil Plannivg of the Atlantic Estuarine Resenrit Society to tire Commitee on Interstate and Foreign Commerce of tire United States Senate Conceining Senate Bili. 2692, "MArine Sciences and Research ACT of 1959"

Whereas man has been interested in the open seas and the coastal waters for centuries, utilizing them as sources of food, routes of commerce, and arenas of warfare; and

Whereas there has developed an increasing realization that man, although he has learned much, must continue to acquire information about the oceans and coastal regions at a much greater rate if he is to promote commerce and narigation, expand aquatic resources, and enhance the general national welfare: Therefore be it

Resolver, That the National Academy of Sciences-National Research Council, and President Detler Bronk, be commended for their foresight and interest in the formation of a Committee on Oceanography ; and be it further

Resolved, That the Committee on Oceanography of the National Academy of Sciences-National Research Council, under the chairmanship of Dr. Harrison Brown, be commended for their labors and devotion to the future of the science of oceanography that resulted in the report entitled "Oceanography, 1960 to $1970 "$ " and be it further

Resolved, That Hon. Warren G. Magnuson and his associates be commencled for introducing Senate bill 2692, "Marine Sciences and Research Act of 1959," into the U.S. Senate of the 86th Congress; and be it further

Resolved, That the Atlantic Estuarine Research Society, whose purpose is to encourage and develop research in the biological and physical aspects of estuaries, support the National Academy of Sciences-National Research Council report entitled "Oceanography, 1960 to 1970 " ; and be it further

Resolved, That all persons interested in and concerned with the evaluation and passage of Senate bill 2692 consider the following points :

(1) It is recommended that representatires from the National Science Foundation be consulted to determine what the enactment of Senate bill 2692 in its mresent form would mean to the National Science Foundation with respect to the establishment of a Division of Marine Sciences ;

(2) It is recommended that should a Division of Marine Sciences be established within the National Science Foundation, the membership of said Division should not be restricted to scientists from universities or institutions receiving assistance from the Office of Naval Research, the Hydrographic Office, the Coast and Geodetic Surrey, the Bureau of Commercial Fisheries, the Atomic Energy Commission, and the Maritime Commission, but should be chosen, regardless of institutional affiliation, on the basis of the merits of the inclividual scientist;

(3) The biological, chemical, geological, and physical aspects of estuarine and other inshore areas should receive at least as much emphasis as those aspects of the high seas, since the coastal and estuarine areas which lie closest to the centers of population are of great importance in terms of national defense and are and will probably continue to be the areas of greatest food and other resource production;

(4) In keeping with this, planning and funds should be deroted to the construction or support for the construction of research ressels capable of working in coastal and estuarine areas, and these ressels should be equipped to do adequate biological, chemical, geological, and physical inrestigations com- 
mensurate with research problems being carried out in these coastal and estuarine areas ;

(5) Sufficient support should be given to those existing organizations planning new or additional shore installations so that the various aspects of oceanography, including the biology, chemistry, geology, and physics of both the offshore and inshore areas can be incorporated in the plans prior to construction;

(6) The allotments of money for basic research in the various phases of oceanography are too small and it is recommended that the National Science Foundation be authorized to appropriate $\$ 100$ million (not to exceed $\$ 20$ million in any one year) for basic research in the various phases of oceanography, including biology, chemistry, geology, and physics, exclusive of construction and operational costs for vessels and shore facilites, and it is further recommended that in such authorization due consideration be given to biological oceanography because of the complexities and interdependence of ecological and physiological systems, and it is further recommended that research grants must be obtained on the scientific merit of the proposed programs ;

(7) In keeping with the need for increased basic research, funds should be increased to $\$ 400,000$ per annum or a larger proportion specified for fellowships, grants, etc., for the encouragement and development of students desiring to become oceanographers and definite proportions of these funds should be set up for the various aspects of oceanography ;

(8) There is insufficient emphasis on studies to determine the effects of atomic radiations on the genetics and somatic characteristics of marine organisms, and therefore it is recommended that the expenditures by the Atomic Energy Commission be increased to $\$ 1$ million per annum to study the normal genetics of marine organisms and to determine the genetic and somatic effects of atomic radiation on these marine organisms ;

(9) The areas and problems involved are so complex and the absolute necessity for an adequate understanding is so great that it is strongly urged that adequate authorizing legislation be framed and passed at once ; and

(10) Since the scientific work recommended by the Committee on Oceanography, the Atlantic Estuarine Research Society and other parties concerned is necessary and urgent it is recommended that adequate funds and the necessary executive authorization be provided to implement the authorizing legislation involved.

DeCember 15, 1969.

\section{Department of Research and Education,} Solomons, Md., May 9, 1960.

Hon. WARREN G. MagNuSON, Chairman, Committee on Interstate and Foreign Commerce, U.S. Senate, Washington D.C.

Dear Senator Magnuson: Your deep interest in wise development of our marine resources and in adequate supporting research is shown by your sponsorship of Senate bill 2692 for the advancement of the marine sciences. The marine environment must be comprehended for the future benefit of this nation and others. Since it is an enormous and complex portion of the earth, investigation must be broadly based and effectively sustained. These concepts are included in your bill, and merit adoption and facilitation.

We have received copies of some of the letters sent to you and other members of the Committee on Interstate and Foreign Commerce. They contain constructive suggestions and reflect the wide interest which exists. It seems to me, however, that the wish of the writers to suggest and discuss possible modifications may sometimes have masked their strong basic support of the purposes of the bill. As far as I can judge, every group interested in sound conservation and intelligent use of the seas wishes to have positive action taken. 
On behalf of the Chesapeake Biological Laboratory, the staff here, and many of my professional associates on the east coast, I would like to convey strong and enthusiastic endorsement of this bill and the concept upon which it is based. We urge that the bill, with such modifications as you find to be necessary, be moved through the legislative processes, enacted, and supported at the earliest possible date. Much of the welfare of the Nation will rest upon such action.

If you feel that modification of detail is desirable, we vigorously recommend to your attention the points listed in the resolution provided to your office by the Atlantic Estuarine Research Society. We believe that these suggestions are wise and would provide the strongest possible approach to accomplishment of the aims of the bill. We would be glad to provide you with additional copies of these points.

We deeply appreciate your efforts and hope that the basic concept of Senate bill 2692 will be effectuated in the near future. Please let me know if we can, in any way, assist you.

Cordially,

\section{Eugene Cronin, Director.}

Nationat Science Foundation,

OFFICE OF THE DIRECTOR,

Hon. Warren G. Magnuson,

Washington, D.O., February 8, 1960.

Chairman, Committee on Interstate and Foreign Commerce,

U.S. Senate, Washington, D.C.

Mr Dear Senator Magnuson: This is in further reply to your letter of January 22, 1960, requesting information concerning support of research in oceanography by the National Science Foundation during fiscal year 1959. For your information, there is enclosed a list of Foundation grants for research in this and related fields during fiscal year 1959.

The total breakdown as follows:

Physical oceanograph :
Research
$\$ 1,000,400$
Facilities
28,400
Total
$1,028,800$
Biological oceanography and limnology :

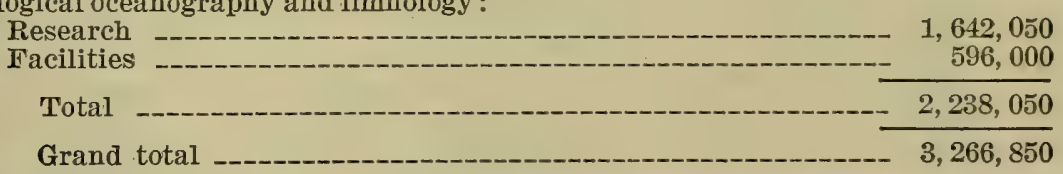

If there is any further information you need, please let us know.

Sincerely yours,

ALAN T. WATERMan, Director. 


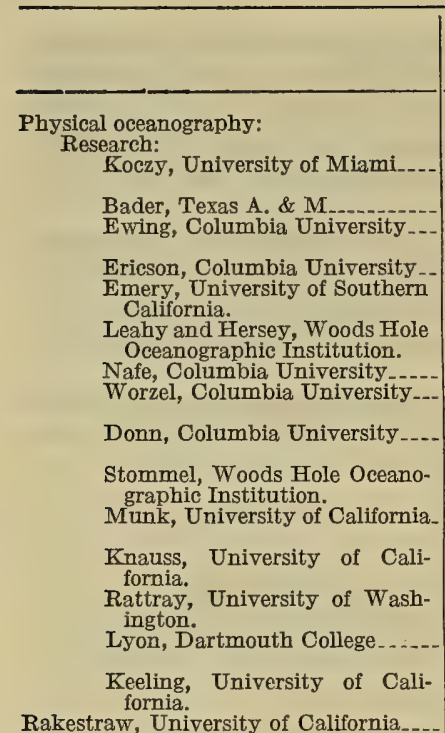

Rakestraw and Keeling, University of California.

Woodcock, Woods Hole Oceanographic Institution.

Bruun, University of FIorida.

Farmer, Woods Hole Oceanographic Institution.

Facilities:

Minot, Woods Hole Oceanographic Institution.

Shade, University of California.

Biological oceanography and limnology: Research:

Gray, Duke University

Backus, Woods Hole Oceanographic Institution.

Hartman and Barnard, Univer sity of Southern California.

Randall, University of Miami.

Shuster, University of Delaware.

Odum, University of Georgia...

Teal, University of Georgia.

Moore, University of Miami

Fleming, University of Washington.

Schevill, Woods Hole Oceanographic Institution.

Schroeder, Woods Hole Oceanographic Institution.

Burbank, Emory University.

Fager. University of California.

Meyers, University of Miami..

Benson, University of Kansas_-

Barlow, Cornell University....-

Johnson, Duke Univer sity

Waterman, Yale University....

Gray, Duke University

Sawyer, University of New Hampshire.

Mattox, University of Southern California.

deSylva, University of Delaware.

Deubler, University of North Carolina.

\begin{tabular}{l} 
Subject \\
\hline \\
Radium Distribution at Water-Seidment \\
Interface. \\
West Mississippi Delta. \\
Marine and Bottom Research in High \\
Southern Latitudes (VEMA Cruise 15). \\
Ocean Sediment Cores.-. \\
Varved Sediments in Santa Barbara Basin- \\
Geophysical Survey of North Rim, Puerto \\
Rico Trench. \\
Gravity Observations at Sea Using a Sur- \\
face Vessel. \\
Observatories at Island Stations, of Sea \\
Level and Long Period Ocean Waves. \\
Collaborative Study of Deep Ocean Cur- \\
rent Systems. \\
Wave Station on San Clemente Island-
\end{tabular}

rent systems.

A Study of Tsunami Waves.

Direct Current

Oceanographic Model Studies of Puget Sound.

A Study of the Rate of Rise of Sea Level as Measured by Radiocarbon Dating.

Meteorological Aspects of Carbon Dioxide and Its Exchange With the Ocean.

Carbon Dioxide and Its Exchange With the Ocean.

Carbon Dioxde in the Atmosphere.......

Sea-Salt Nuclei-Their Origin, PhysicalChemical Nature and Role in Atmospheric Processes.

Wind-Water Relation in Coastal Waters. Directional Spectrum of Water Waves...-

Design Concepts for Research Vessels.....

Towing Tank Reproduction of Nonuni. form Seas.

Distribution and Abundance of Fauna in Transitional Marine Environments. Composition of Oceanic Deep Scattering Layers.

Subsill Faunas of Submarine Canyons...

Ecology of Coral Reef Fishes

Effect of Environment on Shell Structure in Mollusks.

Trophic Structure and Productivity of a Salt Marsh Ecosystem.

Energy Flow of a Salt Marsh Ecosystem.

Level Sea Bottom Communities........

Zoogeography of Some Bathypelagic Species of the North Pacific.

Environmental Cetology

Biology of the Larger Pelagic Fishes of the Western Atlantic.

Ecology and Distribution of Cyathura....

Sand Bottom Communities.

Marine Yeasts of Biscayne Bay -

Paleoecology of Ostracoda in Pamalico Sound.

Respiration of Zooplankton populations

Marine Mycology _.....................

Diumal Vertical Migration by Aphotic Zone Zooplankton.

Fauna of Transitional Marine Environments.

Ecology of Pholis Gunnelis....................

Life History of the Round Stingray......

Systematics and Ecology of Eggs and Larvae of the Delaware Bay Fishes.

Biology and Ecology of Paralichthys Letho- G-8785 stigma.

\begin{tabular}{|c|c|}
\hline $\begin{array}{l}\text { Grant } \\
\text { No. }\end{array}$ & Amount \\
\hline & \\
\hline G-7280 & $\$ 12,000$ \\
\hline $\begin{array}{l}\text { G-5974 } \\
\text { G-6539 }\end{array}$ & $\begin{array}{r}16,400 \\
140,000\end{array}$ \\
\hline $\begin{array}{l}\text { G-6540 } \\
\text { G-6599 }\end{array}$ & $\begin{array}{r}26,000 \\
8,100\end{array}$ \\
\hline G-7438 & 53,700 \\
\hline $\begin{array}{l}\text { G-8221 } \\
\text { G-8866 }\end{array}$ & $\begin{array}{l}30,000 \\
63,000\end{array}$ \\
\hline G-8743 & 25,600 \\
\hline G-8189 & 290,000 \\
\hline G-8760 & 15,000 \\
\hline$G-8761$ & 50,000 \\
\hline G-6598 & 31,900 \\
\hline G-7253 & 3,000 \\
\hline$G-8748$ & 24,700 \\
\hline G-8744 & 26,900 \\
\hline$G-6542$ & 34,000 \\
\hline G-7366 & 83,100 \\
\hline $\begin{array}{l}G-6310 \\
G-6094\end{array}$ & $\begin{array}{l}43,000 \\
24,000\end{array}$ \\
\hline $\mathrm{G}-6002$ & 18,400 \\
\hline G- & 10,000 \\
\hline$G-5838$ & 24,900 \\
\hline $\mathrm{G}-5839$ & 58,100 \\
\hline G-5841 & 10,700 \\
\hline $\begin{array}{l}\mathrm{G}-5941 \\
\mathrm{G}-6154\end{array}$ & $\begin{array}{l}28,000 \\
13,000\end{array}$ \\
\hline$G-6155$ & 17,500 \\
\hline $\begin{array}{l}G-6156 \\
G-6159 \\
G-6168\end{array}$ & $\begin{array}{l}15,600 \\
41,800 \\
16,100\end{array}$ \\
\hline $\mathrm{G}-6171$ & 56,700 \\
\hline $\mathrm{G}-6172$ & 65,000 \\
\hline $\begin{array}{l}\mathrm{G}-7138 \\
\mathrm{G}-7141 \\
\mathrm{G}-7151 \\
\mathrm{G}-7152\end{array}$ & $\begin{array}{r}23,600 \\
30,700 \\
16,000 \\
9,900\end{array}$ \\
\hline $\begin{array}{l}\text { G-7154 } \\
\text { G-7178 } \\
\text { G-8638 }\end{array}$ & $\begin{array}{l}25,800 \\
16,800 \\
15,600\end{array}$ \\
\hline G-8655 & 5,000 \\
\hline G-8693 & 6,100 \\
\hline$G-8704$ & 5,200 \\
\hline G-8774 & 20,000 \\
\hline G-8785 & 21,400 \\
\hline
\end{tabular}


Biolcevical necanography and limmulugy-Contimued

Resparch-Continued

Vernterg, 1)uke University.

Koruicker, University of 'T'exas

I'urner, Woods Hole Oceanographic Institution.

Clarke, Woods IIole Oceanograplic Institution.

Reish, Long Ieach Stato Colloge.

Burkholder, Brooklyn BotanicaI Garden.

Riley, Woods Irole Occanographic Institution.

Castenholz, University of Oregon.

Hartman and Emery, University of Southern California.

Knudsen, Pacific Lutheran College.

Delinel, University of British Columbia.

Dawson, Los Angeles County Museum.

Sparling, University of British Columbia.

Rogick, College of New Rochelle

Voss, University of Miami..

Cable, Purdue Research Foundation.

Emerson, American Museum of Natural History.

Newell, American Miseum of Natural History.

Humes, Boston University...

Trainor, University of Connecticut.

Bullock, University of Now Hampshire.

Meyers, University of Miami.

Clark, Cape Haze Marine Laboratory.

Menzies, Columbia University Norris, University of Minnesota.

Gilbert, Albion College

Dawson, Beaudette Foundation.

Robins, University of Miami.-

Manter, University of Nebraska

Bigelow and Mead, Yale University.

Short, Florida State University.

Humes, Boston University.-.

Kohn, Florida State University.

Suttkus, Tulane University .... Barnard, Columbia University. Pratt, University of Florida.

Snyder and Edmondson, University of Washington.

Goreau, New York Zoological Society.

Patrick, Academy of Natural Sciences, Philadelphia

Smith, University of Michigan Silva, University of Illinois...

Self, University of Oklahoma..-

Brass, American Museum of Natural History.

Breder, American Museum of

Natural History.

Frey, Indiana University.
Comparative Ecology of 'Tropical and Iemperate Zone Fiduler Crabs.

Carbonate Sedimentation on a Living Coral Reel.

Environmental Influenees on 1Reproductive Cycles of Benthic Marine Invertebrates.

Feedine, Metabolism, and Growth of Zooplankton.

Animal Succession in Newly Developed Marine Ilarhors.

Growth Substances in Marine Organisms and in 'l'heir Habitats.

Productivity of the Benthos of Coastal Waters.

Growth of Marine Littoral Diatoms.......

Faunas of Submarine Canyons............

Ecology and Life IIistory of the Puget Sound Brachyura and Anomura.

Effect of Environmental Factors on Oxygen Consumption in Hemigrapsus sp.

The Marine Algae of Pacific Mexico.....

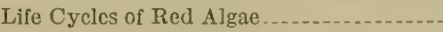

Cephalopods of the North Atlantic -

Marine Digenetic Trematodes of Puerto Rico.

Systematic Studies of Recent Mollusks....

The Living and Fossil Genera of Bivalve Mollusks.

Parasitic Copepoda of Fishes................

The Morphology of the Marine Alga Enteromorpha.

Acanthocephalan Parasites of Northern New England.

Systematic Studies of Marine Fungi......

Syngnathid Fishes of the Red Sen

Abyssal Isopods of the Atlantic Ocean.

Morphological and Cytological Studies of Red Algae.

Systematic Studies of Hawaiian Marine Algae.

The Marine Algae of Pacific Mexico.......

Monograph of the Fish Family Ophididae. Digenetic Trematodes of Fishes of Hawaii Soft-Rayed Bony Fishes of the Western North Atlantic.

Taxonomic and Life History Studies of the Dicyenid Mesozoa.

Systematics of Copepods From the West Indies.

Systematics of Indo-WVest Pacific Marine Mollusks of the Family Conidae.

Revision of the Garfishes...........

Taxonomy of Abyssal Marine Amphipods

Osmotic Properties of Marine Bacteria

Research Training Program at Friday

Harbor Marine Laboratories.

Physiology of Reef-Building Corals ........

Fresh-WVater Diatoms of the United States.

A Manual of the Fleshy Basidomycetes.

Index of Scientific Names of Algae.......

Free Amino Acid Studies of Larval and A dult Cestodes From Three Species of Catfishes.

Sixth Archbold Expedition for Biological Explorations in New Guinez.

Ecological Adjustments of a New Type of Cave Fish.

Phylogeny of Chydorid Cladocerans, and Their Use in Interpreting Lake Ontogeny.

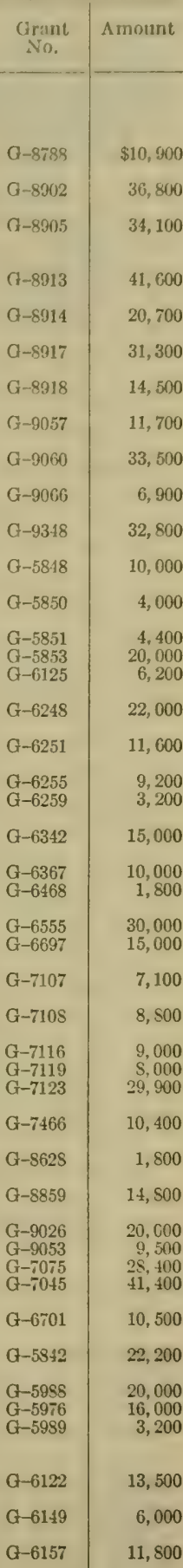




\begin{tabular}{|c|c|c|c|}
\hline & Subject & $\begin{array}{l}\text { Grant } \\
\text { No. }\end{array}$ & Amount \\
\hline \multicolumn{4}{|l|}{$\begin{array}{l}\text { Biological oceanography and lim- } \\
\text { nology-Continued } \\
\text { Research-Continued }\end{array}$} \\
\hline $\begin{array}{l}\text { Edmondson, University of } \\
\text { Washington. }\end{array}$ & $\begin{array}{l}\text { Study of Relation Between Nutrient Sup- } \\
\text { ply and Productivity in Lake Washing- } \\
\text { ton. }\end{array}$ & $G-6167$ & $\$ 42,300$ \\
\hline Byrd, University of Georgia....- & Development of Ochetosomatidae & G-6261 & 15,000 \\
\hline $\begin{array}{l}\text { Yerger, Florida State Univer- } \\
\text { sity. }\end{array}$ & Freshwater Fishes of Florida. & G- -6260 & 5,000 \\
\hline Bailey, University of Michigan- & Phylogeny of Spiny-Rayed Fishe & G-6368 & 18,000 \\
\hline $\begin{array}{l}\text { Hlungerford, University of } \\
\text { Kansas. } \\
\text { Cantino, Michigan State Uni- } \\
\text { versity. }\end{array}$ & $\begin{array}{l}\text { Monographic Study of Micronectidae of } \\
\text { the World. } \\
\text { Effect of Light on Growth, } \mathrm{CO}_{2} \text { Fixation } \\
\text { and Morphogenesis in the Water Mold, } \\
\text { Blastocladiella. }\end{array}$ & G-7493 & 20,000 \\
\hline Wood, University of Rhode & Aquatic Plant Ecology & G-8641 & 4,400 \\
\hline Verduin, Ohio State University- & $\begin{array}{l}\text { Photosynthesis and Respiration in the } \\
\text { Aquatic Environment. }\end{array}$ & G-8643 & 3,100 \\
\hline $\begin{array}{l}\text { Olive, Colorado State Univer- } \\
\text { sity. }\end{array}$ & $\begin{array}{l}\text { Vertical Migratory Rhythmicity of Micro- } \\
\text { crustaceans. }\end{array}$ & G-8646 & 5,750 \\
\hline Williams, Wabash College...--. & Cause of Loss of Pigmentation in Cave & $\mathrm{G}-8691$ & 6,500 \\
\hline Moore, Loyola University.. & enterspecific Relationships in Anostraca & G-8692 & 6,500 \\
\hline Eberly, Manchester College.... & Development of a Metalimnetic Oxygdn & G-8695 & 5,800 \\
\hline $\begin{array}{l}\text { Goldman, University of Cali- } \\
\text { fornia, Davis. }\end{array}$ & $\begin{array}{l}\text { Maximum in Lakes. } \\
\text { Basic Productivity and Limiting Factors } \\
\text { in California Lakes. }\end{array}$ & G-8901 & 23,300 \\
\hline li University & Life History and Ecology of the River & G-8909 & 13,700 \\
\hline $\begin{array}{l}\text { Parker, State College of Wash- } \\
\text { ington. }\end{array}$ & Copepod-Cladoceran Competition & G-8911 & 20,300 \\
\hline Son, Yale Univ & Paleolimn & G-8916 & 25,000 \\
\hline Brool & $\begin{array}{l}\text { Influence of Water Currents on Relative } \\
\text { Growth in Cyclomorphic Daphnia. }\end{array}$ & $\mathrm{G}-9235$ & 18,500 \\
\hline Goin, University of Florida..... & Systematics and Evolution of the Amphi- & G-8625 & 2,000 \\
\hline Herre, Stanford University & of the Genus Usnea in North & G-8645 & 5,000 \\
\hline $\begin{array}{l}\text { Thompson, University of Kan- } \\
\text { sas. }\end{array}$ & $\begin{array}{l}\text { Life History and Cytogenetics of Repre- } \\
\text { sentative Species from the Families of } \\
\text { Green Algae. }\end{array}$ & G-8697 & 12,600 \\
\hline $\begin{array}{l}\text { Conant, Zoological Society of } \\
\text { Philadelphia. }\end{array}$ & $\begin{array}{l}\text { Distribution and Speciation in the Water } \\
\text { Snakes. }\end{array}$ & G-9040 & 10,300 \\
\hline $\begin{array}{l}\text { Hungerford, University of Kan- } \\
\text { sas. }\end{array}$ & $\begin{array}{l}\text { Comparative Morphology and Taxonomy } \\
\text { of the Aquatic and Semiaquatic Hemip- } \\
\text { tera of the World. }\end{array}$ & G-9051 & 35,600 \\
\hline Young, Indiana University .... & $\begin{array}{l}\text { Taxonomic and Ecological Studies on } \\
\text { Aquatic Beetles. }\end{array}$ & G-9229 & 14,000 \\
\hline $\begin{array}{l}\text { Inger, Chicago Museum of } \\
\text { Natural History. }\end{array}$ & $\begin{array}{l}\text { Systematics and Zoogeography of the } \\
\text { Fresh-Water Fishes of North Borneo. }\end{array}$ & G-9231 & 6,800 \\
\hline $\begin{array}{l}\text { Hoar, University of British } \\
\text { Columbia. }\end{array}$ & $\begin{array}{l}\text { Osmoregulatory Function of the Thyroid } \\
\text { Gland in Flat-Fishes. }\end{array}$ & G-8502 & 7,200 \\
\hline $\begin{array}{l}\text { Gordon, University of Califor- } \\
\text { nia, Los Angeles. }\end{array}$ & Osmotic Regulation in Euryhaline Fishes_ & G-8802 & 18,600 \\
\hline $\begin{array}{l}\text { Raney, Cornell University } \ldots . . . . \\
\text { Facilities: }\end{array}$ & Research in North America Ichthyology -- & G-9038 & 13,700 \\
\hline $\begin{array}{l}\text { Armstrong, Marine Biological } \\
\text { Laboratory. }\end{array}$ & $\begin{array}{l}\text { General Support for the Marine Biological } \\
\text { Laboratory. }\end{array}$ & G-8295 & 105,000 \\
\hline Smith, University of Miami.... & Construction of Laboratory Buildings for & G-8338 & 162,500 \\
\hline $\begin{array}{l}\text { Ketchum, Woods Hole Oceano- } \\
\text { graphic Institution. } \\
\text { Bookhout, Duke University.-.- }\end{array}$ & $\begin{array}{l}\text { Ship Operations for Basic Biological } \\
\text { Oceanographic Research. } \\
\text { Expansion of Facilities for Research in } \\
\text { Marine Biology. }\end{array}$ & $\begin{array}{l}\text { G-8339 } \\
\text { G-8749 }\end{array}$ & $\begin{array}{r}250,000 \\
78,500\end{array}$ \\
\hline
\end{tabular}

Re S. 2692.

Woods Hole, Mass., November 16, 1959.

Committee on Interstate and Foreign Commerce, New Senate Office Building,

Washington, D.C.

Gentlemen: Before commenting on the proposed Marine Sciences and Research Act of 1959 I may state that I am Senior Oceanographer Emeritus of the Woods Hole Oceanographic Institution. I have served as consultant in connection with marine problems to the Bureau of Ships, Navy Department, the Beach Erosion Board and the Weather Bureau and was at one time Chairman of the panel on Oceanography of the Committee on Geophysical Sciences, Re- 
search and Development Board, Joplarment of Defense. I am also a past president of the section on Oceanography of the American Geophysical Linion and of the American Soreiefy of Jjmmology and Oceanography aud an at present chairman of the Commitee on Elucation and Recruitment of the latter organization.

I am in complete sympathy with the oljectives and general provisions of this bill. My interest is primarily in the elurational provisions becanse without the recruitment of new persomnel the full benefits of the program cannot be arieved. There is one point of another sort on which I will first comment.

Section 3 provides for the establishment of a Division of Marine Sciences in the National Science Foundation which shall include among its membership representatires of varions gorermmental agencies "and at least six scientists from the universities and institutions receiving assistance from the foregoing agencies." I believe that limitation of the civilian membership to those who are the direct beneficiaries of the act is not in the public interest and that complete freclom should be retained in selecting these representatives. I conseruently suggest that:

Iage 7 , line $1 \pm$ be altered bs inserting a period after the word "Scientist," and that the words "from the unirersities and institutions receiring assistance from the foregoing agencies." be omitted.

Section 10 (1). 18) relates to appropriations to the Department of Mealth, Elucation, and Welfare. It is the only section in which specific sums as enrisaged by the Committee on Oceanogranhy of the National Academy of Science are not stated explicitly. I beliere that the intent of Congress should be made clear by the following insertion:

Page 18, line 21 insert after "law." the sentence "Expenditures for this purpose shall not exceed $\$ 500,000$ in any one year."

The necessary recruitment of men into oceanography will require the fullest utilization of the university facilities of the country. There exist throughout the country numerous institutions deroted to aquatic science, including limnology and fisheries many of which were established before oceanography attained its present prominence. The basic training dereloped in these institutions does not differ in principle from that required by oceanographs and experience has shown that such institutions have been a raluable source of oceanographers. Oceanographers are now being recruited also from among chemists, phssicists, geologists, and others who hare had little contact with the sea, but hare had excellent training in disciplines which are essential to the subject. Such men are an inraluable source of needed talent. Frequently thes hare obtained their doctors degrees but require a year or two of study at an oceanographic institution to complete their training. Explicit prorision for postdoctoral fellowships is needed in order that this source of talent may be drawn on.

In riew of the foregoing considerations I suggest the following changes in the language of the bill :

Page 3, line 25, after "undergraduate" insert "and graduate."

Page 4, line 1, after "biology" insert "limnology, meteorology."

Page 5, lines 2 and 3 omit "oceanographic" and substitute "aquatic."

Page 9, line 2, after "students" insert "and post doctoral fellows."

Page 24, line 14, after "sciences" insert ", and of fellowships for post doctoral training."

Page 27, line 23, after "students" insert "and of post doctoral fellowships."

Page 28, line 1, after "these" insert "scholarships and."

I enclose a copy of $\mathrm{S}$. 2692 amended in accordance $\mathbf{w i t h}$ these suggestions so that they may be read in context.

Respectfully submitted.

ALFRED C. REDFIELD.

A Report by the Committee on Hrdrobiologr of the American Institute of Biological Sciences on the Magnuson Brll (S. 2692)

PREFACE

The Committee on Hydrobiologs of the American Institute of Biological Sciences, composed of representatires nominated bs sereral professional societies having a direct interest in the aquatic sciences (oceanographs and limnologs), met in Berkeley, Calif., on Januars 15 and 16,1960 , to studj and discuss the report of the Committee on Oceanographs of the National Academy of Sciences and Senate bill 2692. 
We commend the way in which the bill implements the report of the Committee on Oceanography, and strongly endorse its objectives.

Because aquatic biology is an integral and important part of aquatic science, this committee has studied with especial care those aspects of the NASCO report and of S. 2692 that pertain to biology. We have concluded that the bill would be more effective in achieving its objectives if some of its provisions were modified.

In response to your request for comments and advice concerning this bill, we herewith submit this report of our deliberations. Our recommendations relate to three general aspects of the bill; namely, the assignment of responsibilities for basic research assigned to various agencies; the education and recruitment of aquatic scientists; and the improvement and expansion of facilities for research in the aquatic sciences.

We draw attention to the fact that oceanographic problems differ only in size and salt content from those of lakes. Limnological centers and inland colleges and universities play important roles in the recruitment and training of aquatic scientists, as well as in research applicable both to oceans and lakes. We therefore use the term "aquatic science" in this report, rather than "oceanography," to emphasize the broader aspects of the scientific field and its nationwide significance.

\section{SUPPORT OF BASIC BIOLOGICAL RESEARCH}

Adequate financial support of basic research is essential to the development of the aquatic sciences. Funds for such research must therefore be available to all institutions engaged, or planning to engage, in the aquatic sciences and their supporting scientific fields such as biology, chemistry, geology, mathematics, meteorology and physics to an extent justified by the scientific merits of their programs. This committee believes that S. 2692, aiming at a considerable expansion of oceanographic and limnologic research on a national scale, provides insufficient funds to underwrite the basic biological research needed for such an effort. We recommend, therefore, that serious consideration be given to increasing significantly the amount of money authorized for research in this important aspect of aquatic science.

We also recognize that the success of the proposed expansion of aquatic science will be determined largely by the manner in which the funds for the support of basic research are administered. We therefore believe that a maximum return for the money invested can best be insured by entrusting the administration of basic research funds to those Federal agencies which now have prime responsibilities in this respect and have gained the confidence of the scientific community. Consequently, the committee feels that the major proportion of such funds should be allocated to these agencies.

For example, the National Science Foundation seems to us the most appropriate agency to administer the major share of the basic research funds. However, the sum of $\$ 37,200,000$ allocated to the NSF for basic research operations over a 10-year period is thought to be wholly inadequate to enable the Foundation effectively to support the fundamental needs of the program envisaged by S. 2692.

The committee is also convinced that the NSF, with the aid of its advisory panels, will wisely administer such funds within the framework of its present organization, and hence the creation of a separate Division of Marine Sciences should not be required by law. If such a division were established, it would probably be necessary to set up subdivisions representing the biological, chemical, physical, and earth sciences; and these would duplicate the existing administrative structure.

The Biological Sciences Division of the Office of Naval Research likewise has performed exemplary service in supporting basic research in aquatic biology, a field that obviously is of interest to the Department of the Navy. This committee therefore hopes to see more adequate reference to basic biological problems under the description of the mission of the Department of the Navy in S. 2692.

The Bureau of Commercial Fisheries of the Department of the Interior, while clearly in a position to pursue basic research and already authorized to grant contracts for this purpose, has a defined major objective in applied science. We believe it desirable to allocate funds to this agency for basic research which is directly related to their mission. However, we feel that the sum allotted by the bill to the Bureau for basic biological research is disproportionately large compared with that allocated to the NSF, the ageney responsible for the support of basic research in all areas of oceanography and limnology. 
The Atomic Wuergy Commission, to which the bill also allots funds for basic: research, has a sperial responsibility in aquatic biology, since many problems concerned with radioactive contamination are new and insufficintly understord. Hence, much of the needed research must be exploratory, and many years will be required to develop a sound basis for solving the problems we face. It seems proper, therefore, that the $\mathrm{ALC}$ arminister a share of the fumbs avalable for basic biological research, and the committee approves the corresponding provisions of the bill.

But we believe that the specific authorization for "*** two major olnen-sea tests of radiological contamination at sea, its effects on marine lif(', and its potential effects for humanity." * * * is scientifically unsoum, because the justitication for these tests on the basis of the stated biologicil purpuses is premature. The committee therefore recommends that this provision be deleted.

The committee has noted with concern that S. 2692 does not seem to recognize the fundamental role of museums as centers of taxonomic and biogcographic research, and that it mentions taxonomic studies only in connection with the Bureau of Commelcial Fisheries.

Taxonomy constitutes an indispensable basis for biological research. Sturies in this area have long been associated primarily with universits-comncted and independent museums, rather than with the Bureau of Commercial Fisherje: Special mention should be mare of the U.S. National Museum ISmilisonian Institution), an independent branch of the Federal Goverument and one of the major world institutions serving biologists engaged in taxonomic research. W'e therefore beliere that the reference to taxonomic studies exclusively in connection with the Bureau of Commercial Fisheries might unduly restrain developments in this fundamental research area, and that other institutions engiger in taxonomic research should qualify for a commensurate share of the research funds. The need for this also follows from the large adrlitional burden which the expanded activities authorized by the bill will place on musemm personnel.

The committee concur's in the sound policy that no agency should be assigned the responsibility of monitoring itself. We thus agree with the bill's lrovision which specifies that regulation and monitoring of the introduction of radinactive materials into the ocean or other waters should be carried out by appropriate agencies outside the AEC. We emphasize, however, that alherence to the principle mentioned above implies that such operations should be financed by funds allotted directly to the agencies responsible for these activities, rather than through the $\mathrm{AEC}$, as provided by the bill.

As another matter of principle, we believe that an operating arency of the Federal Govermment should not be empowered by law to give direction to another. For this reason we feel that provisions such as the incorporation of project TENOC, dereloped by the Department of the Navy, in the Irogram of the NSF should be deleted, since this directire infringes on the freedom of the Foundation to dispense Federal research funds according to its establisheil practices. Moreover, this clause is superfuous inasmuch as sections $1 \%$ and 14 of S. 2692 authorize the Department of the Navy to conduct its TENOC program, and existing law also permits the coordination between agencies that may be needed in such a long-range program.

For the same reasons we recommend deletion of section $13(f)$, lines 14 to 17 , providing that the Department of the Nary may recommend to the NSi institutions qualified to participate in the Navy-sponsored scholarship program.

An important purpose of $\mathrm{S}$. 2692 is the encouragement and support of the establishment and expansion of new and existing resenrch centers for the aquatic sciences. We agree that this is desirable, and therefore endor'se the bill's provision that especially desigued research ships be constructed as part of the developing program.

However, we believe that some of the specifications pertaining to the use of these ships are unduly restrictive. We are deepls concerned about the prorision that they be made arailable to $" * * *$ State institutious engaged to [in] oceanographic research requiring ocean-going scientific ships, with preference given to such institutions which have engaged in such research prior to this act." This proviso discriminates against private institutions as well as against institutions which have not conducted oceanograplic resealch prior to the enactment of the bill. We fear that it would have the effect of hampering one of the bill's avowed purposes, and recommend that such restrictive clauses be deleted. 


\section{EDUCATION AND RECRUITMENT}

Successful expansion of research in oceanography, as proposed in S. 2692, will depend largely on attracting talented personnel to the field. Although no panacea is in view, the provision of scholarships and fellowships will contribute to recruitment in an important way. Existing support of this type is inadequate.

To make optimum use of the educational facilities of our country, and to attract into specialized research in aquatic science highly competent people already trained in the basic natural sciences it is essential to provide also for postdoctoral fellowships. We recommend that consideration be given to the addition of such fellowships to the program proposed.

In addition to these provisions for fellowships, it is also important to assure many more career positions in the aquatic sciences than now exist. These should be established in new as well as in existing centers. We would, therefore, approve more explicit inclusion of this provision in the bill.

\section{FACILITIES}

Aquatic science is particularly dependent on facilities. In general, the facilities most urgently needed for an expanded program in aquatic science are (1) large research ships, (2) smaller research vessels, (3) ships available to smaller institutions for research and training, (4) appropriate shore facilities, and (5) equipment and devices. The committee believes that certain aspects of the bill should be strengthened with respect to these facilities.

Provisions are made for large research ships. Additional funds are also needed, but not provided, for building, outfitting, and operating smaller research vessels for offshore, inshore, estuarine, and lacustrine work. The cost of such smaller vessels is well below that of the large ships provided for, but exceeds the amounts generally available in grants or contracts from existing sources. Therefore, the committee deems it desirable that funds for small vessels be specifically included in the program.

Cooperatively used research and training ships which would permit smaller institutions and inland colleges and universities to participate more effectively in the expanding program in aquatic science also should be specifically provided.

The committee believes that funds provided in the bill for shore facilities to support oceanographic research are unrealistically small, since laboratory space is a serious national limitation in all branches of science. There are many institutions active in aquatic sciences now which are crowded and inadequately equipped. Their needs must be met and, in addition, new centers should be established. In this connection it should be emphasized that shore facilities include basic research laboratories as well as those special facilities needed in support of research vessels. This is implicit in the bill as written, but would clearly benefit from more explicit statements.

Respectfully submitted.

ROBERT W. HIATT,

Chairman, Committee on Hydrobiology, American Institute of Biological Sciences.

AIBS Committee on Hydrobiology :

Theodore H. Bullock, University of California.

Arthur D. Hasler, University of Wisconsin.

Robert W. Hiatt, University of Hawaii.

Bostwick H. Ketchum, Woods Hole Oceanographic Institution.

Charles E. Lane, University of Miami Marine Laboratory.

Dixie Lee Ray, University of Washington.

William E. Schevill, Woods Hole Oceanographic Institution.

Cornelis B. van Niel, Stanford University.

Talbot $\mathrm{H}$. Waterman, Yale University.

UNIVERSITY OF HAWAII, Honolulu, Hawaii, April 18, 1960.

Hon. Senator WarRen G. Magnuson, Chairman, Committee on Interstate and Foreign Commerce:

The Committee on Hydrobiology of the American Institute of Biological Sciences met in San Francisco on April 13 and 14 to discuss further S. 2692 and the many comments received on our report to you concerning recommendations for modifying certain provisions of the bill to make it more effective in achieving 
its objectives. Because of the hearings scheduled on this bill before your committee on April 20 and 21, we should like to reaffirm our original report, and request that it be read into the minutes of the committee meeting. Furthermore, we request that Dr. Bostwick $\mathrm{H}$. Ketchum, Woods Hole Oceanographic Institution, be invited to appear at your committee hearings to present testimony on behalf of this AIBS committee.

We wish to stress particularly our opinions concerning the support of basic biological research in oceanography, as well as our stand on the specific authorization for two major open-sea tests of radiological contamination at sea.

With respect to the support of basic biological research in oceanography we stand firm in our belief that those Federal agencies now having the prime responsibilities for providing basic research funds to the nation's scientists in this broad field are adequate, and suitable. Moreover, they have the full confidence of the scientific community. However, they will need much larger budgets to expand such research significantly. We believe, also, that the Bureau of Commercial Fisheries should suport much more research of a basic nature, especially within its own organization, to carry out effectively its mission of developing and conserving the nation's renewable aquatic natural resources.

To accomplish the Bureau's objectives substantially more funds than they now reecive must be made availabel to it, but the recommended allotment of funds in S. 2692 to this agency and to the National Science Foundation, the agency which should administer the major share of basic research funds in all fields of oceanography, is disproportionate. We do not imply that the allotment specified for the Bureau is necessarily too large, for this amount will have to be adjudicated in relation to their mission established by law; but we believe that the amount allotted to the National Science Foundation must proportionately be greater because of its broader responsibilities in support of basic research in all aspects of the aquatic sciences.

In regard to the proposed open-sea tests of radiological contamination we stand firmly behind our earlier opinion that the authorization of "**** two major open-sea tests of radiological contamination at sea, its effects on marine life, and its potential effects on humanity" is scientifically unsound, and that the justification for them, based on the stated biological purposes, is premature.

We take this view because it seems unwise at the present time to release large amounts of radioactive isotopes (from any source) directly into the sea, because so little data from radiological surveys of organisms from contaminated areas can be correlated with results from controlled laboratory experiments. This means that at this time there is no way to predict the minimum and maximum quantities of any radioactive element which might be accumulated by any single organism or group of organisms, notwithstanding the fact that such predictions would have to be extrapolated and the errors compounded sereral times from the lowest level of life in the sea up the food chains to reach the higher levels of life used directly by man as food.

If such open-sea tests are experimental, as we understand their implications, then the experiments must be devised to test assumption based on theoretical or experimental bases. Controlled laboratory experiments designed to elucidate the fate of radioactive substances released into marine environments hare not yet been sufficiently extensive or intensire to present satisfactory eridence upon which to carry out open-sea experiments and interpretations thereof. Sincerely yours,

ROBERT W. HIATT, Chairman, $A I B S$ Committee on Hydrobiology.

\section{AIBS Committee on Hydrobiology}

R. Bolin, Stanford University.

Theodore H. Bullock, University of California.

Arthur D. Hasler, University of Wisconsin.

J. Hedgpeth, College of Pacific.

Robert W. Hiatt, University of Hawaii.

Bostwick H. Ketchum, Woods Hole Oceanographic Institution.

Charles E. Lane, University of Miami Marine Laboratory.

Dixy Lee Ray, University of Washington.

William E. Schevill, Woods Hole Oceanographic Institution.

Cornelis B. van Niel, Stanford University.

Talbot $\mathrm{H}$. Waterman, Yale University. 


\section{DUKE UNIVERSTTY, \\ DEPARTMENT OF ZOOLOGY, I) urham, N.C., December 17, 1959.}

Commitree on Interstate and Foreigi Commerce,

New Senate Office Building, Washington, D.C:

DeAR SIRS: We appreciate being sent a copy of bill S. 2692 by Senator Magnuson and the invitation to send our comments to your committee. Oceanography is one of the major research fields that has been inadequately supported in the past and it is of the utmost importance that such research be pushed forward as rapidly as possible. In the bill the following statement appears under "Declaration of Policy," "that sound national policy requires that the United States not be excelled in the fields of oceanographic research, basic, military, or applied, by any nation which may presently or in the future threaten our general welfare, etc." It is to be regretted that oceanography, as well as other basic sciences, has to be tied into the cold war with Russia to obtain adequate suplort. If such be the case, however, the United States suffers from comparisun. Russia has more and larger oceanographic vessels than any other country in the world. From published accounts and reports the Russians gave at the September 1959 International Oceanographic Congress in New York, it can be safely stated that their research has been thorough in all phases of oceanography. They have been concerned with basic research which could have little relation to the military effort as well as with practical problems. They have made thorough surveys of large areas of the Arctic, Indian, and Pacific Oceans, and less extensive ones of the Atlantic.

Thus, it vill take the marine scientists of the United States considerable time to equal the Russians in oceanographic research productivity. To carry out the declaration of policy of the Magnuson bill, it is of the utmost importance that all marine scientists be enlisted in the Tenoc program including those from universities, state and private laboratories, as well as those from Federal laboratories.

As members of the Executive Committee of the Duke University Marine Laboratory, we are particularly concerned with the sections of the bill that include biological oceanography. Each member of the executive committee of our laboratory has studied the Magnuson bill and offered suggestions. After considerable and thoughtful discussion, those which we believe to have merit are summarized in the following paragraphs.

The Executive Committee of the Duke University Marine Laboratory, Beaufort, N.C., approves of the general philosophy of the Magnuson bill. We should like, however, to offer the following suggestions for consideration:

(1) We have the utmost confidence in the National Science Foundation and know that this agency is capable of assuming the responsibilities recommended in the bill on pages 1-8.

(2) We wish to emphasize the importance of evaluating the research work (e, p. 6) sponsored by the Office of Naval Research, National Science Foundation, the Atomic Energy Commission, and the Bureau of Commercial Fisheries in various fields of oceanography. We recommend that areas of research be assigned and money be allotted to each agency for the Tenoc program on the basis of quality of research done and competence of the scientists supported by each agency in the past.

(3) It is the policy of the Office of Naval Research, the National Science Foundation, and the Atomic Energy Commission to accept research proposals and have them evaluated wholly on the basis of scientific merit by a panel of competent scientists. If the proposal is approved, the grantee or contractor is notified promptly and money, if available, is allocated to the project. The Bureau of Commercial Fisheries, on the other hand, operates in quite a different fashion. Like the above agencies, this bureau will accept research proposals from outside scientists; however, in many cases, representatives of the Bureau of Commercial Fisheries alone decide whether or not the proposal will be considered. If an examination is made of the manner in which Saltonstall-Kennedy funds have been spent, we believe it can be shown that very few contracts were let to scientists affiliated with State or university-affiliated marine laboratories.

We propose, therefore, that provisions be made in the bill for the Bureau of Commercial Fisheries to handle research proposals in the same manner as do the Atomic Energy Commission, the National Science Foundation, and the Office of Naval Research. In short, we believe paragraph $(\mathrm{g})$ on page 10 is 
entirely too weak. It places educational institutions, private and State marine laboratories completely at the merey of the Bureau of Commercial Fisheries as they have becu when they tried to ohtain contracts under the SaltonstallKennedy Act.

(t) It is noted that the Burcau of Commercial Fisheries will handle most of the funds for biological oceanography. On page 13 it is sugigested, for example, that it be given sums of money to carry out investigitions in (c) marine population sampling, biological surveys, ecological mapping, taxonomic develonment, genetics of marine organisms and estuarine studies. We believe that these are problems in basic research, many of which can be efliciently carried out by marine biologists in private and State laboratories. Many of the scientists in these latter laboratories have a great deal of expericuce in these areas and this experience should not be wasted. Uy to now, basic studies in marine biology conducted by, or with the aid of, these investisators luave been largely supported by the National Science Foundation, and this supjort should continue. Of course, some basic research problems (such as large-scalle population sampling of oceanic fishes, for example) are jerlatls better conducted by the Bureau of Commercial Fisheries. Neverthele:s, the marine biologists in the Bureau have nu to now been more concerined with alunlich research such as pond fish culture, fisheries exploration, the utilizatiou of marine products for human and animal consumption, etc.

Therefore, we suggest that the bill be altered to make certain that marine biologists in private and State laboratories be given an oplortunity to share in the basic biological research to be supported by funds of the Tenoc urogram equal to that given biologists associated with the Bureau of Commercial Fisheries. A major part of the funds allotted for basic resenrch in marine biology should, therefore, be assigned to the proplosed Division of Marine Sciences of the National Science Foundation.

(5) It is recommended that all oceanographic ressels carry scientists in biological, chemical, geological, and physical oceanography and that plans be made for each group to do its work effectively. It is necessars that the results of research by marine biologists be colrelated with the findings of the physical ocennographers, and rice versa. This bringing together of biological and physical data is of fundamental importance in understanding the complexities of the oceans.

(6) It is recommended that section 13 (c) which relates to the construction and operation of shore facilities and laboratories, should slecifs the sumprert of research in all areas of oceanography including biological, chemical, geological, and physical studies.

(7) Section $3(\mathrm{~b})$, page 7 . The last line in this section is rague. Why is the provision made that the Division of Marine Sciences shall include "at least six scientists from the universities and institutions receiving assistance from the foregoing agencies"? Why not make this just "six oceanograjhic scientists from miversities and institutions, some of whom, at least, should be marine biologists"?

We again thank jou for the opportmity to reriew the bill and hope that our proposals will be given serious consideration.

Sincerely yours,

The Executive Comarttee of the Duke

UNIVERSTT MIARINE LABORATORT,

C. G. BoокHоUт,

F. JOHN VERNBERG,

Director.

Assistant Director for Research, Duke University Marine Laboratory.

KarL M. WILBUR,

Chairman, Zoology Department.

I. I. GRAT,

Professor of Zoology.

TVANDA S. HUNTER, Associate Professor of Zoology.

H. J. Oosting,

Chairman, Botany Department.

IV. Divight Billings,

Professor of Botany.

TERry W. JoHnson, Jr.,

Associate Professor of Botany.

$55401-60-10$ 
Universtiy of Miami, The Marine Laboratory, Virginia Key, Miami, Fla., February 24, 1960.

Hon. Warren G. Magnuson, Congress of the United States, U.S. Senate, Washington, D.C.

Dear Senator Magnuson: May I express my appreciation to you for your bill on oceanography (S. 2692). I am happy to endorse the bill in its general aspects, and especially as it relates to biological oceanography and fisheries. I have noticed, however, with a good deal of surprise some of the recent criticisms, especially by biologists. I am convinced that many of them are based on a lack of understanding of the situation.

Several groups and individuals have taken an ill-informed and excessively critical position in regard to the role of the Bureau of Commercial Fisheries in basic research, following this attack by stating that the Bureau should not be entrusted with the support of such research. As you know, the committee on oceanography, including men with the highest qualifications among the various branches of science in the country, spent some 2 years evaluating the program and performance of the agencies which sponsored the study, including the Fish and Wildlife Service. Their report, on which your bill is based, implied a high degree of confidence in the quality of the work of the Bureau of Commercial Fisheries. This view is concurred in by myself and by many other persons familiar with fishery research in this country.

The critics whose opinions I have seen are in many cases unqualified to judge this matter through lack of contact with the work and of careful study of the facts. They particularly question whether the Bureau of Commercial Fisheries has carried out or has the ability to carry out, or support, basic research in the fisheries. Most scientists find it very hard to define "basic" research and even harder to draw a line between "basic" and "applied." It is, therefore, not particularly useful to argue about the Bureau of Commercial Fisheries' record in basic research, as opposed to applied but since this record has come under criticism, I will attempt to refute it by mentioning some of the activities of the Bureau which are undeniably "basic."

These include the discovery of a deep equatorial countercurrent in the Pacific (widely regarded as the most important oceanographic discovery since the war); the methods of culturing larvae of invertebrates, including mussels and clams; work on the uptake and concentration of radioactive substances by marine organisms; the distribution of salmon in the high seas; the taxonomy program of the Bureau in the Smithsonian Institution.

This does not pretend to be a complete list of even the most important programs of basic research of the Bureau, but it should serve to deny statements about the interest and skill of the Bureau in this area. Their ability to do this should be enhanced and this has already been provided for in your bill.

I am anxious also to see the Bureau of Commercial Fisheries given the authority and the proper means of supporting basic research in fisheries outside their own laboratories. They do not now have the proper authority and means. This, again, is not realized by the critics. The Saltonstall-Kennedy program is so constituted that the money can be used by the Bureau either to increase its own program, or to contract with others to do specific jobs. This creates an internal conflict in the Bureau of Commercial Fisheries which is being more and more resolved for them by the Bureau of the Budget, which substitutes SaltonstallKennedy money for regular appropriations, thereby gradually removing these special funds from their original purpose. What is needed is funds for grants for basic fisheries research.

The National Science Foundation has been suggested as the proper agency to receive all the money for research grants and contracts under the bill. NSF, as you are fully aware, has a broad responsibility to support basic research on a nationwide and sciencewide basis. NSF has, on occasion, operated in special fields on a crisis basis, but this is not their chief responsibility nor their intended role. In the long run, we cannot expect them to maintain a sustained interest at a high level of support in any special field, including oceanography.

On the other hand, the Navy has a clear mission to operate in the field of oceanography. Its activities, by necessity, are largely in the physical aspects and not in the biological and fisheries aspects. This leaves a gap which must be filled, I feel, by the Bureau of Commercial Fisheries, since here is where the responsibility for fishery research is placed in the Government complex. It is necessary, then, to give them the capability of supporting such work, in addition to their own research. 
In other flelds, this dual role, of conducting its own research and of supporting research through gramis and contracts to universities and other institutions, is being played actively and successfully by other Govermment agencies. The Navy (with a large granting unit in ONR), the National Institutes of IIealth, and the Department of Agriculture are good examples of this.

It appears important for the Nation to make more use of the many excellent fincilities for resealloh in the universities and independent laboratories. It will not be questioned, I think, that the fisheries are in great need of all the scientific assistance they can get, in addition to that supplied by the l'ederal Govermment. Furthermore, the trilining of oceanographers and fishery scientists that accompanies the research in universities, and which would be greatly strengthened by long-term support of research there, is vital to the Nation in supplying a reserve of scientific persomnel to staff the increased programs envisioned by your bill.

Section 5 of your bill gives the Bureau of Commereial Fisheries authority and direction to "make grants $* *$ * for basic and applied research programs * * *", but section 6 does not clearly follow this with authorizations of appropriations, since section 6e authorizes funds for studies "of utilization of marine products for human consumption *** etc.," while the funds for "marine population sampling, biological surreys, etc.," are given solely to supplement the Bureau of Commercial Fisheries' budget. Furthermore, the money in section 6e can, apparently, be used either by the Bureau itself or be used for grants and contracts. This opens the way to the same fatal difficulties faced by the SaltonstallKennedy program.

It is suggested that the iutent of section 5, that the Bureau of Commercial Fisheries make grants and contracts, be spelled out more clearly in section 6 . I suggest that half the sums named in sections $6 d$ and $6 e$ should be set aside for grants and contracts, the other half to be used by the Bureau to expand its own operation.

The Bureau of Commercial Fisheries would set up an office to handle grants and contracts under this system. They should, I think, also use the system employed by NSF and NIH, sending proposals to a committee (permanent or ad hoc, or a mixture) of qualified scientists outside the Government for evaluation. In this way the scientific merit of proposals would be given a harder scrutiny than they would if only Bureau personnel read them.

I have discussed these proposals with the Director and some of his staff in the Bureau of Commercial Fisheries, and have received a farorable reaction.

I would be pleased to discuss this matter further with you and I would appreciate the privilege of testifying when the bill is considered in committee. I hope it will come up soon. Would you be good enough to tell me whether hearings have been scheduled?

Please be assured of my deep interest in seeing your bill passed, and of my appreciation for the fine efforts you have made in behalf of the fisheries of the United States in sponsoring this legislation. Sincerely,

\section{P. IDYLI, \\ Head, Fisheries Division.}

\section{The OHio State University, NATURAL Resources INSTITUTE, Columbus, Ohio, Mlarch 25, 1960.}

Hon. WARREN G. MagNUSON, Congress of the United States,

U.S. Senate, Washington, D.C.

Dear Senator Magnuson : I have learned recently of jour bill on oceanography (S. 2692) and wish to express appreciation for your interest and initiative in preparing and introducing this desirable legislation. There is, as you hare observed a critical need for basic research concerning our great coastal and inland waters, particularly as it relates to basic productirity of food fishes. Basic research in this area has suffered both from lack of support and especially from lack of consistent support for the long-range studies.

In our experience, the National Science Foundation has not prored to be a satisfactory source of support for such studies. There seems to be a feeling that any study which has any possibility of practical application is not eligible for support from that source. There is thus a need for a basic fisheries research program administered by an agency which is concerned with the outcome of such research. 
It has been reported that there has been some criticism of that part of the bill which provides for administration of research grants through the Bureau of Commercial Fisheries. This criticism is based on the allegation that that agency does not have the ability to carry out or support basic fisheries research. In my experience with the Bureau, this is not a valid criticism. I have had close contact with the Bureau, both as a former administrator of a State fish and game agency and more recently as a member of the U.S. Scientific Advisory Committee to the Great Lakes Fishery Commission. In both capacities, I have been favorably impressed with the appreciation of the need for basic research on the part of the Bureau and their capacity to conduct such research. There are, to my knowledge, few better examples than the splendid basic research conducted through the Bureau which has led to the present methods of experimental control of the sea lamprey in the Great Lakes.

I would wholeheartedly concur in those provisions of the bill which give to the Bureau flexibility in making grants or entering into contracts with agencies such as universities and private research groups who are in the best position to conduct basic research in this area.

I hope that you will be successful in getting this bill favorably considered by the Congress.

Sincerely yours,

Charles A. Dambach,

Director, Natural Resources Institute.

SHIPBUILDERS COUNCIL OF AMERICA, New York, N.Y., April 19, 1960.

Hon. Warren G. MagnUSON,

Chairman, Commitee on Interstate and Foreign Commerce,

Senate Office Building, Washington, D.C.

Dear Senator Magnuson: It is understood that hearings will be held by the committee of which you are chairman on April 20 and 21 on S. 2692, to be entitled Marine Sciences and Research Act of 1959.

Early in 1959, before this bill was introduced, the council sent letters to several legislators including Congressman Miller, chairman of a Special Subcommittee on Oceanography, Committee on Merchant Marine and Fisheries, endorsing the need for increased oceanographic research and study.

The council desires to go on record at this time as strongly supporting S. 2692.

It is noted that section 14 of S. 2692 covers authorizations for appropriations to the Department of the Navy for a 10-year program for a total of 24 ships of varying types as listed in section 14. It is suggested that the Navy be directed to have these ships constructed in private shipyards of the United States.

The incorporation of this letter in the record of the hearing will be greatly appreciated.

Sincerely yours,

L. R. SANFORD, President.

Agricultural and Mechanical College of Texas,

Department of Oceanography and Meteorology, College Station, Tex., March 8, 1960.

Hon. WARREN G. MaGNuson,

U.S. Senate, New Senate Office Building,

Washington, D.O.

SIR : I am writing with reference to your proposed bill S. 2692 entitled "Marine Resources and Research Act of 1959." I wish to express my appreciation for the interest that you and your committee members have shown by the hearings and your proposed bill. I am sure that all oceanographers are aware of your sincere efforts.

There are two specific parts of the bill on which I would like to comment.

(a) On page 7 , lines 5 to 15 , the bill directs that a division of marine sciences be set up in the National iscience Foundation. It also states that "at least six scientists from the universities and institutions receiving assistance from the foregoing agencies" will be included as members of this board. The inclusion of board members from nongovernmental agencies is quite desirable. My question 
arises from the alowe stipulation. If the members were selected from oreminizations receiving financial assistance for oceanographice researeh some problems may arise. 'Jine recipients of funds may find it difficule if not awkwarl to decide on cortain funding problems if this were a function of the boatr. They may likewise find themselves in a similat sitnation with resperet to antrising on the type of research endeavors necessary in oceanograthy. In view of this I feel that at least some of the nongorermmental members should be selected from a much latrere segment of the seientific community. It may be diffente to find scientific organizatims: who do not receive support from the office of Natral fresearch, Atomic Finergy Commission, ete, however, there are those who do not receive sumport of ocemographic studies. I think that these should be included in the potential membership.

(b) On vage 9 , item $\mathbf{f}$, the sum of $\$ 3$ million is requested for fellowships. I agree that additional followships in science are urgently needed. Inowever, I question the stipulation "to graduate students training to become professional oceanographers." 111 fellowships in the sciences should be on a single competitive basis. Only those oceanographers or potential oceanographers who can compete with the best of the chemists, geologists, physicists, ete. should be considered. If a tight disciplinary system were set up it would result in situations where a less qualified individual in one field obtained a fellowship at the expense of a far more qualified person in another area. We cannot afford this; with limited fellowship funds only the most qualified can be considered regardless of discipline. If oceanography or any other discipline cannot attract the capable qualified student, it should surely not be guaranteed fellowship support.

Again let me express my appreciation for your interest in the science of oceanography.

Very truly yours,

\author{
RICHARD G. BADER, \\ Associate Professor of Oceanography.
}

Hon. Warren G. Magnuson,

Chairman, Committee on Interstate and Foreign Commerce,

U.S. Senate, Washington, D.C.

Dear Senator Magnuson : I appreciate your sending me a copy of Senate bill 2692 pertaining to oceanography. It is a very interesting document and will probably instrument expansion of scientific effort in a vital field. You and the committee are to be complimented.

After careful study of the bill I have several suggestions:

(1) Estuarine and inshore oceanographic studies should be specifically emphasized more. Though an understanding of the offshore ocean areas and depths is vital, the continental shelf and its overlying waters and the basy and tidal rivers are biologically more important (if such a comparison can be made) and a significant portion of the funds in the proposed expanded program should be expended on understanding this area of the hydrosphere.

(2) The proposed ships should be so designed, constructed and operated that biological oceanography is fully provided for. These ships should be so constructed as to permit maximum possible observational use at each station and completion of the work at sea. I was favorably impressed with the Russian vessel Lomonosov in this regard. In other words, all disciplines should be served at sea at once, where possible.

(3) The shore facilities should also be adequately equipped and staffed for biological oceanography both in estuarine and inshore work and offshore oceanographic problems.

(4) By its very nature, involving the phenomena of physics and chemistry as well as added complicating phenomena of the biological realm-the life processes, biological research is usually much more complex and difficult than that of other disciplines; therefore, a large proportion of the program should be devoted to biological oceanography.

(5) The amount allotted to the National Science Foundation for basic research in oceanography is far too small. It should be at least $\$ 10$ million a sear or $\$ 100$ million for the 10 -year program. If past performance is ans criterion this basic research will, in the long run, be the most productive portion of the program. It should be supported accordingly. (In the past amounts appro 
priated to the NSF programs have been far less than those allotted to other granting agencies. This is shortsighted, false economy.)

(6) Under the Atomic Energy Committee allotment the sum of $\$ 100,000$ a year for studies of the genetic effects of radioactivity on marine organisms seems far too low judging from the importance of this subject and the difficulties inherent in this type of research. The sum should probably be $\$ 1$ million a year.

May I point out that one of the best ways to promote rapid expansion of oceanographic research, biological and physical, is to make facility grants, fellowships, personnel grants, equipment grants, and research project grants available to universities, colleges and State and private research institutions. Thus, existing marine programs, facilities, and personnel are utilized to their fullest. It seems likely that expansion can probably be most rapid in biological oceanography because there are more biological oceanographers (marine biologists, and allied biological workers) than physical oceanographers. This is probably all to the good because, as was mentioned above, biological problems are usually the most difficult and at the same time of most immediate and significant interest and value. (However, all disciplines are important and interdependent.)

In closing, may I reiterate that all disciplines of oceanography need the boost provided by this legislative action. It is vital to wise use of marine resources, to preparing for future population expansion, to understand our planet and its history, and to our national defense. The chief reason why we now know so little is that funds and interest in marine research have been far too small.

I will be glad to assist your program in any way possible.

With best wishes for success in your efforts, I am,

Sincerely,

William J. Hargis, Jr., Ph. D., Director.

\section{State of MaIne, \\ Department of Sea ANd Shore Fisheries, State House, Augusta, November 30, 1959.}

Hon. WARREN G. MAgNuson,

Chairman, Committee on Interstate and Foreign Commerce,

Washington, D.C.

Dear Senator Magnuson : We were very pleased to receive a copy of jour committee bill, S. 2692, with your request for comments.

The scope and general farsighted provisions of the bill are impressive and its sponsors and supporters are to be congratulated. We are naturally proud that Margaret Chase Smith is one of the sponsors of the bill. We do have a number of comments in regard to this document.

Starting on page 3 , item 4, certain disciplines are listed as being good background for advanced degree work. Why not add mathematics and meteorology because of their direct and important application in the marine field?

We believe that more emphasis should be given to the role of State agencies and their research facilities. Reference to state participation is conspicuously absent in a number of sections of the bill where cooperative endeavors are mentioned ; for example, on page 5 starting on line 19, subsection (c). Likewise, on page 16, lines 4 and 5, State institutions are mentioned, but not agencies. In Maine, marine research work is carried out by a State department. Therefore we are concerned when specific references mention institutions and not agencies of State government.

Considering the relatively large sums of money that are being considered for equipment and facilities, we believe that the money to be made available for fellowships, grants, and other academic aid is very inadequate. Ship and shore facilities will have to be staffed and the marine sciences will have to compete with the current glamour and sppeal to youth of research in the realm of outer space. In contrast and using specific items, page 8 , subsection (e), $\$ 10$ million a year will be spent on specialized equipment. Yet on page 9 (f) only $\$ 300,000$ a year will go for graduate fellowships. This may well satisfy the expected need of those wishing to prepare for Ph. D. degrees, but appears to be a small amount of money in providing for the need of people working for master's degrees, who will be needed in great numbers.

Although fisheries resources studies and the utilization of marine products for human consumption are included, page 13 , subsection (d), we question whether or not these references and the money considered give proper weight to the value 
of biological oceanographic and estuarine work, considering the interrelation of the various portions of the marine enviromment.

If our country is to be strong in the marine fields in all segments, it will be necessury to upgrade the economic status of the industry, although this aspect of the development of the fisheries is alluded to in latge 13 , subsection (e), we question if relatively enough money is being spent on learning more about the economic, social, and legal phases of the industry.

We do hope this bill, or an amended version can be enacted, and money made available to implement it, at the coming session of Congress.

Sincerely,

Ronent L. Dow, Research Director.

State of California

Department of Fish and Game, Sacramento, Calif., BIarch 1, 1960.

Hon. Warren G. Magnuson,

Chairman, Committee on Interstate and Foreign Commerce,

U.S. Senate, Washington, D.C.

Dear Senator Magnuson: This is in reply to your request for comments on your bill, S. 2692 , a bill to advance the marine sciences and to establish a comprehensive 10-year program of oceanographic research and studies. Several requests for comments were addressed to members of this department. Their comments are consolidated in this one reply.

We would like to take this opportunity to congratulate you for sponsoring a bill which will be the means of bringing about an increased understanding of the marine environment. The people of the entire world must turn more to the ocean as a source of food, not to mention a place of recreation. Our knowledge of the sea and its resources must be brought to at least a par with our fast-growing knowledge of outer space.

Perhaps it is because we are close to the problems as we see them in our everyday work, but it seems that your excellent bill has by implication slighted two totally different aspects of ocean research. I am sure that this was not intended, and I would like to suggest that the bill could be strengthened by taking these aspects into consideration. Slight amendments would be sufficient.

I refer first to the insistent emphasis on physical oceanography throughout S. 2692 as compared to the modest mention of biological research, and second to the virtual omission of research agencies other than the Federal Government and universities.

As you know, there is a twofold approach to a study of the sea-physical and biological. The physical approach, of course, is of extreme importance to the satisfactory understanding of an area where defense fleets operate, where commerce moves, and where fisheries and mineral resources exist. We do not wish to play down the importance of physical studies which have been dramatized so effectively in man's imminent conquest of outer space and atomic energy. At the same time, we feel that the biological aspects of the ocean are important from their strategic and food-producing significance and are equally demanding of expanded research.

'I'he emphasis is on physical oceanography throughout the bill, but I should like to call your attention to those specific statements which could be improred.

Following a most excellent general declaration of policy, the bill on page 3 , line 24 commences to stress oceanography. Perhaps this is because the term "oceanography" as used throughout the bill is intended to refer to marine science as a whole. If so, I would suggest changing the mords "oceanography" and "oceanographer" to "marine science" and "marine scientist." Otherwise there will be considerable misunderstanding of the purpose of the bill. Of all the many branches of marine and allied sciences, oceanography is onls one.

On page 4 , lines 8,12 , and 23 we find reference to oceanography whereas on line 20 there is a reference to marine sciences. On page 5 , lines 17 and 18 , both terms are used in such way as to leave the meaning unclear. On page $S$ appear many references to oceanography which might imply exclusion of other marine sciences, and also at the top of page 9 .

Of perhaps greater significance than terminology is our concern orer the emphasis on physical science in the section on the Atomic Energy Commission. We believe biologists rather than physicists should be called on to judge biological and health aspects of atomic radiation in relation to the living resources of the sea and to the people who consume them. 
Your bill could be the mechanism for focusing interest on the biological features of atomic waste disposal, and it is obvious that this was your intention. However, almost all of the money proposed for research could be spent on physical studies if the expenditures were not more fully specified. I respectfully suggest that this section be tightened. We concur with the objectives set forth, but on the basis of experience we urge amendment to insure adequate provision for biological research in the field of radioactivity in the ocean.

The other important area of omission concerns the operations of non-Federal research agencies. As you are aware, the fisheries conservation agencies of many coastal States conduct excellent and valuable marine research programs. All the States of the Pacific coast-California, Oregon, Washington, and Alaska, not to mention Hawaii-have excellent research staffs and facilities, including laboratories and experimental stations, and some have research vessels. I am sure that you are personally acquainted with both the work and the men who are doing it. Surely the know-how and facilities of these State agencies should have a place in any nationwide program of expansion.

We feel strongly that the inclusion of existing programs, staffs, laboratories, and vessels of the State agencies which are vitally concerned would add strength to a nationwide program. Providing for their expansion as part of a coordinated program would insure a broader base for accomplishment than only expansion of Federal agencies.

I am sure that this apparent oversight was not intended by you, and it could be corrected by minor amendment.

The State agencies may or may not be included in references on page 5 (lines 1 to 5 , and 15 to 18 ), page 6 (lines 1 to 10 ), and page 7 (lines 12 to 15 ). Perhaps the expression "institution" would include a fisheries department, or perhaps it refers only to an academy or laboratory. A clarification would be helpful.

It is also not clear on page 9 (lines 15 to 20 ) whether State fisheries research agencies would qualify. Our interpretation would be that they do, but without clarification we could be overlooked when the new program is adopted.

We are not sure what the term "cooperate" means as used on page 10, line 18. Does this mean that Interior would merely work in a cooperative manner or does it imply that Interior will contract with the States? A similar question arises on page 25 (line 9 ).

Throughout pages 12 and 13 the numerous references to expanded programs definitely imply the exclusion of State fisheries agencies which under the Constitution and State laws are responsible for conducting the research upon which conservation programs are based. A more equitable approach would be to include the State agencies. We have no wish to take over, but only to be recog. nized and included in an expanded program. We believe that our accomplishments so warrant.

In the section on the Department of Commerce, which deals mostly with physical aspects, the bill recognizes State agencies and institutions. It would appear that in this field, the responsibilities and rights of the States are recognized. The States are also given some recognition in the section on the Atomic Energy Commission.

Therefore, the omission of the States in the section on the Department of the Interior has us puzzled. I hope I am wrong on this, but without some amendment I am concerned that the highly qualified State agencies which have responsibilities under the law would not be included in an expanded program. This would be regrettable in a program that is so vital to the Nation's survival that everyone capable of helping should be included.

The State of California operates seagoing research vessels and plans to continue doing so. One vessel is fast approaching obsolescence and will soon need replacement. Another is on loan from the U.S. Fish and Wildlife Service. We are vitally interested in continuing our seagoing research. We are sure it has a place in the overall program that your bill envisages. With our men and our know-how we can play an important part in an expanded program if we can share in the expansion. If your bill is a means toward modernizing our research fleet so much the better.

To duplicate the laboratories and staffs of the States could be wasteful. To provide for a coordinated expanded program with everyone pulling his share of the load would be economical and lead to success. 
I trust that the above comments will be helpful to you. Again may I state that the minciples and objectives of your s. 2(6!)'2 neet with our concenrence. Incorporation of the suggestions I have mate will male the bill extremely valuable.

Yours sincerely,

W. T. Sirannon, Director.

\section{The Academy of Natural Sotences of Pinlanelpiima.}

December 16,1959 .

Senator Warren G. Magnuson,

Senate Office Building,

Washington, D.C.

Dear Sevator Magnusox: 1. Both the bill aud the oceanographic repurt of the National A'ademy of Sciences (upon which the bill is based) fail to mention or draw upon the Smithsonian Institution-U.S. National Museum for advice, guidance, or participation.

Comments: For over 100 rears, the U.S. National Museum has engaged in basic research in many phases of the marine sciences, and today has a competent staff of scientists who are currently engaged in taxonomic (classification of organisms), geographical, and ecological studies of marine animals and plants.

The U.S. National Iuseum houses the country's largest collections of marine organisms which are vital for identification and comparative purposes in any international survey program.

The staff of the U.S. National Museum has mans scientists who are greatly experienced in field surveys, marine exploration, and in the problems of preserving and housing oceanic samples and marine organisms.

Recommendation: That, at sometime during the hearings, an administrative representative and at least two scientists "on the lower echelon" be called upon to express their views on appropriate phases of the proposed program.

2. Both the bill and the oceanographic report of the National Academy of Sciences (upon which the bill is based) fail to recognize or offer concrete proposals to solve the immense problem of preserving, documenting, and properly housing the specimens upon which all future biological research and survers will depend.

Comments: The majority of the scientists who prepared the "oceanography, 1960 to 1970 " report are wholly or mostly concerned with the phrsical aspects of oceanography, and although their excellent report deals with many biological aspects, such as fisheries, "mapping of distributions of species," taronoms, and ocean resources, etc., there is insufficient discussion, consideration and recommendations concerning a vital aspect of oceanographic research; namels, the sorting, organizing, preservation and proper housing of biological specimens collected during the 10-year program.

If this phase of the program is inadequately financed, great quantities of priceless specimens will be thrown back into the sea, buried in a chaotic mass of haphazard accummulation, or lost through neglect and improper disposition. While much of the data on physical oceanography can be recorded and preserred in written or visual records, most of the biological data concerning the identity and telltale condition of individuals must be preserved in the form of specimens and samples.

All of our knowledge concerning what organisms exist in the oceans is based upon (and is constantly subject to reexamination) the collections preserred in the leading 50 natural history museums of the world, including $S$ or 9 in the United States. These collections were made by private and Gorernment expeditions and individuals. The results of the first U.S. oceanographic expedition, made in 1832 by Wilkes, were largely lost because of inadequate financial support for the housing of the specimens. The present, approximate number of marine specimens now preserved in United States private and public research museums is about 3 billion; fish ( 20 million), mollusks (50 million), starfish, etc. ( 2 million), worms, etc. ( 1 million), corals ( 1 million), diatoms and other algae ( 4 million), etc. The new 10-year program, if properls carried out, will quadruple the amount of specimens needed for a minimal amount of taxonomic research, and upon which all survey and marine resources work must depend.

It is the history and philosophy of American science that a large part of all scientific endeavors are the function of independent and nongorernmental scientists, and institutions. It is also recognized that direct gorernmental participation in scientific research is an important and effectire adrancement of 
our national welfare and security. We believe a practical and fair balance of responsibility and financial assistance should exist between the activities of citizen scientists and governmental scientists, between citizen institutions and governmental institutions.

Recommendation: That bill S. 2692 of September 11, 1959, be modified and adopted with the following changes and/or additions.

I. Under section 4 dealing with the administrative and financial responsibilities of the National Science Foundation there be added on page 8 , after line 6 the following: "(c) The sum of $\$ 40,000,000$ for the proper preservation and housing of marine specimens." and on page 8 at the end of line 9 there be added the words "and marine biological" and on page 9, line 2 , after the word "oceanographers" there be added the words "or marine biologists".

II. Under the section of "Declaration of Policy," the following changes or additions be made: On page 3 , line 11, after the word laboratory, there be added a comma and then the word "museum." On page 3, line 15, after the word "instruments," there be added the words "methods of preservation of specimens." On page 6, line 17 and line 20, the word "fisheries" be deleted and replaced by the words "marine biological."

3. Both the bill and the oceanographic report of the National Academy of Science (upon which the bill is based) fail to recognize the need or make provision for a suitable or extensive enough National Oceanographic Records Center or a vitally needed center for the survey indexing and dissemination of man's present knowledge of the marine sciences.

Comments: One of the great problems confronting all scientists is their inability to keep up to date with the advances in their respective fields. It is inconceivable that a 10-or-more-year program of investigation can be initiated without some provision for a modern, electronic system of indexing what is already known about the physical and biological aspects of oceanography. Without this tool, which should be international in scope, our research will bungle along on a hit-or-miss fashion. It is especially mandatory in the field of marine resources and the surveying of marine life, that the estimated 600,000 books and articles on marine animals and plants be expertly indexed.

In my opinion, the technical difficulties and specialized knowledge required in this operation will make necessary the guidance and administration of a records center to be set up and run by the Smithsonian Institution. The Smithsonian is certainly the logical place for any taxonomic, biological, or ecological indexing program. However, some opposition to this idea may be anticipated from the administration of the Smithsonian who consider the scientific aspects of their organization to be a research rather than a service function. While I quite support this view, I believe that if sufficient funds and additional personnel were authorized for this purpose, such a service function would be of immense national value and would be in keeping with the Smithsonian's present service functions in the areas of exhibits, publications, dissemination of knowledge, and identification services.

From my own personal standpoint, the broad research program on marine mollusks which the Academy of Natural Sciences of Philadelphia is undertaking requires an indexing of the molluscan literature. We have 30 international participants in our program, and all greatly desire a control on the literature. We shall attempt to go ahead in a primitive fashion with what small private funds are available. Our really only great hope is that our Russian colleagues will evolve and share with us a complete indexing of our field. In my opinion, the country or institution which serves as the brain or nerve center of marine sciences will ultimately command the lead in setting policies and carrying out research programs.

Recommendation: That bill S. 2692 of September 11, 1959, be modified and adopted with the following changes and/or additions:

I. That under section 7 on page 14 concerning the Department of Commerce, on line 22 , following the word "oceanographic" there be added the words "and marine biological and taxonomic."

II. That on page 16 , line 23 , the sum of " $\$ 250,000$ " be deleted and the sum " $\$ 1,000,000$ " be added. That on page 17 , line 3 , the sum " $\$ 100,000$ " be deleted and that the sum " $\$ 1,000,000$ " be added.

III. That serious consideration be given by the drafters of this bill on whether the Smithonian Institution or the Department of Commerce should be responsible for either or both a biological and physical oceanographic records center, and that such accumulated records be made available to national and international research workers and institutions on a nominal cost basis. 
IV. That the drafters of this bill eall upon "indexing experts" from the I)epartment of $\Lambda$ griculture, professional biological socicties and yrivate industry to testify unon the problems of setting up an electronic indexing system.

\section{OTILR CONIRENTS CONCEINING THE BLL}

As a private citizen and research scientist, I would like to reaffirm my approval of and faith in the practices and principles of the kind of Ferbal financial support given through the National Science Foundation. I heartily support and further urge that as much responsibility as possible for the arlministering of basic research funds, as authorized by bill $\mathrm{S}$. 2692 , be done through the National Science Foundation, and that funds for aprlied research, commercial fisheries military research, navigational improvements, etr., be administered by other appropriate agencies.

I understand from casul conversations that the National Science Founclation may not be too happy about the formation of a new and srecial Division of Marine Sciences. This is because such a Division would cut across many of the basic divisions of sciences and the general organization of the NSF. I trust pressures of those looking through the oceanographic telescope will not hamper the broader wisdom and functions of the NSF as a whole.

$I$ have also heard the question from several oceanographers and marine biologists, "where are we going to get the scientists to man 40 new research ships during the next 10 years?" Is our shipbuilding program too large? I take no sides on this question, but merely point up the question.

I do have one small, but concrete example, of how additional research ressels (in the 300-ton class) could materially aid and encourage the rast amount of present-day privately supported surreys of the shallow seas of the world. At the Academy of Natural Sciences of Philadelphia we have begun a new scientific journal which aims to survey, classify, and list all of the marine mollusks of the Indo-Pacific oceans. Through the auspices of the Natural Science Foundation of Pennsylvania and other private contributions we have put 10 major collecting expeditions into the field in the last 5 years (New Guinea, Zanzibar, Ceylon, Samoa, etc.). Three of these were aided by the use of a research ressel which, because of financial difficulties, has now been abandoned. We plan at least another dozen expeditions, supported by private funds, in the next 5 or 6 rears. If a research vessel owned and operated through naval or NSF grants could be put into this area for our use, our private financial contributions would double and assure our making much more rapid and more complete survers of this region. I am sure that other institutions, such as the Bishop Nuseum in Honolulu and the California Academy of Sciences in San Francisco could quadruple their research on shallow water marine organisms if such small research vessels were at their disposal. I am a firm believer that private and gorernmental money for research should compliment, and not oppose, each other.

List of the ranking institutions and museums in the United States which have traditionally housed and preserved marine biological specimens during the past century :

Academy of Natural Sciences of Philadelphia (founded 1812).

Allan Hancock Institute (Los Angeles).

American Museum of Natural History (New York).

California Academy of Sciences (San Francisco).

Chicago Museum of Natural History.

B.P. Bishop Museum (Honolulu).

Geological Museum, Stanford University.

Museum of Comparative Zoology (Harrard University).

Paleontological Research Institute (Cornell University).

U.S. National Museum (Tashington, D.C.).

Atbert M. Linton, President.

The Florida State University, Tallahassee, December 11, 1960.

Mr. WarRen G. Magnuson,

Chairman, Committee on Interstate and Foreign Commerce,

U.S. Senate, New Senate Office Building, Washington, D.C.

DEAR SIR: I have read the bill (S. 2692) for advancement of marine sciences with a great interest. I, working 15 years as a physical oceanographer after graduation of a college, am particularly enthusiastic about the bill, not only 
because my special field of science is encouraged but also because the general welfare of the people in the United States and in the whole world will be enhanced.

It is out of my capacity to make comments on the bill, since I have only a limited experience. However, I was engaged in research of oceanography as a staff scientist of Japan Meteorological Agency for 12 years. Fortunately I could spend almost 3 years in research and teaching of oceanography in this country, including $1 \frac{1}{2}$ years at Woods Hole Oceanographic Institution. Therefore I have a chance to compare the general oceanographic activities in the United States and in Japan. Also I feel it is one of my duties to impart my opinions about improving the marine sciences to the authorities of this country which has bestowed so much benefit upon me.

The following comments on the bill might be mediocre or superfluous like "feet of a snake," as an Oriental proverb says. However, I will be very happy if any of these comments be worthwhile.

\section{INTERDEPARTMENTAL COMMITTEES OR COUNCILS ON THE OPERATION OF OCEANOGRAPHIC RESEARCH SHIPS}

According to the bill about 80 oceanographic research ships will be operated at the end of the 10-year plan. This situation needs an enormous coordination among various agencies which operate the ships in order to avoid unnecessary duplication in surveys and to insure cooperation in problems which need more than a few ships. It seems to me that such committees (or less formal organizations) are urgently necessary even now, because there are rather poor cooperations among different agencies and institutions. For instance, the Gulf of Mexico, on which I am now studying, was surveyed frequently by governmental agencies and some universities. But I think that the coordination of these surveys is poor, although individual works are excellent. Further, almost no information is available in advance about the future plans of surveys for scientists or oceanographers outside the particular institutions which are planning such surveys.

Therefore the functions of proposed committees may be to give informations about the results obtained in the past surveys as soon as possible, at least to scientific circles who are interested in them, to discuss and modify future plans of surveys, to widely ask advices or comments from the scientific circles and, to exchange general informations about operation of the research ships. Several committees of such kind may be established on the regional basis for operating area of the research ships, presumably, the North Atlantic region, the North Pacific region, the Gulf of Mexico region, and other parts of the ocean not directly related to this country such as the Antarctic, the South Pacific and Atlantic, and the Indian Oceans. Each regional committee has to hold a meeting consisting of representatives of individual agencies and institutions and of scientists who are interested in the area, at least twice a year.

\section{TRAINING OF COLLEGE STUDENTS IN THE MARINE SCIENCES}

The marine sciences include almost all phases of basic sciences as well as applied sciences such as engineering and fishery technology. Therefore the subjects are quite educational even to the students who have no intention to become a specialist in the field, when they are adequately taught. The important thing is to rouse the interest of students in the marine sciences. For this purpose several measures are considered: (1) to have good elementary books and textbooks of marine sciences to attract students; (2) to make films and invent educational equipments illustrating many phases of marine sciences and facilities of teaching: (3) to set up courses of marine sciences in colleges as a general science curriculum; (4) to train students on the spot in shore facilities and on board the research ships. This measure may be much promoted if the plans of surveys are known in advance and cooperations between the agencies operating ships and the institutions doing basic researches and education are realized through the committees mentioned in paragraph No. 1 . Such trainings do not only benefit students but also give some remedy for solving shortages of manpower in the technical assistant level.

Further, setup of cultural centers or museums relating to the marine sciences at many communities may also help for arousing public interests in marine sciences. 


\section{COOPERATION WITIY AND TECIINICAL AIDS TO FOREIGN COUNTRIES IN RELATION TO TIE MARINE SCIENCES}

It is almost impossible for any one country to explore all the oceans of the world. The SCOR (Special Committee on Oceanographic Research) set up with the framework of the International Council of Science Union is working on international cooperation of oceanographic explorations on the international basis. Correspondingly, is necessary the national organization which acts as a liason between such an international body and the individual agencies and institutions participating in interational programs. Moreover, it is desirable that such organization does not only coordinate the efforts of individual agencies and institutions but also carry out its own plan of an international scope. Therefore in some occasions it may operate a few research ships which belong to individual agencies under special contracts.

In the North Pacific and the North Atlantic region the committees mentioned in the paragraph one may act dual roles of interlepartmental and international coordination, because the most countries with excellent qualification in oceanography are interested in these regions and are now doing active work.

Technical aids to underdeveloped countries in the marine sciences must be planned jointly or independently with this program of intcrnational cooperation. Some countries in eastern south Asia and Africa are surrounded or faced with the oceans which are rather rich in marine resources. But unfortunately they are unable to utilize these resources owing to lack of knowledges and facilities, although they need such resources more than other cirilized countries. Therefore, dispatches of oceanographic research ships to these countries may contribute to their development by exploring the seas around them and br training the scientists of these countries who will participate in such survess. Further such ships will certainly serve good diplomatic missions.

\section{MARINE SCIENCES FOR FISHING FLEET}

Obriously the adrancement in marine sciences will greatly benefit fishery. However, the true goal for improvement of fishery may not be reached until the prediction of fishing conditions in adequately imparted to fishermen. Such prediction which is based on the oceanographic conditions is particularly important in herring fishing in the northern North Atlantic, salmon fisling in the North Pacific, tuna fishing in the Central Pacific, and shrimp and orster culture on the coast.

In oxder to give precise prediction ample data both in time and space as well as researches about the method of prediction are indispensable. The oceanographic data collected by ordinary research ships are accurate but limited in time and space. On the other hand, fishing fleets corer entire fishing fields with more frequencies than the research ships. Therefore when-

(1) Scientific instruments such as temperature recorder, plancton sampler etc., which need not high precision as required by research ships are equipped by these fishing boats; and when

(2) Crew of these boats are trained in handling of the instruments and in general obserration techniques, the data collected by these boats are raluable not only in the prediction of fishing condition but also in basic research on oceanography. In order to collect these data there may be a center at each fishing area. Fishing fleet may send their data to such centers by radio or in written forms. In return, these centers mas broadcast rarious informations to the fishing fleet during the season, and be responsible for maintenance of the scientific instruments of the boats.

Such plans are not novel. I hare heard that Russia is alreadr sending a fer hundreds fishing boats which are well equipped with scientific instruments to the fishing ground of herring in the North Atlantic. The Forecasting Center at Moscow is giring prediction of fishing conditions 3 to 6 months ahead the fishing season from the data thus collected. In Japan, though in a small scale, this kind of cooperation between the fishing fleet and oceanograph laboratories is done during the fishing season of bonito in the Pacific.

\section{IMPORTANCE OF RESEARCH OF CONTINENTAL SHELF AND COASTAL AREAS}

The immediate importance of Continental Shelf and coastal areas to our daily life can be realized if we consider that the marine resources are mostly found in these areas and our defense problem is to protect these areas against the 
possible attack. From oceanographic point of view these two regions belong to different circumstances. Therefore, the research of these regions may be considered separately.

I do not think an independent institution or agency is necessary for study on the problems on Continental Shelf. However several agencies and institutions which are interested in this area may have a joint committee similar to those mentioned in paragraph one and coordinate their surveys and researches on this area.

Contrary to the Continental Shelf coastal areas including bays and estuaries are studied by various local agencies such as conservation boards and civil engineering departments of States and other communities and most marine, laboratories of colleges as well as Federal agencies such as Beach Erosion Board. Too diversified problems in the coastal areas make it difficult to give any control on the activities of various agencies. However, again in these areas some special committees which are centralized locally may serve in avoiding unnecessary duplications in research and in communicating and distributing the informations obtained by individual agencies.

These comments are as I admit, myself-far from satisfactory. Further I had no time to even refine them, in order to send them before January. Please forgive me for my crude expressions and writing.

Yours sincerely,

Assistant Professor in Oceanography, Oceanographic Institute, Florida State University.

\section{American Shore \& Beach Preservation assoctation,} Washington, D.C., December 29, 1959.

Hon. Warren G. Magnuson,

U.S. Senate, Washington, D.C.

My Dear Senator Magnuson: Senate bill 2692, 1st session, 86th Congress, which you introduced for yourself and a number of other Senators, and which has been referred to the Committee on Interstate and Foreign Commerce, of which you are the chairman, has come to my attention.

As the president of this asociation, which, as its name indicates, is vitally interested in the ocean shores and beaches, and as a retired officer of the Army (Corps of Engineers), and as a former Deputy Chief of Engineers for Construction, and former president of the U.S. Beach Erosion Board, all of which gives me a continuing interest in shore and beach erosion and protection, $I$ am writing to offer my comments.

I have noted the purposes of the bill as summarized in the introductory paragraph, particularly its bearing on research, surveys, commerce, navigation, national defense, ocean resources, etc., and the short title, "Marine Sciences and Research Act of 1959." I am in full accord with the general purposes and objectives of the bill but it seems to me that a most important part of the oceans and ocean floors, the part that this association and I personally are particularly interested in-namely, the ocean shores and near-shore bottoms have been overlooked. Although the shores and near-shore bottoms are as much a part of the oceans as the "deeps" and are of great importance, from all points of view, they are not mentioned in the bill.

To rectify the omission, I must respectfully suggest that the bill be modified to include research, survey, and study of the ocean shores and near-shore bottoms, and to provide for the utilization of the Corps of Engineers of the Army and its Beach Erosion Board, which are the U.S. Government agencies charged with and having cognizance of those areas and matters.

I have not presumed to develop specific suggestions for changes in wording to accomplish the objectives I recommend, but it appears that only minor modications and additions would be required. I will be happy to present additional data and support for my views, if desired.

Most respectfully,

CHAS. G. HoLLE, Major General, U.S. Army (Retired), President. 
The Johns Hopkins University, Baltimore, Md., October $7,1959$.

Hon. Warren G. Magnuson,

Chairman, Committee on Interstate and Foreign Commerce,

New Senate Building, Washington, D.O.

Dear Senator Magnuson: I have read with great interest the cony of bill S. 2692 forwarded to me by the Committee on Interstate and Foreign Commerce and $I$ wish to offer the following comments.

In view of the expanding population of the world and the predictions that our terrestrial food supply will be outgrown, the productivity of the sea is of vital importance to our future. To use the oceans and their food supply wisely it is obviously necessary to pursue marine biology as thoroughly as possible. The micro-organisms of the sea, especially the phytoplankton, are the direct or indirect source of food for most other living things in the sea. A study of these organisms is essential for the future productivity of the ocean. A detailed consideration of the bacteria, viruses, bacteriophage, algae, fungi, and protozoans must be included and all of these studies must be approached from the biochemical, nutritional, genetic, and ecological viewpoints to have a complete urierstanding of the organisms and their environment.

As the Committee on Oceanography has pointed out, progress in marine biology will depend upon the interest, the experience, and the creative imagination of individual scientists. However, the individual scientist must have instruments and facilities, and he must lire in an atmosphere conducive to creative activity. Adequate funding must be available for laboratories and equipment, and such laboratories should have a close and intimate relationship with a creditable university which will enable the laboratory personnel to become a part of the scientific life of such a university.

Earlier this year, I proposed to appropriate officials that an Institute of Iarine Microbiology be established at an existing facility, the Marine Biological Laboratories, Woods Hole, Mass. To build, equip, and aperate a small but adequate laboratory for this purpose would cost approximately $\$ 5$ million for the first 3 -year period. A sum of $\$ 2$ million would be required for an adequate laboratory building and $\$ 1$ million would be required for equipment. After construction, the annual operation cost is estimated at $\$ 532,000$. I mention this because it is $m y$ sincere belief that while bill S. 2692 provides ample funds for the physical sciences aspect of marine research, it does not provide adequate funds for the facilities and equipment required for the most fundamental marine biological research. Postwar derelopments have placed great emphasis on the physical aspects of science, that is, atomic energy, rocketry, with little attention given to the bilogical problems inrolred. Funds granted by Congress to the Federal agencies supporting basic biological research have been quite inadequate (except in the realm of the medical sciences), until now a situation is reached where areas of biology, that is, marine biology, are in dire need of support to derelop the facilities and personnel necessary to cope with the problems confronting mankind.

Bill S. 2692 is a comprehensive and much needed legislative offering. In may respects, it proposes a program as broad in concept as the U.S. IGY program. To avoid the failures of the IGX, it is essential that the funding be adequate for all aspects and that support of the total program not be permitted at the expense of any particular segment. All aspects are extremely important and can achieve the success desired only if given the necessary attention.

I look forward to the success of this legislation and greatly appreciate this opportunity to express my views.

Sincerely yours,

Director, McCollum-Pratt Institute; Chairman, Biology Department.

WOODS HoLE OCEANOGRAPHIC INSTITUTION,

OFFICE OF THE DIRECTOR, Woods Hole, MLass., January 28, 1960.

Hon. WARren G. MAgNuson,

Chairman, Committee on Interstate and Foreign Commerce, U.S. Senate, Washington, D.C.

DeAr SENATOR Magnuson: I am glad to respond to your invitation to comment on S. 2692 which you introduced in the 1st session of the 86th Congress. 
It is very heartening indeed to observe the congressional interest in oceanographic research which the actions of your committee express.

The history of oceanographic research in the United States reflects the periodic reviews of the subject by special committees established by the National Academy of Sciences. The first such committee, appointed in 1927, recommended the establishment of an oceanographic research center on the east coast of the United States and this Institution at Woods Hole was created in response to this recommendation.

The latest report of the National Academy on this subject entitled "Oceanography 1960-1970" reflects a great deal of study and consideration by distinguished scientists engaged in the several parts of the study of oceanography. Although people in this field are not unanimous on any particular feature of the program recommended, I believe oceanographers everywhere subscribed to the general objectives and recommendations of the report. Similarly, the TENOC report, which has been approved by the Chief of Naval Operations, represents an imaginative and carefully considered estimate of the general kind of program needed in this field.

I would like first to comment on Senate Resolution 136. It is heartening to those engaged in this field to observe these warm and prompt expressions of interest in oceanographic research and the recognition of its importance, not only for our national security but also for the potential benefits which are certain to result from a greater knowledge and understanding of marine sciences. At Woods Hole we have been pleased with the interest shown by another committee in Congress, the Special Subcommittee on Oceanography of the Committee on Merchant Marine and Fisheries, some of whose members visited this laboratory last summer.

We were particularly impressed by the thoughtful drafting of Senate Resolution 136, in its enunciation of policy and avoidance of restrictions which might hamper the flexible growth of such a long-range program. It is certain that new knowledge growing out of the program itself will furnish the basis for changes in emphasis and that new discoveries will require the inclusion of wholly new kinds of activities.

The first recommendation concurred in by your committee in its declaration of support of oceanographic research in Senate Resolution 136 concerns the need for substantial expansion of basic research. Our knowledge of the oceans and the phenomena which occur within them is still relatively primitive compared to the other geophysical sciences. Additions to our knowledge of the oceans can come only from basic research in which the investigator is seeking to discover new facts and is without immediate concern as to the way in which these facts may become usefully applied to economic or other practical objectives.

There seems to me to be wise and appropriate recognition of the need for interagency cooperation in order to achieve the goals set forth in the Senate resolution. Likewise the recognition of the benefits from international cooperation in oceanography which were so vividly demonstrated in the course of the International Geophysical Year program are suitably highlighted in your resolution.

It is more difficult for me to evaluate S. 2692. The declaration of policy follows closely the provisions of Senate Resolution 136. The remaining sections are evidently intended to constitute a legislative expression of means for implementing the program recommended by the National Academy committee and also embodied in the TENOC report. As such, it seems to me that such expressions of congressional approval and support are to be welcomed. The questions I would raise relate not to the purposes which seem to me admirable but to the particular means proposed in the bill for the achievement of these objectives. Questions which arise from careful consideration of this bill are as follows:

1. Is the enabling authority in the bill needed to allow the several departments and agencies to carry out their parts of the proposed 10-year program in oceanographic research? To the extent that the departments and agencies already have adequate authority, further legislation on this subject may confuse instead of promote the objectives which the committee has so clearly in mind.

2. May not the freezing of numbers of ships or dollars for specific purposes at this time reduce the flexibility which is so important in capitalizing on new knowledge which may call for changed emphasis? It is my impression that the numbers used in the Academy report and in the TENOC report were intended to be illustrative and minimal rather than definitive. An expression by your committee of its support of the scale of the programs proposed by the Academy 
and in the TENOC report would certainly be desirable. I would houe that there might be another way of indicating this support which would avoid the dangers of inflexibility and implied ceilings.

3. Would the coordinating mechanism of the Jivision of Marine Scoiences in the National Science Foundation be preferable to the neans already established through a subcommittee of the Federal Council of seience? The several parts of this program fall maturally within the purposes of several departments and asencies. Coordination of their policies and prosrams relaterl to this 10-year program is clearly needed. The means suggested in the draft bill would appear to allow a voice by representatives of the Office of Naral Research, the IIydrographic Office, the Coast and Geodetic Survey, the Bureau of Commercial Fisheries, the Atomic Energy Commission, and the Maritime Administration in the program of the National Science Foundation. The aretivities which go to make up the total program will appropriately be carried out within the scientific agencies of the several departments involved and at institutions outside the Government operating with support from one or more of these agencies. The subcommittee of the Federal Council of Science, being composed of all agencies concerned in the program and represented on equal and coordinate basis, may be better suited to provide the coordination for the total program.

I am glad to have had the opportunity to submit these views and to express my satisfaction at the interest of rourself and rour associates in the science which is the central purpose of the Woods Hole Oceanographic Institution. Because it brings together the efforts of scientists from many different disciplines, it is sometimes difficult for those outside the field to risualize what oceanographers actually do. We will be very pleased indeed to have you, your associates or your staff risit Woods Hole where we might show you something of the current research in oceanography.

Sincerely yours,

Paul M. Fye.

Departacent of Geology and Geophysics,

Massachusetts Institute of Technologr, Cambridge, Mass., January 14, 1960.

Committee on Interstate AND Foreign CoMmerce,

U.S. Senate, New Senate Office Building, Washington, D.C.

Gentlemer : Before his death Vice Adm. Edward L. Cochrane handed me a copy of $\mathrm{S} .2692$ and suggested that $\mathrm{I}$ read it and communicate $\mathrm{m} y$ reactions to sou in case I wished to do so. I am pleased, therefore, to comment on this bill which seems well designed to advance the recommendations of the Committee on Oceanography of the National Academy of Sciences-National Research Council.

I strongly support the recommendations that are included in the reports of the Committee on Oceanography referred to in the preceding paragraph, and beliere that if these recommendations are carried out, we will have taken long steps forward in improving our position in oceanographic research. The one comment that I would make about the recommendations is that they do not sufficiently emphasize the great importance of education and the training of manpower for the marine seiences.

The much-expanded program envisioned in your bill will require many welltrained physical and biological scientists. These scientists will have to be trained and then led to become interested in some aspect of our phrsical environment.

I note with approval that the bill provides for fellowshins for the training of students in the marine sciences and for assistance to educational institutions in the form of equipment and teachers' salaries. I fail, howerer, to find the emphasis that I would like to see placed on the scientific manpower problem which I consider to be of first importance to the entire program in oceanographr. There are few institutions of higher learning in the United States that offer advanced training in the marine sciences. Good as these are, they not only need to expand and diversify their programs, but it would definitely be in the national interest to encourage and support the creation of new courses of instruction in the marine sciences at other institutions.

Although the bill is primarily concerned with the marine sciences, I feel strongly that recognition should be taken of the close coupling between the oceans and the atmosphere and between the oceans and the land areas. There is greater need than ever before to recognize this close relationship between the

$55401-60-11$ 
oceans, the atmosphere, and the solid earth, not only by scientists who are engaged in gaining a better understanding of our physical environment in all of its aspects, but also by our Federal agencies and bureaus which must think in terms of natural resources and national defense. Any support, therefore, that can be given to one of the broad areas of earth science will inevitably provide some support for the others. The program envisioned in your bill, therefore, has my very strong support, and we propose here at M.I.T. to take immediate steps to carry out some of the major objectives envisioned in your bill and recommended by the Committee on Oceanography (NAS-NRC).

Two specific actions may be mentioned. We are submitting an application to the Office of Naval Research through Dr. James H. Wakelin, Jr.'s office for funds to support a 5-year program of oceanographic research and instruction at M.I.T. which will involve close cooperation with the Woods Hole Oceanographic Institution. Concurrently we are submitting an application to the National Science Foundation for funds to start a 5-year graduate research training program in the earth sciences. These two proposals are closely coupled parts of a plan to develop at M.I.T. a major center for earth sciences. In organizing the program of this center we need support in every phase of earth science. The proposals mentioned are primarily for support in oceanography. I believe that your bill would be of very great assistance to Federal agencies and bureaus in providing for them a way by which they can help institutions like M.I.T. to carry out the training and research programs that we feel we are competent to conduct.

I am most enthusiastic about your bill and hope very much that it can be passed by Congress. If there is any way in which $I$ can be of assistance to your committee, please let me know.

Sincerely yours,

ROBERT R. SHROCK, Chairman.

Massachusetts InstTute of Technology, Department of Meteorologt, Cambridge, Mass., December 10, 1959.

Re S. 2692.

CommitTeE on Interstate and Foreign CoMmerce, U.S. Senate, New Senate Office Building,

Washington, D.C.

GentLemen: I am pleased to have the opportunity to comment on this bill which is designed to advance the recommendations of the Committee on Oceanography of the National Academy of Sciences-National Research Council.

I first wish to state that I strongly concur in the need for an expanded program of oceanographic research and surveys. I have had the opportunity to meet with, and to study the reports of, the Committee on Oceanography and feel that their recommendations are sound and are well designed to accomplish oceanographic research and surveys so urgently needed in the national interest.

The greatly expanded program envisaged in this bill will require a considerable number of well-trained scientists. Research is done by people and no amount of equipment will lead to important advances in knowledge without a sufficient number of able and dedicated scientists. I note, with approval, that the bill provides for fellowships for the training of students in the marine sciences. I also note the authorization, on page 18, of assistance to educational institutions in the form of equipment and teachers' salaries. I am nevertheless somewhat concerned that more emphasis is not placed on the scientific manpower problem which I consider to be of overriding importance to the entire program. There are very few institutions of higher learning in this country which offer abvanced training in the marine sciences. All of them require facilities and teaching staff and it may be in the national interest to encourage and support the establishment of courses of instruction in the marine sciences at a number of additional institutions.

I note with concern the almost complete absence of reference to the essential relationships between the oceans and the atmosphere. The only specific reference is in paragraph (e) on page 15 in which the Weather Bureau is directed to undertake a comprehensive study of the interchange of energy between the oceans and the atmosphere. Omission of more reference to the atmosphere by the Committee on Oceanography was due to the existence of a companion committee of the National Academy of Sciences-National Research Council, the 
Committes on Atmospheric Sciences. All knowlediceable oceanorraphers ambl meteorolosists agree that the interrelationships between the atmosphore and the ocenns are so all-pervasive that the two media shomld properly be comsidored as a simgle system. The recommendations of the Committes on Atmosnherice Science have not been incorporated into proposed lemislation because it has not seemed that lecrislation was necessarily required. It would be extremely unfortumate both for oceanography and for the atmosplieric sciences if inclegendent legislative approaches were to erect nnatural barriers between these inherently interdependent scientific fields. I am certain that the Committee on Interstate and Foreign Commerce would not wish to see this occur and it is with this thought in mind that I call attention to this omission in an otherwise exrellent bill.

If I may be of any assistance to the committee in connection with the hearings on S. 2692 please let me know.

Sincerely yours,

Henty G. Houghton.

NarRagan SETt Marine Laboratoky, UNIVERSTTY OF RHODE ISLAND. OFFICE OF THE DIRECTOR, Kingston, $R, \dot{I}_{\text {, , October } 15,1959 .}$

Senator Warken G. Magnuson, Chairman, Interstate and Foreign Commerce Committee, New Senate Office Building, Washington, D.C.

Dear Senator Magnuson: I wish to acknowledge receipt of a copy of Senate bill S. 2692 incorporating the recommendations of the Committee on Oceanography and the project TENOC of the Office of Naral Research. I cannot emphasize too strongly the importance of this bill in providing for research essential as a basis for national defense and the proper exploitation of the resources of the sea.

Mrs. Fish and I have been engaged in Office of Naval Research project research at the Woods Hole Oceanographic Institution and this laboratory since 1946 and are familiar with Navy-supported oceanographic research at most of the other marine laboratories. The accomplishments cannot be measurerl in dollars and cents and must continue to be supported with Federal fonds if the United States is going ot maintain its international standing because State and private institutions cannot, themselves, support oceanographic research.

I hope that the Committee on Interstate and Foreign Commerce will let me know if at any time I can be of service in support of this important legislation. Very sincerely yours,

Charles J. Fish, Directior.

STANFORD UNIVERsity, Stanford, Calif., October 5, 1959.

Hon. Warren G. Magnuson,

Chairman, Committee on Interstate and Foreign Commerce, U.S. Senate Office Building, Washington, D.C.

Dear Senator Magnuson. Thank you very much for the copj of bill S. 2692 dealing with the proposed support for and expansion of the oceanographic inrestigations under the sponsorship of the U.S. Government. I have read this bill with great interest and congratulate your committee and others responsible for its formulation. The support proposed in this bill will enable the United States to accomplish much of the sadly needed research on the multitudinous problems involved in oceanography and fisheries resources and place the United States in the forefront of oceanographic endearors among the nations of the world.

I strongly recommend careful study of all of the aspects of the bill, and sincerels hope that such a study by the committee and bs other Senators and experts will result in a favorable reporting of the bill to the floor of the Senate, followed by passage of the bill. I firmly beliere that increased emphasis needs to be placed on oceanographic studies by the United States and that such studies will advance the well-being of our people and the safety of the Nation.

Very sincerely yours, 
LockheEd Aircraft CoRP., Burbank, Calif., September 30, 1959.

Hon. Warren G. Magnuson,

U.S. Senate, Committee on Interstate and Foreign Commerce, New Senate Office Building, Washington, D.C.

SrR: Thank you very much for your letter of September 18, 1959, enclosing S. 2692, the proposed Marine Sciences and Research Act of 1959. It is encouraging to see that you are taking the lead with a strong and constructive interest in our country's need for greater effort in oceanography and related activities. Also, I am delighted to see that Senator Engle of California is a cosponsor of the bill.

Beyond any question, S. 2692 is a vital and valuable step forward. It is clearly written and seems to cover requirements for the next few years in very adequate fashion.

My only suggestion would be that perhaps the sum of $\$ 250,000$ capital outlay for a records center (p. 16, line 23) should be increased to roughly $\$ 1$ million. Also, the yearly operating figure for the records center (p. 17, line 3 ) should be raised somewhat.

Please accept my congratulations on a fine beginning. I only hope that the Senate will consider the bill favorably during the next session.

Sincerely yours,

\section{J. E. LIPP, Corporate Director of Development Planning.}

\section{Convair, \\ A Division of General Dynamics Corp., San Diego, Calif., November 12, 1959.}

Mr. Warren G. Magnuson,

Chairman, Committee on Interstate and Foreign Commerce, New Senate Office Building, Washington, D.C.

Dear Mr. Magnuson : Studying the proposed bill S. 2692, Marine Sciences and Research Act of 1959, we find that it agrees closely with the minimum requirements suggested by National Academy of Sciences as set forth in several reports published by the Committee on Oceanography.

We agree with the committee's suggestions as far as they go. Accordingly, the bill appears to be a good one.

One thing must be pointed out. The funds proposed (sec. 8: p. 16, line 23; p. 17, line 3) for creation of a National Oceanographic Records Center (NORC) are not adequate. If this facility is to constitute more than a gesture the total amount called out in the bill for capital equipment and operation of NORC should have its decimal point moved to the right one place. This would result in minimum acceptable support.

New methods of data acquisition, processing, and storage are beginning to be used in oceanography. These methods were developed principally for missile and aircraft flight testing, where they have been used successfully for more than a decade. We presently are conducting a study, for Office of Naval Research, on oceanographic instrumentation to make recommenadtions in this very matter.

To keep up with these improved methods (and the increased volume of oceanographic data forseen) NORC must be prepared to store data in modern ways. Among these are IBM punched cards, or perhaps Fosdic or magnetic tape. Machines must be available to sort, encode, and file the data, and to search for data automatically. These methods are now being used in various (and not always compatible) ways by the U.S. Weather Bureau, the Bureau of the Census, and many private concerns including our own:

Experience shows that these methods are expensive. Like mass production and automation the expense is more than offset by the increase in output per dollar spent.

NORC is much needed. Like everything else worth doing this is worth doing right. It would be unfortunate to create this key facility based exclusively on methods or philosophies that are already 10 or 20 years out of date. Sincerely, 


\section{Atrantic Stateg Marine Fismeries Commission,} Mount Vernon, N.Y., MI arch 28, 1960.

Re S. 2692.

Senator WARREN G. MAGNuson,

Chairman, Committee on Interstate and Foreign Commerce,

U.S. Senate, Washington, D.C.

My Dear Senator Magnuson: Although no formal action on your bill $\therefore .2692$ has yet been taken by this commission, I believe it is proper for me to say that it has aroused much interest both among the members of the commission and more particularly their scientific advisers. Because of the commission's longtime interest and support of biological and oceanographic research, I assume that the commission would favor in principle the objectives of your bill, although there might be some diversity of opinion as to certain details.

For example, one member of our biological committee, Dr. William J. Hargis, director of the Virginia Fisheries Laboratory, had sent me a copy of his letter of October 8, 1959, to you complimenting you and your committee and offering some specific suggestions as to facilities and equipment and for increasing the appropriations for certain items. We have also had some correspondence from other members of the same biological committee expressing general approval in the whole but asking for interpretation of some clauses.

It is for these reasons that $I$ think it proper to say that this commission and its advisers are genuinely interested in S. 2692 and hope that copies of any amendments that may be suggested will be sent to us prior to our annual meeting in September so that if formal action by the commission seems desirable at that time, it can be taken.

Speaking as an individual, I believe S. 2692 is a farsighted measure which recognizes the great need for increasing our oceanographic research in a wide cooperative program. It seems to me that the important thing is to agree on the objectives and get the big program started. Later, if experience indicates need for modifications of procedures, that can be done by amending the act.

With appreciation of your kindness in supplying material to us from time to time, I am,

Sincerely yours,

WAYNE D. HEYDECKER, Secretary-Treasurer.

\section{(The comments from the Government agencies follow :)}

\section{Executive Office of the President,}

BUREAU OF THE BUDget,

Washington, D.C., April 13, 1960.

Hon. Warren G. Magnugon,

Chairman, Committee on Interstate and Foreign Commerce,

Washington, D.C.

My Dear Mr. Chatraran: This is in response to an informal request by committee staff for the views on S. 2692, a bill to advance the marine sciences, to establish a comprehensive 10-year program of oceanographic research and surveys; to promote commerce and navigation, to secure the national defense; to expand ocean resources; to authorize the construction of research and survey ships and facilities; to assure systematic studies of effects of radioactire materials in marine environment; to enhance the general welfare; and for other purposes.

While recognizing the merit of strengthening the marine sciences. the Bureau has serious reservations about the necessity and adrisability of enacting S. 2692 .

As far as we can determine, the various agencies engaged in or supporting research in the marine sciences alreads hare adequate legislative authority to continue or expand their work in this field. Accordingly, we believe that the enactment of S. 2692 to be unnecessary.

We are further concerned over the general approach which the bill takes in authorizing specific sums of money for rarious activities and programs of the Federal agencies engaged in the marine sciences. No field of science remains static. In this day and age there is a constant need for review of scientific requirements and redirection of research programs. It does not seem adrisable, therefore, to earmark dollar amounts for specific agency activities or to delineate the composition of scientific activities in detail as S. 2692 undertakes to do.

We recognize the interest of the committee in seeking to strengthen the marine sciences. However, such strengthening not only can take place under existing 
authority but is already underway as reflected in the 1961 budget. In the budget message, the President specifically refers to the steps being taken to augment Federal support of the marine sciences since the report of the National Academy of Sciences on this subject. The budget provides for a substantial increase in Federal expenditures in this field, from $\$ 38$ million in 1960 to $\$ 56$ million in 1961, exclusive of certain military expenditures related to survey work n oceanography. We believe this gives appropriate recognition to the special needs of oceanography and the marine sciences for additional support from Federal agencies, and that together with increased aid from private sources, it should permit a significant expansion of research in these fields.

For the reasons given above, the Bureau would oppose enctment of S. 2692.

Sincerely yours,

Phillip S. Hughes,

Assistant Director for Legislative Reference.

\section{Comptroller General of the United States,}

Washington, November 17, 1959.

Hon. Warren G. Magnuson,

Chairman, Committee on Interstate and Foreign Commerce,

U.S. Senate

Dear Mr. Chatrman: Further reference is made to your letter dated September 17, 1959, acknowledged on September 21, requesting the comments of the General Accounting Office concerning S. 2692, 86th Congress, 1st session, entitled "A bill to advance the marine sciences, to establish a comprehensive 10-year program of oceanographic research and surveys; to promote commerce and navigation, to secure the national defense; to expand ocean resources; to authorize the construction of research and survey ships and facilities; to assure. systematic studies of effects of radioactive materials in marine environments; to enhance the general welfare; and for other purposes."

In the consideration of the bill, we recommend the following corrections and clarifications:

The reference in line 5, page 15 , to "the preceding item (a)" apparently was. intended to read "the preceding item (c)."

Section 7 (f) directs the Maritime Administration to construct ships of designated tonnage. However, section 8 does not authorize any additional appropriation to the Administration for this purpose. If it is intended that other funds are to be used for this purpose, it is recommended that the bill sostate. Also, it is not clear whether the ships required to be constructed by section 7 (f) are in addition to ships authorized to be constructed by other sections of the bill.

Section $8(d)$ does not place any limitation on the cost of operating new Coast and Geodetic Survey ships, while an annual limitation is imposed on the Bureau of Commercial Fisheries by section $6(b)$ and on the Navy by section 14 . We do not know whether this was an oversight or was intentional.

The last sentence of section 10 states "Appropriations authorized in this section. shall be in addition to other appropriations provided for such department or office to carry out its duties under law." However, we are unable to ascertain. where any appropriation has been authorized in such section.

We also recommend that a general provision be included in the bill to the effect that all agreements for grants in excess of a specified amount, e.g., $\$ 50,000$, contain a provision that the Comptroller General of the United States or his duly authorized representatives shall have the right to examine any directly pertinent books, documents, papers, and records, of the grantee relating to the purpose of the grant, for a period of 3 years after the last payment under the grant.

We recognize that the question whether legislation of this type is necessary is strictly a matter of policy for determination of the Congress, on which we express no opinion. However, we would suggest that the matters hereinabove set forth be given serious consideration by your committee in its deliberations. on the bill.

Sincerely yours, 
Department of the Navy,

OfFtce of tile Secretary,

Ofhioe of Legislative AfFatrs,

Washington, D.O., April 19, 1960.

Hon. Warken G. Magnuson,

Chairman, Committee on Interstate and Foreign Commerce,

U.S. Scnate, Washington, D.C.

My Dear Mr. Chamman: Your request for comments on $\mathrm{S}$. 2692, a bill to advance the marine sciences, to establish a comprehensive 10-year program of oceanographic research and surveys; to promote commerce and navigation, to secure the national defense; to expand ocean resources; to authorize the construction of research and survey ships and facilities; to assure systematic studies of effects of radioactive materials in marine environments; to enhance the general welfare; and for other purposes. has been assigned to this Department by the Secretary of Defense for the preparation of a report thereon expressing the views of the Department of Defense.

The purpose of S. 2692 is as stated in the title.

While the Department of Defense concurs in the objectives of this bill, it does not consider enactment of S. 2692 necessary to achieve these objectives. In general the agencies of the Department already have adequate legislative authority to continue and expand research in the marine sciences. In this connection it should be noted that the expenditures of the Navy for oceanography are expected to increase from $\$ 17$ million in 1960 to $\$ 23$ million in 1961 . For the Government as a whole expenditures will increase from $\$ 38$ million in 1960 to $\$ 56$ million in 1961.

If, however, favorable consideration is given to S. 2692 the Department of Defense would have the following suggestions to offer regarding the provisions of such proposed enactment:

Sections 2 and 3 of the bill propose to establish a Division of Marine Sciences in the National Science Foundation in which there is an interagency committee ostensibly to develop and encourage the continuing national policy and program for the promotion of oceanography. The establishment of such a division should be based on the needs and desires of the Foundation. It does not seem appropriate howerer to extend the National Science Foundation's authority into applied research activities the establishment of which the proposed division might authorize. The National Science Foundation should continue to support basic research and programs to strengthen scientific research potential in all of the sciences including specialized fields such as oceanography which may from time to time require particular emphasis.

The Subcommittee on Oceanography of the Federal Council for Science and Technology has proposed that under the Federal Council a permanent interagency committee be establisher to exercise program control and coordination of the national oceanography program. The subcommittee as a precedent for this form of management has demonstrated its effectiveness in the 6 months of its existence.

Section 7 of the bill provides for the establishment within the Department of Commerce of a National Oceanographic Records Center. The Subcommittee on Oceanography has recommended and it is generally accepted in the scientific community as being more appropriate that the National Oceanographic Data Center be established at the Hydrographic Office with joint policy guidance and financial support to be provided by the Navy, the Coast and Geodetic Strres, the Bureau of Commercial Fisheries, the National Science Foundation, and the Atomic Energy Commission. This permits the utilization of existing facilities, equipment, and personnel. The expansion of the present phrsical plant can be more rapidle accomplished and at considerably less expense than the establishment of a second installation.

It is recommended that provision be made for such joint policy guidance and financial support as is necessars to insure that all of the Federal requirements are fulfilled. This can be accomplished by revision of section 6 to provide for participation and financial support of a National Oceanographic Records Center by the Bureau of Commercial Fisheries and rerision of sections 8(a) and $S(b)$ to provide for similar support and participation by the Coast and Geodetic Surrey.

The Nary's research program TENOC for 10 years in oceanography is recognized as the cornerstone of the national program. TENOC is now being rerised to include all phases of oceanography such as research, development, survers, 
and long-range requirements for ship and facility construction. It, therefore, appears appropriate that the portion of section 14 relating to ship construction should be worded in general terms similar to the provision calling for the construction of new shore facilities. The Navy oceanographic shipbuilding program should be developed within Navy and approved by. Congress as a portion of the Navy's total shipbuilding program in accordance with established procedures.

It is noted that the Department of Health, Education, and Welfare is not included in S. 2692. This Department is contributing to oceanography with studies of radioactivity in the oceans and could also participate in an educational program which is essential to train the manpower required for an expansion of the national effort in oceanography. Further legislative authority is not needed by this Department, we understand.

Pursuant to sections $426-426 \mathrm{~h}$ of title 33 of the United States Code, the Department of the Army, through the Chief of Engineers and the Beach Erosion Board; has a primary interest in nearshore oecanography and the interaction between the oceans and the land (shore and near-shore bottom). In order that this interest may be given recognition, it is recommended that the following revisions be made in $\mathrm{S} .2692$ :

In the fourth line of the title, add "and coastal" after "ocean".

On page 3 , line 17 , and page 8 , line 16, after "buoys" add "instrumented marine towers, wave gages,".

On page 6, line 1, after "Standards," add "the United States Army Corps of Engineers (including the Beach Erosion Board),".

On page 7, line 13, after "Administration," add "the Beach Erosion Board of the United States Army Corps of Engineers,".

On page 28 , insert the following new heading and new sections 15 and 16 and renumber present general section 15 as section 17 :

\section{"DEPARTMENT OF THE ARMY}

"SEc. 15. The Secretary of the Army is authorized and directed, with such funds as may be appropriated or otherwise made available to him, to undertake a ten-year program of study and research by the United States Army Corps of Engineers through the Beach Erosion Board, as part of the general program for the development of the marine sciences in the United States. In furtherance of the purposes of this Act, the Secretary is authorized and directed to carry out, in addition to programs now under way, the following activities relating to physical oceanography in the near-shore areas of the Atlantic and Pacific Oceans, the Gulf of Mexico, and the Great Lakes, which areas include the zone from the shore to the 50 -fathom depth contour in the oceans and lakes, and bays and tidewaters connected therewith:

"a. Request and obtain cooperation from other Government agencies having an interest in the marine sciences and ocean surveys, and cooperate with educational institutions and laboratories devoted to the marine sciences and oceanography, and with other public and private organizations and persons who may be of assistance.

"b. Contract with qualified scientists, research laboratories, research organizations, or educational institutions to undertake basic and applied research studies and experiments in the laboratories and in coastal waters, in furtherance of the purposes of this Section.

"c. Undertake in coastal waters studies of the action of waves, wave currents, tides, tidal courrents, and large-scale ocean and littoral currents.

"d. Study and evaluate the interaction of the atmosphere, the sea, and the land as they affect the waves, currents, tides, surges, hydrographic contours, and hydrographic changes in the coastal zone.

"e. Establish observation stations in coastal waters to determine the shortterm, seasonal, and yearly changes in waves, currents, and hydrography in the area surrounding the station.

"f. Develop, construct, or acquire instruments and equipment for the furtherance of the program of studies authorized in this section.

"g. Determine the sources of the bottom materials in the coastal area, the rates and methods of movement of these materials, and the effects on the coastal hydrography of changes in the rate at which these materials reach the coastal zone. 
"h. Study the mechanics and effects of density currents encountered in the coastal area on the current velocities, current patterns, hydrography, interchange of waters, and rates of sedimentation.

"SEC. 16. In order to carry out the policies of this Act and of S. Res. 136, $86 t h$ Congress, and to provide for the participation of the Department of the Army, including either or both military or civil functions activities, in the general program for the development of marine sciences in the United States, there is hereby authorized to be appropriated to the Department of the Army, during the ten-year period beginning July 1 of the first fiscal year following approval of this Act, the following sums, not to exceed $\$ 2,000,000$ per annum:

"a. Such sums as are necessary for the investigations and activities described in section 15 relating to investigations in physical oceanography in the nearshore zone.

"b. Such sums as are necessary to purchase, develop, or acquire and operate the scientific equipment required for investigations in physical oceanography in the near-shore zone, including but not limited to amphibous craft, floatng craft, fixed platforms, buoys, current meters, wave meters, tide gages, sound equipment, direct density measuring equipment, turbulence meters, underwater cameras, and underwater television equipment, and other instruments and laboratory for oceanograph research in the near-shore zone.

"c. Such sums as are required for expansion and equipping of shore facilities as are necessary to support the program of investigations in physical oceanography in the near-shore zone.

"d. Such sums as are necessary to provide funds for contracts with qualified scientists, research laboratories, research organizations, or educational institutions to make investigations into physical oceanography in the near-shore zone."

In addition to the foregoing, it is recommended that the following specific changes be made in S. 2692 :

Page 3, line 4, after the word "research" insert "and marine surveys." This is suggested as being more descriptive of the provisions of S. 2692 .

Page 3, line 6, change lines 6 and 7 to read, "the National Academy of SciencesNational Research Council. This program should include, but not be limited to the-".

Page 3, lines 11-13, substitute : "modernization of existing and construction of new Government and civilian laboratory and shore facilities adequate to service and supplement the research and survey fleets;". This is suggested to permit flexibility in the utilization of existing facilities.

Page 3, lines 15 and 16, change to read: "research tools, devices, instruments, and techniques which may include but not be limited to bathyscaphs and other manned".

Page 3 , line 25, change to read: "among undergraduate students of mathematics, physics, engineering, chemistry,".

Page 4, line 22. It is recommended that the Federal Council for Science and Technology establish the interagency mechanism for management of the national program in oceanography vice the establishment of a division within the National Science Foundation for this purpose. The functions of this management mechanism should be similar to the duties and responsibilities outlined for the Division of Marine Sciences in S. 2692.

Page 10, line 16, change to read: "(g) Request and obtain cooperation from and cooperate with other gov-".

Page 12, line 13 , change to read: "or procuring facilities for such studies which may include but not".

Page 14, par. (b). It is recommended that this paragraph be deleted and that formal recognition and support be given the Hydrographic Office as the National Oceanographic Records Center by revision of sections 13 and 14 . It is further recommended that provisions be made for such joint policy guidance and financial support as is necessary to insure that all of the Federal requirements are fulfilled.

Page 16 , line 6, change to read: "oceangoing scientific ships, with preference given to such agencies and".

Page 22, line 13, substitute "basic" for "basis".

Paze 22, line 20. To provide greater flexibility and to be consistent with the general authority of the Office of Naval Research, the following is suggested as a substitute for lines 20-22: "Provide funds by contract or otherwise to scientists, Government and non-Government research laboratories or institutions in 
futherance of the purposes of this Act, such funds to be used for basic and applied research, the purchase of equipment,".

Page 23, line 3, following "basic" insert "and applied". This suggestion is offered as being descriptive of existing authority.

Page 23, lines 12 and 13, following "laboratories" substitute "and provide related instruments and equipment to support effectively the expendéd program of basic and applied oceanographic research and hydrographic". This suggestion is for completeness and accuracy.

Page 23, lines 17 and 18, change to read: "vehicles for ocean research and exploration, which may include but not be limited to bathyscaphs and other manned submersibles,".

Page 24, lines 3 and 4, change to read: "(e) Continue and expand the Navy's support of marine studies substantially as proposed in project TENOC or the Navy's revised long range oceanography program".

Pages 24 and 25, par. (h) and (i). As a positive means of implementing the authority contained in these provisions, it is recommended that section 13 of $\mathrm{S}$. 2692 include a provision to amend section 7394, title 10, United States Code, by adding:

"The Secretary of the Navy is authorized to furnish maps, charts, and other publications and products of scientific value of the Hydrographic Office without charge to educational institutions, laboratories, and other public and private organizations and persons when it is determined that to furnish such information is in the national interest."

Existing statutes are adequate to cover the furnishing of such information to commercial interests but they are construed as making impossible the free distribution of material of scientific value.

Page 25, line 7, change to read: "(i) Request and obtain cooperation from and cooperate with other govern-..".

Pages 26, lines 1-20. It is recommended that the portion of this section relating to ship construction be worded in general terms similar to line 5, page 27 , for the construction of new shore facilities.

Page 27, line 5. Change to read: "for modernization, improvement, and expansion of existing shore facilities for basic research and for construction of new shore facilities for basic".

Page 27, line 8. Change to read: "for modernization, improvenent, and expansion of existing shore facilities for survey work and for construction of new shore facilities for survey".

Page 27, line 10. It is recommended that the following substitution be made for the present language beginning on line 10 and extending through line 21 . The substitution is offered for consistency with authority granted elsewhere in S. 2692 and in some instances reflects instrumentation already in use or in research and development stages under the cognizance of the Department of the Navy.

"for engineering needs for ocean exploration and research which may include bathyscaphs and other manned submersibles to be used for research, wave measuring equipment, systems engineering for reduction of data, manned and unmanned buoys for automatic continuous oceanographic recording, icebreakers and submarines modified or converted for scientific use, vessel positioning system, acoustical equipment and telemetering devices, current meters, measuring devices for direct density, turbulence and radioactivity, and underwater television, seismic equipment, automatic continuous biological sampling devices, precision salinometers, precision echo sounders, towed temperature recorders, magnetometers, and other instruments and laboratory equipment for oceanographic research ; and".

This report has been coordinated within the Department of Defense in accordance with procedures prescribed by the Secretary of Defense.

The Department of the Navy has been advised by the Bureau of the Budget that there is no objection to the submission of this report on $\mathrm{S}$. 2692 to the Congress.

$$
\text { Sincerely yours, }
$$


OFFiCe OF THE SECRETARY OF THE Treasury,

Washington, April 25, 1960.

Hon. Warren G. Magnuson,

Chairman, Committee on Interstate and Foreign Commerce,

U.S. Senate, Washington, D.C.

My Dear Mr. Chairman: Reference is made to your request for the views of this Department on S. 2692 , to advance the marine sciences, to establish a comprehensive 10-year program of oceanographic research and surveys; to promote commerce and navigation, to secure the national defense; to expand ocean resources; to authorize the construction of research and survey ships and facilities; to assure systematic studies of effects of radioactive materials in marine environments; to enhance the general welfare; and for other purposes.

The Department is not in a position to state whether new legislation is necessary to carry out the proposed program of oceanographic and marine research or whether it could be carried out by the departments and agencies specified in the bill under their existing authority. However, the Department would like to point out that the bill fails to recognize important interests that the Coast Guard has in many phases of the proposed research prograns. For example, the Coast Guard is charged with the enforcement of all applicable Federal laws upon the high seas and waters subject to the jurisdiction of the United States and the administration of a safety program upon these waters covering all matters not specifically delegated by law to another Federal agency (14 U.S.C. 2). The Coast Guard, in its management of the international ice patrol service, conducts oceanographic surveys of the ocean areas in the North Atlantic and collects and disseminates ocean data (46 U.S.C. 738a(d)). Coast Guard vessels serving on ocean station duty collect and furnish limited oceanographic data to the U.S. Navy Hydrographic Office (14 U.S.C. 90). Icebreaking vessels are maintained and operated by the Coast Guard as one of its primary duties (14 U.S.C. 2, Executive Order 7521). The Coast Guard also has responsibility for regulating the carriage of explosives and other dangerous articles by vessels (46 U.S.C. 170).

Inasmuch as the Coast Guard already has authority to conduct programs in oceanography, it would not seek further authorization for these programs. However, should your committee take favorable action on this bill, the Department would suggest appropriate recognition of the oceanographic activities of the Coast Guard, along with those of other agencies.

The Department has been advised by the Bureau of the Budget that there is no objection to the submission of this report to your committee.

Very truly yours,

A. Gilmore Flues, 


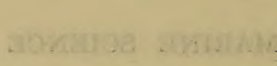

